\title{
Official statistic-making as a social practice: the UK 'Measuring National Well-being' programme
}

Matt Jenkins

School of Geography, Politics and Sociology 



\begin{abstract}
The thesis examines the construction of official statistics using the qualitative case study of the UK Office for National Statistics' 'Measuring National Well-being' programme. Its major original contribution is to critically engage with the making of official statistics, theorising their construction as a social process. This provides novel ways of explaining the form and content of official statistics. It also furthers debates on 'wellbeing' through an examination of the concept's theoretical and institutional history.

The research argues that official statistic-making is an activity conducted by actors with agency. This agency is not taken into account by existing accounts of the nature of official statistics, which are more abstract and which do not engage with the statisticmaking process. It is argued that attention to the social processes of official statisticmaking make a fuller understanding of the form and content of statistics possible.

This argument is supported by an examination of the 'Measuring National Well-being' programme. The institutional and theoretical context for this programme presents a number of challenges to existing accounts, highlighting the need for agential action. This context is explored through semi-structured interviews with those involved in the creation of the programme, triangulated against secondary material such as meeting minutes produced by the Office for National Statistics and published statistical outputs.

In the specific case of the 'Measuring National Well-being' programme, the research finds a high degree of autonomy for those constructing the programme. This freedom was used to position the programme within wider European and international statistical contexts, rather than domestic political ones. Despite being a programme in a new area of social research, the final content of the programme fitted within established ways of thinking partly as a result of path dependency created by the statisticians' preestablished ways of working.

More generally, it is argued that approaching the construction of official statistics as a social process helps explain the form and content of the statistic. The research demonstrates that it is possible to trace linkages between the features of the final statistic and social interactions which gave rise to them. It is argued that this is applicable beyond the case study used and beyond statistic-making in the UK.
\end{abstract}




\section{Acknowledgements}

My gratitude and thanks to my supervisory team of Andy Pike, Joe Painter and Mike Coombes. Without their support and guidance, this thesis would be considerably worse than it is. I hope I haven't been too frustrating as a student over the last three years. Also to the various members of support staff, particularly Carole Allan, Jenny Dawley, George Kania, Heather McGrath and Susan Robson, who have borne me with patience; this research would not have been done without them.

The first submitted version of this thesis benefited from the insightful comments and criticism of Rhys Jones and Karen Scott. The present version is better as a result, and I am glad for it.

I am also very grateful to the many people who've supported me non-academically through my thesis, in particular Alex Baker, Maria Bakola, Gemma Bone, Ben Coulson, Lily Harding, Tessa Holland, Paul McFadden and Cahir O'Doherty. Without their isnpiration, support and guidance, I would be considerably worse than I am. I hope that over the last three years I've been able to give them as much joy as they have given me.

Finally, I am grateful to my interview participants, who cannot be thanked here individually. They gave their time without asking for anything in return. I hope, should they ever read this, they will feel I have been fair to them. I have certainly tried to be.

This research was undertaken with funding from the ESRC, grant number ES/J50082/1. 


\section{Contents}

Abbreviations $v$

Chapter Introduction: Problematic, Context and Motivation for the Study 1 One

Chapter How have official statistics previously been understood?

Two

Chapter Epistemology, methodology and research design: how might

Three official statistic-making be examined and understood?

Chapter The institutional context of the 'Measuring National Well-being'

Four programme: the Office for National Statistics and the place of official statistic-making within UK policy-making

Chapter The theoretical and policy context of the 'Measuring National

Five Well-being' programme: well-being theory and statistical practice

Chapter Questions of practicality: how the institutional context of UK

Six statistic- and policy-making shaped the 'Measuring National Well-being' programme

Chapter Questions of theory: how the theoretical context of UK statistic-

Seven and policy-making shaped the 'Measuring National Well-being' programme

Chapter Understanding official statistic-making as a social process

Eight

Appendices

$A$ : Membership and meeting attendance of the Advisory Forum and Technical Advisory Group

$B$ : Material sent to prospective interview participants $C$ : Headline measures of the 'Measuring National Wellbeing' programme

$D$ : Outputs of the ONS' 'Measuring National Well-being' programme

$E$ : Things I did when I should have been doing other things

References 
Figures and tables

Figure Classes of statistical actor and their activities

1.1 .

Figure A schematic time-line of the statistic-making process in the case

3.1. of the 'Measuring National Well-being' programme

Figures The well-being frameworks of the ONS, OECD and Eurostat

$90-1$ 5.1 .

Figure A taxonomy of well-being research

5.2 .

Table Interviews conducted

3.1 .

Table Key documents consulted

3.2. 


\begin{abstract}
Abbreviations
AF - Advisory Forum (a body which advised the Office for National Statistics during the statistic-making process of the 'Measuring National Well-being' programme)

APS - Annal Population Survey (a survey device used in the collection of data for the 'Measuring National Well-being' programme)

CMEPSP - Commission on the Measurement of Economic Performance and Social Progress, commonly known as the Stiglitz-Sen-Fitoussi Commission (a commission established by the French President to advise on amendments to GDP; report published as Stiglitz, Sen and Fitoussi 2009)
\end{abstract}

CSO - Central Statistical Office (a fore-runner of the Office for National Statistics, the central government department tasked with collecting official statistical data)

Defra - Department for the Environment, Food and Rural Affairs (a central government department, notable for their production of the statistical programme 'Sustainable Development Indicators')

EU-SILC - European Union Statistics on Income and Living Conditions (an EUwide survey undertaken in the UK by the Office for National Statistics which includes questions on well-being)

GDP/GNP - Gross Domestic/National Product (two closely related measures of economic activity used as indicators of economy-level performance)

GSS - Government Statistical Service (the professional body of statisticians working across UK Government departments and non-departmental agencies)

GSS-MAC - Government Statistical Service Methodology Advisory Committee (the quality control body for statistics produced by the Office for National Statistics)

IHS - Integrated Household Survey (a survey device used in the collection of data for the 'Measuring National Well-being' programme)

MNW - 'Measuring National Well-being' (a programme of the Office for National Statistics)

NPM - New Public Management (a family of theories around the organisation of public services and bureaucracies)

OECD - Organisation for Economic Co-Operation and Development (an international thinktank and best practice body, aiming at the promotion of economic development and trade)

ONS - Office for National Statistics (the central government department tasked with collecting official statistical data)

TAG - Technical Advisory Group (a body which advised the Office for National Statistics during the statistic-making process of the 'Measuring National Well-being' programme)

WEMWBS - Warwick-Edinburgh Mental Well-being Scale (a measurement device for positive psychological functioning) 



\section{Chapter One \\ Introduction: Problematic, Context and Motivation for the Study}

\subsection{Introduction}

Official statistics, economic and social, are ubiquitous in everyday life, playing a central role in policy-making, media discourses and in shaping popular conceptions of the world (Dorling and Simpson 1999a; Holt 2008; Matheson 2010; National Statistics 2002; Office for National Statistics 2010a, 2013e). They act as 'evidence', objective statements to inform policy decisions and to assess the quality of those decisions (Bumstead and Alldritt 2011; Economic Secretary to the Treasury 1999; Keat 1979; Performance and Innovation Unit 2000b; Porter 1995; Prime Minister and Minister for the Cabinet Office 1999). As such, they are much contested, with the appropriateness or robustness of a particular statistic within a particular debate routinely challenged (Dorling and Simpson 1999a; Levitas and Guy 1996). However, while questions of technical or definitional accuracy, or of applicability, are continually raised with respect to given statistics, the practice of statistic-making and the status of statistics as 'evidence' are less controversial. For example, while unemployment figures have been the subject of much historical controversy, those challenging them seldom suggest that unemployment statistics should be abolished completely, instead offering suggestions of adjustments (Dean 1995; International Labour Organization 2013; Levitas 1996a; Walters 1994). This is true more generally; where there is a challenge to an official statistic, it often comes in the form of another statistic, and the solution is a revised or alternative statistic, one piece of evidence being replaced by another (Cameron 2010; Working Party on the Measurement of Unemployment in the UK 1995). The practice of official statistic-making itself is rarely challenged; official statistics as a technology of the state are naturalised, their ontological, epistemological and ethical aspects unquestioned (Carmargo 2009).

Official statistic-making is not merely ubiquitous, but also has the potential to impact the world it records. Official statistics have discursive power; they both set the definition of a phenomenon and define it as a phenomenon worth paying attention to (Levitas and Guy 1996; Porter 1995; Starr 1987). Supporting this second point, Townsend (1996) has argued that successive governments rejected calls to produce poverty statistics, as these would offer official sanction to what was formerly an issue framed by pressure groups and academics; by not producing statistics, governments could deny there was a problem to be studied. This dual power of definition and framing is important because, unlike the physical world where, quantum states aside, observation does not change the phenomenon observed, the existence of representations of the social world can lead directly to changes in that world. The relation of official statistics to the external world is two-way: the statistic observes the external world, but also makes it amenable to action and establishes incentives and disincentives for it to match the definition of the statistic (Miller and Rose 2008; Rose 1991; Rosenthal and Weiss 1966). This is particularly the case where statistics are used as the basis of public policy; definitions imposed by the statistic become tied to sanctions or entitlements for the people or things they are imposed on.

Their role in defining and potentially shaping the social world, together with their ubiquity, gives official statistics a power and importance within everyday life. That power and importance establishes official statistics as phenomena which need to be 
understood as part of wider debates around the relations between state and civil society. Such an understanding cannot be reached without a corresponding understanding of official statistic-making, the process by which the form and content of the official statistic is arrived at. It will be argued that while there exist several theories of the role that official statistics play within society, there is a gap around the understanding of the statistic-making process. Very little research has addressed the question of how official statistics are made, of how their influential definitions are arrived at. This is a gap which the present research seeks to address.

\subsection{Defining official statistic-making as a social practice}

For the purposes of this research, official statistics are defined as: counts or measures, and derivative calculations of these, compiled by, or on the behalf of, a state actor for the instrumental purpose of monitoring economic or social activity. This definition is descriptive rather than theoretical; it attempts to encompass outputs of the state which would conventionally be considered 'official statistics', not to establish and police some theoretical boundary against which such outputs might be assessed. Such a definition encompasses outputs ranging from administrative data collected by local government, to national projects which establish sociological categories, such as the Indices of Multiple Deprivation.

Several descriptive additions can be made to this working definition. One is that an official statistic is a made object, created by professional actors working within institutions or branches of institutions specialised for the creation of statistics (see National Statistics 2000). Officially, these actors are departments of the state: in the UK legislation, the official statistic is defined only in terms of the corporate body that creates it, rendering the official statistic an interaction between impersonal entities: the bodies desiring, creating, and using it (Statistics and Registration Services Act 2007). As an instrumental monitoring device, the official statistic is designed for a purpose, under given circumstances and conditions of possibility, and enacted under such circumstances and conditions (such as budgetary constraints, e.g., Matheson 2010, p.2). As an implication of this definition, the official statistic is historically and spatially contingent; that is, the statistic and its existence are not fully determined by the statistic's content. In other places and times the statistic may not exist, or may take a different form.

The present research will explore a further claim: that official statistics are not the product of impersonal corporate state actors, but of individual actors within them. This shifts the focus of the definition; rather than being a product of systems of state interaction, the official statistic is a social product, arising from the interactions of individuals working within the state. This claim builds on the work of Jones (e.g., 2007) and, to a lesser extent, Peck (e.g., 2001) and Rhodes (e.g., 1992) that the state is a fundamentally 'peopled' entity. While individuals within state bodies are subject to the structures of those bodies, this work argues that they cannot be reduced to them; they are not neutral intermediaries between the institutions they are embedded in and the outputs they produce. Rather, they operate with agency, embodying a variety of identities, subjectivities, aims and beliefs. These, and the actions which flow from them, 
are shaped by a range of interests, motivations and institutional positions. They are capable of acquiescing to, resisting and shaping the institutions and rules they operate under. This does not do away with structures - state actors are still subject to the rules and institutions they are embedded within - but does allow that such structures are flexible, and so need to be understood in relation to the actors who inhabit them (Mann 2003).

This reading of agency and structures draws on some of the insights of Giddens' work (especially Giddens 1984), without being a full endorsement of structuration theory. In particular, it utilises his characterisation of individuals as knowledgeable, sometimes acting reflexively but often acting on the basis of practical consciousness. While nonreflexive activity will normally serve to reproduce existing social systems, agents have the ability to alter them through deliberate acts. However, the reading departs from structuration theory in allowing a greater role for structures as things which confront agents. As Archer (1982; see also King 2010 and O'Boyle 2013) shows, Giddens' account renders structure inert as it exists only through the instantiation of individuals. This underplays the role of structural constraint (and enablement), and offers no guidance on how or under what conditions agents can act to change structures. Instead, structures are conceived of here as social relations, permitting differential degrees of freedom to agents in their actions (Burkitt 2015). In allowing for both knowledgeable actors and structures which pre-date them which they must negotiate, this reading of agency is in line with the structural-relational reading of Jessop (2001, 2008; Jessop, Brenner and Jones 2008; see also Biebricher 2013; Gill 2009, 2010; Jones 2007; Kelly 1999)

These agents operate within a peopled state (see particularly Jones 2007; also Rhodes 2005). Following Mitchell (1991), 'the state' here is not conceptualised as a monolithic entity which stands outside of and separate from 'civil society' (for an analogous argument from the perspective of 'civil society', see Latour 2005). Rather, what is conventionally read as 'the state' is a "structural effect" (Mitchell 1991, p.94), produced and reproduced through the actions of agents, not the least of which is the production of official statistics. This is the counterpoint to the theory of agency sketched above; the state exists in the social relations of institutions, regulations and technologies in which agents operate. Such structures are flexible, but not completely so. They are also permeable, with agents from outside formal structures conventionally thought of as being part of 'the state' being able to gain access and act to produce state effects; and with agents within such 'state institutions' also carrying with them identities from outside (such as professional or personal identities) (Jones 2012). Consonant with Painter's (Painter 2006) account of the state as an imaginary, 'the state' acts as a motivation for beliefs and actions of agents both within and without its formal structures, and these beliefs and actions in part construct it (Mitchell 1988; Wilson 2001). 'The state', on this reading, goes beyond the formal structures of government institutions and outputs, it embraces Statistical Actors who may act within those structures temporarily, as well as those (and members of the Statistical Audience) who never join such structures but who invest them with authority. 'The state' here is peopled in the dual sense that its formal structures are filled with agents who can shape those structures; and that those structures themselves are social relations, ongoing interactions between people which are concrete but impermanent (Burkitt 2015; see also Jessop 
2001, 2008; Jessop, Brenner and Jones 2008).

This definition of official statistics as the work of interacting agents within a peopled state has a major implication for the understanding of them: if actors are capable of influencing outputs through their negotiation of structures, then those outputs are partly dependent on the actions of those actors. This contingency is obscured both by the naturalisation of official statistics discussed above, and by understandings of statistics as the product of undefined corporate bodies. Rather than being abstractions produced by abstractions, official statistics understood in this way become concrete manifestations of social processes.

Such a high-level description raises a large number of questions about the nature of the actors involved, of their agency, of their context, and of the decisions that they make. These are empirical questions. A priori, as an initial conjectural framework to structure investigation, an act of official statistic-making would seem to require at least the following stages: the identification of a phenomenon to be counted, the normative decision that this phenomenon should be counted, the definition of what constitutes an occurrence of that phenomenon, repeated application of that definition in an act of counting or measuring, the collation of these counts according to some accepted method into a statistical instance, the publication of this instance for an audience, the interpretation by this audience according to the intentions of the statistic's designers or their own. Each one of these stages is subject to the agential analysis above; actors are required to make decisions, but will do so within the limits set by their existing context.

There are multiple actors involved in such a process, and three classes may usefully be distinguished. The Commissioning Actor is that which proposes the statistic, identifying the phenomenon to be counted and determining that it should be counted. They may also define what constitutes an instance of the phenomenon. The Statistical Actor designs and enacts the statistic. This can involve defining the phenomenon, but will include repeated application of a definition, collating these counts and publishing them as a statistical output. The Statistical Audience receives, interprets and uses that output. As these names imply, the Statistical Audience is usually, but not necessarily, passive in the process, receiving statistics but having little input into their creation. In contrast, the Commissioning and Statistical Actors act, using agency to negotiate institutional structures and create a statistic where there was no statistic originally. This conjectural framework is presented as figure 1.1.. 


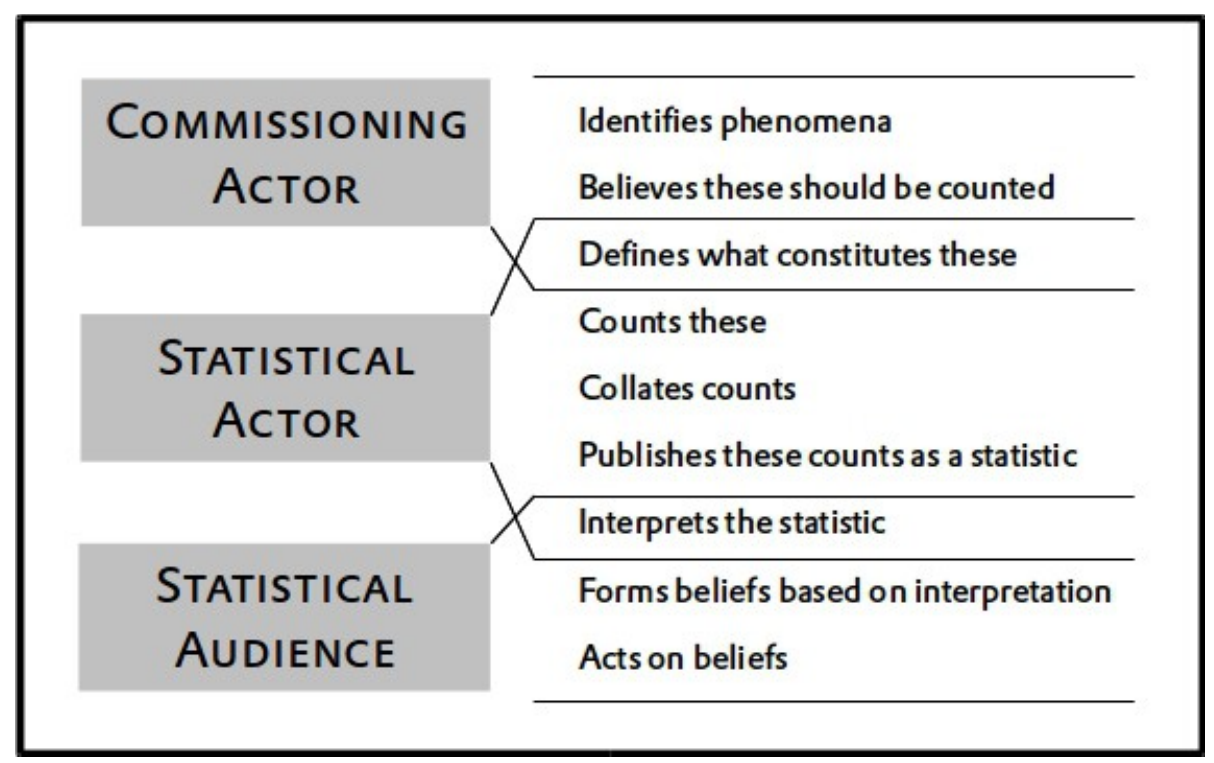

Figure 1.1. Classes of statistical actor and their activities

The boundaries between these classes of actor and their roles are blurry and complex. Commissioning Actors, for instance, will often be part of the Statistical Audience commissioning the official statistic for their own use - and may also act as Statistical Actors - advising on the composition of the statistic. Similarly, the Statistical Actor, often a professional and specialised body, stands in particular socio-spatial relations with other statistical and non-statistical agents such as Commissioning Actors in other parts of the state and members of the Statistical Audience as users of statistics. They may draw in these groups as temporary Statistical Actors to shape their work, or incorporate feedback from non-statistical agents in later iterations of a statistic. This creates a complex picture of individuals with multiple roles and positionalities, interacting with each other to produce the statistic. The relative power of actors, and with it their ability to shape the statistic according to their own aims, will impact on the final form and content of the statistic.

With multiple classes of actor comes the possibility of disagreement over the appropriate form and content of the official statistic. The classes of actor are heterogeneous within themselves, containing multiple individual actors in multiple roles (Acker 1989). This extends the possibility of disagreement, allowing it to occur within as well as between classes as actors and classes relate to and interact with each other in complex ways. The Statistical Actor, for example, may involve international policymaking bodies setting standards for statistical composition; teams of statistical designers, taking advice from academic institutions or colleagues in other institutions; actors responsible for conducting data collection formally attached to the statistical body, collecting as part of other duties (for instance within local government), or employed by a third party in the private sector; various actors involved in validation or quality-checking, both in terms of data collected and of methodology; actors involved in presentation, publication and dissemination. There is again no guarantee of agreement between these various individual actors; the desires of designers may not mesh with the standards set by international best-practice, for example. 
This initial conjectural framework, then, while based on a very simple categorical division of actors and their activities, reflects an interactive process which is not at all simple. It highlights the importance of the relationships between actors, and of their agency within their categorical structures. The output of such a model is highly indeterminate. Commissioning Actors, for example, cannot request a statistic and guarantee that the final product fully will capture their intention. Indeed, the framework suggests that 'the intention' of Commissioning Actors is, itself, a complex social product which is open to multiple interpretations even amongst members of the Commissioning Actor. Similarly, from the other end of the process, the outcome as received by the Statistical Audience is a contingent product, reflecting any number of debates and compromises between and within Statistical Actors.

A particular aspect of this contingency is geographical, as social and institutional contexts are necessarily spatial (Elden 2004; Lefebvre 1991, 2003, 2009). Official Statistical Actors are embedded within particular institutional contexts: their powers, remit, budgets and responsibilities are determined by their specific institutional settings. They are called on to count along pre-determined national and sub-national boundaries by Commissioning Actors at levels from local to supranational, which they must do within local limitations of power and resources (Mann 2003). Even when following preestablished non-local methodology, the end product of the statistic-making process will be the result of local adaptations or the adaptation of local conditions to fulfil the requirements of the statistic (see, for similar arguments relating to other branches of the state, Gill 2009, 2010; Jones 2007). Statistical Actors stand in particular socio-spatial relations to the Commissioning Actors and Statistical Audience. The statistic cannot be separated from its institutional context, and this context must be understood if the statistic is to be.

The focus on social processes, then, has wide-reaching implications. These are generally under-examined in existing accounts of statistic-making. While accounts of particular statistics exist, produced both by Statistical Actors and actors within the Statistical Audience, these do not usually reflect the full complexity of the statistic-making process as posited above. Normally written after the process of statistic-making, and so after any debate, resistance and compromise has occurred, these present post hoc justifications of decisions already made, often referring to external standards or requirements which, themselves, go unjustified (see, for example, Beaumont 2011, 2012; Jones and Fender 2011). After the fact, the teleology of the statistic appears inevitable, a progression from conception through technical debates to the final statistical output without reference to the aims, desires or beliefs of actors or classes of actor.

If the conjectural framework above is taken as a starting point, then such accounts appear unconvincingly incomplete explanations the official statistic. Denying this appearance of inevitability, and suggesting instead that statistic-making is a social process, raises the question of how the interactions of the specific agents involved in its creation and the specific institutional context of a statistic have impacted on its final form and content. This research aims to outline the official statistic-making process and through this to deepen understanding of official statistics as its outputs. What, exactly, is 
being done and by whom when official statistics are made? Why are they doing it? How do these aims and actions intersect in the production of the statistic? The answers will be different for each official statistic produced, but by investigating specific institutional contexts, which will be subject to general conditions of possibility and constraint, broad conclusions may be drawn.

\subsection{The 'Measuring National Well-being' programme as a case-study of statistic creation}

The conjectural model of statistical creation above involves numerous a priori assumptions which can only be checked with reference to actually existing statistics. Similarly, the questions which arise from a consideration of the statistic-making process cannot be resolved through reference to theory alone.

One approach would be to consult existing accounts of particular statistics or systems of statistics such as National Accounts (see, for example, Goldsmith 1950 or Kuznets 1938). However, as argued above, such accounts tend to pay very little, if any, attention the activity of statistic-making. It may be possible to see evidence in these of a small number of technical disagreements or compromises between actors, but the day-to-day human solutions, institutional or methodological limitations or practical simplifications which determine the form and content of the final statistic are omitted. While such accounts might be supplemented with personal testimony about the process by individuals involved, in the case of long-established statistics this may not be possible.

The 'Measuring National Well-being' programme offers an opportunity to make this supplementation. On 25 November 2010, David Cameron became only the second sitting Prime Minister to launch a programme of statistical research by the Office for National Statistics. ${ }^{1}$ Building on a famous speech by Robert Kennedy, he noted that the traditional measure of national progress, GDP, counted 'something of an immigration free-for-all', 'something of a cheap booze free-for-all', and 'something of an irresponsible media and marketing free-for-all', which contributed to growth but which did not 'improve lives' (Cameron 2010, np.). ${ }^{2}$ The solution was a new statistical programme, not tied to economic measures, to address the question of 'quality of life'; the 'Measuring National Well-being' (MNW) programme. Developed over several years, this saw its first release in 2013 (Office for National Statistics 2013e, f). The programme eventually encompassed 41 headline measures reported twice annually, with a range of submeasures reported as part of less frequent 'domain' reports (see Appendix $\mathrm{C}$ for a list of measures, and Chapter Three, Allin and Hand 2014 and Scott 2012 for a fuller account of the programme).

At the point at which the present research commenced, the programme was still in development (see, for example, Government Statistical Service 2013); while there had been numerous statistical releases since the project was launched in 2010 , it was still

1 The first was Wilson, launching the publication Social Trends in 1970 (Nissel 1970; Moser 2000).

2 Kennedy had mentioned air pollution, the 'chaotic sprawl' which destroyed the natural environment, napalm and the materiel for combatting race riots (Kennedy 1968). In comparing the two lists, it is hard not to be reminded of the opening lines of Marx 1852. 
open to adjustment in light of feedback from Commissioning Actors or the Statistical Audience. The currency of the project meant that Statistical Actors, both within the ONS and their advisory bodies, were still accessible, which allowed them to be questioned on the nature of their work. It also meant that there were on-going decisionmaking processes which could be opened to scrutiny. Unlike established statistical series, where the process of statistic-making has been routinised and the original determinants of the statistic lost, the 'Measuring National Well-being' programme permits an examination of official statistic-making as a living social practice. Also unlike established series, the programme is being developed in an era of 'open government', meaning that minutes of advisory committees, responses to public consultations, and other evidence of internal discussions should be freely available for scrutiny.

The MNW programme has some interesting features as an official statistical programme. It owes its origin to criticisms of an existing set of official statistics, GDP (see Cameron 2010 as indicated above; also Stiglitz, Sen and Fitoussi 2009), so exemplifies the pattern of statistical solution to an existing statistical problem discussed in the opening section. At the same time, it seeks to record a phenomenon, 'well-being', the definition of which is disputed within the theoretical and empirical literature (see, for a discussion, Scott 2012 and, for an example, Tomlinson and Kelly 2013). ${ }^{3}$ As an official programme, the statistic intervenes in this debate, setting the terms on which 'well-being' will be used within wider state discourse. The grounds on which this intervention is made thus has wider ramifications, outside of official statistics and within broader discussions around social policy.

Doubts cast on the programme by the Statistical Audience (see, for example, Office for National Statistics 2012a), offer further reasons for interest. Statistical Actors have had extensive engagement with members of the Statistical Audience within the general public, academia and government, incorporating them into the design process. The extent to which these Audience members were included as Statistical Actors is unusual in official statistic-making practice, and will present additional complexities for the social production process. That it has occurred at all is interesting, suggesting either a shift in practice demanded by shifting social norms and expectations of public bodies, or a sense on the part of Statistical Actors within the ONS of a peculiar sensitivity in relation to the MNW programme. It is worth noting that this incorporates the Statistical Audience earlier than suggested in figure 1.1., an example of the blurred lines between Statistical Actors and Statistical Audience. How typical this is, and what influence it had on the outcome of the programme, are open empirical questions.

As a final point of interest, the programme arises at an interesting social juncture for the UK. At the time of the project's commencement, devolved governance on the part of the constituent nations of the UK was well established, bringing with it increased fragmentation and specialisation within government and public policy. The Office for National Statistics was complemented by the statistical wings of the devolved Scottish Government and Northern Irish Administration, while still acting on behalf of the Welsh Devolved Administration and the remaining parts of the UK through its role as overall

3 It is also disputed in non-academic literatures; see, for example, de Saint-Exupery (1971) or Dickens (2003). 
UK executive statistical body. The Scottish Administration, rather than replicating the ONS programme, devised one of their own which was very different ('Scotland Performs'; see Scottish Government 2011). How these local political geographies impacted on the programme will have implications for the practice of official statisticmaking in general.

The 'Measuring National Well-being' programme, then, offers the potential to investigate statistic-making as a social practice, and has a number of particular theoretical and institutional features which will offer insight into that practice. Using the conjectural framework above as a starting point, this project will examine the MNW programme to explore the social practice of official statistic-making within the UK institutional context.

\subsection{Outline of the thesis}

On the argument of this chapter, the actual activity of official statistic-making cannot be ignored if a full understanding of official statistics is to be reached. Chapter Two explores existing literature on official statistics. It will argue that this falls into two broad categories: critical readings, largely Foucauldian and Marxian in outlook, which suggest that official statistics are tools of the state used for purposes of social control; and native accounts, predominantly from Statistical Actors, suggesting that statistics are neutral objective representations of the external world. It will be argued that both these approaches underplay the act of official statistic-making; in as far as it is represented at all, it is treated as occurring within a black box and uncontested. By the arguments of the present chapter, such readings are at best incomplete and at worst contribute to the naturalisation process by reducing the published statistic to the inevitable outcome of a smooth process. Chapter Two will highlight the gaps created by such approaches, particularly around the actions and intentions of the multiple Statistical Actors and suggest that the literature around social constructionism offers ways of understanding these gaps. Building from this examination, it will propose a key research question to be answered:

Does an examination of the social process of official statistic-making add to the understanding of official statistics' form and content?

This over-arching question will then be broken down into four sub-questions for examination as the research proceeds:

(1) How can the official statistic-making process be understood as a social process?

(2) What are the components (institutions, theories, individuals, technologies, \&c.) of that process?

(3) How do these components interact to produce the official statistic?

(4) What are the implications of this for an understanding of the official statistic?

Chapter Three will define an epistemology which derives from the claims made in the 
present chapter about the essentially social nature of official statistic-making. From this it will be argued that the most appropriate research methodology for answering the questions set out in Chapter Two is one based around direct engagement with Statistical Actors through interviews and the study of their formal and semi-formal written outputs. From this, a research methodology will be outlined, built around and justifying the choice of the 'Measuring National Well-being' programme as a case study. A key feature of this methodology is its focus on the institutional and theoretical contexts of the statistical programme and, separately, its focus on the negotiation of these contexts by Statistical Actors. This division allows the research to avoid collapsing into a fully agential or fully structural viewpoint, recognising the interplay between Actors and their contexts (see, for similar arguments, Jones 2007, Ch.1). By defining a research methodology and case study, this chapter represents a contribution to the literature around official statistics by allowing the explication of the official statistic-making process. It is unusual for new statistics to be created, so the process of their creation has previously not been observed and its details are currently unknown.

Chapters Four to Seven will follow this methodology through. Chapter Four will examine the institutional structure of the 'Measuring National Well-being' programme, looking at the history of the Office for National Statistics and of the policy-making structures of the UK state within which it sits, up to 2010 when the statistical programme was launched. This examination will draw out themes of institutional constraint and opportunity which the Statistical Actors responsible for the programme will need to navigate in the process of constructing the statistic.

This chapter makes contributions to the literatures around the Office for National Statistics and policy-making structures in the UK. In the case of the former, it extends previous accounts of the organisation, taking account of organisational and legislative changes over the last twenty years. In the case of the latter, it brings together accounts from multiple disciplines, offering a fuller picture of policy-making than any of them offer alone.

Chapter Five will follow the same model as Chapter Four, but will focus on the theoretical structure of the 'Measuring National Well-being' programme. This encompasses both the multi-disciplinary literature around 'well-being' and historical and recent attempts to quantify well-being within statistical programmes. It will note the complexity of 'well-being' as a topic for quantification and the historical difficulties around it, underlining the challenges Statistical Actors face in operationalising it.

This chapter makes contributions to the literature around well-being, extending the work of others such as Scott (2012). It surveys accounts from several disciplines to produce a fuller account than is usually found. It contributes to the literature around well-being measurement, extending and modifying the work of authors such as Bache (2013; Bache and Reardon 2013).

Chapter Six will examine interviews with and writings by Statistical Actors to explore how the institutional context of the programme was navigated. It will argue that the programme was more strongly influenced by international actors than domestic policymaking concerns. Aspects of the programme are explained in terms of the difficulty 
Statistical Actors had in co-ordinating these two competing sets of concerns; particularly, this is shown to explain the failure of the programme to serve the needs of domestic policy actors. It will argue that other features of the programme were influenced by budget limitations and the restriction on possibilities that this created. It will also argue for the importance of public understanding as an aim which altered the design of the programme.

Chapter Seven will follow the model of Chapter Six, but explore how Statistical Actors, both part of the Office of National Statistics and drawn from a variety of academic disciplines, negotiated the theoretical complexities of 'well-being'. It will argue for a certain degree of path-determinacy, with conceptions of well-being favoured by economists being privileged in discussions. This led to the programme favouring mechanical conceptions of well-being over more holistic ones. Such debates became embodied in individuals, highlighting the personal and agential nature of official statistic-making. Such embodied responses led to a variety of features of the programme. A further key finding is that measures were included for practical reasons, with theoretical discussions about their appropriateness avoided.

Chapter Eight will draw this research together, addressing the questions outlined in Chapter Two (see above). It will argue that the official statistic-making process can be understood as a social process and that this does aid the understanding of the form and content of official statistics. This will be illustrated with features of the 'Measuring National Well-being' programme, such as its inclusion of 'Human Capital' as a submeasure. In doing so, the chapter will suggest that the conjectural model outlined in Section 1.2. stands as a good working model for the official statistic-making process, and point to the ways in which the particularities of the 'Measuring National Well-being' case study apply to official statistic-making more generally. The findings of the research will be compared with the literatures examined in Chapter Two, suggesting ways in which the understanding of social processes can extend both critical and native accounts of official statistics. This chapter will also note the limitations of the present research, and suggest ways in which future research may overcome these and build on its findings. 



\section{Chapter Two \\ How have official statistics previously been understood?}

\subsection{Introduction}

The previous chapter argued that official statistics were created by agents and suggested that the precise activities of those agents - their interactions with each other and the world around them - was likely to be important in shaping the form and content of those statistics. One implication which was drawn from this was that the intentions of both those commissioning the statistic (the Commissioning Actors) and producing it (the Statistical Actors) might not be fully realisable. That is, the circumstances of production - the constraints and opportunities offered by technology, resources, institutional setting, the beliefs and capabilities of the Statistical Actors themselves, and so on made the output of the process contingent. Any given official statistic may well have taken a different form, or had a different content, if the actors producing it, or the circumstances in which it they produced it were different.

The present chapter examines existing literatures around official statistics in particular, and around statistics more generally. It will argue that existing literatures take an abstract approach to official statistics, seeing them as natural objects within larger processes. In the case of critical readings of official statistics, such as those proffered by Foucauldian and Marxian writers, the official statistic is treated as a technology of control, a relatively unproblematic translation of an intention to control by some political actor or actors. In the case of more native accounts of official statistics, those made by statistical producers themselves, the statistic is treated as a more-or-less accurate representation of the external world, a relatively unproblematic translation of observations into manipulable inscriptions. This chapter will argue that both these approaches are too abstract: while they offer potential explanations as to the existence of particular statistics, they cannot explain why those statistics take the particular form that they do. The examination of the process of official statistic-making represents a gap in the literature and a gap in the understanding of the form and content of official statistics.

The chapter will then draw on a social construction literature, both directly engaged with statistics and more broadly, to develop the ontology sketched out in the conjectural model of Chapter One. This will help highlight the implications of understanding official statistic-making as a social process, particularly the complexity and contingency of the statistics themselves. It will be argued that attention to the social process by which objects are made offers new ways of understanding their form and content, and that applied to official statistics this allows a way to move beyond high-level theories.

The argument presented is not one of the incompatibility of approaches; both critical and native approaches are capable of accommodating accounts of the official statisticmaking process. Rather, the argument is that an understanding of the process changes the terrain on which existing theories need to operate. For the critical accounts, the contingency of the official statistic raises questions of the relation between the intention behind the official statistic and its use; if there is a gap between an intention to control and the official statistic used for control, how does control come about? For the native accounts, contingency raises questions about the nature of the representations that 
statistics provide; if the form and content of the official statistic is contingent on circumstance, to what extent is the statistic a representation of its object rather than the object a product of the statistic?

The chapter will proceed as follows: Sections 2.2. and 2.3. will examine the critical and native literatures around statistics and official statistics in turn. Section 2.4. will then examine social construction literature as a complement to these. The chapter will conclude in Section 2.5. by drawing out four empirical questions which arise from approaching official statistics as the products of social processes.

\subsection{Critical readings of official statistics: Foucauldian and Marxian accounts of official statistics as technologies of control}

The present section will examine the role that official statistics play in Foucauldian and, to a lesser extent, Marxian writings. In the case of the former, the role is central: as Foucault argues in his writings on governmentality (e.g., Foucault 1991a), the modern state exerts its power on the level of the population rather than the individual and this level is both acted on and largely known through statistics. The inscription and aggregation of individuals numerically by official statistics acts as a concretisation of the concept of 'population', providing something above the individual on which the state can act. At the same time, statistics, and official statistics in particular, act as regimes of truth to constrain the actions of individuals, influencing the ways in which they selfgovern.

While there is an obvious affinity between Marxian and Foucauldian theories of governance, official statistics play a much smaller role in the writings of Marx and his followers. While both made use of official statistics as counter-information to illustrate social conditions under capital (see, for example, Braverman 1998; Engels 2009; Marx 1990), a use that later critical scholars have continued (e.g., Dorling and Simpson 1999b), there have been relatively few direct theorisations of official statistics by Marxians. However, what work there is (Irvine, Miles and Evans 1979) and broader Marxian critiques of rationality (see Adorno and Horkheimer 1997) can usefully be read in dialogue with Foucauldian theorisations to develop a reading of official statistics as a form of social control.

Such a instrumentalist reading is not structurally out of step with native pronouncements on official statistics. The Office for National Statistics, for instance, explicitly links their work to policy and through this to individuals' lives (see, for example, Matheson 2010; Office for National Statistics 2013b) while the Organisation for Economic Co-operation and Development publishes its social statistical programme under the motto 'better policies for better lives' (Organisation for Economic CoOperation and Development 2013a). Official statistics are intended by their creators to have a role in intervening on the external world, particularly through making it easier to administer. The distinction between the critical and native approaches is in the object of the official statistic's instrumentality: while native accounts claim that official statistics are designed for use in improving lives, a critical reading would suggest instead that they are designed to establish a dichotomy of 'improved' and 'unimproved' lives and to 
manage the 'problems' of the latter.

It will be argued that such critical readings, while useful, are incomplete. They tend either to start with the reality of the official statistic and deduce its intention to control from its features or use; or to move from a theorised intention on the part of its Commissioning Actors to the statistic's features or use. In both cases, the work of the Statistical Actors are treated as a black box and assumed away. This is not to claim that statistics cannot be forms of biopolitical or class control; instead, the following review aims to highlight that they are not necessarily so, meaning a gap exists around the question of how such control comes about.

\subsubsection{Official statistics as a Foucauldian technology of government}

For Foucault, the modern state is not a concrete entity, but a system of power based around a rationality of governance predicated on the non-physical control of populations (Foucault 1991a, 2008). This can be contrasted with earlier feudal states, where systems of government were based on the direct coercion of individuals; where such systems ensured compliance with their aims through the power over life, the modern exercise of governmentality ('government rationality') secures its aims through a manipulation of public discourse. This manipulation of discourse creates entities, such as 'the nation' or 'the economy' that are not real in the sense of 'concrete entities existing in an external world', but which are true in the sense of 'abstract entities which can be meaningfully discussed and shown to have impacts on individuals'. As Foucault explains in an example of this distinction: "Politics and the economy are not things that exist, or errors, or illusions, or ideologies. They are things that do not exist and yet which are inscribed in reality and fall under a regime of truth dividing the true and the false." (Foucault 2008, p.20; see also Dworkin 1982, Ch.7, which makes the same point somewhat less opaquely).

Such 'regimes of truth' and the entities they define have 'transactional reality' (Foucault 2008, p.297); their definitions limit what is possible for individuals in the external world. Governmentality acts with and within such regimes, both bringing them into being and acting within their limitations. Key amongst these entities, for Foucault, is 'the population', an abstract entity which is 'made true' largely by statistics and official statistics as regimes of truth (Foucault 1991a, p.99). In isolation, any given individual can have no conception of 'the population'; their lived experience is of interactions with family, friends and community (c.f., Porter 1995). Statistics allow aggregate effects to appear that are not apparent at the individual level, and simultaneously open up these effects to management. 'The population' here is analogous to Latour's (2005; or, for that matter, Thatcher's 1987) 'society'; it is an emergent effect of the activities of individuals when framed within a particular regime of truth.

Foucault argues that the collapse of feudalism led to a shift in the accepted object of government rationality from the individual to the population, and a resultant shift in the techniques suitable for the exercise of that rationality. There was, for Foucault, a shift from 'sovereignty' as exercised on an individual to 'security' exercised through them via biopolitical control. Such control comes through a manipulation of regimes of truth that 
create a self-governance on the part of individuals (Foucault 1991a). As an example of such biopolitical control, Foucault offers the example of 'madness', a discourse which has the transactionally real effect of defining 'normality' and acceptable behaviour, with the consequence that a set of reactions and institutions becomes necessary to police the boundary between the two (Bordieu and Wacquant 2001; Foucault 2001). Less dramatically, contemporary 'nudge' theory seeks to use behavioural psychology, a regime of truth structured around population-level generalisations, to shape the actions of individuals (Fisher 2009; Jones, Pykett and Whitehead 2013; Thaler and Sunstein 2008; Whitehead, Jones, Pykett and Welsh 2012).

An important aspect of these regimes of truth is their apparent naturalness. Foucault (2008) offers the example of 'the economy', which is claimed to operate according to natural, empirically discoverable laws. Such laws, as natural, are neutral; once the causal universe that the regime of truth invokes is accepted, it is no longer possible to talk about the consequences of actions normatively. The market is no longer a place where justice is adjudicated, but one where truth is; the outcomes of exchanges are right or wrong, not fair or unfair. This invocation of natural, causal laws has clear roots in Enlightenment rationality (see Adorno and Horkheimer, 1997, and the discussion below); it attempts to understand individual entities and events as the outcome of aetiologies divined through the observation of a mass of cases.

Situating official statistics within a tradition of Enlightenment thinking allows them to be seen as a special case of statistics more generally. Knowing an object requires the invention or use of technologies of knowing, modes of representation which allow the entity in question to be depicted and so made amenable to deliberation and argument (Latour 1987; Porter 1995). Underlying this is an assumption that individual entities or events are commensurate in some way, that they are tokens of a larger type. Without this assumption, there can be no object at all in the sense that there is no type of which the given case is token. There can also be no statistic, only a collection of anecdotes about individual objects (what Foucault calls the 'singularity', Foucault 1991b). The existence of an official statistic is predicated on a regime of truth in which the commensurable aspect is essential to the object and its individual aspects are unimportant. The official statistic becomes part of the regime of truth, defining the essential nature of the object which it counts.

By reducing the complexities arising from individuality, previously vague domains are translated into information which is stable, mobile and comparable. In the case of the official statistic, this creates new information that provides 'calculating power' (Rose 1991); it allows governmental actors to influence the development of the domain across widely dispersed populations (Hopwood and Miller 1994; Miller and Rose 1990). The categories defined by the statistic become transactionally real, having concrete effects within the domain that the statistic has helped define (Foucault 1991b, 2008; see also Kalpagam 2000 on the role of statistics in structuring reality in areas of colonial occupation). This is because, again, the individual has been reduced to a component of the 'population', subject to the laws which have become apparent at that level and so to the interventions which those laws suggest. Most particularly, the governmental concern shifts from being the control of individual acts themselves and instead the management of the rates of those acts across the 'population'. 
Important within the official statistic is the conception of the 'normal', set at the level of either an 'average' individual or some politically defined optimum or minimum. This arises from the re-presentation of individuals as an aggregate which allows the definition of extremes ('abnormality'), and so targets for governance (Miller and O'Leary 1994). Such targets arise naturally from the definition of a domain as one to be governed, with statistics becoming both a marker for such a domain and an instrument for co-ordinating the process the government seeks to direct (Foucault 1991a). Castel (1991) has argued that this culminates in governments seeing individuals as collections of risks defined by probabilistic laws, with the role of government becoming risk management. This is the logical conclusion of a population-based approach, seeing the individual merely as a component of the aggregate, rather than constitutive of it. These risks need to be managed preventively, a decision which separates diagnosis from treatment. 'At-risk' sub-populations are defined and resources targeted, regardless of actual experiences by individuals of 'abnormality' as defined (Office for National Statistics 2013c).

In this way, official statistics become 'technologies of calculation', a literal representation of processes and events away from where they occur and in the places where decisions are to be made about them (Miller 1991). These sites may be dispersed, with the site of statistical creation being distinct from the sites of both data collection and the site of decisions and actions taken on the basis of the statistic. This is possible because the common language of statistics (Miller and Rose 2008; Porter 1995) enables multiple 'centres of calculation' (Latour 1987, 2005). This is a transformation of the domain of government, enabling an aggregation of events to be made across space and time. By revealing statistical norms they also construct policy norms, allowing evaluations to be made and interventions to be targeted. The statistics create the domains they record, a 'population' or 'an economy' arising form diverse and dispersed individuals and phenomena (Rose and Miller 1992).

In performing this role, official statistics are a technology of governance, supporting the programmatic aims of state actors (Hopwood and Miller 1994; Power 1997; Rose and Miller 1992). Governmental rationalities have a moral form and are epistemological in nature, articulated in relation to some conception of the nature of the object governed. The official statistic defines that nature by saying what it is that is being counted. This acts as a gate-keeping mechanism, influencing the decisions of individuals indirectly by setting the conditions under which their behaviour will be counted. Power (1994, 1996, 1997) gives a comparable account of the audit process, which alters business behaviour by requiring it to be auditable. By defining 'employment' or 'happiness' or 'well-being' in a particular way, only those aspects which meet the definition are open to targeting. The remaining complexity of an individual's circumstances is invisible to the governing actor and irrelevant to their concerns. Increasingly, this complexity can become less relevant to the individual too, as all the incentivisations offered by governing actors relate to the phenomenon as defined, not as experienced. In this light we can read claims such as those made by UK Statistics Authority that official statistics are "essential to the proper functioning of a democratic state" (Bumstead and Alldritt 2011, p.1; see also European Statistical System System 2015); the statistic plays a role in defining the nature and functioning of the state, and is in turn defined by understandings of what the 
'democratic state' consists in (Prewitt 1987).

However, this dual aspect of governmental action, technological and programmatic, leads to the failure of government action. The technological solution can never fulfil the programmatic aims because its necessary abstraction from the nature of the object being governed leads to its inadequate representation (Miller and Rose 1990). Individuals are different and are in different circumstances, so applying a causal relation which works in the majority case will fail in individual ones. More than this, the causal relation is only relating to a particular, isolated part of the individual's circumstances, while ignoring the rest. This skewed attention leads to other problems arising through lack of care. The solution to one 'problem' which the statistic defines leads only to another. In this sense, regulation (and the statistics which inform it) is always failing (Miller and Rose 2008).

\subsubsection{Marxian approaches to statistics}

Despite the use made by Marx of statistics, both official and unofficial, as evidence underpinning his arguments (see, for example, Marx 1990) and a tradition which follows this use (see, for examples, Baran and Sweezy 1966; Braverman 1998; Engels 2009), there is little explicit engagement with the nature of statistics within Marxian writing outside of the chapters in Irvine, Miles and Evans (1979). However, an argument can be made for a comprehensive implicit engagement with official statistics within Marxian theory. A simple form of this argument would note the role of government as the caretakers of the interests of the bourgeois class (Marx and Engels 1992), and read all their activities, including the official statistic, as a means to this end. A development of this argument would note the relations between the economic base of capitalist production and its expression through governmental forms (Marx and Engels 1977). Such an argument allows the consideration of the official statistic as a technology of control in a manner akin to Foucauldian readings, but technologies which form part of a wider superstructure obscuring the true nature of the social world. A further extension would encompass the critique of epistemology and prevailing social forms typified by Adorno and Horkheimer's (1997) critique of the Enlightenment rationality which underpins statistical methods.

On such a reading, official statistics are expressions of the capitalist system. They are only possible because labour power is traded as a commodity, allowing human beings and their activities to be denominated in a common fashion as economic entities, rationalising their various qualities and properties and allowing them to be compared (Shaw and Miles 1979). It is this which underpins the commensurability which official statistics require (Porter 1995), rendering the individual (Doel 2001), or individual object interchangeable with other items denominated in the same fashion (Marx 1990).

This is a reification; the social relations which give rise to people, skills and objects are obscured in statistics and official statistics which instead treat them as context-free data. Reification is both a tendency within the capitalist system (Lukás 1971) and a necessary act for statistics to be possible; the qualities of subjects must be reduced to quantities, humans rendered as objects to be counted (Parker 1999; Vaneigem 2003). By 
abstracting from their properties and homogenising them under capital, individuals and acts can be aggregated into theoretical abstract entities such as the 'nation' or the 'economy'. These and, by implication, the individuals and acts which make them up, become the subject of impersonal forces, statistical regularities such as 'recession' or 'competition'. Instead of seeing individual circumstances as arising from localised choice and political decision, they are subsumed in supposedly universal forces. In this way, the deeper meanings of actions and events are obscured (Lukás 1971).

This is the ontological inversion, the treatment of people as things (Hacking 1991; Marx 1990). The statistic acts as a fetish, a way of masking the true nature of circumstances, hiding the individual and the power relations which have produced their situation. This acts in the same way as the commodity fetish: there one is confronted with a commodity which appears as a natural object, here one is confronted with data about an abstract entity which appears as a natural object. In both cases, the actual object is hidden by the veil of production, a process of obscuring the social meanings and values inherent in the object (Olsson 2000). This mirrors the Foucauldian move to the population rather than the individual; what is seen is the movement in the abstract output, not that output's expression in the lives of individuals. All that is visible in the official statistic is the movement in the reified object, not the social circumstances which it is formed from. As such, the statistic alienates its subject from their subjectivity (Sartre 1968).

Later authors read this homogenisation of the individual as a unit under capital as a natural extension of the mythic fatalism of Enlightenment thinking which abandons the idea of the social and of individual control in favour of grand impersonal regularities. What cannot be abstracted from in this way is abandoned as subjective or phenomenological, ostensibly in an effort to obtain neutrality by replacing a normative discourse with a positivist-empiricist one (Adorno and Horkheimer 1997). The abstraction inherent in statistics is of a piece with the division of labour under capital, which values people only for abstracted aspects of their being, the alienated labour which makes the system possible. The product of that labour, its purpose and use value, is lost in the exchange value which is all that is counted in economic statistics (Young 1979).

Statistics and official statistics are required because the capitalist division of labour creates complexity within production processes which requires co-ordination, while at the same time the alienation it rests on creates contradictions which need to be managed if they are not to impede the accumulation of capital (Harvey 1985, Young 1979). This is particularly the case at the national level, where the committee of the bourgeoisie who run the economy need to make sure that actions taken by members of their class in their own best interests do not impede the reproduction of the class as a whole (for instance, that wages are not suppressed below the point at which labour can no longer reproduce itself). Shaw and Miles (1979) see the growth of official social statistics as an explicit response to such contradictions; an interest in unemployment, for example, arising from the need to regulate the size and revolutionary potential of the reserve army of labour. On this reading, official social statistics stand as a complement to economic ones, ${ }^{4}$

4 It is worth noting the reification of 'economic' in this division of official statistics in opposition to, rather than as a part of, 'social', exemplified by the separation of statistics in UK official publications such as Social Trends and Economic and Labour Market Review. 
showing where accumulation is threatened by the living conditions of the labouring classes. Only the state has the resources to conduct data collection on the scale required and its position serves to co-ordinate the interests of the otherwise competing capitalist class. Such statistics are necessarily geographical in their nature, as social problems have spatial expression and the state extends over territory (Brenner 1997, 2004; Brenner and Elden 2009; Elden 2004; Lefebvre 1991, 2009; Soja 1985)

According to this interpretation, the state, which strives to present itself as apolitical, and the statistics it produces, which are presented as neutral technological solutions to apolitical problems, are both nakedly political. They are attempts by the owners of capital to secure their ability to accumulate and to aid them in that accumulation (Miles and Irvine 1979). The extent of this presentation is marked; in the UK context, official statistics are produced by an arms-length government body under an independent National Statistician, one of whose responsibilities is correcting party-political misuses of officially produced statistics (National Statistics 2000). This explicit depoliticisation masks the role the state is playing in the maintenance of the conditions for the reproduction of capital; the independence of the individual producing the official statistics is unimportant when the statistics themselves reproduce the dominant ideology. In this way, official statistics allow both the control of productive processes and social control, as well as the legitimation of policies designed to achieve these (Atkins and Jarrett 1979).

In agreement with the Foucauldian account, such Marxian readings assert that statistics are not uncovering 'reality'. Instead, they are acts of prestidigitation, showing isolated elements of phenomena out of context as if it were the phenomena and not the context which were important. These statistics act as spectacles, meaningless in themselves (it matters not to the unemployed person that unemployment has fallen generally), but acting as grand gestures pretending to meaning (people will vote to re-elect a government who brings unemployment down, as they are 'good on the economy', pretending to offer a security which the economic system denies) (Debord 1995, 1998; Wark 2013).

\subsubsection{Questions left by Foucauldian and Marxian accounts of statistics and official statistics}

These two critical accounts offer broadly consistent readings of statistics and official statistics. In both accounts, the specificity of the object of an official statistic is sacrificed for an imposed generality. This creates an abstract statistical object which is taken to be a concrete object in the real world. By representing the statistical object in the abstract, political actors are able to talk about it, consider it and act on it. In this, the abstract concept comes to have real effects on individuals, limiting the scope they have for action. Such a mode of control was the intention of official statistic in the first place either as a result of governmental rationality or of a class rationality expressing itself through governance.

Before considering the gaps left by these accounts, it is worth noting a number of differences between them. One is the role official statistics are playing in their analysis. 
The Marxian account is quite straightforward: the official statistic shares features, principally reification and fetishisation, with other forms of capitalist abstraction, allowing these features to be explained in the same way. Official statistics are incidental, a case study within a wider model of capitalist activity. In the Foucauldian account, official statistics should be more crucial, but tend to only be mentioned in passing: they are taken to be a technology of control because that is what governmentality requires. The precise form and content of the statistic tends not to be examined; merely by virtue of being an official statistic, whatever their object is they are a form of control.

To varying degrees, both accounts have trouble dealing with the question of intention. In both cases, the official statistic is generated somewhere within government with the intention of permitting the control of the population. That there is an intention to control is assumed. However, there is a question of how this intention is conveyed through the statistic-making process. The danger here is that of affirming the consequent. If the starting point of an analysis is that the state is known by its actions, as it is in Foucauldian theory, or that all cultural activity under capitalism reflects capitalist modes of production, as it is in Marxian theory, then the official statistic, as an activity of the state, can be nothing but an expression of political control. The actions of those designing the statistic are under-determined as there was no way they could have acted which would not have brought about such control. The precise form and content of the statistic cannot be explained; they appear, post hoc, as the inevitable result of a teleology whose existence precedes them. (It is worth noting that this is generally true of the actions of state actors in both theories, partly because neither Foucault nor Marx was especially concerned with the specific internal workings of the state.)

Such a post hoc analysis also tends to treat the production of the official statistic as a black box. Both approaches have explanations as to why Statistical Actors might produce an object which allows for governance of individuals in the external world. In the case of the Foucauldians, it is because they are thinking in terms of the 'population' to start with; the official statistician, by virtue of being a statistician, is operating within a regime of truth in which biopolitical control is inevitable. For Marxians, the Statistical Actor is a part of the committee of the bourgeoisie that is the state, and shares their class concerns. Again, though, this doesn't help explain the form or content of a statistic: why has control been sought in this particular way? Ironically both explanations tend to homogenise official statistics just as these statistics homogenise individuals, seeing them all as tokens of a type rather than as entities in their own right.

This is particularly problematic for later Foucauldian theories which accept that the actors within the state are diverse (Miller and Rose 2008) and that those in the centre are often confounded by those who are more peripheral (Rose 1991). In this way the theory allows both that the official statistic is designed as a technology of control, but also that there is no guarantee that it will turn out to be usable as one. Miller and Rose (2008) go further, suggesting that the technologies of control always fail to meet their programmatic aims; that no official statistic can operate quite as it was intended to. The precise nature of the statistic arises from contestation and does not (quite) meet the aims set for it. This makes their aims unknowable, as, by assumption, the actions the statistic allows are not necessarily what it was intended to allow; resistance and contestation intercede between intention and outcome. To come at this from the opposite side, if 
government and regulation always fail as some Foucauldians have claimed (Miller and Rose 1990; Power 1994, 1996, 1997), it seems important to consider how things fail and for what reasons.

The problem for Marxian accounts is similar but somewhat cruder. If the argument is accepted that statistics are developed in the interests of capital, as a way of monitoring the effects of contradictions and the resources available to capital, then it matters who is doing the monitoring. Even when both Commissioning and Statistical Actors are drawing on the same body of economic theory, there can be no guarantee that the outcome of the design process will be the statistic the Commissioning Actors require. Technical restrictions around what it is possible to measure, how much funding is available, existing statistical best practice, and so on may limit what is achievable. This will need to be negotiated amongst the Statistical Actors, whose class composition is potentially heterogeneous in terms of origins and will be broadly petty bourgeois rather than capitalist in terms of present interest. How a statistic arises which serves the needs of capital from agents who are not themselves capitalist and who may not consciously act in the interests of capital, becomes a live question.

\subsection{Native accounts of official statistics: how the statistical profession considers} its output

The critical theories surveyed above can be broadly understood as being rationalist in their outlook. They start from the premise that categories are being originated by Commissioning or Statistical Actors, and then imposed on an external world. While these categories gain a transactional reality, shaping that external world, they lack truth, in that they are not discovered from that world. Accounts by official statisticians themselves, and by academic statistical theoreticians, can be broadly categorised as empiricist. They start from the premise that there is a phenomenon or quality in the external world which can be observed, and then proceed to define that phenomenon or quality in terms of its observable characteristics. They are thus strongly tied to an empiricist world view and the scientific method (Lindley 2000). This definition allows counting to occur by ensuring commensurabilty: for the purposes of the statistic, there is an identity between two phenomena or entities meeting the definition, they are the object the statistic describes and, for the purposes of the statistic, nothing more (Bandyopadhyay and Forster 2011; Hand 2004). (For fuller accounts of rationalism and empiricism, see Benton and Craib 2011; Hammersley 2000; Hindess 1977).

In both critical and native assessments of statistics and official statistics there is a correspondence between the object of the statistic and objects in the external world. The difference between the assessments, on this argument, is whether the object precedes the statistic or vice versa. For example, the Office for National Statistics and the National Statistician describes the organisations' vision as: "To be widely respected for informing debate and improving decision making through high quality, easy to use statistics and analyses on the UK's economy and society." (Office for National Statistics 2013b, p.9; see also 2010a; Matheson 2010). The 'UK', its 'economy' and 'society' are taken here to be real entities which the statistic observes and analyses. The official statistic may 
capture these more or less well, with their 'quality' being both a function of their accuracy when compared with the external world and the rigour of their attempts at capturing it, but there is something in the world external to the official statistic there to be captured. We can contrast this directly with Foucault's denial of 'society' as an $a$ priori entity and his claims instead that it is an a posteriori rationalisation within broader regimes of truth around ideas such as 'economy' and 'liberalism' (Foucault 2008).

The reference to 'decision making' in the vision statement above points to the official statistic as being instrumental, again an assessment which is shared with critical readings. They assume a regularity in phenomena that can be observed through data collection and thus allow influence through policy intervention. This is clearest in the reception of statistics by certain parts of the statistical audience; when employment rates fall, or inflation increases, causal and systemic explanations are given (see, for example, Cameron 2013). Statistics are treated as records of phenomena within a causal universe, impacting on and being impacted by other entities and phenomena. Statistics suggest action or reaction, to affect inputs to change the statistical outcome or perhaps to respond to a statistical outcome which cannot itself be influenced. Again, there is agreement here between critical readings and native ones in as far as the desire for influence of the external world directs the statistic; however, while the instrumental purpose seen by the critical reading is essentially malign, here it need not be. The vision statement above assumes a decision-maker for whom the statistic is a neutral tool; the 'improvement' of their decisions which it enables is relative to their purpose, which lies outside the remit of the Statistical Actor.

It should be noted that this claim to instrumentality arises largely from the specific contexts of UK, European and global official statistics (encompassed in the example of United Nations, Organisation for Economic Co-Operation and Development, International Monetary Fund and European Union 1993). It is possible to conceive of official statistics which are not collected with any instrumental purpose. This is easiest to imagine in situations where a purpose formerly existed, or where there is a normative value attached to the object but no intention to influence it or the actions of others. However, it is possible that an official statistic could exist recording an object merely for the sake of recording an object. ${ }^{5}$ The fact that such ornamental statistics are rare again places official statistics firmly in the Enlightenment tradition in which the understanding of the world is intrinsically linked to action on it (Adorno and Horkheimer 1997).

The neutrality of the official statistic derives from its empiricist underpinnings: as the objects of statistics are independent of beliefs about them, the task of the official statistic is to represent that object as accurately as is possible. Accuracy, expressed in terms of 'quality' (Office for National Statistics 2013b) here has the two standard

5 It can be argued that such statistics may already exist - I am unaware of any official use of the statistics on the most common names given to new-born children, which are published every year by the Office for National Statistics. The 2014 version lists a number of potential users and uses, including "Journalists who report and produce articles on the popularity of names", but agents of the state and their uses are not included (see Office for National Statistics 2014a, p.6). I myself use this set of statistics in the present research as a way of anonymising interview participants (see Chapter Three). 
components of accuracy in the natural sciences, validity and reliability. Official statistics must rest on a definition which captures the phenomena under question (they must be 'valid') and must do so free of bias (they must be 'reliable'). Accuracy in this sense is achieved through making statistics replicable: publishing methodologies, making them both subject to external inspection and repetition by peers. Within official statisticmaking bodies, such as the ONS, hierarchies of quality control exist to enforce methods of accepted best-practice and settled bodies of epistemology. Clearly, there are decisions to be made by the Statistical Actor about how best to measure the object in question, but these are always limited by the object itself. Two different Statistical Actors, operating within different contexts, may differ in their ability to measure an object and so produce different official statistics but the existence of the object in the external world acts as standard of quality. One official statistic will be 'better', more reliable and valid, than the other and both statistics could 'better capture' the object if a more reliable and valid methodology was used.

If this summary is accurate, and it will be argued below that it is, then the process of official statistic-making is essentially one of representation. There exists an object in the external world and the task of the Statistical Actor is to characterise it as best they can. That characterisation will be primarily guided by technical arguments aimed at securing the most theoretically valid and the most procedurally reliable representation. It will be observed that examples of accounts of official statistics by their producers tend to emphasise such technical arguments. However, if, as Chapter One suggested, the Statistical Actor has agency and acts within a context-specific set of opportunities and limitations, there remains the question of why a given technical argument has been found convincing. Where there are multiple ways of characterising an object of varying validity and accuracy, how has one been settled on?

\subsubsection{An example of a native account of official statistics: Human Capital}

To illustrate the arguments made above, and some of the problems inherent in them, this section will explore the consultation and release documents around the Office for National Statistics' 'Human Capital' statistic (Jones and Fender 2011; Office for National Statistics 2012c, d). This statistic is interesting because it acts to define an object in the external world which is both abstract in nature and of relatively recent 'discovery'. While it can be argued that there was an understanding of human capital as far back as the writing of 'the father of statistics' William Petty (1899), and similar concepts appear in the writing of the statistical pioneer Galton (1909), its theoretical development dates only as far as the 1960s (Becker 1962, 1980; Mincer 1962, 1974; Schultz 1961, 1962, 1970). It can be noted that there is still a 50 year gap between the theoretical development of this object and the creation of an official statistic to capture it, a point which will be returned to below. Part of the task of the official statistician in developing the 'human capital' statistic is in establishing 'human capital' as an object in the external world, rather than something of a merely theoretical nature.

As the consultation paper on human capital estimates defines it, "At the individual level we can think about [human capital] as measuring a person's competencies, knowledge, 
social, personality and health attributes, including creativity." (Office for National Statistics 2012c, p.6). This draws on a definition from the Organisation for Economic Co-Operation and Development, (Organisation for Economic Co-Operation and Development 2001, p.17), where human capital is "The knowledge, skills, competencies and attributes embodied in individuals that facilitate the creation of personal, social and economic well-being." There are, in these definitions, clear claims to an external world; there is an abstract entity, 'human capital', comprised of other entities, both concrete and abstract, which can be observed. (This runs counter to arguments such as those of Blaug, who denies that any such entity exists; see Blaug 1972, 1976, 1985)

In the very name of the object being described by the statistic, there is a conception of it as an economic entity. It is a form of capital. Immediately this presents problems for a purely rationalist reading of the statistic, as it is not apparent that a 'person's competencies, knowledge, social, personality and health attributes, including creativity' are economic properties. However, once they are treated as such it is possible to make empirical observations of them: by comparing starting levels of knowledge, for example, and finishing levels of financial income it will be possible to place a monetary value on an individual's knowledge. Such a valuation is justified on the basis of links between the factors of human capital and economic performance at both the individual and national levels (Office for National Statistics 2012c, pp.8-9).

In this way the statistic follows from empirically observable features of the external world. It is, though, clearly selective in the features it observes: the factors listed as part of human capital equally contribute to non-economic outcomes, such as happiness or community cohesion. That the economic causal relation is being highlighted is a result of the purpose of the statistic:

"Human capital is a driver of economic growth and therefore, in order to better understand the dynamics of an economy, it is important to measure accurately the stock of human capital assets. Stocks of capital are also a useful measure to monitor sustainability. Therefore, as part of the Measuring National Well-being Programme, ONS has published estimates of human capital to compliment existing measures of fixed capital."

(Office for National Statistics 2012c, p.2)

The statistic is devised as a means of better understanding the economy which, in turn, impacts on sustainability and 'National Well-being'. "[M] easurement is very important due to its implications for policy" (Office for National Statistics 2012c, p.8). The definition of the statistic here sits within a much larger causal universe in which there are observable objects such as 'the economy' and 'sustainability' which are the subjects of policy. That these are legitimate subjects of policy is not questioned by the consultation paper, and nor is the nature of the causal universe into which the statistic falls. The observation of human capital is not independent of pre-existing beliefs about the existence of the economy or the viability of intervention through policy, rather it follows from them. The statistic is here presented as independent of politics: 'human capital' is counted because it is important, and is important and can be counted because 
it uncontroversially exists (Keat 1979). Such a position is not uncontested; the existence of 'human capital' is disputed by authors outside of the neoclassical paradigm (Bowles 1970; Bowles and Gintis 1975, 1976; Fine 1997)

Having broadly defined human capital, the consultation paper (and, more fully, Jones and Fender 2011) goes on to operationalise it (Office for National Statistics 2012c, pp.12-18). Here it notes a number of contested aspects of human capital, centring both on what counts towards it and what outputs count in its valuation. Once these issues are resolved, further decisions must be made, for instance relating to the present valuation of future returns. As the paper observes, alternative assumptions can result in radically different statistical values.

The consultation paper elicits responses from potential users on these decisions of methodology, again underlining the instrumental nature of the statistic. Although an empirical observation of the external world, it is directed in a particular fashion and to a particular end. For example, Office for National Statistics 2012c, p.12 observes "This narrow focus reflects the view that these "experimental" monetary measures potentially can be integrated into a conventional economic accounting framework." However, while these 'monetary measures' are accepted as imperfect, the approach is seen as amenable to improvement; Jones and Fender (2011, pp.22-23) lists a number of areas for future research which would develop the statistic while Office for National Statistics (2012c) is an explicit call for suggestions for improvements. These are not attempts to construct a better unreal or purely discursive object, but attempts to better capture the aspects of a real object that are relevant to users. The statistic, imperfect as it is, exists because human capital exists in the external world and having any statistic which meets the basic requirements of validity and accuracy is more useful than having no statistic.

\subsubsection{Questions arising from a native account of statistics and official statistics}

One thing to note about such a native account of official statistics, in comparison with the critical accounts considered earlier, is its acknowledgement of the process of statistic-making. The documents reviewed have been clear that decisions have been made. These decisions have been specific, dealing with exact technical choices rather than the stylised 'desire to achieve control' which appears in Foucauldian and Marxian accounts. The basis for those decisions draws attention to the contingency of the statistic-making process: it is not the case that there is a single, obvious 'best method' and the 'quality' of a method is in part determined by non-theoretical factors such as resources or data-collection abilities.

However, what these documents show is a dispersal of the decision-making process. As a starting point, it is not clear who has originated the official statistic. While it argues that its measurement is "important due to its implications for policy" (Office for National Statistics 2012c, p.8), the ONS does not suggest any specific commissioning demand beyond human capital's position within a wider 'well-being' measurement programme. Indeed, the consultation document is partly aimed at soliciting information on how the statistic might be used and so adapted to better suit that use. The motivating force behind the statistic is that an object important to policy in the external world is not 
currently being observed statistically, which leaves economic accounts of wealth incomplete; that physical capital is measured within the national accounts, but not intangible capital. The ONS cite various international bodies, political, statistical and non-governmental, who have suggested that this incompleteness is a problem, and do so in a manner that suggests that they, as Statistical Actors, agree. There is no suggestion, however, of a direct demand by potential users.

This complicates critical readings, as conceptions of official statistics as technologies of control now have to account for statistics which do not originate with domestic policymaking actors. Another example of this would be the System of National Accounts which were developed over a matter of decades by diverse academics, government actors and official statistic-makers internationally (United Nations, Organisation for Economic Co-Operation and Development, International Monetary Fund and European Union 1993) and to which policy-makers are subscribed by long-standing international treaties. This is not incompatible with a critical reading of official statistics, but necessitates a reading of 'government' which is amorphous and multi-scalar, not simply operating at the level of a single state and its agencies.

At the same time, the dispersal of decisions through consultation complicates a simple reading of the statistic as empiricist. While the statistic is still claiming to observe an object in the external world, the questions of what it observes and how are still open. For all the technical discussion about the merits of different ways of measuring human capital, options were constrained both by what was possible and what was desired. Another example would be official statistics relating to unemployment, where historically two different statistics have existed and their validity been debated within public discourse: the 'claimant count', based on government-controlled access to unemployment benefits, and International Labour Organisation definitions applied to national surveys. The former is open to easy political manipulation (Levitas 1996a; Working Party on the Measurement of Unemployment in the UK 1995). The latter is open to debate (International Labour Organization 2013), but its acceptance and incorporation into domestic official statistics lies out of the hands of Statistical Actors. The selection of the statistical method is not simply a neutral, technocratic act, but has political aspects.

It is possible to go further, and observe that the act of quantification itself, over and above what is quantified, is a choice that has been made. This is not apparent at the level of the native account as the natives themselves are a part of that choice; the existence of the ONS is predicated on quantification as a form of knowledge about the world. As discussed above, quantification requires commensurability, that the things counted are, in some sense, the same (Cartwright 1994; Porter 1995). Discussing social statistics, Doel (2001) argues that this is not the case; that human individuals cannot be meaningfully treated as tokens of the same type. This can be taken as akin to an extension of a critical realist position that an understanding of the context of the object is necessary for understanding the object itself (Sayer 2000). This position is implicitly rejected by the existence of official statistic-making as an activity.

While it is possible to incorporate context within the framework of an official statistic (for instance, stratifying objects by social group or geographical location), removing 
some of the politics from the act of counting, it is not possible to remove politics from the decision to count. The official statistic starts from the position that official statistics are possible, that there are regularities to be observed. The observation of regularities is not a neutral act, but an interpretive one. This is nicely illustrated by Percy and Dolman (1953), who examined the death certificates issued by doctors in neighbouring counties in the United States. Despite having the same standards by which to categorise causes of death and the same training in how to apply these, doctors in different places were interpreting the same symptoms as evidence of different proximate causes. At some point in the engagement with the external world, there will always be a judgement. The grounds of this judgement are not set by the definition of the statistic as there will always remain the question of how to apply the definition.

There are, then, a number of questions that a technocratic account such as those offered by native readings of official statistics leave unresolved. If, as has been argued, official statistic-making is not a simple matter of translating empirical reality into numerical representations, it is necessary to ask how and why the statistics are being made. How do Statistical Actors relate to Commissioning Actors; how are questions of technical accuracy balanced against questions of instrumental need; how, in general, are political concerns resolved within the statistic-making process? These are social questions, which native accounts avoid.

\subsection{Complements to critical and native accounts from the social construction literature}

It has been argued that the three approaches surveyed above are incomplete. All three provide straightforward accounts of the official statistic which move from a conception, either in the form of a desire to control or of an external world to be represented, to the statistic itself. However, it was argued in Chapter One that there is human mediation between the conception and the official statistic. The technology of control must be realised by the makers of official statistics, the world to be represented must be translated by them. This mediation is only considered by these approaches in an abstract fashion: Foucauldian and Marxian approaches focus on the generalised form of official statistics as 'technologies of calculation', native approaches in empiricist exercises of representation. In both cases, the mediation is technocratic and neutral, a pursuit of 'the best way' of achieving the official statistic's instrumental aims.

This amounts to placing official statistic-making in a black-box, with official statistics acting to illustrate pre-existing explanatory frameworks rather than standing as objects of investigation in their own right. Chapter One argued against this black-box treatment. As the native approaches above acknowledged, decisions are made within the statisticmaking process on how best to represent the statistical object. While there are clearly technical grounds for opting for one mode of measurement over another, Chapter One pointed to a number of other potential grounds such as the limitations of resources or technology. Critical accounts suggest others by highlighting the political aspects of statistic-making to which the Statistical Actor will need to respond alongside any technical concerns. In dialogue with each other, then, the three approaches surveyed 
here underline the need for an examination of the statistic-making process itself.

Such an examination, considering the actions and reactions of individuals with agency within the statistic-making process, could be usefully informed by the literature on social construction. This literature emphasises human activity and interaction in the creation of knowledges such as bodies of statistical theory and the concepts which official statistics hope to capture. It suggests that the created object is a reaction to or a negotiation of its context, with that context similarly a reaction or negotiation to what came before in a fluid and dynamic system. This offers another way to consider official statistics, one which complements those examined above.

\subsubsection{What would it mean to say that 'official statistics are socially constructed'?}

After Hacking (1999), two types of claim to social construction might be distinguished. One is the mundane observation that objects are made by people. This clearly applies to the official statistic as an output; it is not a naturally occurring object, it is made by Statistical Actors. However, it is also true of the official statistic as a form of knowledge. Statistic-making is a form of metrology, and like all other measurements it requires social acceptance (see Proverbs 11:1). Just as a metric of distance is defined by common agreement and there is no necessity to the metre or mile, the scale of the statistic is a defined yardstick for something more basic (Duncan 1984). At the same time, 'accuracy' or 'efficiency' are defined in terms of publicly accepted standards (Power 1994, 1996, 1997; MacKenzie 1981; Miller 1991; Miller and O'Leary 1987), meaning that the acceptance or rejection of the agreed measure rests on a network of other theories and definitions. As Alonso and Starr (1987) and MacKenzie (2009) argue, this is a political process in two different ways. The first is that the decision to count an object is a function of power relations, particularly in the case of official statistics which originate in the actions of government agencies. The second is that the official statistic has impacts on the world, both in directly shaping actions and in highlighting the object of the statistic as normatively important in some way. There are echoes here of the critical approaches discussed above; it is possible to read metrologies as regimes of truth which make it legitimate to say some things ('this distance is a mile') while delegitimising others ('this distance is just').

Building on this weak claim, a stronger claim would develop the idea of socially agreed definitions to consider the social world in which they, or any knowledge, are agreed (Searle 1995). The need for a metrological definition of a phenomenon and, indeed, the conceptual apparatus which allows the understanding of that phenomenon as something requiring such a definition, arises in relation to the knowledge, belief structures and aims of social actors (Latour 1987). It is not only that the measure requires social agreement, but that there needs to be social agreement that a measure is desirable (Hacking 1999). On this reading, not only is the official statistic socially constructed, but it is constructed on the basis of social knowledges, out of social knowledges and on the basis of social interactions between such knowledges (Searle 1995).

Theory precedes action at this point and the measure is constructed to allow the 
representation of what is already believed to be there (Burchell, Clubb and Hopwood 1985; Hopwood and Miller 1994; Porter 1995; Power 1997). Miller and O'Leary (1987) describe this process in relation to standard costing, an accounting method used to cost activities carried out under normal conditions. This method was desired by government actors in response to what they saw as a crisis of national productivity. The method changed the way in which firms viewed their businesses, highlighting different aspects of their activity and linking them together in new ways. This had the effect of confirming the 'crisis' which the government was seeking to solve; the new calculative norms brought individuals within the reach of efficiency calculations, subjecting them to new behavioural norms to which they did not immediately match up. The measurement both flowed from pre-existing theory and served to confirm it.

The tight relation between theory and observation, then, is not accidental. The observation of the object, event or phenomenon arises alongside the theory which defines it (Marginson 1997). This definition may have far-reaching effects; Power (1994, 1996, 1997), for example, observes the way in which the requirement for audit alters the way businesses organise themselves, as they re-arrange their operations to ensure they are visible and auditable. This is more than the definition merely conforming to the theory under which it was designed, the technology for observation is altering what is observed. Similarly MacKenzie (2009) and Callon (2007) argue that the efficient markets hypothesis creates the type of markets it believes exist by shaping the behaviour of participants in existing (non-efficient) markets. In both cases, it is not that the definition of the phenomenon is proved by that phenomenon being found, but that the phenomenon is only occurring in that specific form as a result of the definition.

This can be read as a complement to the critical approaches of earlier sections. The twoway relation between the theory and reality corresponds to the idea of the 'regime of truth', the structured discourse which allows some things to be said but not others. Here a series of regimes - about populations, economies, the neutrality of quantification, and so on - interact and combine, creating a new regime expressed by the official statistic which then acts to limit the possibilities of the external world. It is the blindness to the social nature of this process which is being critiqued in the Marxian account of fetish objects. However, unlike the critical positions above, the social construction approach emphasises the contested nature of theory; as the theory arises through social activity, it is shaped by it. The Statistical Actor works using their own conceptions of theory, in interaction with others with potentially different conceptions, within the limits of their resources and abilities. The official statistic created then feeds back into theory, impacting on the external world which it records.

This argument extends native accounts of official statistics discussed above. In the case examined, that of human capital (Office for National Statistics 2012c; Jones and Fender 2011), there was a claim that human capital was observable in the external world and that the official statistic worked towards measuring this accurately and reliably. Theories of social construction would suggest that this was a partial account, in places an incorrect one. 'Human capital' can be seen as existing in the external world only because of the frameworks of understanding applied to it: theories about 'capital', the treatment of education as an investment, re-imagining human life in terms of income streams, and so on (see for a general argument about the situatedness of economic 
theory Dunford and Perrons, 1983). It can be measured only because of prior agreement on measurement techniques, mathematical tools, statistical processes and so on. Following its 'discovery', as Foucault suggests (2008), its existence allows individuals to target their 'human capital' in a calculating way by making it visible and linking it to structures of incentives (Sointu 2005 makes a similar argument about 'well-being'). The official statistic is a true reading of the world but only because there has first been social agreement on what 'true' is. For critical theorists, 'true' is a function of power, but for native accounts this need not be insidious. Hand (2004), for instance, talks about the 'pragmatic' aspect of statistics, the question of whether they serve the purpose set for them, reading this as a technical rather than a political question. However, as Martin (1981) notes, looking at the activities of the US Statistical Bureau, the pragmatic element always comes first; the definition of the statistic follows the political need for the statistic, not the other way around.

This emphasis on the social creates a sense of contingency within official statistics which is much more obvious than in the accounts discussed above. While it is understandable that Statistical Actors may not see the contingent nature of the theories they engage with ('human capital', for instance, is shaped by existing accountancy frameworks, but these frameworks are never questioned), there are moments of interaction where new theories or modes of action become possible. For instance, Duncan (1987) notes the way that technological improvement in the conduct of the US Census, specifically the move to using punch-cards, increased efficiency in data analysis and so allowed more questions to be asked. This opens up new areas for exploration which were not there previously, prompting a dialogue between theories of objects in the external world which do not yet have quantified aspects and theories of quantification which are then applied to them. This extension of the statistical contrasts with that identified by Government Statisticians' Collective (1979) who saw later technological developments as ways of de-skilling and down-sizing workforces; the statistical boundary is not expanded, but how the statistic is carried out is adjusted. This adjustment is possible because of theories which accept the identity between machine and human activities and the removal of aspects of the statistic-making process from being questions of judgement to questions of technical routine. In these contrasting approaches to new technology can be seen a set of social processes: mediating preexisting theories, attitudes, aims, priorities, and so on.

Such an approach can be critiqued. Schwandt (2000) and Craib (1997) both note the danger that constructionism collapses into relativism; if all knowledge is situated within locally negotiated contexts, there is no standard by which any knowledge can be said to be 'true' or 'false'. This is an incomplete criticism, however. While it has force if one comes from a naive realist standpoint, from a social constructivist standpoint it merely seems to be describing the theory: knowledge is contingent and local and one cannot, merely on the basis that it is locally true, suggest it applies more globally (Denzin and Lincoln 2000). Schmidt (2001) goes further, arguing that constructionism, by implying that behaviour and motivational factors are constituted by social norms rather than merely conditioned by them, is reductionist and does away with agency. This seems to overstate the case, implying a 'social' entity external to the individuals within it; such an entity has been strongly argued against by, among others, Latour (2005; see also Lincoln and Guba 2000). As a final critique, social construction may be taken as 
claiming that there is no material basis to knowledge, that the official statistic is entirely discursive. This is a misreading; constructionism argues that the meaning of the material world is entirely discursive. It is possible for observers to agree that the object of the official statistic exists, but this is separate from the question of what that object is. That question can only be answered through socially shared meanings; it is perfectly possible, to take the above example, to deny that there is such a thing as 'human capital', even accepting the existence of humans, their educations, and so on.

\subsubsection{Agency in the statistic-making process}

This social process of official statistic-making happens across multiple sites and multiple scales as the 'social' itself is multiply constructed. In the human capital example, the ideas of the economy and the population acted as givens, but the theory that humans could be treated as capital was taken to require justification. That theory had been developed by economists, primarily at the University of Chicago, as part of a larger theoretical project pushing the bounds of their methodology outside its usual areas of application. The Statistical Actors grounded their work within this body of theory, where their arguments were accepted, and within wider international contexts, where the official statistic was accepted, while acknowledging wider public disagreement or incomprehension towards the measure (Office for National Statistics 2012c). The Statistical Actor, then, has a role in moving theories across social contexts. They must act within the limitations of theory, looking for what they believe to be there, but that belief is the product of a subject position which may not be universally shared.

They are, themselves, embedded within social contexts, so are equally limited by their circumstances. That is, not only are Statistical Actors reacting to each other and to the wider theoretical currents of their society, but they are also interacting with non-human objects and structures such as institutions, technology and resource constraints (c.f., Latour 1987, 2005, who would see non-humans and humans as 'actants' with equal importance in the creation process). Hacking (1999) describes this as the 'matrix' in which construction occurs, an interaction of institution, media, social setting and social actors in which an idea is situated. The object of the statistic sits within a matrix involving: historical economic and statistical theory; ongoing developments within academia; international policy networks; domestic political arguments and debates; media generated moral panics; the institution of the ONS with its internal hierarchy, equipment, funding; and so on. The Statistical Actors navigate this matrix, acting on it and with it.

Various aspects of this matrix have been examined along constructivist lines, particularly the body of statistical methodology and theory which official statisticmaking draws on. Atkins and Jarret (1979) observe the arbitrary nature of statistical significance testing as a check on 'reality', highlighting the close link between our methods of claiming validity for scientific knowledge and the nature of the knowledge we attain. MacKenzie (1981) observes the political or philosophical projects which formed the background of many statistical techniques themselves, such as the way that basic correlation techniques arose out of the eugenicist conceptions they sought to test 
(for example, see Galton 1909). Hacking (1999), Barnes (1991) and Latour and Woolgar (1986) extend this further, noting that the structures of scientific and mathematical enquiry themselves are built around contingent aims and needs. The native approach in which statistics are neutral, technocratic representations of the world is challenged by this approach; instead they are a particular mode of thought which arose for specific reasons but which has now become naturalised.

As Hacking (1999) claims, all stories of social construction are histories, in as far as they relate to decisions which have been made over time. In addition to the practice of statistic-making and the ideas which it rests on, official statistic-making bodies exist for historical reasons. Their current institutional forms are the result of various funding, political and administrative decisions. Their personnel have aims and desires shaped by their immediate circumstances and their lives. On a social constructivist reading, all of these impact on the practice of statistic-making into which any specific statistic fits. That is, the practice of statistic-making is a social process which could be otherwise; the nature of this social process interacts with the specific situation of any given statistic, its theories or political context.

This approach allows a fleshing out of the idea of the conjectural framework introduced in Chapter One. That model suggested a simple division of responsibility within the statistic-making process, with a specialised Statistical Actor standing between those who commissioned the statistic and their audience. Social construction theory suggests the range of influences and restrictions which the Statistical Actor works under by positing them as part of a dynamic system, acting and reacting to their theoretical and functional contexts. This approach goes beyond those surveyed previously; it does not deny the theoretical positions they claim (those of control or of an empirically verifiable external world) but questions the influence of those positions in the process. While they may potentially motivate the act of statistical production, they are not, on this reading, the end of the story.

\subsection{Conclusions and empirical questions}

The present chapter has moved from the conjectural model of Chapter One, which emphasised the role of individuals with agency in the making of official statistics, to a consideration of two broad accounts of statistics and official statistics. In what have been called 'critical' accounts, those written from a Foucauldian or a Marxian perspective, official statistics are technologies of control. They exist for an instrumental purpose, imposing frameworks on the world to shape behaviour. In what have been called 'native' accounts, those offered by official statisticians themselves, there is a similarly instrumental purpose but one which involved abstracting from the complexities of an observable external world with the aim of making that external world manageable for policy-makers.

It has been argued that both these accounts overlook the act of statistical creation by supposing that the instrumental purpose is unproblematically achieved; that there is a direct relation between the intention to control and the official statistic, or the external world and the official statistic. This has the effect of reducing the understanding of 
official statistics to a post hoc exercise: they take the form they do because they seek to control or to represent reality, so their features occur as expressions of this aim. However, Chapter One argued that the intention to control or to represent was not the only potential influence on the statistic-making process. While control or representation may be the over-riding objective for Statistical Actors, they are objectives which would be balanced against others and against other constraints, such as those offered by resources, technology, statistical theory and so on. If this argument is correct, the form and content of the official statistic are not simply an expression of control or representation, but partial expressions of these within the context of the statistic's creation.

The present chapter expanded on this argument by examining literature on social construction. This literature is sensitive to the social process of creation, presenting it as a dynamic system of interactions between creators and their contexts. The representations produced by creators are highly contingent and, in the hands of other Statistical Actors in other places with other aims, may have been otherwise. It was noted that this approach could be used as a complement to critical and native understandings, uncovering the pathways through which such accounts would need to operate.

There is, on the arguments of these two chapters, a gap in the literature around the making of official statistics and particularly its social aspects. On the basis that official statistics play a major role in public life and academic thought, this gap is one which it is important to fill. The present research aims to fill this gap, asking the question:

\section{Does an examination of official statistic-making as a social process add to} the understanding of official statistics' form and content?

If the process of official statistic-making has not been previously examined, as has been argued, it may be for good reason. The critical or native accounts may be correct, and the relation between desires for the statistic and the output of statistic-making be relatively unproblematic. The ontological model of Chapter One, which suggested points of agency and disagreement, may be incorrect or over-stated. Having offered justifications for conceiving of official statistic-making as a social process, it is necessary to investigate whether such beliefs hold. The test of this will be whether or not such a conception allows the explanation of aspects of the form and content of official statistics that could not be explained by pre-existing theories. Are there elements of the official statistic which were previously inexplicable that can be explained when the activities of agents are taken into account?

This over-arching aim can be broken down into four research questions:

(1) How can the official statistic-making process be understood as a social process?

(2) What are the components (institutions, theories, individuals, technologies, \&c.) of that process?

(3) How do these components interact to produce the official statistic?

(4) What are the implications of this for an understanding of the official statistic? 
The first of these seeks to fill the gap in the literature around official statistics which is created by the black-box approach of both critical and native accounts. At the moment, it is not clear what happens when an official statistic is made. The ontological model of Chapter One has provided reasons for exploring it from the perspective of agents interacting with each other and their contexts. However, the treatment in Chapter One was, necessarily, abstract and suppositional. There is left an empirical question of what official statistic-making actually entails and what its social aspects involve.

The second research question builds on this. Social construction theory suggests that individuals exist in dynamic systems of interaction, rather than in the static relationships between intention and process suggested by critical and native theories. Such systems will be different for different statistics as both individuals involved and the context which they must negotiate will be different. However, at a higher level, there will be commonalities between statistics, arising from their common assumptions around commensurability and instrumental purpose. The black-box nature of existing accounts creates an explanatory need for question one, as what official statistic-making entails is unknown. Question two organises this into a more general theoretical framework.

If the process is dynamic, as the social construction literature suggests, then agents are continually shaping the outcomes of official statistic-making by their interactions with each other and their context. As in question two, this will be observable both on the level of the specific statistic and more generally. Question three asks how these interactions shape the form and content of the official statistic, taking seriously the arguments put forward in the first two chapters of the contingency of the final form. How do the components of social process come together to create the statistic?

The fourth question asks how considering official statistic-making as a social process provides insights different from the critical and native accounts surveyed in the present chapter. It has been argued that they underplay agency and contingency, taking official statistics as relatively unproblematic outcomes of relatively linear processes. Are there elements of official statistics which are better explained when the statistic-making process is attended to, rather than being taken as a given? If so, how does this complement or challenge the existing theories?

Taken together, these four research questions capture the aim of the research project, by using a new approach to explore the official statistic-making process and examining whether this approach offers new ways of explaining the official statistics which are produced.

Having established the aims and questions which the research will address, the following chapter will outline a methodology and research design which will allow them to be answered through exploring the particular case study of the 'Measuring National Well-being' programme. 



\section{Chapter Three \\ Epistemology, methodology and research design: how might official statistic-making be examined and understood?}

Chapter One outlined some broad ontological claims about official statistics: that they were objects, made by individuals within social relations and contexts, specific conditions of opportunity and constraint. Chapter Two related this to existing accounts of official statistics, arguing that both native and critical models disagreed with this set of claims. It proposed instead that the ontological claims of Chapter One were better represented by taking a social constructionist approach towards official statistics. The present chapter works through the implications of this suggestion. If an official statistic is a social construction, what can be known about it; what epistemology is implied by this ontological claim? Having established this, it will be possible to outline a way of investigating official statistics which is sensitive to their nature. The success or failure of such an investigation will provide an answer to the overall research question outlined in Chapter One, 'Does an examination of official statistic-making as a social process add to the understanding of official statistics' form and content?'.

The chapter proceeds as follows: Section 3.1. will build on the ontological claims of Chapter One to develop an epistemology of the official statistic, outlining what can be known about it. Section 3.2. will move from this epistemology to sketch a general research methodology capable of capturing its features. Section 3.3. will argue that the 'Measuring National Well-being' programme, briefly introduced in the first chapter, provides opportunities for gaining such knowledge. A research design which is sensitive to the nature of the programme will then be outlined in Section 3.4.. A consideration of ethics will be made in Section 3.5., and a general framework for analysis outlined in Section 3.6.. The final section, 3.7., will provide a summary of the arguments of the chapter.

\subsection{Epistemology: what sort of thing is an official statistic?}

The claim of Chapter One was that official statistics were created by Statistical Actors, standing between Commissioning Actors, who require statistics, and a Statistical Audience, who receive statistics. It was argued that each of these sets of actors were heterogeneous within themselves, involving multiple individuals with differing objectives, interests, influence and power. Such individuals embody these objectives, interests, influence and power, relating to each other as social representatives of these. It was also argued that the set of actors was porous: interacting and exchanging ideas, resources and influence with agents and agencies outside of itself (for instance, Statistical Actors may include those who have acted as Commissioning Actors and those who are primarily members of the Statistical Audience). The interactions and abilities of Statistical Actors were shaped by multiple factors, such as the institutions they are a part of, technology, theory, material resources such as finance, staffing levels and time; and their control over these.

On this model, the making of official statistics is a complex set of interactions, with its outcome contingent in the sense that a change in the conditions that the Statistical Actors need to negotiate, or a change in the Actors working on the statistic, could result in a very different official statistic being created. From this it was argued that 
knowledge of the statistic-making process and its components was important to understanding the official statistics which were produced. This is because the form and content of the official statistic is a product of the interactions both between Statistical Actors and between Actors and their context.

Such knowledge would take into account the fact that the Statistical Actors themselves and their context differ substantially across time and space. What will be counted in a statistic is a function of diverse factors, such as what is considered politically feasible to count, what it is technologically possible to count, what can be coherently counted given resource constraints, what agents consider to be theoretically valid to count, and so on. These will partially be a function of institutional form, making the official statistics of one nation or collective somewhat different from those of another. It will also partially be a function of time, as technologies, access to material resources, institutional settings, and so on, change. These two factors, institutional form and historical capabilities, are in constant interaction, as will be seen in the development of statistics by the Devolved Administrations of the UK (see Chapter Four); devolution creates a new demand for official statistics to serve new political bodies and purposes, new institutions in which to make such statistics, new desires to innovate in statistics as a form of differentiation from existing UK-level approaches, and so on. In this example can also be seen roles for place and for scale; new political geographies have created new places, devolved nations which didn't exist previously for many statistical purposes, the devolved-national being a scale which for many official statistics previously did not exist.

However, despite this heterogeneity across statistical contexts, there will also be points of commonality between different Statistical Actors. For example, many official statistics are subject to international guidelines on their construction, which will restrict the freedom of Statistical Actors to innovate and which will work to standardise the conditions of official creation across bodies. Similarly where a single institution produces multiple statistics, as is the case in the UK's Office for National Statistics or in the various Whitehall departments which maintain statistical collections, the institutional context for those multiple statistics is held in common. Statistics here will be subject to the same quality controls, the same professional culture, Statistical Actors will be subject to the same training programmes, and so on.

As outlined briefly in Chapter One, this conception of Statistical Actors draws on Giddens' structuration theory of agency (Giddens 1984). In particular, it notes the interaction of individuals and their environment, suggesting that structures and agents are co-constitutive of each other. However, as observed by, among others, Archer (Archer 1982), Giddens' account collapses structure into agency by characterising the former as a lived set of rules and behaviours. While this does reflect the interplay of structure and agency, with each shaping the other, it underplays the relative strength of structure. Structure precedes agents, it is something they confront (O'Boyle 2013). In the case of Statistical Actors in the UK, they are confronting the institutional structures of the Office for National Statistics and UK policy-making, and the various theoretical bases for the statistics they are making. As Burkitt (2015), and authors taking the strategic-relational approach (Allen and Cochrane 2010; Jessop 2001, 2008; Jessop, Brenner and Jones 2008; Jones 2007) suggest, it is more accurate to think of structures 
as social relations. That is, structures are flexible, but variably so; agents will have varying degrees of freedom of action. Statistical Actors may have influence over the statistic, but this is limited. How limited, and in what ways, is an empirical question.

These considerations mean that the knowledge of the production of a single official statistic will be, in many ways, particular. A full description of the statistic-making process, were it possible, would describe only the creation of a single official statistic, created by a single set of time- and space-bound Statistical Actors. However, the impact of time- and space-bound factors of some sort is a necessary feature of all official statistics. A sensitivity to these factors as influencing the form and content of the official statistic will, then, allow transferable conclusions about the creation of official statistics to be drawn.

Given the emphasis placed in this account on the social nature of the statistic-making process, high-level accounts such as the critical and the native accounts examined in Chapter Two (Sections 2.2. and 2.3.) are necessarily incomplete. They view official statistics as in some way inevitable: their form follows from the role that they are to fulfil, be it the faithful representation of external reality or some form of social control. On the argument of Chapter One, this inevitability is more apparent than actual. To understand the form that the official statistic takes, it is necessary to understand how it was made and so what possibilities of form were open to it.

Two ways of obtaining such understanding suggest themselves. One would be to become a Statistical Actor and participate in producing statistics, in the manner of Government Statistician's Collective (1979), or to observe Statistical Actors at work. Such participation or observation would allow a knowledge of matters of institutional form, technology, professional opinions and understanding, theoretical debates between Actors, and so on. Alternatively, similar knowledge could be gained by talking to Statistical Actors about their work, and through triangulating this with secondary material such as policy documents, meeting minutes and public statements. This method would also capture issues of institutional form, technology and so on, the social contexts which official, technical, accounts do not record.

In some ways, the former method of direct participation or observation is preferable. It provides access to elements of the statistic-making process which Statistical Actors may feel, consciously or otherwise, are too quotidian to merit discussion but which none-theless influence what official statistics are possible. For example, Latour and Woolgar (1986), in their study of 'laboratory life' note the ways in which only certain forms of 'solution' are acceptable within scientific discourse, and that these were applied to 'problems' which only appeared as such as a result of the structure of that discourse. For the scientists in question, their approaches and the problems they approached were selfevident; for Latour and Woolgar, they were open to critique from outside the social context that the scientists moved in. It took outsiders entering that world to make its assumptions apparent (similar arguments are made by Knorr Cetina 1999). A similar entry into the world of official statistical creation, into its 'hidden abode of production' (Marx 1990, p.279), could uncover both the actively hidden and that which, for Statistical Actors at least, is hidden in plain sight. 
On these grounds, attempts were made to gain access to two different national-level official statistic-making bodies as both an observer and as a participant observer. In one case, no reply of any sort was received from the statistic-making body; this was likely the result of having no access to gate-keepers within the organisation but relying instead on publicly available forms of contact. In the second case, it appeared that access would be granted but, having secured involvement from the Statistical Actors themselves, their 'Human Resources' department refused access. There are a number of potential reasons for this, primary among them the likely lack of a procedure for allowing temporary access to an environment where confidential data is handled on a daily basis. While these failures do not prove that direct observation as research method is not possible, it did prove impossible in this particular case.

The second method, that of discussion with Statistical Actors accompanied by an examination of their outputs, is less likely to pick up on subtleties of day-to-day life of Statistical Actors, but it does have some advantages when compared with direct observation. In particular, it establishes a distance between the Statistical Actors and the particular statistic they produce by calling on them to actively reflect on the process of statistic-making. Thus while the knowledge of the specific statistic is likely to be impaired, it may be possible to get a firmer understanding of generalities as Statistical Actors and the secondary material arising from their work place their work within a wider context of statistic-making.

However, such methods also have clear disadvantages, most pressingly that all data is mediated rather than collected by the researcher, and thus subject to the potential rewritings of memory or deliberate institutional manipulation. A further difficulty is created by the distance between the creation of the official statistic and its investigation. As the statistic-making process becomes more remote in time, it will become harder to access the documents and personal accounts of its creation. The majority of official statistics have been being collected for a very long time, meaning there are few individuals able to talk about the conditions of their creation. Unless there is a historical account explaining how decisions were made, this means that knowledge of the social production of statistic-making is lost. To study the social processes of official statisticmaking, there needs to be an example of a statistic developed recently, whose creators and their accounts of creation are still accessible.

\subsection{Methodology and research design}

These requirements, of a recent official statistic whose Statistical Actors and their outputs remain accessible, suggests a case study approach. Stake (2000) distinguishes three forms of case study: intrinsic, where the case is studied as an interesting subject in its own right; instrumental, where the case is examined as a means to understanding wider processes of which it is an example; and collective, where numerous cases are studied with a view to establishing a picture of the population of which they form a part. Although he acknowledges that this delineation is approximate, and that any particular study may have multiple aims, it is a useful distinction. Given the arguments above that the nature of the official statistic-making process is social, and so that any particular official statistic embodies, to use Lund's (2014) typology, a concrete case of both the 
specific and the general, an instrumental case study or studies is most appropriate to the present research question.

The possibility of multiple case studies was ruled out by the failure to gain access to multiple official statistic-making bodies. While access was possible with one nationallevel body, attempts to access sub-national level bodies were unsuccessful (see below for a fuller discussion). Given the limited number of official statistics which are newly created and so accessible for study, and the inability to access other national-level bodies discussed above, this lack of access meant that only one case study was possible. Following the observations above and the inability to conduct direct observations of the Statistical Actors, this case study would need to be accessed using interviews.

Like the official statistic-making it seeks to investigate, an interview is a social process (Briggs 1986). As Kvale (1996) and Silverman (2000) observe, an interview is not an empiricist uncovering of external truth, with the participant offering up facts to the interviewer. Rather, interviews represent the simultaneous and two-way processes of interpretation, validation and communication; they are texts negotiated between the interviewer and participant (see also de Sola Pool 1957; Fontana and Frey 2000; Briggs 1986). As a result, the interview process (and subsequent analysis) needs to be sensitive to its narrative nature (Holstein and Gubrium 1995); a sensitivity which inclines towards semi-structured interviews offering the participants the maximum opportunity to direct the conversation, reciprocity in information-giving between interviewer and participant, and a sharing of interpretations by the interviewer with the participant (Oakley 1981; Phillips and Johns 2012; Terkel 1988, 2004).

The negotiated, and so partial, nature of interview texts places a premium on triangulation between interviews within the case study. It also again highlights the desirability of multiple comparable case studies. However, as Silverman (2011), makes clear, comparison of cases is not the only way of validating interpretations of those cases. As a result of various open data initiatives in the public sector, there is a large amount of secondary material surrounding official statistic-making, including meeting minutes and commentaries on statistical outputs. In addition to these records there are also documents (to use Lincoln and Guba's 1985 distinction); Statistical Actors publish discussions within theoretical and professional literatures. These can be drawn on to supplement accounts from a specific case study, allowing more reliable conclusions to be drawn than could be drawn from interviews alone.

The triangulation and contextualisation process can also go further than this. If, as argued, an official statistic is an object made by individuals under conditions of opportunity and restraint, then the materials drawn on in a case study can be read as artefacts created under particular material conditions and embedded within social and ideological systems (Hodder 2000). That is, there is a background to the official statistic, a set of institutional and theoretical conditions which form the framework within which the Statistical Actors operate, and this can be examined prior to embarking on the case study as a way of situating it. For example, national-level official statistics in the UK are largely the responsibility of the Office for National Statistics (ONS). The institutional form of the ONS - its history, structure, professional make-up, relation to government and policy, integration into international frameworks of statistic-making 
practice, and so on - will set some of the opportunities and restraints within which the statistical programme is constructed. Similarly, the statistical programme must be in dialogue with existing bodies of theory around the statistical object, and with previous efforts at measurement; these form the theoretical landscape in which a new statistical programme will sit. Both institutional form and theoretical background can be examined, giving an understanding of the social context with which the Statistical Actors must engage. These will be specific to the case study, but transferable in as far as all official statistics must engage with a social context of some kind (Law 2004).

This suggests a two-stage investigative process, similar to that of Lincoln and Guba's (1985) 'naturalistic inquiry'. Once a case has been selected, the first stage will need to examine its broad social context. What are the institutional and theoretical situations which Statistical Actors must deal with? While offering a grounding for the particular official statistic, this will also point to more generalisable aspects of the official statisticmaking process. The knowledge gained from this will allow the direction of case study interviews, enquiring of participants how their social context was negotiated in the statistic-making process. This can be done in dialogue with secondary materials, using interview responses, official outputs and 'grey' literature as triangulation points against each other to gain an understanding of the case.

\subsection{Selection of a case study: The 'Measuring National Well-being' programme}

The UK Office for National Statistics' 'Measuring National Well-being' programme meets the requirements as a case study for this research. At the time of the commencement of the interviews for this study (Autumn 2014), the programme was four years old (as dated from its launch, see Cameron 2010; Matheson 2011; and figure 3.1. below) and was still under-going development. Indeed, it did not get its first statistical release until late-2012 (Office for National Statistics 2012b), and its novel components were not awarded 'National Statistic' status (the methodological kite-mark awarded to official statistics in the UK by their ombudsman) until two years later (UK Statistics Authority 2014a). This meant that it was still possible to speak with those who had been involved in its creation about the statistic-making process and what it entailed; there were Statistical Actors available who were able to recall how the statistic-making process had been conducted. The importance of this recency was underlined by approaches to some individuals involved in the early stages of the statistic-making process who, just three years later, were unable to recall what their role had entailed. This recency is unique, certainly for a large-scale programme; it is rare for official statistic-making bodies to embark on entirely novel statistical programmes. The 'Measuring National Well-being' programme allows an insight into official statisticmaking which is not often available.

There is also a certain amount of secondary literature surrounding the 'Measuring National Well-being' programme which can be triangulated with the opinions of those involved in the statistic-making process. This includes meeting minutes of various committees established to advise the ONS on the creation of the programme, minutes of committees outside the ONS who advised on the quality of the programme, and accounts and critiques written by those involved in the statistic-making process (such 
(Allin 2013, 2014; Allin and Hand 2014; Tomlinson and Kelly 2013). This is, relatively speaking, a wealth of material: statistics developed earlier, particularly those which predate the ability to easily and publicly publish minutes and reports online, lack such evidence of the statistic-making process. Its presence makes it easier to triangulate and expand on the interview accounts of individuals involved. It also allows for improved targeting of questions by highlighting areas of particular interest or expertise for participants, ensuring that in interviews conversations occur on subjects which they are able to comment on.

While there exist other novel statistical programmes, such as those looking at 'human capital' or environmental accounts in the UK (Jones and Fender 2011; Office for National Statistics 2014d) and developments of the national accounts at the European Level (Eurostat and European Commission 2013), these lack the size or scope of the 'Measuring National Well-being' programme. Indeed, in the case of human capital and environmental accounts, they are developed either in conversation with or as direct components of the programme (Office for National Statistics 2012e). Such efforts provide fewer opportunities for investigation: their output is smaller and fewer Statistical Actors are involved in their creation. They are also less prominent than the first statistical programme to be launched by a Prime Minister since the 1960s (when Harold Wilson launched the journal Social Trends, see Allin and Hand 2014; Moser 2000), reducing the incentive for Statistical Actors to make time to explain them to a researcher. The climate of publicity around the 'Measuring National Well-being' programme is likely to improve access to research participants by making scrutiny both more usual and more legitimate.

The 'Measuring National Well-being' programme also developed within a wider international context; similar programmes were being developed in 2010 at European and Organisation for Economic Co-operation and Development (OECD) levels, and comparable efforts were also made at the national level in other countries and at the sub-national level of the Devolved Administrations within the UK (Australian Bureau of Statistics 2012; Commission of the European Communities 2009; Directors General of the National Statistical Institutes 2010; European Statistical System Committee 2011; Scottish Government 2011). This offered another way to consider questions of generalisability, by opening up space for comparisons between the work of the ONS and that of other organisations. This would provide more insight into the way that particular institutional peculiarities shaped programmes across territories.

In terms of interviews, this international and sub-national comparative research proved impossible. An attempt to secure access to Statistical Actors within a Devolved statistical body proved unsuccessful as internal guidelines precluded statisticians from talking to external actors, including academic researchers, about their work (essentially closing this particular activity of the state from external scrutiny). While access was gained to Statistical Actors working within an international statistical body, the resulting interview was withdrawn by those more senior in the organisation as it was not deemed compatible with the official statements of the organisation's practice (unattributed email, 10 July 2014). This latter body subsequently failed to fulfil a promise to vet and answer written questions. Both the offer to answer only questions which they could control, and their subsequent failure to do so, equally closes this body to external scrutiny; 
subsequent enquiries only met with directions to their website which contained highlevel accounts of the concepts and purposes of the programme but little engagement with the process of its creation.

However, while interview access to external bodies was not possible, their outputs were still available for scrutiny, as was high-level information about their institutional arrangements and histories. This makes it possible to compare some aspects of the UK programme with its international counterparts, helping to isolate aspects of the programme which arise from peculiarities within the economic, social, political, cultural and institutional contexts of the UK which Statistical Actors working on the 'Measuring National Well-being' programme must navigate.

Equally valuably, the 'Measuring National Well-being' programme was produced by a public institution. The Office for National Statistics is the central government department responsible for the production of many of the UK's official statistics, legislated for by the Statistics and Registration Services Act 2007. This allows the contextualisation of the programme, as there is a certain amount of institutional literature that can be drawn upon, as well as public pronouncements of politicians, on the nature, funding and strategic direction of the organisation. This will serve to inform and to contextualise interviews with Statistical Actors.

The selection of the 'Measuring National Well-being' programme also allows for a greater generalisation of the findings of this study to other official statistics. While not the only creator of official statistics in the UK, the ONS is the central specialised body, and so a great many of the official statistics which play a role in public discourse in the UK will share with the 'Measuring National Well-being' programme an institutional background, professional context and agential worldview for Statistical Actors, constraints and opportunities provided by technology, and so on. In many cases, the same Statistical Actor will work on multiple official statistics. This provides the potential that findings will be generalisable from the 'Measuring National Well-being' programme to the majority of other official statistics in use in UK public discourse. Similarly, there exist internationally similar models of centralised official statistical creation, meaning that a focus on the work of the ONS may provide insights into official statistic-making outside of the UK context.

For these reasons, the 'Measuring National Well-being' programme is a good candidate as a case study for an investigation of the official statistic-making process. It is accessible using methods which are appropriate to the epistemology outlined above, and has aspects which make it broadly representative of official statistic-making practice.

\subsection{The research methodology as applied to the 'Measuring National Well-being' programme}

Having outlined an epistemology, the methodology that flows from that, and a case study suitable for the application of that methodology, it is possible to specify how that methodology will be applied in practice. The methodology detailed in Section 3.2. above had two stages: an initial stage in which the institutional and theoretical context 
of the case study would be investigated, and a second stage which drew on this to inform interviews and analysis of secondary material related to the case study.

The first stage will deal with the institutional and theoretical context of the 'Measuring National Well-being' programme as it stood in 2010. The context of the official statistic has economic, social, political and cultural dimensions, so this first stage seeks to situate the Office for National Statistics within the historical and socio-political context of the UK and to situate 'well-being' within its historical, theoretical and statistical contexts more broadly. These will be explored through a review of relevant secondary literature (Chapters Four and Five). Once this background to the programme has been sketched, it will be possible to proceed with an empirical investigation of how this background influenced and shaped the statistic-making process.

This exploration of the institutional and theoretical context represents an original contribution to the literatures around statistic-making in the UK and well-being (although, in relation to the latter, in places it replicates the work of others, such as Scott 2012). It is necessary because if, as the preceding two chapters have argued, an official statistic is a social construction, it is important to know what it is constructed out of. If those creating official statistics have agency in the sense outlined in Chapter One, it is important to know where they will be called upon to make decisions and what the likely limitations on their decision-making powers are. Establishing this context involves examining secondary data around key institutional and theoretical structures, principally the Office for National Statistics, the role of statistics within the UK policy-making, well-being and statistical developments around well-being. These structures act as prerequisites for the 'Measuring National Well-being' programme, and the programme represents an expression of them. It is important, then, to understand their histories and the debates which informed their current forms. Such forms and such debates will inform the actions of Statistical Actors, and so an understanding of them will inform the questions that put to them in the second stage of the research.

The broad outlines of the statistic-making process in the case of the 'Measuring National Well-being' programme are sketched in figure 3.1. below. It runs from the public launch of the programme in July 2010, through the first statistical release in July 2012 to the point at which the subjective well-being measurements, which were the programme's most novel component, were granted the 'National Statistics' kite-mark by the UK Statistics Authority. At this point the programme can be said to be 'constructed', as it has reached a stable and approved form (see also Self 2014, the ONS' reflections on the 'Measuring National Well-being' project). Also indicated are two public consultations (the 'National Debate' and a consultation on proposed components of the programme) and two key advisory committees in which the staff of the Office of National Statistics were supplemented by Statistical Actors from outside the organisation. (Outputs of the programme are given in Appendix D.) 


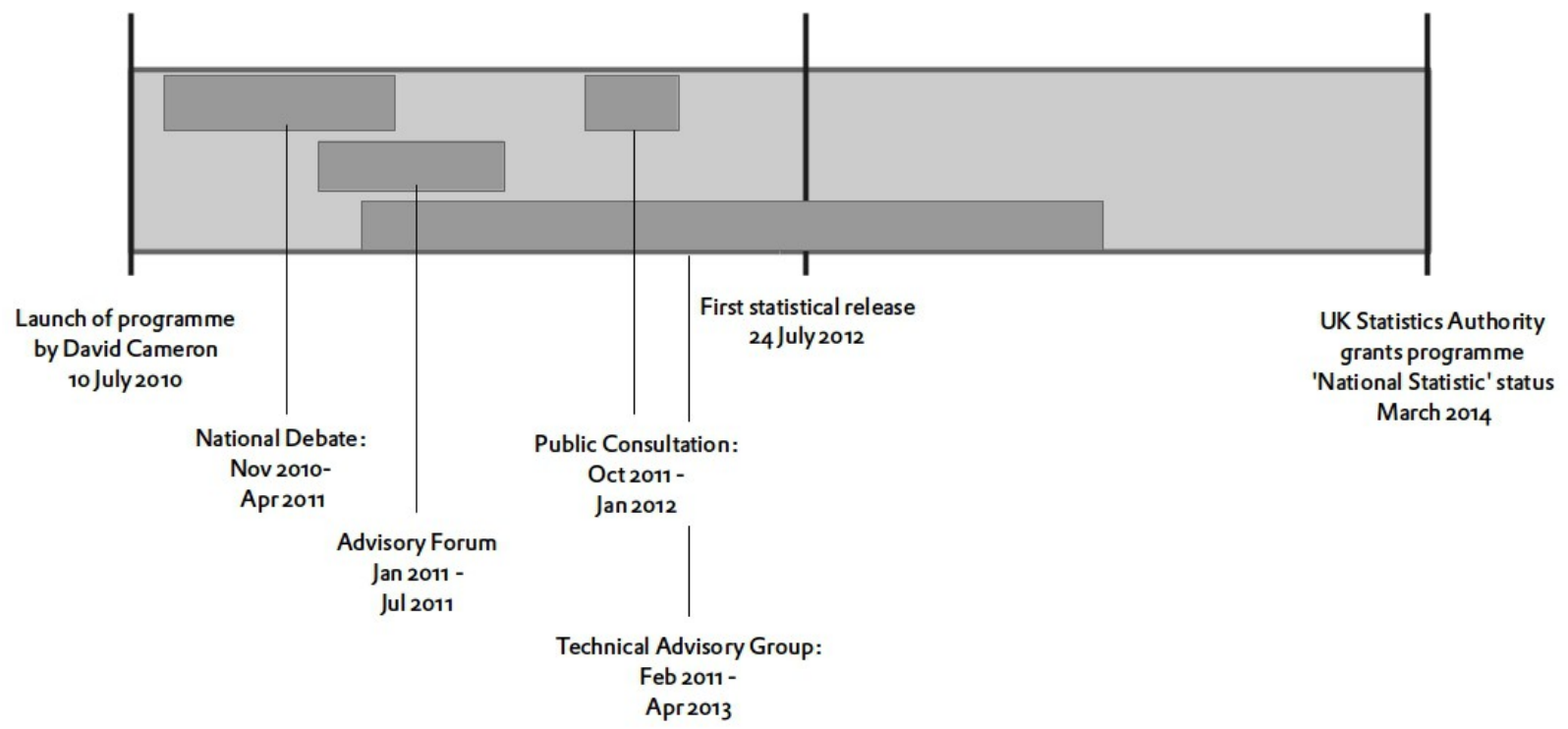

Figure 3.1. A schematic time-line of the statistic-making process in the case of the 'Measuring National Well-being' programme

These two advisory panels are moments of interaction between the three categories of actor sketched in Chapter One, where the aims and objectives of different groups, embodied in individuals, come into contact. They are the Advisory Forum, which met twice in early 2011, and the Technical Advisory Group, which had its first and last meetings in February 2011 and April 2013 respectively. On these bodies sit representatives from Whitehall Departments, Devolved Assemblies, non-governmental organisations, international statistical organisations, and academics (see Appendix A). The Advisory Forum also includes representatives from business. These are extensions of the Office for National Statistics, incorporations to inform its activities of additional actors of varying knowledge, positionality, power and influence. As extensions of the Office for National Statistics, these individuals become temporary Statistical Actors, internal to the official statistic-making process. As such, they provide pools of individuals who can be interviewed regarding the process of construction for the 'Measuring National Well-being' programme in addition to those at the Office for National Statistics itself. The two advisory bodies also produced sets of minutes, available online (with varying degrees of clarity and exactitude), which can be scrutinised to provide context and support to participants' accounts. The interviews and secondary material, as well as the contextual materials of Chapters Four and Five, serve to triangulate and substantiate each other, allowing greater confidence in the robustness of their analysis than any of them could in isolation. Both bodies also produced a certain amount of internal written material, principally email communication discussing the development of the programme. This was, unfortunately, inaccessible.

The composition of the two different bodies necessitated two different approaches to gaining access to participants. As the minutes of the Advisory Forum do not list who attended meetings, it is impossible to say what extent of engagement individuals had with the group, and so all members were contacted and asked for information on their involvement. However, as will be discussed further in Chapter Six, the Advisory Forum predominately consisted of individuals who were in the elite in their fields - winners of 
Nobel memorial prizes in the case of academics, holders of public honours in the case of civil servants and leading members of the business world (see Appendix A). Initially these individuals were approached through a personalised email invitation, sent to email addresses made public online, accompanied by the explanatory letter given as Appendix B. The email indicated why the individual was being invited out of all possible participants, emphasising the knowledge and expertise that they would offer the project. Where contact details were not available online, inquiries were made by phone to potential gatekeepers within their organisations, such as press offices.

Due to the seniority of the individuals recruited for the Advisory Forum, it was difficult to secure interviews with this group; initial queries gained only three interviews (out of a potential pool of 46). As an adaptation in response to this lack of availability, those who had declined to be interviewed and those who had not yet been invited were contacted by email asking for a brief written account of their involvement. 18 responses, either from the individuals themselves or their staff, were gained in this way. Combined with the three interviews gained, between these two approaches this represents a response rate of a little under half ( 21 of 46, 46\%). To increase uptake in written responses, it was made clear that these would be used in an exploratory, off-the record fashion, would be anonymised and would not be quoted in the research.

The Technical Advisory Group was a larger body, with 37 listed members but with a further 53 individuals attending one or more meetings. The minutes of the Group's meetings list attendance, which made a purposive sampling strategy possible based on potential interviewees' level of involvement in meetings. For example, six of the 37 listed members did not attend any meetings, and 59 individuals in total attended no more than one of the eight meetings held (see Appendix A). On the assumption that involvement in meetings proxied for involvement in the statistic-making process as a whole (including non-meeting-based activities), this information allowed the focusing of interviews on Statistical Actors who had been closely involved with the advisory process. In total, thirteen interviews were held with Group members, a little over a third of those approached (35 were approached, giving a 37\% response rate).

In total across the two groups, 16 interviews were conducted. These covered representatives of all the major groups involved as Statistical Actors in the statisticmaking process: the ONS (two interviews), international bodies (one interview), Whitehall Departments (six interviews), Devolved Administrations (one interview), international bodies (one interview) and academics (five interviews). One interview was secured through personal connections between staff within the University and those within the Office for National Statistics; similar connections were used in unsuccessful attempts to secure interviews with actors in other statistical bodies. Another interview was secured through contacts made by the researcher in person at a research conference. Efforts were made to expand the pool of interviewees through snow-balling; in a number of cases interviewees recommended other actors for interviews, and allowed the researcher to use their names as an introduction. This was notably unsuccessful when trying to secure more participants from the ONS: the senior figure interviewed acted as a gate-keeper and refused requests to speak with further members of their team. Any lack of quantity of interviews is compensated for by quality: the two ONS figures interviews represented key actors within the construction of the programme and the 
interviews conducted with them were the most lengthy in the research (both approaching an hour in length). In general, due to the theoretical sampling strategy undertaken, the sixteen interviews represented many of the individuals most closely involved in the programme and so those most able to offer information on it.

The interviews also capture a range of Statistical Actors: from those who can be thought of as 'permanent', in the case of those at the ONS itself; through those regularly involved in statistic-making, which includes both academics and government actors; and down to those who were involved only in the construction of the 'Measuring National Well-being' programme, as was the case with some of the academics. These differences were reflected in the interviews: some Actors spoke with an eye to maintaining on-going relationships, others in light of their regained outsider status.

The interviews were conducted by telephone over the summer of 2014. This method, rather than face-to-face interviewing, was selected partly as a result of the dispersal of interviewees across the UK and Europe (with further potential interviewees in North America). Another factor was the difficulty in scheduling face-to-face meetings with academics, civil servants and representatives of international organisations, all of whom had pressures on their time. Where face-to-face interviews were attempted, they were in all cases cancelled as more pressing priorities arose for participants. Telephone interviewing allowed the flexibility for participants to select a time to be involved in the research, which may have increased the response rate. Interviews lasted between 30 minutes and an hour, depending on how much the participant wanted to say.

The style of the interviews drew on work around language ideologies, particularly that of Briggs $(1986,2007)$, and also the literature around the negotiated nature of the interview discussed above (Kvale 1996). This literature argues that interviews do not represent straightforward transmissions of thoughts contained within the interviewee's mind, but instead that they are dynamic responses to the constraints of the interview setting. The interviewer cannot be neutral within the interview process; the very fact of asking questions influences the information obtained (Collins 1998; Kitchin and Tate 2000). Neither is the interviewee neutral, as they are able to an extent to control the information provided in their responses. As a result, the interview represents a negotiation of the relationship between the positions of researcher and researched; a negotiation which occurs alongside other relationships of relative power, distance, solidarity, and so on (Koven 2014). (That is, both interviewer and interviewee are treated as agents within a social relation, in keeping with the suppositions of the research.) Considering this, as much as possible interviews were conducted as conversations, with the researcher interspersing questions with comments on participants' replies and responses (Koven 2011; see also Oakley 1981). As will be discussed below, interviews were written up as narrative notes, rather than transcripts, allowing participants to respond to the representation of what they had said and adjust the tone as they felt appropriate.

Interviews were semi-structured, built around themes identified in the research into the programme's institutional and theoretical context (see Chapters Four and Five), and were conducted without a standardised interview schedule. This was partly because the diversity of participants meant that a standardisation of questions would have been 
inappropriate, and partly because it allowed questions to be revised and developed both within and across interviews. This meant that many of the themes discussed in later interviews were different from those discussed in earlier ones as new aspects of the statistic-making process became apparent. Instead, conversations were built around broad themes based on what was known about the participant's background and institutional or theoretical position, and developed in response to the participant's replies. This ensured that questions could be sensibly directed to participants and that time was not wasted on asking material that was a matter of public record. Following Mikecz (2012), this also reduced opportunities for interviewees to offer 'public relations' accounts of their work. (Indeed, as noted above, one interview was retrospectively withdrawn from the study precisely because managers within the interviewee's organisation felt it to be have strayed far from the publicly available account of their work. While disappointing, this can be taken as an indication that the interview was successful in its aims.)

Interviews were not recorded. In some early cases this was because of explicit opposition by interviewees; with later interviews it was done partly to ensure consistency in approach across participants and partly as a deliberate tactic to avoid formality within the interview setting as discussed above. Notes from these meetings were then written up, clearly labelled as non-verbatim narrative accounts, and sent to participants to comment on if they so they wished. Again, this was an attempt to avoid the appearance potentially given by a transcript that it, and the interview it records, are a straightforward representation of thoughts within the interviewee's mind. As Bucholtz (2000) makes clear, transcripts are not neutral objects but contain within them a series of representational decisions (see also Hodder 2000). Producing narrative notes made the representational nature of the account of the interview clear, gave warning of the representational nature of the account which would be taken in later work, and offered the opportunity for these representations to be challenged as an extension of the negotiations of the interview itself. This seemed a natural expression of Lincoln and Guba's (1985) observation that interviews should be handled narratively, as it made clear to participants that this was how their interviews were being handled. Several participants took this opportunity, correcting misunderstandings and adjusting for tone, and these were incorporated into the interview notes. In a small number of cases, participants did not respond to the sending of the notes; comments were invited a second time from these participants, and they were told that non-correction would be taken as a sign of acceptance that the notes were a fair representation of the conversation that occurred.

In one case (a seventeenth interview), as discussed above, the participant requested that the notes be withdrawn as their manager did not feel that they represented the views of the organisation. This was done, and this interview does not appear in the research. Although that participant offered to respond to written questions, they did not, and they also failed to respond to requests to reproduce the email correspondence between themselves and the researcher. As a result, this correspondence is also excluded from this research.

For reasons discussed in the section below (3.6.), participants were fully anonymised. A list of interviews appears as table 3.1.. 


\begin{tabular}{lll}
\hline Date & $\begin{array}{l}\text { Participant } \\
\text { (anonymised) }\end{array}$ & Institutional Position \\
\hline 5 June, 11am & Oliver & Academic (Statistical theory) \\
2 July, 4pm & Jack & International organisation (Statistician) \\
17 July, 10.30am & Harry & Academic (Economics) \\
23 July, 10am & Jacob & Devolved Administration \\
4 August, 12pm & Charlie & NGO (Social policy) \\
8 August, 4pm & Amelia & Central Government (Whitehall) \\
22 August, 11am & Jessica & NGO (Public health) \\
2 September, 3pm & Ava & Academic (Public health) \\
9 September, 12pm & Thomas & Academic (Sociology) \\
11 September, 11am & Oscar & ONS \\
11 September, 2pm & Emily & Central Government (Whitehall) \\
12 September, 2.30pm & William & ONS \\
8 October, 10.30am & Isla & Central Government (Whitehall) \\
8 October, 2.30pm & James & Central Government (Whitehall) \\
10 October, 10.30am & George & Academic (Psychology) \\
14 October, 2pm & Alfie & Central Government (Whitehall) \\
\hline
\end{tabular}

In addition, there are 5 sets of emails declining involvement, 18 written responses to the enquiry "What was your involvement?", 1 withdrawn interview and a number of off-record conversations. These are not used as primary data within the research, as they all lacked formal approval from participants for such a use.

Table 3.1. Interviews conducted

In addition to interviewing and eliciting written comments directly from Statistical Actors, material around the Advisory Forum and Technical Advisory Group were also analysed. This represents two sets of minutes for the Advisory Forum and eight sets of minutes for the Technical Advisory Group; also the Terms of Reference for both groups and a number of supporting presentations and discussion papers which were presented to the Advisory Group. These were all available on the Office for National Statistics' website at the time of the research. An email enquiry to the programme team in July 2014 confirmed that these represented all the meetings held by both groups (a question 
which arose partly because several scheduled meetings, particularly of the Advisory Forum, did not take place).

The evidence gathered from interviews and this secondary material produced by Statistical Actors was supplemented by minutes of the Government Statistical Service Methodology Advisory Committee (GSS MAC), a group which sits above the ONS within the UK official statistical hierarchy, and whose role is to inspect and advise on official statistics which have been brought before them. They discussed the 'Measuring National Well-being' programme in their meeting of 19 June 2013, and these minutes were included in the research because this inspection procedure is a key part of the UK official statistic-making process. On similar grounds, the report of the UK Statistics Authority considering whether the personal well-being component of the ONS' programme was of sufficient quality to be badged a 'National Statistic' was also considered (UK Statistics Authority 2014a).

Finally, a certain amount of non-meeting-related secondary material was collected and synthesised with the primary data obtained in interviews. This secondary material includes published outputs of the programme written by those at the ONS; and 'grey literature', material about the programme written by those involved in it but not written under the official auspices of the ONS. As with the interviews, this secondary material reflects the range of permanent and impermanent Statistical Actors, including both material written by those at the ONS and those who were only involved in the shortlived Advisory Forum (as in the case of Tomlinson and Kelly 2013).

The purpose of this synthesis is to contextualise and triangulate the material gained in the primary interviews. It serves both to inform interviews, by offering official accounts of events within the statistic-making process, and to situate the accounts of interviewees within the impersonal (but not impartial) official narrative. This is important in a study such as this, because the individuals involved in a social process are socially positioned; they have interests, objectives, beliefs, and so on. This means that experiences of events may differ across Statistical Actors. How these experiences are expressed by different interviewees, and how they are recorded in the official accounts, may differ. An account of the social nature of the process of official statistic-making needs to take account of such differences.

A complete list of materials considered appears as table 3.2.. 


\begin{tabular}{|c|c|c|c|}
\hline Date & Type & Author & Title \\
\hline 2011 & $\begin{array}{l}\text { Terms of } \\
\text { reference }\end{array}$ & ONS & Advisory Forum, Terms of Reference \\
\hline 2011 & $\begin{array}{l}\text { Membership } \\
\text { list }\end{array}$ & ONS & Advisory Forum, Membership List \\
\hline 2011 & $\begin{array}{l}\text { Terms of } \\
\text { reference }\end{array}$ & ONS & $\begin{array}{l}\text { Technical Advisory Group, Terms of } \\
\text { Reference }\end{array}$ \\
\hline 2011 & $\begin{array}{l}\text { Membership } \\
\text { list }\end{array}$ & ONS & $\begin{array}{l}\text { Technical Advisory Group, } \\
\text { Membership List }\end{array}$ \\
\hline 5 January 2011 & Minutes & ONS & Advisory Forum, minutes, $1^{\text {st }}$ meeting \\
\hline February 2011 & $\begin{array}{l}\text { Consultation } \\
\text { paper }\end{array}$ & $\begin{array}{l}\text { Dolan, Paul; } \\
\text { Layard, Richard; } \\
\text { and Metcalfe, } \\
\text { Robert }\end{array}$ & $\begin{array}{l}\text { Measuring subjective well-being for } \\
\text { public policy }\end{array}$ \\
\hline 4 February 2011 & Minutes & ONS & $\begin{array}{l}\text { Technical Advisory Group, minutes, } \\
1^{\text {st }} \text { meeting }\end{array}$ \\
\hline 11 April 2011 & Minutes & ONS & $\begin{array}{l}\text { Technical Advisory Group, minutes, } \\
2^{\text {nd }} \text { meeting }\end{array}$ \\
\hline 21 June 2011 & Minutes & ONS & $\begin{array}{l}\text { Technical Advisory Group, minutes, } \\
3^{\text {rd }} \text { meeting, seminar on measuring } \\
\text { children's and young people's well- } \\
\text { being }\end{array}$ \\
\hline 25 July 2011 & Minutes & ONS & $\begin{array}{l}\text { Advisory Forum, minutes, } 2^{\text {nd }} \\
\text { meeting, }\end{array}$ \\
\hline 26 January 2012 & Minutes & ONS & $\begin{array}{l}\text { Technical Advisory Group, minutes, } \\
4^{\text {th }} \text { meeting }\end{array}$ \\
\hline 29 March 2012 & Minutes & ONS & $\begin{array}{l}\text { Technical Advisory Group, minutes, } \\
5^{\text {th }} \text { meeting }\end{array}$ \\
\hline 30 May 2012 & Minutes & ONS & $\begin{array}{l}\text { Technical Advisory Group, minutes, } \\
6^{\text {th }} \text { meeting }\end{array}$ \\
\hline $\begin{array}{l}3 \text { December } \\
2012\end{array}$ & Minutes & ONS & $\begin{array}{l}\text { Technical Advisory Group, minutes, } \\
7^{\text {th }} \text { meeting }\end{array}$ \\
\hline 15 April 2013 & Minutes & ONS & $\begin{array}{l}\text { Technical Advisory Group, minutes, } \\
8^{\text {th }} \text { meeting }\end{array}$ \\
\hline 19 June 2013 & $\begin{array}{l}\text { Agenda/Min } \\
\text { utes/Papers }\end{array}$ & $\begin{array}{l}\text { GSS } \\
\text { Methodology } \\
\text { Advisory } \\
\text { Committee }\end{array}$ & $\begin{array}{l}\text { GSS MAC, minutes, meeting to } \\
\text { discuss 'Measuring National Well- } \\
\text { being' }\end{array}$ \\
\hline 2013 & $\begin{array}{l}\text { Journal } \\
\text { article }\end{array}$ & $\begin{array}{l}\text { Tomlinson, } \\
\text { Michael; Kelly, } \\
\text { Grace P }\end{array}$ & $\begin{array}{l}\text { 'Is everybody happy? The politics } \\
\text { and measurement of national } \\
\text { wellbeing' }\end{array}$ \\
\hline 2013 & $\begin{array}{l}\text { Conference } \\
\text { paper }\end{array}$ & Allin, Paul & $\begin{array}{l}\text { 'New statistics for old? The case of } \\
\text { the UK Measuring National Well- } \\
\text { being Programme' }\end{array}$ \\
\hline
\end{tabular}


2014

2014
Book chapter Allin, Paul

Book
'Measuring wellbeing in modern societies'

Table 3.2. Key documents consulted

\subsection{Framework for analysis}

As outlined in Chapter One, the social process of official statistic-making is envisaged as the interactions of agents with each other and with their context. This context is both institutional and theoretical, and will have social, economic, political and cultural dimensions. The first stage of the research methodology, as outlined in Section 3.4. above, is to explore those institutional and theoretical contexts. 'Context' in this sense is the conditions of enablement and constraint that faced agents when the work on the 'Measuring National Well-being' programme commenced in July 2010; what powers did they have to create official statistics, and what limited these? Or, in the terms of the theory of agency laid out above, what are the structures which agents are confronting, and how flexible are they? Such structures are the products of historic processes of contestation around institutional or theoretical features. To take a concrete example which will be discussed more fully in Chapter Four, throughout the history of the Office for National Statistics and its predecessor organisations there have been debates over whether statistic-making should be centralised or dispersed. Such debates are expressed through institutional arrangements, which provide the Statistical Actors with particular responsibilities for producing national statistics, but particular powers around what data they can access and what other bodies they must deal with.

As a result, the exploration of institutional and theoretical context takes a historical approach to the Office for National Statistics, the role of official statistics in the UK policy-making context, the development of 'well-being' theory and the development of well-being measurement, and looks for areas of contestation. These areas act as potential landmarks in the institutional and theoretical context which the Statistical Actors must navigate. This takes the form of an exploration of primary literature such as government position-papers and theoretical academic articles and secondary literature such as institutional histories. These are analysed to draw out key themes and debates which Statistical Actors face in 2010 when the 'Measuring Well-being' programme opens. These themes and debates give an idea of the structures which agents face, the flexibility of these structures and of how agents have previously dealt with them.

The extent to which such themes and debates impact on the process of official statisticmaking is an empirical question which frames the handling of the interview and secondary material. There is thus a bi-directional triangulation involved in this method, with the exploration of context serving to situate empirical analysis, and that analysis acting to validate the exploration of context. Again, the model of Chapter One posited Statistical Actors as agents, so the interviews and secondary material was analysed in relation to context with agency in mind. Where did Actors interact with each other and their context, and how? As a starting point, the areas of contestation identified in the 
exploration of institutional and theoretical contexts were used to frame questions; to reuse the example above, Actors were asked about the ways in which they interacted with bodies outside of the Office for National Statistics. As well as reacting to context, however, Actors reacted to each other as embodiments of theory and institutional position, so attention was paid to areas where Actors agreed or disagreed with each other. In both cases, the interest lay in how Actors, as agents, resolved the challenges of official-statistic making.

Primary data from interviews and secondary data such as meeting minutes were used in an iterative manner. Prior to interviewing participants, minutes were examined to see what participants' contributions, if any, had been, and how they related to the themes identified in the examination of the theoretical and institutional context. Based on the interviews, secondary material was re-visited to develop or corroborate claims. This allowed the positionality of interviewees to be explored more fully; interviews with different Actors could provide distinct viewpoints on the same interaction, with meeting minutes providing a more distant (although often no less interested) standpoint.

Information from early interviews was used to inform later interviews, allowing newly discovered areas of agential interaction to be explored. This was possible because of the semi-structured nature of interviews; no attempt was made to keep questions consistent throughout interviews, instead questions were shaped to the interviewee. Again, the interest of the interviews was in uncovering areas of agential interaction with their context and each other, so questions focused on the themes and debates raised in the exploration of institutional and theoretical context and on the ways in which were expressed in interactions between agents. Of particular interest were areas of agreement and disagreement between agents, and the ways in which agents acted to influence the outcome of the official statistic-making process.

Material was coded manually, around the themes identified in the theoretical and institutional context, using the on-screen highlighting tools of the LibreOffice Writer software for Linux (The Document Foundation, 2013-5, main-build versions 4.1. and 4.2.). Wherever possible, printing was avoided to minimise the research's environmental footprint. Material from the interviews around the themes was concatenated into master thematic documents, which were then supplemented with similar extracts from the secondary material. While more labour-intensive than using bespoke qualitative analysis software, the cumbersome and repetitive nature of this process ensured a close familiarity with the empirical material and served to establish the arguments of the empirical chapters iteratively as the material was examined.

\subsection{Ethics}

The research process raised a number of ethical issues, both at the design stage and as it developed. The design was approved by the Ethics Committee of the University of Newcastle (email from Wendy Davison, 5 May 2014). When issues arose later in the research, particularly around the use of material which participants hadn't explicitly approved for use such as emails declining involvement, the Committee was referred to again. In all cases, their decisions were followed. 
As a matter of course, participants were anonymised to ensure both that they were comfortable speaking of issues which may prove sensitive (for example, where there were disagreements between Statistical Actors) and to protect their confidentiality should anything sensitive be said. Anonymisation was achieved using the most recent list of 'Baby Names in England and Wales' (Office for National Statistics 2014a). As a list of the most common names given to new children in the year of the research, this was felt to be neutral way of assigning names to participants. Alternative schemes which did not use names were discounted on the grounds that they risked obscuring the social nature of both the statistic-making process and the research process by de-emphasising the human nature of participants. No attempt was made to ensure that the assigned names 'matched' those of participants, for instance on grounds of ethnicity or class; such a process would have involved too many assumptions on the part of the researcher and could potentially have weakened the anonymisation. Instead, the first male interviewee was given the most common male name for newborns ('Oliver'), the second male interviewee was given the second most popular ('Jack'), and so on.

As will be clear from this method, while names were not 'matched' to participants on ethnicity or class grounds, they were 'matched' on the basis of gender. This proved unavoidable, as the gender of actors within the statistic-making process was felt by some research participants to have impacted on the way the statistic was made (see Chapter Seven). Gender-identification was not a question that was asked in interviews; although it was considered in some of the later interviews, when it became apparent that it was important for the research process, it was always discarded as sitting too uncomfortably with questions about the statistic-making process. As a result, it was necessary to make ascriptions of gender to participants which may not reflect the way that they self-identify. This has a knock-on effect on the analysis of gender as an issue within the statistic-making process; the fact that gender in this study is ascriptional acts as a caveat on any conclusions drawn. Where it is explicitly discussed, the gender of participants will be asterisked to signify its ascriptional nature (i.e., "*male", "*female").

To fully achieve anonymisation, the full job titles of participants are also not used in this study. To do so would have allowed participants to be identified. Instead, participants were categorised into broad categories by professional background: ONS, international organisation, academic, Whitehall Department, Devolved Assembly and NGO (see Appendix A). In some cases it was necessary to identify academic participants further, giving some idea of their discipline as a framing for their interview responses. Again, this was done as broadly as possible: economics, public health, sociology, psychology, statistical theory. The vagueness of these labels was necessitated by the relatively small numbers of Actors from any given background involved in the process: while there were, for instance, seventeen academics listed as being members of the Technical Advisory Group, eight were economists (either working in economics departments or with 'economist' in their job title), leaving the remaining nine distributed across the four other disciplinary backgrounds which have just been identified. Identifying the disciplines of this remainder (or, identifying more precisely the sub-discipline of economics which the economists practised) would have compromised their anonymity. 
Similarly, in a number of places references made by interview participants to their employers, or references that would have identified employers, have not been quoted in this study.

While these measures will help prevent participants from being identified by nonStatistical Actors, there remains the danger that they may be identifiable by others involved in the official statistic-making process as the pools of potential interviewees are so small. This was raised by a number of participants throughout the research. The approach of using narrative notes rather than transcripts mitigates the danger of identification somewhat, as many of the distinguishing verbal mannerisms of participants are lost. Beyond this, the content of the notes was negotiated with participants; all interviewees were offered the opportunity to correct or amend their notes, and many of them did. In two cases, participants also requested and were given copies of the parts of the research in which their interviews were cited. This allowed them to amend or clarify their texts as appropriate; in one case, this led to a different extract being used to ensure that the participant was comfortable that they were not identifiable. In one further case, an extract from an interview was used but was not attributed, even anonymously. It is unlikely that these methods will have been completely successful in making participants unidentifiable, but they were sufficient to make participants comfortable in the use of their material.

As discussed above, in one case a participant asked for the account of their interview to be withdrawn from the research. This was done (email to unattributed, 10 July 2014), and the interview is not referred to outside of the present Chapter. A later request to this (non-)participant to include the email correspondence regarding the withdrawal within the research went unanswered. As it was agreed between the Ethics Committee and the researcher it would be inappropriate to include this correspondence without explicit approval from the (non-)participant, this too has been excluded from the research.

Informed consent for the interviews was obtained using a standard covering letter, informing participants of the nature of the research, its planned uses, their right to withdraw and to refuse to answer questions, and the anonymisation protocol (see Appendix B). In a number of interviews, this was expanded on verbally in discussion with participants. As discussed above, in addition to considering the account of the conversation, a number of participants were also offered the option of seeing the use of their material within the research; although they were not offered the right of veto on anything written, this would offer them the opportunity to further discuss questions of sensitive material with the researcher, allowing the researcher to adjust material to fully protect their anonymity. This offer was taken up by two participants.

\subsection{A note on positionality}

In keeping with the arguments on agency above, the critique of empiricist approaches in Chapter Two, and the wide body of literature around issues of reflexivity (see, for example, McDowell 1992; Oakley 1981; Rose 1997), some comments should be made on the attitudes and approaches that I held during the research. ${ }^{6}$ Although perfect self-

6 For the avoidance of irony, this section breaks with the passive voice an is written in the first person. 
knowledge is as implausible as full and neutral truth in any other situation, I think it is possible to highlight some of the attitudes and beliefs which shaped my interactions with participants (and all those who assisted and supported this research) and my understanding of the data I gathered.

I would like to mention two things, which felt central to me at the time. One is my faith as a Buddhist. Rightly or wrongly, I have always felt academia to be unwelcoming of faith. Despite having largely abandoned the idea of rationality, there are still some things seen as irrational. I spent a lot of time re-justifying my attitudes in acceptable terms; it was fine for me to believe in impermanence so long as I claimed it was because I was a philosophical anti-essentialist, I could argue for the basic equality of all sentient beings if I waved my hands at Marxian or Feminist literatures, I could talk about the cocreation of person and universe on a moment-by-moment basis so long as I referenced the debates around structure and agency. This felt slightly absurd; it is not possible to avoid having an ontology or an epistemology, and ultimately they exist beyond justification; they are the point where reasons give out and we are left with something basic and brute (see Cohen 2000). One of the reasons I am so attracted to the arguments of Adorno and Horkheimer (1997) is my sense that I have had to replace one ultimately groundless epistemology with another more fashionable one in exactly the manner they describe.

However, were I not a Buddhist, I doubt I would have been drawn to the research topic I was. It is hard for me not to see the acknowledgement of agency (both in statistics and satistic-making) as normative, rather than strictly intellectual, questions, and I was caught several times by my supervisors and at conferences unwittingly going beyond what could be justified with argument because I felt a position to be morally questionable (an example would be my approach towards neoclassical economics). When I understood that this was what I had done, I did my best to park my moral beliefs in the interests of academic argument although this seems an odd thing for me to do. These questions matter, ultimately, for normative reasons and it seems strange not to acknowledge that. $^{7}$

The other thing I felt to be shaping my thoughts and approach to the research is what had been described as 'imposter syndrome' or 'perceived fraudulence' (a phenomenon first identified by Clance and Imes 1978; see also Barcan 2014). I left university after my undergraduate degree feeling myself to be stupid and out of my depth. Having earned my way back in through a competitive process and now having several years 'passing' I do not feel any cleverer or more comfortable. I have accepted that I have done well for a stupid person, but I would rather be at ease. This sense of fraudulence expressed itself both in a tentativeness in my writing and in my interviewing. I was acutely conscious that I, an unimportant and stupid person, was taking up the time of

For the purposes of full disclosure, it is written after the research was submitted for examination. While I was always conscious of the disconnect between the agential reading of the official statisticmaking process and the pretence of neutrality in its writing up, it was only when formally permitted by my examiners that I felt comfortable breaking with the dominant academic writing style. I am grateful for having been given that permission.

7 As a postscript to this: this section commenting on the fact that faith cannot be talked about in the Academy was originally somewhat longer. Those I passed it to for comment suggested I cut it back, which, I think, nicely underscores my point. 
my interviewees, important and intelligent people. The sense of social awkwardness this engendered made interviewing one of the most stressful and unpleasant experiences of my life. When interviews went 'badly', the feeling of predicted and deserved personal failure made it very difficult to continue them, when they 'well' the feeling that I could have done more or asked 'better' questions was inescapable. Under such circumstances, methodological texts calling for the establishment of rapport with participants felt like cruel jokes. A more confident person would have handled things differently. ${ }^{8}$

\subsection{Summary}

Chapter One argued that the making of official statistics were underpinned by a social process, the interaction of Statistical Actors with each other and with their social context. Chapter Two argued that existing literature around official statistics was not sensitive to this social process, and that this resulted in a gap in the literature. Building on social constructionist literature, the present chapter argued that a social process requires a research methodology sensitive to Actors' own experience of statistic-making, its context and their interactions with each other.

For this reason, a research methodology was outlined which focuses on interviews with Statistical Actors, triangulated with secondary material originating in the statisticmaking process. For reasons of access and of data availability, the 'Measuring National Well-being' programme was selected as a case study for investigation. Applying the research methodology to this programme resulted in two necessary steps. The first, to be covered in Chapters Four and Five, is an examination of the institutional and theoretical contexts in which the programme sits. These will outline the terrain which the Statistical Actors will need to navigate. The process of navigation will be examined in Chapters Six and Seven, through an exploration of the empirical material gathered.

This research methodology deals with the specific case of the 'Measuring National Wellbeing' programme, but is applicable to other official statistics in other times and in other places. It attempts to explore the institutional and theoretical contexts of the case, and all official statistics will have an institutional and a theoretical context; and it attempts to explore the interactions of agents with this context and with each other, and Chapters One and Two have argued that all official statistics will involve Actors with agency in their creation. The methodology should be valid beyond both the specific case of the 'Measuring National Well-being' programme and the specific circumstances of the Office of National Statistics. How far this is the case will be examined in Chapter Eight.

8 I would like here to thank my supervisory team of Andy Pike, Mike Coombes and Joe Painter for their support throughout my studies. My sense of being out-of-place is my own, and is despite their acceptance and guidance of me as a scholar. 


\section{Chapter Four \\ The institutional context of the 'Measuring National Well-being' programme: the Office for National Statistics and the place of official statistic-making within UK policy-making}

The preceding chapters have argued that the 'Measuring Well-being' programme, as an example of an official statistical programme, is a social construction. As such, it must be constructed from something. This chapter examines the institutional context in which the programme was made: the Office for National Statistics, who are responsible for the creation of the programme; and institutional structures and policy-making processes of government of which they form a part. This context is culturally- and place-specific; while all modern nations have statistic-making bodies and practices of policy-making, the UK has a specific history which includes fragmented governmental responsibilities, centralised control and devolution of power. These, and other peculiarities, can be expected to have an influence on the form and content of the official statistical programme. An understanding of the form that these took in 2010, when the 'Measuring National Well-being' programme was launched, will provide indications of the challenges and constraints, as well as opportunities, which the agents constructing the programme must react to.

This chapter will explore the institutional context of the ONS, focussing on themes derived from an engagement with literature around the institution of the ONS, and from the empirical material of Chapters Six and Seven. Section 4.1. opens with a brief history of the Office for National Statistics and its institutional predecessors before proceeding thematically, examining key themes in this history. Rather than attempting to recount the much longer history of the UK state, Section 4.2. will focus on the last 15 years of government, examining particularly the thematic areas which arose from the history of the ONS. The challenges Statistical Actors face which are specific to the ONS and the wider context in which the organisation sits will be drawn out.

This chapter provides a further critique of the theories examined in Chapter Two by highlighting the specificity of the institutional context in which official statistics are produced. It also acts as a grounding for the empirical work of Chapters Six and Seven, where those involved in the process of official statistic-making will discuss themselves the context of their work and the impact this context has on it.

This chapter makes a contribution to the literature around the Office for National Statistics, extending previous institutional histories such as Ward and Doggett (1991) to incorporate the changes to the structure of official statistics in the UK made by the Statistics and Registration Services Act 2007. It also represents the fullest account of the ONS not written under the organisation's auspices, which allows it to take a more critical stance. The section on policy-making in the UK brings together material from several academic disciplines, notably Geography, Politics and Management Theory. This synthesis of material contributes to the literature around policy-making by offering a wider perspective than any one of these disciplines offers alone. 


\subsection{The Office for National Statistics}

\subsubsection{A brief chronology of official statistics in the UK}

Official statistics are defined by the relevant legislation as those statistics produced by agents of the Crown (Statistics and Registration Services Act 2007). The first specialised institutional body for the production of such statistics in the UK was the Statistical Department of the Board of Trade, established in 1832 (Shaw and Miles 1979). Prior to its establishment, statistics were created by state agencies, but in an $a d$ hoc manner in response to specific legislative requirements (such the Bills of Mortality issued by the Worshipful Company of Parish Clerks, Collier 1854, or the figures collected by the Inspector General of Imports and Exports following its establishment in 1695, Shaw and Miles 1979). The Statistical Department differed from these in that it was both a permanent structure exclusively tasked with the ongoing creation of statistics and one with the purpose of making statistical returns more easily available and usable (Ward and Doggett 1991). This latter purpose represents an expansion in the conception of statistics, from being monitoring devices which permit reactions along predetermined lines to being information sources on which novel state and non-state interventions can be based (Porter 1986).

This shift in conceptualisation gradually extends across government; for much of the nineteenth and early twentieth centuries there is a slow expansion of statistical collection through an increasing number of state bodies specialising in statistics for discrete purposes, largely restricted to statistics demanded by legislation (Davidson 1995). (This can be compared with the more systematic collection of data for administrative purposes undertaken in Germany around the same time which gave 'state-istics' their name, Shaw and Miles 1979). These result in statistics which are limited in their coverage, are not co-ordinated to provide any overall picture of society or economy, differ widely in coverage and methodology and which, as a result, do not always cohere or agree. This lack of coherence and agreement becomes a problem during the Second World War, leading to the foundation of the Central Statistical Office (CSO) to better co-ordinate the activities of the wartime state (Moss 1950). Following the War, this was expanded to allow the conduct of a more interventionist social and economic policy. Such policy and its informational needs necessitated the creation first of a separate Business Survey Office and then of an Office of Population, Census and Surveys in the late 1960s and early 1970s to handle increased legislative demands for statistics and to centralise statistics previously produced across different branches of government (Rayner 1980a, b; Ward and Doggett 1991).

This proved the high watermark of central statistical production (Government Statisticians' Collective 1979). In the years that followed, staffing levels and output were reduced and public access to statistics restricted on the principle, articulated by the Rayner Review (Rayner 1980b), that official statistics existed primarily to serve the needs of government. Over the next twenty years, statistics become more centralised as diverse government statistical bodies were merged into the CSO. The two largest of these were the merging into the CSO of the Business Survey Office and statistical divisions of the Departments of Trade and Industry and of Employment in 1989 (Ward and Doggett 1991), and the combination of the CSO and the Office of Population, 
Census and Surveys in 1996 to form the Office for National Statistics (Office for National Statistics 1996). With this latter merger, the Director of the ONS was also given responsibility over the Government Statistical Service, the professional collective of statisticians working within government departments, as well as acting as the government's chief statistical advisor.

This arrangement was confirmed by the Statistics and Registration Services Act of 2007, which merged the ONS and the Statistics Commission, which formerly supervised it, to form the UK Statistics Authority. The Authority took over responsibility for monitoring the quality of official statistics, including those created by the Office for National Statistics as the Authority's executive agency. The Act also created the role of 'National Statistician', taking on the ancillary roles, such as heading up the Government Statistical Service, previously held by the Director of the ONS but allowing the day-to-day operation of the Office to be undertaken by a full-time Director General (UK Statistics Authority 2013). The UK Statistics Authority is a non-ministerial government department, operating at arms-length from central government. In addition to producing statistics through the ONS, it also monitors the quality of all official statistics, assessing them for compliance with a Code of Practice (UK Statistics Authority 2009). In 2010-11 it had a budget of around $£ 159$ million (excluding one-off funding for the 2011 Census and for special projects such as the development of the 'Measuring Well-being' programme, which between them accounted for a further $£ 142$ million) (Office for National Statistics 2010b).

\subsubsection{Centralising and de-centralising impetuses in the history of UK official statistics}

Statistical work in the UK is decentralised. This ensures that statistics are close to policy in such vital and diverse areas as health, education, employment and crime.

National Statistics (2002, p.11)

Historically, statistics in the UK have been organised on a decentralised and devolved basis, with government departments and Devolved Administrations producing statistics for their own purposes. In addition, the UK Statistics Authority exists as a nonministerial government department. Under the Statistics and Registration Services Act 2007, which created the Authority, it acts both to create statistics itself through the Office for National Statistics, and to regulate official statistics produced elsewhere. 'Official statistics' are defined by their origin, not by their content, as those produced by "a government department, the Scottish Administration, a Welsh ministerial authority, a Northern Ireland department, or any other person acting on behalf of the Crown, and such other statistics as may be specified by order by a Minister of the Crown, the Scottish Ministers, the Welsh Ministers, or a Northern Ireland department" (Statistics and Registration Services Act 2007, Section 6). This creates a system of decentralised 
and devolved statistical creation with certain statistics, primarily those involving largescale surveys in their production, centralised within the ONS.

The great advantage of a decentralised system is that its statistics can be responsive to the localised needs of users (Rayner 1980b), but this comes at the expense of a joinedup system capable of imposing uniform standards of collection and analysis or of creating a single coherent statistical picture of the nation (Statistics Commission 2008). The 2007 Act is a compromise between these two possibilities, with the UK Statistics Authority acting as a scrutinising body for official statistics across government and the National Statistician as both chief executive of the UK Statistics Authority, and so ultimately responsible for the statistics produced by the ONS, and head of the body of statisticians distributed across other departments, the Government Statistical Service (GSS). In practice, the National Statistician's focus is the latter, acting to maintain professional identity and standards across the decentralised system, while the day-today management of the ONS lies with a Director General (UK Statistics Authority 2013). Within the ONS sits a 'Methodology Group', responsible for the quality of the methods of statistics created, and at the level of the GSS is a 'Methodology Advisory Committee', which considers the methodologies of statistics from across the GSS (including the ONS) on an invitational basis.

Competing pressures for centralisation and decentralisation can be seen throughout the history of the ONS and its predecessors, as the conception of official statistics shifts from being one of $a d$ hoc and isolated responses to particular administrative problems to a broader conception as a "a window on society and the economy, and on the work and performance of government" (UK Statistics Authority 2009, p.2). The earliest modern example of a national-level official statistical record in the UK is the Domesday Survey of 1086 (Wood 1999), which sought to calculate and record valuations of the land which was owned by the King but managed on his behalf by tenants-in-chief (Galbraith 1974). This was very much a one-off effort, designed to solve the difficulties that the Norman conquest, with its wholesale changes in land tenancy from English to French proprietors, caused for tax collection. No central agency was established to carry out the Survey; instead it utilised existing local land valuation records and local networks of governance (Harvey 1971), which were returned to as sources for tax assessment in the centuries which followed. There is no conception here of the statistic as a longitudinal device to show change or progress, or as an open-ended tool for enquiring about social and economic conditions; instead it is an administrative solution to an administrative problem.

Similar observations could be made about the parish registers of baptisms and deaths introduced by the Second Henrician Injunctions of 1538 (Cromwell 1910). While these represent an on-going form of data collection and did later provide the basis for mortality statistics in major cities like London in the seventeenth century (Collier 1854), they were not formally collected into centralised national records or official statistics until the Births and Deaths Registration Act 1836, three-hundred years later. Their introduction is initially a solution to the legal problems of parentage and inheritance at a local level, they are later used, particularly in London, by the wealthy as a local index of health, but they do not form the basis for any broader assessment of national-level demographics and are not collected and compiled to do so. 
The creation of the Statistical Department of the Board of Trade in 1832 can be read in this context as a limited centralisation brought about by (and in response to) the development of multiple decentralised statistics. Starting with the Corn Act of 1770, Parliament had increasingly legislated for specific statistics to inform policy, particularly in the areas of taxation and tariffs. ${ }^{9}$ This resulted in an increasing burden of data collection across central government departments and the problems caused by a lack of co-ordination, leading to the Department's creation. The degree to which this impulse to centralisation is limited can be seen by the rejection, in the same year that the Statistical Department was established, of the Parliamentary Committee on Public Documents' recommendation that a Central Statistical Office be created. Despite a series of statistical departments appearing across government to deal with specific administrative problems, while lay statistical societies were being established to examine social issues, such rejections continue throughout the late nineteenth and early twentieth centuries (Ward and Doggett 1991). The grounds for these rejections are similar to modern grounds, that centralisation would impede administrative flexibility, that uniformity of collection and analysis is neither entirely possible nor entirely desirable and that a centralised body would over-reach itself and create statistics which served no particular administrative need (see Allsopp 2003; Rayner 1980a).

However, in opting for a decentralised system, the problems of incoherence of data, duplication of effort and lack of coverage occur. This became a problem during the Second World War when the needs of co-ordinating an entire economy necessitated data covering that economy in its entirety. The piecemeal system which had grown up, with its duplication and disagreement, was insufficient to meet these needs (Rayner 1980a; Ward and Doggett 1991). However, the Central Statistical Office which arises does not replace the decentralised system, but only absorbs parts of it. As the concept of statistics as a 'window on the economy and society' (UK Statistics Authority 2009, p.2, see above) takes root following the War, further bodies are set up to manage particular types of statistic - the Office for Business Surveys and Office of Census and Population Surveys - centralising aspects of statistical creation within bodies which form separate nodes within a fragmented system. This fragmentation is geographical as well as organisational: the Scottish and Northern Irish Censuses remain the responsibilities of their respective Registrar Generals (Census Act 1920, Census Act (Northern Ireland) 1969).

Mergers of these bodies, both with each other and with other statistical departments within government, in 1989 and 1996 bring about an ONS which centralises a large number of statistics covering numerous aspects of economy and society in one body, but they do not bring about a fully centralised system. Indeed, in some respects, the system has become less centralised since the creation of the ONS in 1996, as a result of devolution and regional policy (Allsopp 2003). It is in this context the 2007 Statistics and Registration Services Act sits: it attempts to provide uniform standards across all official statistics, without ceding control of statisticians not managed by the UK Statistics Authority to that body, without granting the Authority power to mandate

9 The Corn Act of 1770, attempted to regulate corn prices through a system of returns published in the London Gazette; it was followed by the Importation and Exportation Act of 1789, which centralised these returns as a responsibility of the Board of Trade. See also Barnes (1930). 
quality control procedures on statistics it does not create, and without allowing the Authority to determine what a statistic is for the purposes of its legislative responsibility to monitor statistics (Public Administration Select Committee 2013). It leaves the Authority as a unitary body with the dual responsibilities of creating statistics and inspecting them for quality, with a reporting line to Parliament, under a National Statistician with reporting lines for their various responsibilities to Parliament, the Prime Minister, the Chancellor (as Minister of Statistics), the Devolved Administrations and to the courts. This complex of interlocking responsibilities and reporting lines can be seen as an attempt to unify the centralised and decentralised views of statistics, as simultaneously offering a broad picture of society and economy and as restricted responses to administrative demands. There is debate as to how successful it can be in these aims (Holt 2008; Macfarlane 2007; Thomas 2007).

The Statistical Actors of the ONS, then, are in the position of creating statistics independently, but for the use of others and within a diverse field of other official statistical creators. Their remit is 'national', while that of Statistical Actors within policy-making bodies are specific and thematic. The way the Statistical Actors of the ONS integrate their work with the wider fragmented governmental system is an empirical question.

\subsubsection{The geographical complexities of Official Statistics}

While the ONS is able to "produce and publish statistics relating to any matter relating to the United Kingdom or any part of it" (Statistics and Registration Services Act 2007, p.9), its ability to map or co-ordinate social or economic life as a central body operating under its own initiative is limited. It operates alongside decentralised and devolved bodies who make their own statistics outside of both its and the UK Statistics Authority's direct control, and is unable even to scrutinise statistics produced by Devolved Administrations without invitation. It is also constrained both by a reliance on central government funding and by its legal responsibilities to produce statistics as demanded by Parliament, Ministers of the Crown, existing legislation and international agreements. The Statistics Authority, and through it the ONS, then, are centrally funded but subject to decentralised demands, limiting their room for manoeuvre and the independence which the 2007 Act grants them.

Decentralisation and devolution also leads to a complex geography of statistical production and output. The Allsopp Review (Allsopp 2003) noted both the large number of regional bodies at varying scales either requiring or producing statistics and the inability of the ONS as it was configured to provide such statistics itself. The ONS predominantly produces statistics at a national scale. This means that it gears its samples to national, not regional, estimates and so selects them to be nationally, not regionally, representative. As a further complication, 'national' in this sense tends to mean 'English', due to over-sampling by the Devolved Administrations where genuine UK-wide statistics are required. At the same time, economic figures tend to be collected at the enterprise-level, rather than on any geographical basis, making it hard to locate the impacts of economic activity. Both these factors hamper the production of regional estimates, making them "necessarily more subjective and less accurate than national 
equivalents." (Allsopp 2003, p.5).

Things are further complicated by the historically ad hoc origination of statistics. Allsopp (2003) noted varying geographies used for crime, health and education data, arising from their distinct administrative boundaries. Various statistics exist on different bases in the different constituent parts of the UK, both for historical reasons (as in the existence of three separate Registrars General for England and Wales, for Scotland and for Northern Ireland) and reasons of more recent devolution (as in the range of statistics created solely for Scotland by the Scottish Government). All statistics produced by official sources that are not Devolved responsibilities fall under the Statistics Authority's quality-control, and the 2007 Act gives them the right of inspection (Section 16 of the Act; although requests to inspect can be refused by the Minister responsible for the statistic). The sheer number of statistics produced by various bodies limits the application of this right, leading the Statistics Authority to focus on those statistics it has been invited to accredit and any high profile statistics which it hasn't (see, for example the request for inspection by Scholar 2011, and its reply Duncan-Smith 2011). The diverse needs of creators necessitates a wide variety of methods, including the use of diverse geographical and temporal units and differences in sample coverage and differences in reporting and dissemination. These are not generally commented on by the UK Statistics Authority unless they are explicitly brought to its attention.

As a further set of influences on its Statistical Actors, the ONS exists in a global context, both subject to international standards and requirements and influential in their creation (UK Statistics Authority 2009, 2013). This can be seen as a further tier in the multi-level nature of official statistics' production, further limiting the autonomy of the ONS. What statistics are produced and how are, to some extent, out of the ONS' control.

In addition, then, to navigating their position within fragmented governmental departments, the Statistical Actors of the ONS must navigate between fragmented scales and geographic areas of government. Their 'national' remit creates challenges for official statistics that need to be applied to smaller scales; the devolution of policy and with it statistical monitoring is likely to have further complicated these challenges.

\subsubsection{The interaction of funding concerns and policy need, and the limitations they impose on the scope of official statistics in the UK}

The preceding subsections have noted shifts over time in ideas around the purpose of official statistics. For long periods, government data collection was resisted as an inappropriate state intrusion into the lives of individuals. This resistance came both from the individuals themselves, as in the case of the parish registers of birth and death introduced under Henry VIII (Cromwell 1910, p.40 fn.), and from politicians and officials, as in the case of the long resistance to a national census (Shaw and Miles 1979). This stance softened considerably in the period immediately following the Second World War, leading to the expansion of social statistics which culminated in the establishment of Social Trends, the annual compendium of social statistics, in 1970 (Nissel 1970). This represented the high watermark for statistics as tools for understanding society. The Rayner Review of 1980 instead argued for a tight link 
between statistics and policy need: "We have found the [Central Statistical] office too heavily committed to serving the public at large. We must ask whether value for money is encouraged when the office is based on meeting regular generalised demand for statistics (relatively independent from current policy preoccupations) through publications." (Rayner 1980b, p.7, emphasis as original). Those statistics not directly tied to policy could be supported only if users were prepared to pay for them, and those tied to policy would only be made available to outside users if they were prepared to pay for their publication.

Rayner's argument against statistics meeting generalised needs brings together the concerns of a decentralised system, aiming primarily at solving discrete policy problems, and a mistrust of the idea that broader social goals are an appropriate target for statistics-based interventions. This position was disputed at the time by those outside government (Hoinville and Smith 1982; Thomas 1984), and has been relaxed more recently, at least rhetorically: the ONS claim that their work has the broad aim of 'understanding the UK' (Office for National Statistics 2010a, frontispiece). However, this understanding remains partial and tied to policy objectives and cost constraints, with 'value for money' being written in to the Code of Practice for Official Statistics as a requirement for their work (UK Statistics Authority 2009). This is illustrated by a recent review and consultation by the ONS of its statistical outputs in response to budget cuts (Office for National Statistics 2014c). This noted that $80 \%$ of the ONS' output was legislatively required, with the largest bodies of outputs being 'economic and business statistics' and 'labour market statistics', with additional basic demographic statistics inherited from the old Registrar General and statistics on income and living conditions and healthcare (p.2). This establishes a central core of statistics engaging with the economy at the heart of the ONS' work. Of those statistics suggested as candidates for discontinuation, the majority related to social conditions: detailed statistics on mortality, on inequality, on suicide, on health (p.3). Many of these survived the cut because they were used by multiple government departments. Where statistics were more closely tied to the aims and objectives of a particular department, such as statistics on deaths from Clostridium difficile, they were to continue only if they could be funded by the department in question (Health, in this case) (p.4). Of the seven outputs cut completely, only one could be thought of as 'economic', that relating to 'the UK Business Output', while statistics on subjects such as adoption, cancer incidence, injury and poisoning mortality would cease to be produced in their current form (p.4).

This review highlights several things. One is the peripheral nature of social statistics within the ONS' wider programme; the core of their work centres on legislated requirements for economic statistics such as the National Accounts and inflation indices. Another is the policy-specific nature of many of the statistics it collects; as an example, the statistics relating to Clostridium difficile were first produced in 1999 (Office for National Statistics 2013a), arising out of the politicisation of 'hospital superbugs' (Washer and Joffe 2006). Their vulnerability in the recent review is at least partly a function of a decline in their political salience as hospital safety has improved and media attention has moved on to other things. This policy-specific nature of statistics underlies the movement of statistics from the ONS to Whitehall departments; by shifting Clostridium difficile statistics to the Department of Health, the ONS makes the statement that such statistics are a specific, rather than a general concern, tied to the 
objectives of a single department rather than forming a part of any wider 'understanding of the UK'.

Another point to note is the social statistics which were deemed immune from possible cuts. The ONS has an ability to collect statistics which is unmatched and unmatchable by the private sector; it has a larger reach, established structures of collection, some power to compel replies from individuals (as in the case of the Census), access to administrative records in certain areas, and a larger budget than anything realistically available in academic or private polling institutions. This ability is exemplified in statistical programmes such as the Annual Population Survey and the British Longitudinal Study. While these programmes were subject to 'efficiencies' in the 2013 review, they were not considered for curtailment (Office for National Statistics 2014c). This is partly due to the role they play within legislated statistics, particularly those relating to the labour market and required by European Union membership, but also because of their role in 'understanding the UK'. There is a tension between the demands for policy-linked statistics established by the Rayner Reviews and cemented by budget limitations on the one hand, and the desire to maintain programmes that cannot be conducted by anyone else. In this can be seen echoes of the tensions between centralisation and decentralisation: the ONS, as the UK's central statistical producer, has the scope to produce over-arching statistics which might inform policy across departments, but often finds itself tied in to statistics where a specific policy use can be demonstrated. These can be passed on to the departments they benefit, but this leaves the ONS with statistics that are more peripheral to the concerns of any specific policymaking department.

The combination of a decentralised system and a concern for cost will always privilege those statistics with direct economic applications. There are a number of reasons for this. One is that the body funding the ONS is the Treasury, who act as the major consumer of economic statistics giving them influence as both funder and user. Another reason is that the overwhelming majority of statistics required by statute and international agreement are economic, meaning they form a higher proportion of statistics which are non-negotiable (Office for National Statistics 2014c). Finally, the cost of large-scale social surveys means that, in a pinch, cutting them can provide large and instantaneous cost-savings and that they are less cost-effective to establish or expand. While programmes of social monitoring may meet diverse policy aims and be used by diverse users, these three factors restrain the ONS' freedom to expand on its stated objectives of 'understanding the UK'.

The Statistical Actors of the ONS, then, must balance not only the needs of a fragmented Statistical Audiences against their own national remit, but do so within cost constraints. This balance is likely to be difficult to achieve: should their programmes be too general, they will lack users; too specific and they lack a rationale for ONS, rather than departmental, production. In either case, the justification for the funds to produce the statistic will be hard to make. Once established, the programme must be set against those protected by legislation in the event of funding cuts. Such a balancing act is likely to influence the form and content of the statistic concerned. 


\subsubsection{The tension between excellence and cost}

Since its period of expansion in the 1960s, the CSO (and later ONS) has been subject to continual pressures on staffing levels and budgets. A paper written by rogue statisticians in the 1970s outlined the human costs of these in terms of increasing automation, deskilling of work and the contracting out of aspects of the Statistical Actor's role (Government Statisticians' Collective 1979). These cuts were largely borne by junior staff - Ward and Doggett state that the Rayner Review's cuts to staffing levels of $25 \%$ came without a single Statistician being made redundant, a fact which implies swingeing cuts to those in lower pay-grades (Ward and Doggett 1991, p.85). These cuts led to a series of concerns in the press and in Parliament over the quality of statistics, culminating in the Pickford Review of Economic Statistics (Pickford, Cunningham, Lynch, et al. 1989). Concerns remained, being cited by, for example, the Chancellor John Major in the foreword to a book celebrating the history of CSO (Ward and Doggett 1991, p.ix) and Prime Minister Tony Blair in the introduction to the White Paper 'Building Trust in Statistics' (Economic Secretary to the Treasury 1999, p.iv).

What such concerns and debates highlight is the trade-off between cost and quality of official statistics. Even when supplied to the ONS by third parties, data is not without internal cost - the process of compiling the statistic and disseminating it takes both time and money. One of the consequences of the Rayner Review was a reduction of quality checking (Rayner 1980a), with resultant declines in quality that led to the Pickford Review (Pickford, Cunningham, Lynch, et al. 1989; although that review argued that the cuts had not contributed to the loss of quality but were merely coincidental with it, p.11). With such issues in mind, the National Framework document which accompanied the creation of the ONS explicitly called for a balance between quality and cost, with the National Statistician responsible for a continual assessment of which statistics are necessary and which can be obtained elsewhere (Office for National Statistics 1996, np.). By the time of the 2009 Code of Practice for Official Statistics this had softened markedly, with statistical producers being called on instead to balance costs and quality relative to the use of the statistic (UK Statistics Authority 2009, p.11).

There are a number of ways of achieving this. One is the use of alternative data sources; both Rayner (1980a, b) and Allsopp (2003), separated by nearly a quarter of a century, call for better use of administrative data, and this is one of the options currently under discussion in a consideration of the conduct of the Census (Office for National Statistics 2013d). This is not something the ONS can control themselves, however; permission to access such data can be difficult to obtain and in some cases will require legislation (Public Administration Select Committee 2013), which offers a potential explanation as to why this remains largely a suggested course of action and not a reality. Another is the possible opposition on privacy grounds that any opening up of administrative data would cause; reminiscent of the 1538 objections to parish registers, above, the recent creation of Care.data to centralise medical records (and, particularly, that database's openness to third parties) has been strongly opposed on privacy grounds (Kirby and Pickover 2014).

An alternative is the outsourcing of data collection to third parties, with management of quality conducted through service-level agreements, as suggested by Pickford (Pickford, 
Cunningham, Lynch, et al. 1989, p.31). This works to decentralise the system further, the ONS becoming primarily a sub-commissioning body (commissioning operationalised statistics which were themselves commissioned by government actors), responsible for quality control. There are also possibilities of re-using or re-purposing existing data, as has been done in many of the components of the 'Measuring National Well-being' programme.

What all these approaches represent, however, is solution to a problem of policy, and not one of statistics. 'Value for money' is a product of both the cost of the statistic, and of what purpose the statistic is meant to serve and for whom; it is a question of whether the use value of the statistic justifies the exchange value (Hoinville and Smith 1982; Working Party on the Measurement of Unemployment in the UK 1995). There can be seen in the historic expansion and contractions of the ONS and its predecessors, and the ongoing pressure for 'cost-effectiveness' and the reduction of burdens on data providers, an implicit debate about what purpose statistics serve and how good they need to be. The suggestion has been made by those outside government (Thomas 2007) that 'cheapness' is often proxied for 'value for money' when central funding for official statistics is made, and that, despite a shift away from the emphasis on statistics as primarily for government use seen in the 1980s, the uses made by non-governmental actors are still systematically discounted (Macfarlane 2007).

This, too, has implications for the Statistical Actors involved in the 'Measuring National Well-being' programme. They must produce a programme which is reliable and valid, on a budget, balancing statistical integrity and cost. This will be impacted by the discussions of the ONS' position within government earlier: if cost-effectiveness is a function of a statistic's use, the onus is on the Statistical Actors of the ONS to provide something usable.

\subsubsection{Debates around the integrity of statistics}

The complex relation of the ONS and government, caused both by the budgetary control of the latter and by the use of statistics to further governmental aims, has produced ongoing concerns about quality and political interference in official statistics. The most famous of these was the debate around unemployment statistics in the 1980s where definitional changes continually reduced the count downwards, a debate most clearly analysed by Working Party on the Measurement of Unemployment in the UK (1995). Governmental voices have periodically highlighted the dangers these concerns pose to trust in statistics, particularly by the public as secondary users receiving statistics as political pronouncements and justifications (Blair and Johnson in Economic Secretary to the Treasury 1999, pp.iv-v; Matheson 2010, 20; Major in Ward and Doggett 1991, p.ix; Public Administration Select Committee 2013; Rayner 1980b; for the same issue in an international context see Kamen 2002).

Statistical Actors, both official and lay, have argued that the source of such worries about integrity tend not to be the statistics themselves but the way they are used (Thomas 2007; Working Party on Official Statistics in the UK 1991). Where concerns have arisen over political interference, as in the case of unemployment statistics in the 
1980s, there was never any question of the statistic being inaccurate but only that the definition on which it was based made it less meaningful than statistics based on alternative definitions (Working Party on the Measurement of Unemployment in the UK 1995). That statisticians themselves are not the source of mistrust is upheld by the three studies the ONS has carried out into statistical trust (Bailey, Rofique and Humphrey 2010; Simpson, Beninger and Ormston 2015; Wilmot, Jones, Dewar et al. 2005), despite these reports being cited in official reports as evidence for public concerns about integrity (e.g., Public Administration Select Committee 2013). The most recent survey, for instance, suggested that fewer people trusted ONS statistics than trusted the ONS itself $(81 \%$ as against $88 \%)$, and that the most common reasons for mistrusting statistics was political manipulation $(29 \%)$ and vested political interest in the numbers $(23 \%$; see p.12 of the report for these figures). In light of political fears around trust in statistics, it is also worth noting that this $88 \%$ who express trust in the ONS is considerably higher than the $42 \%$ who trusted the government in the same survey (Simpson, Beninger and Ormston, 2015), or the $24 \%$ who trusted the government in the most recent Eurobarometer survey (European Commission, 2013). While the Public Administration Committee opine that trust in statistics is essential to democratic debate (Public Administration Select Committee 2013, p.5), they appear to be putting the cart before the horse; if the politicians using statistics are not trusted, it seems unlikely that the statistics themselves will be.

The Statistics and Registration Services Act 2007 presents an organisational solution to this political problem, merging the Statistics Commission into the ONS as two components of the UK Statistics Authority, moving the ONS further from government by making it a non-ministerial department and giving the National Statistician an explicit role in criticising misuse of statistics by political actors. As Thomas (2007) predicted and the Public Administration Select Committee (2013) have shown, this has not disentangled official statistics in perception or reality from the work of government. However independent the ONS is nominally, their products are inseparable from politics; their statistics are commissioned by political actors, used to illustrate political points, and subject to definitional restrictions by (political) regulation and international (political) agreement, and quality and coverage restrictions by (politically determined) budgetary constraint.

Some effort has been made to resolve this through a kite-marking system introduced in the Act, under which statistics meeting particular quality standards are labelled 'National Statistics', and through an emphasis on explication of statistical data (both previously required under the National Framework document, Office for National Statistics, 1996). The Act also establishes a Code of Practice which includes guidelines on the separation of statistics and commentaries on them to avoid their integrity being impacted by politicisation (UK Statistics Authority 2009, p.7); reference to this Code is also made within the Ministerial Code (Cabinet Office 2010). Both the kite-mark system and the Code of Practice aim to establish a Chinese Wall between supposedly neutral empirical facts and their political readings. The effectiveness of such walls, however, will always be limited when the origins and public use of statistics are largely political; however trusted the ONS, there will always be doubts about the statistics themselves. A further limitation arises from ignorance; it is unlikely that anyone outside government or academia is aware of the difference between a badged and an unbadged statistic (a point 
made by Public Administration Select Committee 2013, p.19).

This presents a further set of challenges for the Statistical Actors of the ONS to navigate. Not only must they produce a statistical programme with integrity, it must be seen to have integrity. From the survey evidence above, this is difficult to achieve. The 'Measuring National Well-being' programme was launched by the Prime Minister (Cameron 2010) giving it an explicit political construction which may have been to its disadvantage.

\subsubsection{Summary: the ONS as an institution}

These five themes, which run throughout the history of the Office for National Statistics - centralising and de-centralising tendencies, questions of scale and geography, financial pressures, tensions between excellence and cost and questions of integrity place the Statistical Actors of the ONS in a complex position in 2010 at the outset of the 'Measuring National Well-being' programme. They stand at the centre of a decentralised system, subject to demands from diverse users, many of which they cannot negotiate. They must maintain both a fixed number of statistics, often to non-negotiable international quality standards, while having a largely non-negotiable budget. The diverse demands and supplies of data result in uneven temporal and geographic coverage of its statistics. Their remit requires that they maintain quality at the same time as cost-effectiveness, under the foregoing constraints. They are responsible for the integrity of statistics which is generally only questioned for political and not statistical reasons, while submitting to political oversight and demands which historically have posed threats to the integrity of its statistics.

These challenges must be negotiated by the Statistical Actors constructing the 'Measuring National Well-being' programme. For instance, how will the need for statistics that can be used by policy-makers be balanced against the need for theoretically valid statistics? How will demands for local or regional coverage be balanced against concerns about cost? Supporting the arguments of the preceding chapters, these challenges highlight the role of agency in the statistic-making process. It is not simply a matter of articulating control or depicting empirical reality; such aims, if held, are held within an institutional context which must be navigated if they are to be achieved.

\subsection{Policy-making and the UK state}

The previous section has outlined the history of the Office for National Statistics, and some of the challenges which it operates under. However, the ONS cannot be understood separately from the wider context of government and policy-making in the UK. As has been shown, within that context, the ONS acts as an arms-length producer of official statistics for the purposes of policy-making. By its own accounts, key amongst its roles is to ensure the evidence base on which policies can be made (see, for example, Office for National Statistics 2010a, p1, "Our statistics and advice enable 
informed decisions to be made."). For this reason it is important to examine the wider policy-making framework into which the ONS fits, to understand what output is expected of it.

This section will proceed via a thematic examination of the last 20 years of UK policymaking. The themes selected are versions of those which arise out of discussion of the previous section: centralisation and decentralisation, the integration of policy within wider decentralised national and trans-national policy-making networks, the move towards 'evidence-based policy' and the current shift towards the 'austerity state' within a wider context of neoliberal state forms. These themes impact directly on the Statistical Actors of the ONS in their role within an arms-length state body providing statistics for other state bodies. The time period for examination has been selected to encompass devolution, which the last section identified as being key to the arrangement of the fragmented, decentralised system of official statistics in the UK.

\title{
4.2.1. Historic fragmented centralisation within UK policy-making
}

\begin{abstract}
"Too often, the work of Departments, their agencies and other bodies has been fragmented and the focus of scrutiny has been on their individual achievements rather than on their contribution to the Government's overall strategic purpose."
\end{abstract}

Modernising Government (Prime Minister and Minister for the Cabinet Office 1999)

Historically, government and policy-making powers in the UK have been based around discrete agencies at numerous geographical scales (Department of the Environment, Transport and the Regions 2000; Performance and Innovation Unit 2000b; Rhodes 1992). Foremost among these has been the Whitehall Department, agencies of central government with responsibility across the whole of a broadly defined domain, such as 'Home Affairs' or 'Education'. Executive power within these departments is held by the Minister, a temporary political appointee of the Prime Minister of the elected government, while administrative functions are performed by the apolitical, impartial and more permanent Civil Service (Fawcett and Gay 2005). While many functions and responsibilities, particularly relating to policy implementation, are devolved to other branches of government such as Local Authorities, policy-formation, supervision and, crucially, funding, are held at the centre (Rhodes 1992).

While this produces a centralisation of power within Whitehall Departments as the key institutions of the state this power is fragmented along departmental lines. That is, central government holds the majority of policy-making power, but its responsibilities are divided across departments with separate and sometimes competing aims, objectives and resources. In practice, the affairs of state do not follow sharp classificatory boundaries and there will be some occasions where the interests of Whitehall Departments directly conflict; the Strategic Policy Making Team of the Cabinet Office offer the example of increasing tax rates, which may be desired by the Treasury for spending purposes, but opposed by the Department for Trade and Industry on the 
grounds of harming international competition for business investment (Strategic Policy Making Team 1999). Traditionally, where policy needs intersected, they would be dealt with within the Cabinet system of government: at ministerial level the Prime Minister would arbitrate policy conflicts, with cross-departmental committees operating at the Civil Service level to co-ordinate informational needs (Fawcett and Gay 2005). This system fell into abeyance from the Thatcher administration onwards, as Prime Ministers asserted more control over policy, co-ordinated through their own departmental team and the Cabinet Office (Jordan 1994; Rutter and Harris 2014). The result of this was greater centralisation, but also greater failure of centralisation: under a Cabinet system, overall governmental direction was, to some degree, a matter of shared vision; under a system of Prime Ministerial command, this is no longer the case (Jordan 1994). While it is possible to constrain the actions of Whitehall Departments through Public Service Agreements with the Treasury or the system of Regulatory Impact Assessments (see discussions below), it is less easy to direct them.

The limitations to this approach were laid out during the Blair administration, initially in the White Paper Modernising Government (Prime Minister and Minister for the Cabinet Office 1999), but also in a series of follow-up reports by the Audit Commission (2000), National Audit Office (2001), Office for Public Services Reform (2002), and Performance and Innovation Unit $(2000 \mathrm{a}, \mathrm{b})$. Broadly in line with the principles of New Public Management theory (see below), these suggested that the world in which policy was to intervene was increasingly complex and that the fragmented system, "though necessary for administrative purposes" (Prime Minister and Minister for the Cabinet Office 1999, p.23), was maladapted to deal with such complexity. The separation of responsibilities meant, at best, a blind-spot for policies which cut across departmental boundaries and, at worst, that departments had incentives not to deal with such policies because they would cost in terms of resources but bring no benefits in terms of meeting department-specific performance targets or Public Service Agreements (Butler 1993). Policies were thus seen in isolation, rather than as part of an interactive system of actors and aims (National Audit Office 2001).

These are problems which will not be resolved by the usual administrative solutions, such as shifting responsibilities between departments ('skills', for instance, has historically moved around Whitehall, between the Department for Education and the Department for Business, as governments and government priorities change). The institutional weakness of the centre of government (Harris and Rutter 2014), means that even a Prime Minister is limited in their ability to push through policy aims; they are dependent on departments to carry out their will, which means that their plans are subject to departmental priorities and buy-in.

To respond to this, the Blair administration set up a number of cross-cutting methodology bodies, such as the Performance and Innovation Unit (led by Geoff Mulgan, who went on to sit on the ONS' Advisory Forum for the 'Measuring National Well-being' programme) and the Prime Minister's Delivery Unit, to deal with policydevelopment and implementation; and cross-cutting policy bodies, such as the Exclusion Unit and Rough Sleepers' Unit, to deal with specific policy areas which crossed departmental boundaries and which had historically fallen between departments as a result. These had predecessors, most notably in light of the previous section the 
Efficiency Unit which operated under Rayner in the 1980s to review and rationalise the activities of Whitehall Departments, but reached a prominence and a scale under New Labour not previously seen (Rutter and Harris 2014). They also build on the work of cross-departmental networks, think-tanks, training bodies and non-ministerial government agencies such as the Government Statistical Service, the professional organisation of statisticians across government; the Institute for Government, a charity promoting best practice in governance; the Civil Service College (and its successors), which trained civil servants; and the Central Policy Review Staff (and its successors), which reviewed policy (Jenkins 1992).

Reviewing the effectiveness of these new cross-cutting units, Rutter and Harris (2014; Harris and Rutter 2014) note the intractability of the fragmented system. Where units were successful, it was due to a combination of narrow remit and focused Prime Ministerial backing; where the problem was more diffuse and the issue less central to the Prime Minister's concerns, departments could safely ignore the efforts at centralised control without repercussions. An insight into this can be found in a document by the Strategic Policy Making Team (1999) surveying best practice in Whitehall: when trying to find out how departments were using evidence in policy-making, they were only able to gain responses from half the departments surveyed; in following up non-responses, some departments were not even reachable by phone (p.16). Even in this crossdepartmental project which made light demands on the departments' time and almost no demands on their resources, it was difficult both to access and engage departments. As a further insight into the embeddness of the fragmented culture, the same report concluded that departments should establish their own, separate, best practice units. This is despite the near contemporaneous observation by the National Audit Office (2001) that many policy decisions were not even vertically, let alone horizontally, integrated and so were failing to consider the needs of those arms of government which would be implementing the policies which Whitehall departments had devised centrally. Quite how best practice was to be discovered independently under such conditions is unclear.

Summarising this period, Fawcett and Gay (2005) suggest that the New Labour government were able to improve policy-making capacity at the centre of government, but not increase joined-up activity. New Prime Ministers Brown and Cameron both initially cut back on central administration, and were then forced to expand it again, a result of what Lodge (2014) describes as the tension between the desires for coordination and decentralisation. Brown and Cameron shared a mistrust of an expansive central apparatus, preferring to leave departments to their own devices, only to find that cutting back on the central apparatus left them unable to co-ordinate the actions of those departments (Harris and Rutter 2014, p.14). This desire for control over departments at the heart of government is echoed in the relationships between those departments and the local and regional administrative bodies who implement policy; departments mistrust the capabilities of these bodies to carry out policy and fear the financially and politically costly mistakes which might arise if they are given freedom to devise their own policies (Jordan 1994).

While the Prime Minister has limited power to ensure that policy objectives are met by independent departments, the Treasury, as ultimate funding body, is able to exercise a 
considerable amount of influence. The first Comprehensive Spending Review of the New Labour administration (Chancellor of the Exchequer 1998) noted the need for cross-cutting policies, and suggested that the way funding was allocated to departments on yearly cycles precluded their development. As a result, the Treasury under Brown moved to a three-year funding cycle, supported by a system of Public Service Agreements (PSAs). These made departments (and ministers) directly accountable for performance by setting a series of measurable targets (again, in keeping with the managerialist theories of New Public Management, see below). While largely avoiding these somewhat crude measures, the Coalition government of 2010 retained accountability to the Treasury through the implementation of 'business plans', departments proving they are 'sound' in advance of being given funding, rather than in assessment of the funding they have already received (Harris and Rutter 2014; Rutter and Harris 2014).

The fragmented system is naturalised within thinking about policy-making in the UK (as evinced, again, by documents such as the Modernising Government White Paper, Prime Minister and Minister for the Cabinet Office 1999, which consider the lack of joined-up policy-making to be a side-effect of an otherwise functional system, not evidence that the system is non-functional). Yet it is worth noting that it is not the only way in which government functions can be organised. The Scottish Government since the election of the SNP administration in 2007 has organised around specific aims and objectives, codified in the 'Scottish National Performance Framework', rather than departmental remits (Scottish Government 2011). Such an approach avoids the coordination problem faced by the fragmented system by diffusing responsibility across portfolio-holding ministers and civil service teams.

This fragmented policy landscape is the other side of the fragmented statistical landscape described in Section 4.1.2.. Statistical Actors within the ONS have a national remit for a cross-cutting concern; they are to measure 'national' 'well-being'. The policymakers who use such statistics have more specific concerns, such as 'defence' or 'education'. The extent to which they are interested in such a broad programme, and the ways in which a programme might be made useful to them, are empirical questions.

\subsubsection{Regionalisation, devolution and internationalisation as counters to centralisation}

The previous sub-section has suggested that power is geographically centralised in Whitehall, but fragmented across different departments. These operate through largely separate networks with dispersed agents, implementing policy at a variety of scales. The Modernising Government White Paper (Prime Minister and Minister for the Cabinet Office 1999) noted, for instance, over 100 different sets of regional boundaries used in the United Kingdom: while much was done at the Local Authority level, there were different boundaries for the delivery of health services, the police, the fire service, waterways, water authorities, and so on. As Hogwood (1996) points out, this fragmentation of delivery mirrors the fragmentation of central policy: borders are drawn by function, not by territory. The result is a panoply of agencies of varying size and 
powers, sometimes competing in aims and objectives (and producing and demanding official statistics, see Allsopp 2003). While generally dependent on central bodies for funding, direction and legitimacy, this does not equate to dominance by the centre; rather the dispersal of power which comes from local implementation leads to an unevenness in the expression of central policy. While devolution has brought intermediary levels of government to London, Northern Ireland, Scotland and Wales, in England there is no intermediate regional tier between central government and other sub-national or regional delivery bodies. This makes co-ordination and quality control more difficult for the centre, and standardisation all but impossible.

This is most noticeable at the Local Government level, which is difficult for the centre to control both because of its large number of local actors and because of the legitimacy they gain from local democratic processes. Relevant to the well-being agenda which the 'Measuring National Well-being' programme forms a part of are the 'power to promote well-being' written into the 2000 Local Government Act, and extended to other local policy actors through the 2008 Parish Councils (Power to Promote Well-being) (Prescribed Conditions) Order (Healey 2008) and 2008 Local Transport Act. These granted Local Authorities an ability to act to promote the economic, social or environmental well-being of their areas, without defining what 'well-being' entailed in this context. This allows greater diversity of activity by Local Authorities by providing new grounds of justification for acting outside legislated responsibilities where the new action doesn't contravene existing laws limiting function. The 2007 Local Authority Targets (Well-being of Young Children) regulations (Hughes 2007) specifically incorporate well-being into existing statutory responsibilities, the 2011 Localism Act legislates the power to promote well-being into a general duty of consideration when applications were being made by outside bodies to take on the provision of Local Authority services, and the 2012 Public Services (Social Value) Act extended this duty to all public contracts. Again, all three fail to specify what 'well-being' means in this context. Both the power and the duty can be seen as central attempts at policy-making, but their effect is to create diversity in modes and methods of provision. This effect is strengthened by the lack of vertical integration between policy-makers and delivery bodies outlined in National Audit Office (2001).

Devolution (through the Scotland Act 1998, Northern Ireland Act 1998 and Government of Wales Act 1998, the last of these replaced by the Government of Wales Act 2006 and the first amended by the Scotland Act 2012) has further complicated this picture by providing new sub-UK power centres. Although the precise powers devolved to the Administrations differ, as a broad outline the Westminster Parliament retains control over matters such as the constitution (including the devolution settlement itself), foreign affairs and defence, leaving the bulk of policy in health, education and social welfare to the Devolved Administrations. Williams and Mooney (2008) point out the unevenness of this, in the sense of the greater powers which apply to Scotland, and its incompleteness, in the sense that the Treasury retains financing power. These two issues combine in the limited tax-raising powers which apply to the Scottish Executive: the 1998 Act provided the ability to adjust income tax upwards or downward by three pence in the pound, the 2012 Act increased this to ten pence while also allowing the Executive to borrow. This provides the Scottish Executive with more freedom to act over their greater fields of responsibility than is the case in Northern Ireland or Wales. The 
devolved system is thus both asymmetrical and hierarchical in terms of the powers it redistributes.

Despite these limits, even in Wales and Northern Ireland, the power of policy-making and distributing funds in devolved areas has led to a reconfiguration of geographies of social policy delivery. Willams and Mooney (2008), for example, note that numerous charities operating in the area of social provision have acted to separate their Welsh operations from their English ones, incorporating the former as separate bodies. This results in essentially new stakeholder bodies, accessing newly-specific funding streams, in the pursuit of local political objectives (see also Jones, Goodwin and Jones 2005). Those objectives themselves are set partially in contradistinction to policies set at Westminster, as Devolved Administrations have attempted to assert their independence (particularly in Scotland, where the Scottish National Party government asserted their political independence from Westminster by successfully demanding that the UK government agreed to a referendum on national independence). The result is a dispersal of power into regionalised bodies which directly compete with the centre for influence with their local electorate and have the scope to compete also in ideological aims. At the same time administratively speaking, much of what they do must interact with Whitehall, particularly where funding is concerned, because central policy over, for instance, health will have a knock-on effect on Devolved institutions (Goodwin 2013; Goodwin, Jones and Jones 2005). These new administrative relations change the audiences and uses for existing statistics, and create demands for new ones (UK Statistics Authority 2014b).

As a final complication to this sketch of the UK administration, various powers and functions have been dispersed to multilateral bodies - economic, political and civil and various duties imposed by them. A statistical example is the United Nations System of National Accounts (United Nations, Organisation for Economic Co-Operation and Development, International Monetary Fund and European Union 1993): by treaty, the UK is bound to producing certain kinds of data in certain kinds of ways. This is further legislated as the European System of National Accounts, which also sets time-frames by which this data must be produced (Eurostat and European Commission 2013); and agreements exist to provide this data to organisations of which the UK is a member such as the OECD and World Bank. While representatives from the UK have input into the form these take, influence is limited meaning that the design of official statistics as a function of government is out of domestic hands. The responsible domestic body, in this case the ONS, is then obliged to do their best with the requirements they receive from the international body. While the impetus may be international, the funding for action on the part of the domestic organisation tends to be strictly national, dividing the demand for action from the supply. This can have the consequence of squeezing the organisation fulfilling the policy as they face more onerous requirements without a corresponding change in resources. (This is one potential explanation for the difficulties the ONS came into when meeting the new requirements that GDP include the black economy; see Magnanti, 2014.) This pattern is repeated across Whitehall departments, who are beholden to laws and regulations implemented at the European level, and through international treaties.

The policy-making landscape in the UK is thus an asymmetrical, variegated and a 
complex one, with myriad policy-making bodies, networks, stakeholders and actors; distributed at multiple scales; with numerous centres of power. This is not unusual for modern government, and might be expected in a mature and advanced political economy. However, the UK system holds these features while simultaneously seeking to retain power in the centre of government, producing a system which is centralised but fragmented. It is into this that the Statistical Actors of the ONS step, through the Statistics and Regulation Services Act 2007, as both a central provider of statistics to stakeholders at multiple scales. They must interact with these diverse bodies and their diverse interests, balancing these against their own needs as discussed in the previous section.

\subsubsection{New Public Management theory, evidence-based policy-making and cost- benefit analyses}

At several points in the discussions above, 'New Public Management' (NPM) theory was mentioned as a guiding principle for recent state actions. While there is arguably no single coherent NPM paradigm (Barzelay 2002), the theory represents an approach to the organisation of public services based on the principles of marketisation and managerialisation. These principles suggest that services will perform best when they are subject to market or quasi-market competition and where staff are subject to clear performance monitoring (Denhardt and Denhardt 2000; McLaughlin, Osborne and Ferlie 2002). 'Perform best' here is articulated in terms of efficiency; increasing unit output per unit of funding (Newman 2002).

Although the early writings on NPM are published in the early 1990s (Hood 1991; Osborne and Gaebler 1992; Pollitt and Harrison 1992), reforms of the Civil Service going back to the 1980s share features with the theory as it came to be articulated. The Rayner efficiency reviews (Rayner 1980a, b), for example, emphasised the opening of routine government functions to the market and the re-organisation of monolithic departments into separate 'executive agencies' which were self-contained and specialised. These would have independence from central government in their day-today operations but operate according to aims and objectives set centrally (Brown 1992). The ONS' predecessor, the Central Statistical Office, was made such an agency in 1991 (Office for National Statistics 1996; Ward and Doggett 1991). This move was accompanied by the 'Financial Management Initiative', which presented the managers of new executive agencies with strict financial targets (Gray and Jenkins 1992). The New Labour administration continued this trend, both breaking up departments through full and semi- privatisations, and through extending systems of performance management (see, particularly, the 1998 Comprehensive Spending Review Modern Public Services for Britain, Chancellor of the Exchequer 1998). The effects of this increased fragmentation of government, and the resultant need to find ways to re-join diverse functions, have already been discussed; they are noted in the White Paper Modernising Government (Prime Minister and Minister for the Cabinet Office 1999), and highlight a tension in NPM theory between the desire to increase efficiency through giving bodies more independence and the need to co-ordinate those bodies to achieve greater goals (Newman 2002). 
One way of ensuring such co-ordination is through greater scrutiny of the activities of independent parts of government, both in the form of greater auditing and inspection burdens (Office for Public Services Reform 2002; see also Power 1997) and through the establishment of 'Public Service Agreements', sets of performance targets for public service agencies which were set in return for funding (Chancellor of the Exchequer 1998). The Coalition Government replaced these with 'Business Plans' which are structurally similar but which are less strongly tied to performance outputs (House of Commons Treasury Committee 2010). Both of these have relatives in the form of the Treasury's Green Book and Magenta Book (HM Treasury 2011a, b), which outline the conditions under which departmental or local governmental schemes will be eligible for funding. A key requirement of funding is the performance of a cost-benefit analysis on proposed schemes, showing that the proposal brings the most benefit for the least cost when compared with other feasible options. As Siltala (2013) observes, this acts to centralise power within the Treasury, rather than decentralising it to departments and agencies.

In these ways, co-ordination is at least partially secured by limitations on what bodies can do if they are to secure the funding they need to continue operating. The move from performance targets to business plans, combined with the Green Book's ongoing concern with cost-effectiveness, privileges economic rationality as an underpinning of policy. The current (2011) edition of the Green Book is the 2003 version with additional guidance based on Fujiwara and Campbell (2011) concerning the use of subjective wellbeing measures in the evaluation of non-monetary goods (HM Treasury 2011a, p.1; see also next chapter). This represents a shift in the evidence-base acceptable for policy from the qualitative and normative and towards the quantitative and monetary (e.g., Cabinet Office 2013). It is no longer enough to say that a policy will improve people's lives, there now needs to be an assessment of by how much, for a given investment, and whether the same expenditure could have improved lives by more elsewhere. This is in keeping with a re-imagining of citizens receiving public services as "customers", actors who choose within a market for services (see particularly Office for Public Services Reform 2002).

This should not be overstated. 'Cost effectiveness' remains a matter of judgement and does not completely replace political concerns. Additionally, large sectors of government such as Local and Devolved Authorities, do not have to submit their policies to scrutiny of this kind unless they are securing non-routine funding. However, when the ONS sought funding for the 'Measuring National Well-being' programme in 2010, they will have needed to follow the 2003 Green Book guidelines, and the data the programme produces, particularly that on subjective well-being, can now be utilised across government agencies under the 2011 Green Book guidelines. When the ONS says of the programme, "[pertinent well-being measures are] crucial to allow for effective development and appraisal of policy for individuals to use information to identify ways of improving well-being" (Matheson 2011, p.2), this is the context in which the statement sits.

The use of cost-benefit analyses and subjective well-being are tokens of a broader type of the New Public Management programme, that of 'evidence-based policy'. From the Modernising Government White Paper onwards (Prime Minister and Minister for the 
Cabinet Office 1999), the Blair administration called for policy to be more clearly based on evidence, and to be evaluated as a source of evidence for future policy (Legrand 2012). Through this, it was hoped that the "old arguments about government" (such as "big government against small government" or "interventionism against laissez-faire", p.1) could be dispensed with, re-basing policy technocratically around issues of 'modernisation' and "getting government right" (p.1). The Strategic Policy Making Team (1999) observed that while there were some areas, such as health, which had a tradition of evidence-based practice, social policy was very rarely based on tested interventions. This they blamed on the view that there is "little consensus amongst the research community about the appropriateness of particular methodologies or how research evidence should be used to inform policy and practice" (p.35), although a later report by the Performance and Innovation Unit (2000b) also noted that "that demand for good analysis is not fully integrated in the culture of central Government" (p.12), suggesting that the problem of evidence lies as much with civil servants as with academia. This is supported by the work of Smith (2010), who interviewed 61 academic researchers, civil servants, ministers, journalists and research funders involved in public policy work around health inequalities and found that "not a single interviewee claimed that post-1997 health inequalities policies had been significantly based on research evidence" (p.180, emphasis as original). Instead, a policy was formed and then evidence was found to support it.

Various academics, in response to criticisms around a lack of evidence-use in policymaking, noted the limitations of research in a policy context. Davies and Nutley (2002) note that the Strategic Policy Making Team (1999) report was itself incredibly loose on what counted as evidence, ranging from stakeholder consultations, through model-based estimates, to results from split-sample trials. While there was a clear hierarchy of evidence-types in health, ranging from meta-analyses at the top to qualitative case studies at the bottom, the same wasn't true in social policy due of the contested nature of desired outcomes, and contestations around what would count as evidence of those outcomes.

Pawson, Wong and Owen (2011) note that the practical domain into which policy enters is non-uniform over both time and space; and interactional, impacting on practitioners and recipients who in turn impact on it. These facts limit the generalisability of what evidence there is, limiting the usefulness of initial evidence relative to an ongoing iterative process of evidence-based adaptation across the life (and spaces) of a policy. As above, this acts as a limit on centralised policy-power: such power is exercised locally by local agents, and is thus uneven in its expression. Frey and Lederman (2010) suggest that the overlooking of this by central agencies is based on a two-fold optimism: that policy can be rationally assessed, and that policy-making can be made rational. In this context, hopes of moving beyond 'old arguments' and into an era of technocratic rationality (Prime Minister and Minister for the Cabinet Office 1999, p.1; see also comments by Legrand 2012) are sadly misplaced; what is treated as evidence and how it is used are political questions in the same way that debates over 'big or small government' are.

Where 'evidence' does exist in a form broadly accepted by the academic community, there is little sign of it being utilised. Bambra, Smith, Garthwaite, et al. (2011) noted the 
similarity of recommendations made by three major, government-commissioned, public health inquiries thirty years apart: Black (Department of Health and Social Security 1980), Acheson (1998) and Marmot (see Marmot and Bell 2012). While the evidencebase had shifted somewhat (there was more evidence on which to base claims about the social determinants of health and ill-health in the later reports, for example), the policy recommendations produced were fundamentally the same. Where they did differ, this can be read as due to an understanding by the later authors that they needed to tailor the evidence to the government in power, since anything, however solidly-based, which countered ideological preconceptions would be ignored. The author of the latest review, writing half a decade before his report (Marmot 2004), foreshadows this reading by arguing that there is a limited role that evidence can, or should, play in the political process. Evidence is merely one of many factors which should influence a policy, meaning that there is a distinction between evidence and its policy implications. As an additional challenge to the theory of New Public Management, Levy (2010) argued that central government in the twenty-first century remained hierarchical and bureaucratic, rather than horizontally organised and innovative.

Such behaviour complicates the claims made in Performance and Innovation Unit (2000a) that official statistics, produced by the ONS and guaranteed by the National Statistician (as proposed in the Building Trust in Statistics White Paper, Economic Secretary to the Treasury 1999, and legislated in the Statistics and Regulation Services Act 2007), will act to provide an accepted and shared knowledge-base from which policy-making actors can proceed. The 'evidence' of the official statistic is always evidence of something (Thomas 1996); and as Porter notes, it fills a known gap in knowledge; it reports on things that the administrator does not know first-hand (Porter 1986). It was noted above that the most common reasons given for mistrusting statistics was that they were misused politically (Simpson, Beninger and Ormston 2015), and this remains an insurmountable problem as the gaps that are being selected for evidential intervention are selected not by statisticians but by politicians. The hopes of New Public Management that a technocracy is possible rest on an over-optimism about 'evidence'; even when it is itself neutral, it is only one part of a larger set of bases for decisionmaking and will be interpreted within the context of that larger set.

This further complicates the role of Statistical Actors. They are creating official statistics as a form of evidence, but it is evidence of a potentially contested and uncertain kind. This relates back to the questions of use and integrity raised in sections 4.1.4. and 4.1.6.; any statistical programme must be valid, but will survive only in as far as it is used by policy-makers. Its use is political, but its construction cannot be.

\subsubsection{Fast-policy networks and best practice}

An aspect of the evidence-based policy movement has been the movement to what Peck (2002) describes as 'in-sourcing' of external knowledge, bringing those from outside formal democratic politics and the Civil Service to lead departments or sit on committees. This can be seen as an extension of the traditional use of outsiders as portfolio-holding ministers within the House of Lords, and on Royal Commissions and 
similar Parliamentary Enquiries (see Burton and Carlen 1979). Rutter and Harris (Rutter and Harris 2014; also Harris and Rutter 2014) note an expansion of the traditional pool of relevant expertise used over the last 20 or so years, with the inclusion of privatesector consultants and self-appointed 'think tanks' within the process of policy-making (extending the role they had previously played advising party-political policy). Crouch (2013) attributes this trend to the New Public Management movement, which encourages government agencies to behave more like private sector corporations, hiring in expertise when needed rather than nurturing and maintaining it in-house, and turning to corporate figures as advisers and managers. Increasingly, this undercuts the democratic basis of governance, as power and decision-making are vested outside of domestic frameworks in international bodies and agreements, and outside of popular franchise, in lobbyists, corporate political sponsors and 'revolving doors' between politics and business (Crouch 2004). New Public Management theory legitimises this through its emphasis on service delivery over service provision; politicians are able to rationalise the reduced influence of democratic structures on the grounds that what matters is how efficiently something is done, not who does it (Crouch 2013). As an example of this, the Office for Public Services Reform, established during the second New Labour administration, stated: "It is the Government's job to set national standards that really matter to the public, within a framework of clear accountability, designed to ensure that citizens have the right to high quality services wherever they live." (2002, p.10). The role of government here is as procurer and inspector, not deliverer or owner, of services.

An effect of this broadening of the advice base has been the creation of what Peck (2002) describes as 'policy communities' which operate cross-nationally and form 'fast policy networks'. The temporary in-sourcing of expertise to advise on policy-making establishes external actors as policy experts, whose temporary position frees them to advise on policy elsewhere. They thus move between organisations at national and international scales and across public and private sectors, transmitting knowledge between them. At the same time, the nesting of regional, national and international structures (for instance, the role the ONS plays in its interactions with Eurostat, the OECD and the United Nations, as well as the professional membership of Statistical Actors within the ONS in the UK Royal Statistical Society and the International Statistical Society), leads to a similar sharing and exchange of knowledge. Peck, Theodore and Brenner (2012; see also Peck and Theodore 2012) argue that the effect of this is not a simple transferral of policy models, but the co-construction of models in multiple places at similar times. They argue that what is travelling, with the mobile and inter-linked members of policy communities, are not designs of policies but transformative conceptual schemas (Peck and Theodore 2010). Peck (2002) gives the example of 'workfare' policies, schemes to encourage the unemployed to take up work through a combination of training and the reduction of their welfare benefits; this policy started as a small-scale local innovation, and travelled across the Anglophone world, not as a set of concrete prescriptions but as a collection of general principles adapted to local conditions.

Such a network necessarily runs somewhat counter to the trends of regionalisation and fragmentation discussed above. As Peck, Theodore and Brenner (2012) point out, while the underlying rationale of policies may be multilaterally endorsed, their expression is 
site-specific. The regional implementation of a national policy runs into the problems of vertical non-integration found by the Performance and Innovation Unit (2000b), with non-heterogeneous actors attempting to fulfil broad policy aims with non-heterogeneous means. Thus while the centre can set Public Service Agreements or other targets to be met, how they are met is beyond their control. This is of obvious import for official statistics, which gain part of their value from their ability to compare circumstances across polities. A performance standard must be standardised across locales if it is to indicate relative success or failure; however, while the performance standard may be standardised, the conditions under which institutions perform are not; the same output represents a different outcome in different times and places. The central standards and the central tools, such as official statistics, which enforce them, in this way exemplify the 'model logic' of Peck, Theodore and Brenner's (2012) networks. They dis-embed the local output from its local inputs, pre-emptively depoliticising them as 'successes' or 'failures' according to standards set outside of the locale on which their output impacts.

For the Statistical Actors of the ONS, the 'insourcing' of knowledge and the existence of fast-policy networks establishes a further set of social relations to be negotiated, alongside those with Central and Devolved government. It brings the 'Measuring National Well-being' programme into dialogue with those at European and international levels. How these are navigated and what effect they will have on the form and content of the official statistic is an empirical question.

\subsubsection{Austerity and moves toward 'smaller government'}

A final trend which will be pertinent to the ONS' work in 2010, at the origins of the 'Measuring National Well-being' programme, is the governmental austerity agenda and the attendant reduction in public social provision. There have always been debates over the legitimate role and scope of government: in addition to the examples discussed in section 4.1.2., initial attempts to collect a national Census were rebuffed as overreaching (Shaw and Miles 1979). Over the last 30 years, the New Public Management approach has seen an increasing shift from state delivery of services to state provision of privately delivered services. On top of this, the 'Measuring National Well-being' programme occurs at a time of contraction in the national economy during which all three major UK-wide parties shared a narrative that government had overspent and needed to cut back on the services (and attendant costs of those services) which it delivered.

In practical terms, Pearson, Page and Trafiacante (2014) observe that the 2010 Spending Review, under which the ONS received funding for the 'Measuring National Well-being' programme, specified deep cuts to central Whitehall staffing numbers as well as wider cuts to budgets for activities. In real terms, budgets were cut by $19 \%$ across Whitehall, with "a particular focus on cutting senior Civil Servant posts" (Gay 2010, p.8). This meant that less people were available to departments with more thereby required of those remaining. How departments handled this varied widely, but the authors report widespread disaffection amongst civil servants who found themselves personally having to do more with severely constrained resources. There are echoes here of the rogue 
Government Statisticians Collective (1979), who wrote their account of official statistical production at a similar time of government redundancies (or, as Pearson, Page and Traficante, 2014, obscenely put it, a period in which people were 'managed out of the organisation', p.22).

Konzelmann (2014) notes both the lack of theoretical basis for policies of austerity, and a wealth of empirical evidence which suggests it is counterproductive. From this he suggests, echoing arguments made by Peck (2010), that austerity is an ideological end in itself, not a means to any political or policy goal. This ideological base, and its presentation of this in terms of economic necessity, has led to what Schäffer and Streeck (2013) describe as a 'decline in democratic buy-in', as the public no longer feel capable of changing things. In this context, it is possible to read various aspects of the Conservative manifesto (Conservative Party 2010) - such as commitments to localism or the devolution of social provision to 'The Big Society' - as ways of discursively recasting the withdrawal of government support and competence as an empowerment of individuals and communities. 'Well-being', and the commitment to it through a public statistical programme, is also amenable to such a sceptical reading. Not only does it deliberately shift the basis of national performance away from a GDP figure which, as a result of the financial crisis, was not looking healthy (Cameron 2010), it also provides a discursive commitment to 'well-being' at a time when austerity is likely to negatively impact on it. This commitment to 'well-being' makes it easier to justify austerity as an economic rather than a political project; austerity is something that has to be done, but the Government remains concerned about 'well-being'.

This, again, creates questions for Statistical Actors concerned with the integrity of the official statistics they produce. The relationship of the 'Measuring National Well-being' programme to wider trends in policy-making raises questions around the presentation of the programme and around the balancing of policy-makers and the public as members of the Statistical Audience.

\subsubsection{Summary: official statistics within the UK policy-making context}

This last point returns to the concerns about statistical integrity discussed above: although nominally independent of central government, in 'Measuring National Wellbeing' the ONS will be producing a statistical programme about a political issue and in a political context. This raises immediate questions about what items will be included in the programme, whether the programme will be used to produce a single headline figure or be left as a series of indicators, and so on. At the same time, the ONS is fitting within a larger system of government, with potential users of the programme distributed across Whitehall, Devolved Administrations and local government. This raises questions around how the programme is designed and constructed to take account of, or to ignore, the interests of these users. The ONS is also fitting within larger international networks, both of statistical practice and of well-being theory, which will add competing aims and objectives to those of domestic bodies. And they will do all of this on a fixed budget, at a time when resources, both in terms of finance and personnel, are being squeezed. 
4.3. Some concluding remarks on the institutional context of the ONS in 2010

This chapter has briefly outlined the institutional history of the Office for National Statistics, and its place within the wider context of UK policy-making both as an agency of government and as a producer of tools and materials used in organising government. It has shown the complicated terrain in which the Statistical Actors of the ONS stand part of an apolitical organisation producing data for political use, engaging with a fragmented but centralised system of governance, and so on. This terrain must be navigated: there is no obvious 'right answer' which the ONS can produce which will allow either the political control of statistical objects (as suggested by the 'critical' theories surveyed in Chapter Two) or which will guide a neutral empirical representation of an external reality (as suggested in the 'native' theories of Chapter Two). Rather, the evidence of this chapter supports the relevance of a social constructionist approach; by highlighting some of the constraints under which the statistical programme is made, constraints which the Statistical Actor must negotiate.

The survey in this chapter has emphasised the themes which run through the literature around the ONS and UK policy-making. How these themes play out in the day-to-day lives of Statistical Actors and what themes have importance in their lives do not appear in the literature but are empirical questions which will be tackled in Chapters Six and Seven. Before then, it is necessary to survey the theoretical material from which the 'Measuring National Well-being' programme might be built. This will be done in the chapter which follows. 



\section{Chapter Five \\ The theoretical and policy context of the 'Measuring National Well- being' programme: well-being theory and statistical practice}

The previous chapter examined the institutional context of the 'Measuring National Well-being' programme: the Office of National Statistics and the broader policy-making structure of the UK state. This highlighted a number of potentially competing aims and objectives, constraints and considerations which flow from the ONS' institutional history and form, and from its place within the wider institutional structure of UK policy-making. These will necessarily impact on the form of the statistics which the ONS produces, including outputs from the 'Measuring National Well-being' programme, as these set the context in which Statistical Actors operate. As explored in Chapter One, actors have agency, so this context does not determine the official statistic which will be produced but it will shape it by providing a structure in which action takes place. It is an empirical question how, and to what extent, this is the case; this question will be examined in Chapters Six to Eight.

Before that examination can be undertaken, it is necessary to examine the theoretical context of the programme: both of 'well-being' as it is constituted in academic literature, and of previous attempts to translate this conception into statistical programmes. The justification for this is the same as that for the examination of institutions in the previous chapter; in attempting to understand statistics as social constructions, it is necessary to consider what it is they are constructed from. With that in mind, this chapter will progress by examining the literature surrounding well-being and, separately, UK and international attempts to create well-being, or well-being-like, indicators over the last 60 years.

While the second of those tasks will undertaken in the same chronological fashion as the two prerequisites examined in Chapter Four, the first will instead be undertaken taxonomically. The reasons for this will become obvious, but can be briefly stated: 'well-being' is a chaotic conception (Sayer 1981, 1985, 2000), incorporating a number of distinct constructs approached in a number of different ways. To try and expound a history of the development of these would be an overly complex and uncertain endeavour which would risk losing the fundamental differences between conceptions under a weight of similarities in development. By examining the concept taxonomically, it is possible to indicate historical development and origins while highlighting the disparate nature of the ideas that the Statistical Actors of the ONS have available for incorporation into the 'Measuring National Well-being' programme. One of the contributions which the present study makes is to the literature on well-being; it is unusual for a study to survey the construct as it is used in multiple disciplines.

Section 5.1., then, will explore the diverse nature of concepts of well-being, examining divergent terminologies which appear in discussions around 'well-being'. Section 5.2. will examine how these differences are expressed in empirical research and note the implications this has for programme construction. As a lot of ground is covered by these sections, a brief Section 5.3. will recap some of the major themes raised. The chapter will then proceed with Section 5.4., which addresses the history of well-being and related statistical programmes, both official and unofficial. Again, due to the breadth of material covered, a summary of this material will appear as Section 5.5.. The chapter 
will end in Section 5.6. with a brief summary of the key points raised in Chapters Four and Five, and the complexities that the programme's context create for the Statistical Actors of the ONS in their construction of the programme. This provides the working material for the empirical research of Chapters Six and Seven, which will ask the question of how important the various complexities are, if at all, and how the ONS went about negotiating them in the case of the 'Measuring National Well-being' programme.

This chapter makes an original contribution to the literature around well-being, bringing together accounts from multiple disciplines which do not normally interact, notably economics and positive psychology. In some respects it replicates the work of others, such as Scott (2012), however in the breadth of material surveyed and the taxonomic approach it takes it represents an extension of such work. The section on the history of well-being measurement also represents an extension of existing work, such as that of Bache (2013; Bache and Reardon 2013) and Allin and Hand (2014).

\subsection{The diverse nature of concepts of 'well-being'}

Any attempt to understand 'well-being' is immediately complicated by indeterminacies of terminology. Stoll, Michaelson and Seaford (2012), in a sympathetic review of the research around the concept and its possible implications for national policy, note slippages in usage between 'well-being', 'life satisfaction', 'happiness' and 'subjective well-being' (p.8). As will be seen in the discussion of taxonomy below, these are distinct constructs: 'subjective well-being' refers to individuals' assessments of their well-being, which may include assessments of their happiness or their satisfaction with life, while 'well-being' can include non-subjective measures such as health or income. To this list of terms can be added 'quality of life', which is used both interchangeably with 'wellbeing' and as an aspect of it focussing on the material conditions of life (as in Organisation for Economic Co-Operation and Development 2013a). There is also 'progress', which suggests a teleology to human conditions and to 'well-being' and occurs particularly in policy-contexts (as in Cameron 2010; see also the work of former Cabinet Secretary Gus O'Donell; O'Donnell, Deaton, Durand, et al. 2014) or as correspondent of well-being (as in the Organisation for Economic Co-Operation and Development 2013a model). Sometimes used is 'welfare', which has a longer history within social policy and tends to refer to material conditions rather than to individual capabilities; in the context of well-being, it is usually preceded by the word 'economic' (as in Fujiwara and Campbell 2011). Often, these words will be used interchangeably or thrown together without distinction, making it unclear exactly what 'well-being' is believed to consist in (Kearns and Andrews 2010).

Such ambiguities of usage stem both from the close relatedness of concepts and from the diverse sources of discussion. For example while there are clear technical distinctions which are recognised in the psychological literature, for instance between 'happiness' (an affective state) and 'life satisfaction' (an evaluative state) (Diener, Suh, Lucas and Smith 1999; Diener and Seligman 2004), these do not always carry through to other academic fields. For instance, Layard $(2003,2005)$, treats answers to both 'how happy are you' (affective) and 'how happy are you with your life' (evaluative) as data on 
'happiness'. Such distinctions are further obscured when empirical data is encompassed within a broader discourse of 'well-being', both by researchers (see, for example, Blanchflower and Oswald 2004, 2008, who title their papers with 'well-being' but review research into 'life satisfaction') and policy-makers. As an example of the latter, the Whitehall Well-being Group (2005), in their review of the use of 'well-being' across central government departments in the UK found that while the term was widely used, it was normally not specifically defined and was used differently by different departments. However, distinctions between constructs do exist and they follow quite clear conceptual boundaries, and obscuring them under the rubric 'well-being' can give a false impression of a coherent programme looking into a closely-defined holistic concept subject to empirical analysis. As Diener and Seligman (2004) assert, such a programme does not exist. In its place are top-down attempts which start from the researcher's idea of what 'well-being' comprises, and then attempts to draw together research on specific constructs felt to be relevant (see, for example, Dolan, Peasgood and White 2006). This leads to the slippages noted above, as research from diverse fields are gathered under the label 'well-being', sometimes being distorted in the process to make sure they fit.

Such diversity of conceptions of 'well-being' and its components is not new. What has been considered as 'the good life' or 'true happiness' (both of which are concepts related to but distinct from 'well-being') has been debated for at least as long as there is recorded debate (see White 2006). This feeds directly into well-being research: one strand of research, the 'eudaimonic', takes it name from Aristotle's discussion of what it meant to 'live well' in the Nicomachean Ethics (Aristotle 2002); ${ }^{10}$ other strands, of 'preference satisfaction' and the 'hedonic', owe debts to Utilitarianism (Bentham 1962; Mill 1962). Already in disagreement with each other, both these attempts to define happiness have been rejected by other philosophers for a variety of reasons. Kant, for example, suggested it was impossible for an individual to know in advance what would make them happy, debarring both Aristotle's pre-planned individual excellence and Bentham and Mill's centrally-planned social system (White 2006). Similar arguments being made by modern critics of well-being research (see, for example, Johns and Ormerod's, 2007, claim that "the concept of happiness is inherently subjective and is not necessarily connected to what most people would deem moral", making it impossible to plan or legislate for, p.20). Given the openness of the historical discussion around happiness, it is unsurprising that the research context around its modern cousin 'wellbeing' is similarly diverse.

The effects of that diversity are shown in figures 5.1., which are a series of conceptual frameworks produced by different organisations interested in the questions of 'wellbeing' or 'quality of life'. Again, there is a difference in terminologies, the ONS (figure 5.1.a) and OECD (figure 5.1.c) models discussing 'well-being' and Eurostat (figure 5.1.b) choosing instead 'quality of life'. There are also differences in what is included: for example, Eurostat suggest 'economic and physical safety', which has a parallel in the OECD's 'personal security' but no correspondent in the ONS' model. The OECD bring four types of capital to the fore as necessary for the sustainability of well-being, while

10 Although, it should be noted that little more than the word 'eudaimonia' is taken from Aristotle's philosophy, that being a theory of ethics based on the 'excellences' of the 'soul', which are functions of human rationality. Importantly, the 'flourishing' individual for Aristotle is one whose attainments are believed by their peers to be worthwhile, not someone who feels their own life to be worthwhile. 
the other two distribute them across their domains. In general, while there are overlaps in the concepts the three models are using, at this high level there are clear differences in emphasis and composition. There are obvious potential explanations for such differences in approach: the three organisations vary in political aims, access to data, abilities to collect and aggregate information, the nature of their audiences. Nonetheless, they are all talking about a single (or, at best, a small number of very tightly interlinked) concept in different ways. This selection does not exhaust the possibilities for conceptualising well-being either, as Tomlinson and Kelly (2013) show when they highlight issues of social cohesion, national identity, the sustainability of development and the distribution of assets as missing from the ONS' programme (and, they might have added, also largely missing from the Eurostat and OECD programmes).

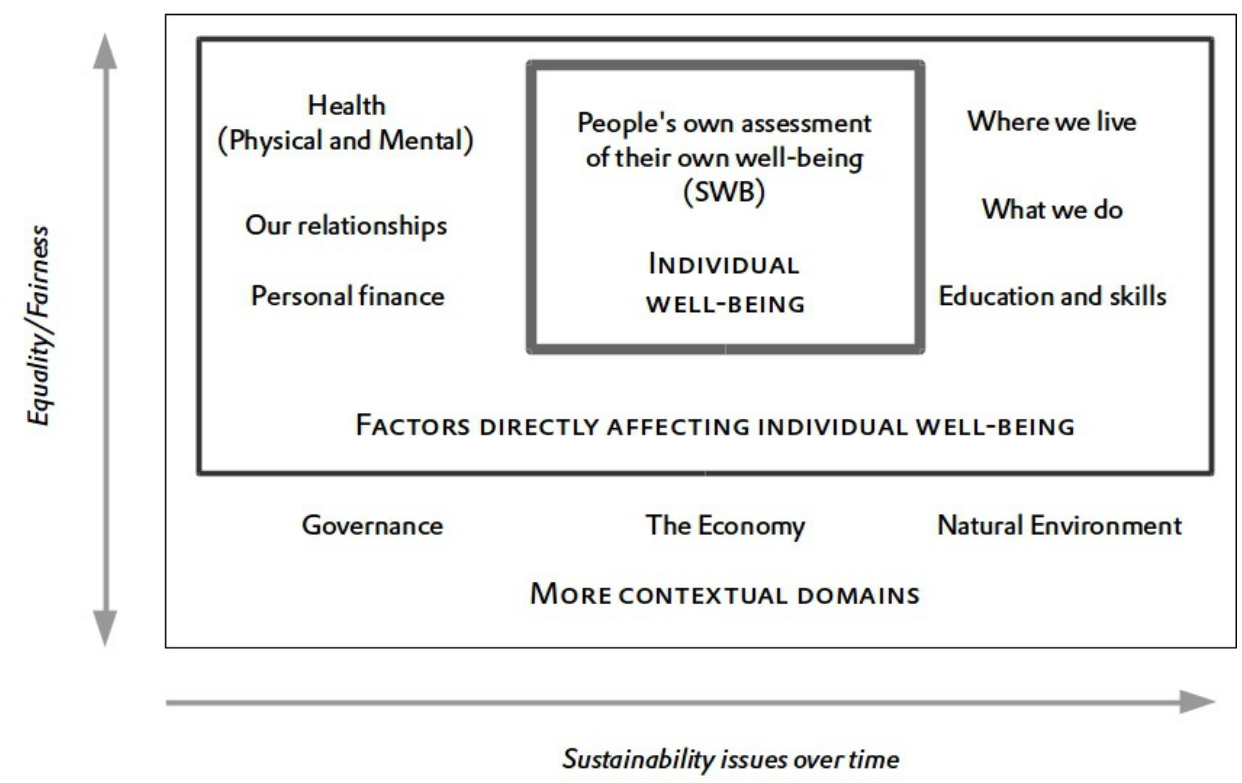

a. The ONS framework (redrawn from Beaumont 2011, p.2) 


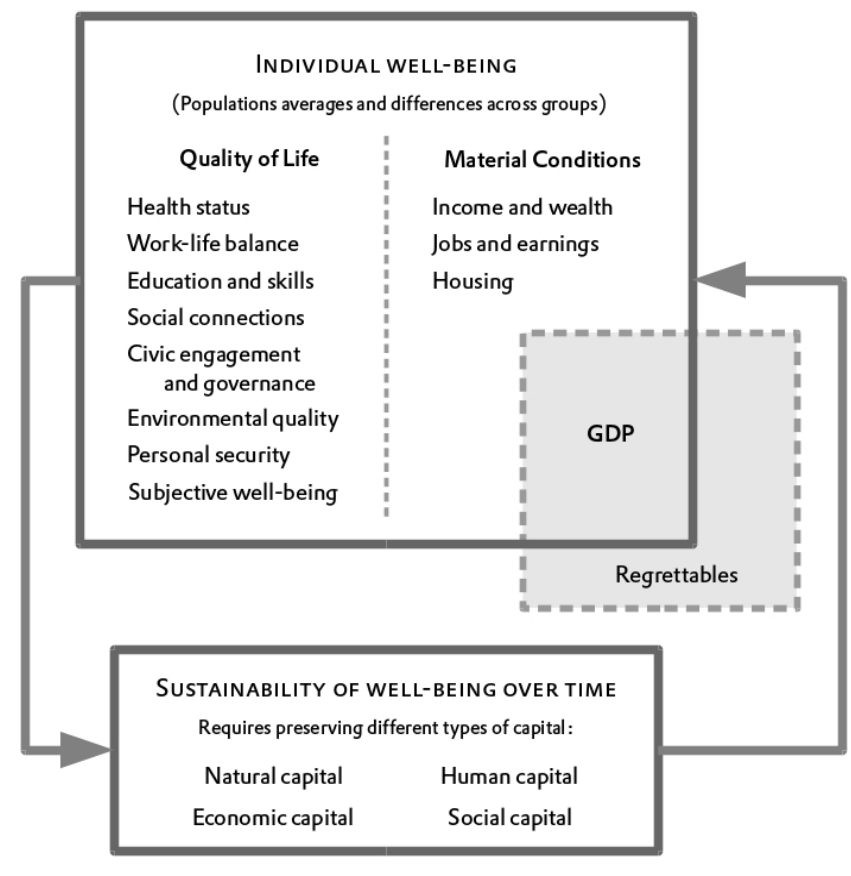

b. The OECD framework (redrawn from Organisation for Economic Co-Operation and Development 2013a, p.4)

Note: 'Regrettables' in this framework are 'negative externalities', by-products of GDP which are harmful to well-being.

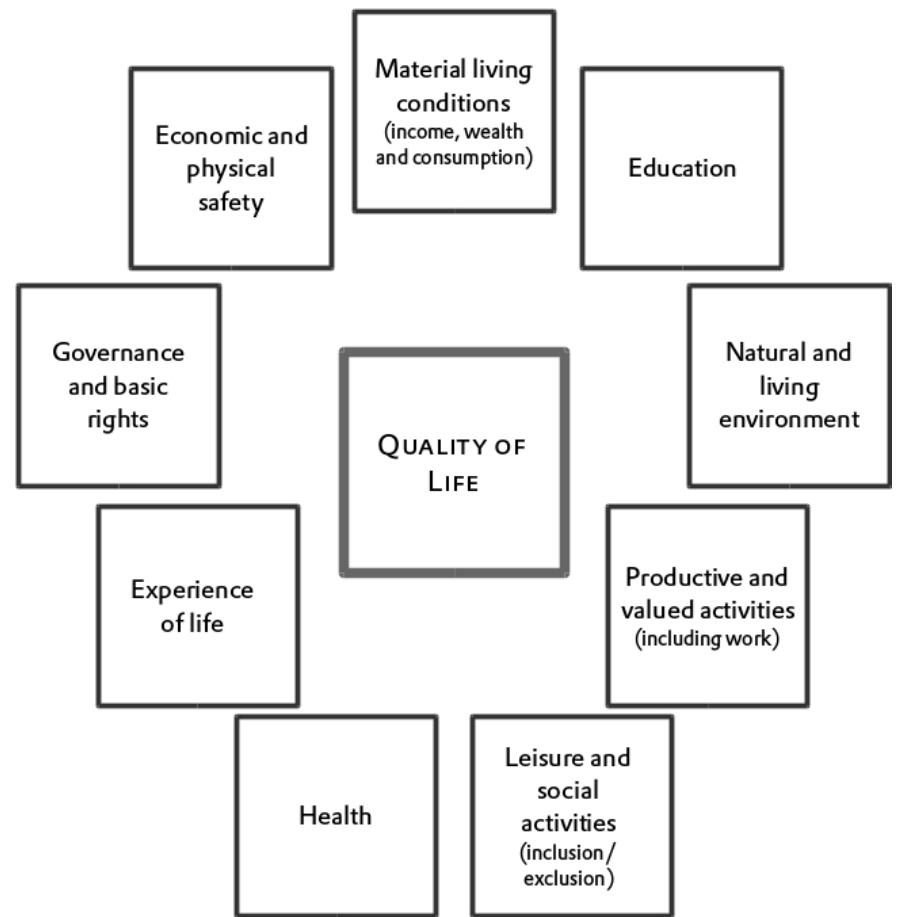

c. The Eurostat framework (redrawn from http://ec.europa.eu/eurostat/web/gdp-andbeyond/quality-of-life/data, accessed 9 May 2015)

Figures 5.1. The well-being frameworks of the ONS, OECD and Eurostat 
As a final observation on the ambiguities of terminology, in as far as a holistic concept 'well-being' is developing or being sought by researchers and policy-makers at all, this does not mean that academics and policy-makers were not previously interested in what might now be called 'well-being'. As HM Treasury (2008), somewhat defensively, make clear, "Governments already factor well-being considerations into the overall balance of economic, social and environmental policy. Economic policy does not generally seek to prioritise growth per se, but as a means to higher aggregate welfare." (p.3; see also Atkinson 2005). There is here, again, an equating of 'well-being' and 'welfare', and the claim that well-being (or welfare) is the ultimate aim of policy. Donovan, Halpern and Sarjeant (2002), reviewing the status of research into life satisfaction and its implications for policy, make a similar point, arguing that nations, generally, are trying to 'progress' in some sense (p.43, although they acknowledge that what nations are progressing towards is a politically disputed question). From this perspective, recent explicit focus on 'well-being' as a holistic concept, as in the case of the 'Measuring National Well-being' programme, are not radical departures from pre-existing concerns, but attempts at making such behaviour more scientific by linking judgements with evidence (O'Donnell, Deaton, Durand, et al. 2014).

This diversity of conceptions of 'well-being' is not necessarily problematic: if 'wellbeing' is a subjective state then a plurality of approaches may be more useful than any monolithic construction. However, the lack of any established and agreed model raises questions for the Statistical Actors of the ONS about what counts, and what to count, as 'well-being'. They will be in the position of creating a monolithic construction, as a statistical programme is necessarily a closed set of measures, without any existing agreement of what to include and the real possibility, given the history of disagreement, that no such agreement is possible.

\subsection{The diverse approaches to conceptualising and measuring 'well- being'}

There has been widespread research across a number of disciplines into 'well-being', most notably in psychology and the behavioural, developmental and environmental subbranches of economics. However, as discussed above, these disciplines have not agreed on what 'well-being' consists in, leading to the development of several distinct approaches. Figure 5.2 is an attempt to order the diverse literatures around well-being, based on Schyns (2003, as reproduced in Noll 2005) and updated with material from Dolan, Peasgood and White (2006) and Dolan, Layard and Metcalfe (2011). It outlines the key strands of well-being research and the measures which have been developed within them. A major division in approaches can be discerned within the literature between observed and stated measures.

In observed measures, the researcher decides what contributes to well-being and measures this directly. An example would be indicators of unemployment - in as far as unemployment is considered detrimental to well-being, its levels can be observed and the conclusion drawn that well-being is increasing when unemployment is falling and vice versa. In stated measures, individuals are asked directly for their evaluations of 
their own well-being, which leaves them to define for themselves what contributes to that evaluation; an example would be subjective well-being measures, where individuals are asked to assess their own happiness or satisfaction with life without there being any prior assumptions by the researcher that employment status, to take the example already used, contributes to this.



Figure 5.2. A taxonomy of well-being research

Within these two divisions, three major approaches towards constructing and observing well-being can be discerned (highlighted in bold in figure 5.2.): stated evaluations, where individuals give a personal assessment of their internal states and opinions; preference satisfaction approaches, where individuals indicate through real or hypothetical actions how much they would give up to secure an outcome; and objective lists, where observations are made of phenomena or objects thought to contribute to well-being. These approaches will be briefly explored below.

It will be argued that these three approaches and their various sub-categories do not relate to a holistic construct of well-being, but that they are all at least potentially valid components of a larger construct. Further, none of them is exhaustive: assessments which rested solely on stated personal evaluations while ignoring observed social conditions (or vice versa) would be incomplete; as separate constructs, it is possible for these two approaches to reach different conclusions about overall well-being. This creates a challenge for the Statistical Actors of the ONS; if they are to avoid incompleteness in the 'Measuring National Well-being' programme, they will need to find a way of making diverse approaches to 'well-being' cohere.

\subsubsection{Stated evaluation approaches}


A broad body of research in the disciplines of psychology, health and economics looks at stated evaluation approaches, which ask individuals to assess various aspects of their lives. This research encompasses evaluations of the self, hedonic and eudaimonic personal assessments, and evaluative assessments of social conditions.

Stated evaluation approaches ask individuals to give a global judgement of their life, its conditions or of an aspect of these. The standard approach used in economics is ask individuals 'how satisfied are you with... ?', allowing them to respond using binary options or Likert scales. This approach can also be used to obtain individual assessments of collective organisations or phenomena (as in, 'how satisfied are you with the government?' or 'to what extent do you feel safe?'). Hedonic approaches look at the experience of individuals, asking them to record their affective or psychological state rather than a assessment of satisfaction. Eudaimonic or 'flourishing' approaches ask the individual how worthwhile or meaningful they feel their life is, or the extent to which they have a sense of purpose. In all cases, individual assessments are aggregated to reach conclusions about how larger entities such as countries are doing: the entity is happy in as far as the majority of its citizens are happy (Dolan, Layard and Metcalfe 2011).

This approach has been widely used in economics with authors such as Dolan, Layard, Metcalfe, Donovan and Oswald, all of whom went on to advise the Office for National Statistics on the 'Measuring National Well-being' programme, developing lines of research utilising it (Dolan, Layard and Metcalfe 2011; Dolan, Peasgood and White 2006, 2008; Dolan, Peasgood, Dixon, et al. 2006; Layard 2005; Blanchflower and Oswald 2004, 2008). It is relatively cheap and easy to administer, requiring as little as a single question which can easily be slipped into established surveys to yield a large dataset. Doing so provides data amenable to statistical analysis; by treating this data as an outcome measure, regression modelling can be used to 'explain' well-being in terms of other measures in the survey. Existing surveys which ask for stated evaluations of well-being, such as the Gallup World Values poll, provide large datasets going back decades which allow 'satisfaction' or affect ratings to be linked with other variables (Heukamp and Ariño 2011). The fruits of this research is summarised by Dolan, Layard and Metcalfe (2011), Dolan, Peasgood and White (2006, 2008), Dolan, Peasgood, Dixon, et al. (2006), Donovan, Halpern and Sargeant (2002) and Layard (2005).

The underpinning for such work was laid by psychologists who showed that constructs such as 'happiness' or 'satisfaction' were robust and valid (Diener and Seligman 2004). Historically there were concerns that individuals, while able to have meaningful discussions about such constructs, may not have meant the same thing by them. This was of particular concern cross-culturally, where there were fears that cultural biases would influence responses. More broadly, there were also concerns that emotional states were susceptible to performance biases under experimental conditions; and that responses were volatile and unstable over time. Together, these response effects would lead to unreliable measures. A large amount of early research in psychology centred on clearing away these concerns, and showing that individuals could accurately report conditions like 'happiness' and 'satisfaction', which were impacted in expected ways (for example, that 'happiness' declined in the wake of negative events), were relatively stable over time, and were impacted by biases in experimentally controllable ways (Diener, 
Suh, Lucas and Smith 1999).

This body of psychological research allowed economists to build on their existing Utilitarian preference models. Mainstream economic theory models individuals as rational actors seeking to maximise 'utility' through purchases in the market (Keen 2011). This leads to a post hoc nature to economic argument: purchasing decisions are assumed to express utility-maximising behaviour, but cannot be shown to (Brockway 1995). Subjective well-being allows a way of characterising 'utility' directly, allowing it to be related empirically with both market and non-market activities. This led to a body of research, summarised by, among others, Dolan, Peasgood and White $(2006,2008)$, Donovan, Halpern and Sargeant (2002), Layard (2005) and Johns and Ormerod (2007), which used regression techniques to separate out the determinants of stated evaluations. The majority of findings of this research are not greatly surprising: divorce, bereavement, unemployment and insecurity are associated with more negative stated evaluations and affect, while marriage, faith and social ties are associated with more positive ones. There has been great debate, however, around income: Easterlin (1974), using data from a series of international polls found that within countries greater income was associated with more positive personal stated evaluations, and that between countries greater income per head was associated with higher average positive evaluations. However, within countries, as income per head increased over time there was no corresponding improvement in average stated evaluations. This finding became known as the 'Easterlin Paradox', that income appears to impact on stated evaluations at any given point in time, but not to influence it over time.

This paradoxical finding is cited by Cameron (2010) and the Conservative Party's policy-review team (Quality of Life Group 2007) in justifying statistical programmes which look beyond national economic output. It has, however, been disputed on a number of grounds. One is that the stated evaluation data it is based on was largely from a discrete three-point scale, meaning that any average change in national stated evaluation would require a large-scale movement of individuals between points on the scale (which means, in practice, a large number of people moving from the middle category to either the top or bottom). This gives average ratings a high degree of stability. Further, unlike the income with which it is being compared, the evaluation scale is necessarily bounded, meaning that at the hypothetical point where the whole population is giving the maximum possible positive stated evaluation, their average happiness cannot increase with their income (see Johns and Ormerod 2007 for a fuller exposition of this argument). Counter to this, authors such as Layard (2005) have noted that there are, in fact, differences in average national stated evaluations, and that individuals do change stated evaluations over time, suggesting that these measures are valid. Increasingly, data is available using longer scales, which also reduces the practical, if not the conceptual, severity of the critique.

A second objection is that the paradox arises from a mistake in the scales used. If income is placed on a logarithmic, rather than an absolute, scale, the relation between income and positivity of stated evaluation is restored (Stevenson and Wolfers 2008). If accepted, this explanation shifts the focus of debate by suggesting diminishing returns to income. This represents a challenge to simple GDP-based measures of economic welfare; if income is of different values to different individuals, then happiness is best 
maximised by a focus on equalising distribution rather than maximising totals.

Authors such as Layard (2003, 2005), whose work became influential in policy-making circles and who went on to contribute to the ONS programme (see following chapter), and policy-makers such as Cameron (2010), accept the paradox to be genuine. If this is so, there are a number of potential explanations: that income is only weakly related to positive stated evaluations; that income is a positional good, so absolute income is less important than relative income; that increases in income are important in the short term, but that in the long term individuals become habituated to them and so return to a baseline level of stated evaluation (the so-called 'hedonic treadmill' argument) (Layard 2005). These explanations are not mutually compatible and lead to diverse policy recommendations, but are all supportable given present research and the acceptance of the Easterlin Paradox.

Again, some terminological ambiguity should be noted in the research above; economists do not always distinguish different measures of subjective well-being from each other or from 'well-being' more generally. Layard in particular tends to talk about this in terms of 'happiness', but rests his findings largely on evaluative statements around 'satisfaction', rather than on affective ones (e.g., Layard 2003).

Research into affectual states has, however, distinguished them from measures of 'satisfaction'. 'Satisfaction' as an evaluation seems to incorporate both assessments of immediate conditions and a comparison of these conditions with desires or expectations; Linley, Maltby, Wood, et al. (2009) in a review of the field separates such 'subjective well-being' measures from 'psychological well-being' measures, which are directly concerned with immediate psychological functioning. The most basic of these 'psychological well-being' measures are measures of affect; questions related to happiness, sadness or anxiety.

As a further complication to the confounding of self-evaluation and affective measures, there are questions whether the latter can be captured by single questions at all. Kahneman, Krueger, Schkade, et al. (2004) and Watson, Clark and Tellegen (1988) note that affect measures fluctuate over time, so devised methods for the more detailed observation of movements in evaluations of affect. These methods required much more intensive data collection, such as the collection of multiple single-question responses over an extended period of time. Researchers in the field of positive psychology have taken this further. Observing that much prior research had focussed on pathologies, researchers looked instead at what led to positive functioning (see Diener and Seligman 2004 for a review). A variety of instruments and approaches have been used, such as the Warwick-Edinburgh Mental Well-being Survey (WEMWBS), designed for NHS Health Scotland (Stewart-Brown, Platt, Tennant, et al. 2011; Tennant, Fishwich, Platt, et al. 2006). Such approaches are very different from single-item stated evaluations: while they rest on self-report, they consider well-being as a set of capabilities, rather than outcomes, to be imputed from responses not simply read from them. This requires multiple-item surveys which are much harder to relate to external factors through mechanical causal models.

Two things should be noted about the distinction of 'subjective well-being' and 
'psychological well-being' measures. One is, as above, it is a distinction that is not always made when using stated well-being evaluations. Where 'happiness' data and 'satisfaction' data is used interchangeably, for instance in building an evidence base around correlations between well-being and other factors, there is a clear danger that like is not being compared with like: in the one case there is an evaluative state which incorporates both present conditions and beliefs about what those conditions should be; in the other there is simply a judgement about affective state. (Layard, Mayraz and Nickell, 2008, argue that such an equivocation of measures is justifiable, as country rankings based on average citizen satisfaction scores and average citizen happiness scores are similar. This only shows that the measures are partially collinear, however, the critique that they are distinct theoretical constructs remains.)

The second is the difference in data generated by the two approaches: 'subjective wellbeing' measures are single answers to single questions; while the same can be true of simple affective measures, there is the danger that these are capturing short-term and unrepresentative states. More extensive research instruments which try to avoid this danger produce data much less amenable to mechanistic, causal analysis of regression model. Instead, the data they produce is more detailed and seeks understandings of individual situations rather than generalisable conclusions. This makes it less easy to generate policy conclusions from in the manner of Layard or Dolan (Layard 2005; Dolan, Layard and Metcalfe 2011; Dolan, Peasgood and White 2006, 2008; Dolan, Peasgood, Dixon, et al. 2006).

That such extensive instruments are not utilised in policy-orientated research is due to a difference in aims and outlook between their economist authors and, particularly, positive psychologists. These authors treat single evaluative measures, such as 'happiness' or 'life satisfaction', as outcome measures (see, particularly, Blanchflower and Oswald 2004, 2008; Layard 2005). Subjective well-being here takes on the simple, mechanical form of the regression models used to analyse it, collapsing complex personal evaluations and states into simple generalisations about the relation between stated evaluation and everything else on the survey. For the psychologists, such as Stewart-Brown (Stewart-Brown, Platt, Tennant, et al. 2011; Tennant, Fishwich, Platt, et al. 2006), who sat on advisory panels for the 'Measuring National Well-being' programme, 'well-being' is not simply a state, but is a component of a wider self; it is a capability which mediates interactions with the external world, rather than being a simple product of factors within that world. This points to divergent ethoses of wellbeing; to put it somewhat crudely, for the economists well-being is a universal state subject to universal patterns and laws, for those in public health it is a personal state to be understood in a personal context.

Eudaimonic measures are different again, conceptually falling somewhere between stated evaluations and hedonic statements. They ask individuals how 'meaningful' or 'worthwhile' their lives are, which is a global evaluation which will be influenced by psychological functioning and refer to how the individual feels they are doing in terms of personally-held values. Research in this area is new and developing, and there are disagreements over whether this constitutes a distinct construct from, particularly, stated evaluations (see Delle Fave, Brdar, Freire, et al. 2011). However, a battery of eudaimonic questions have been incorporated into surveys feeding the European Union 
Statistics on Income and Living Conditions (EU-SILC) (Huppert, Marks, Clark, et al. 2008), suggesting that the field is taken seriously by researchers and official bodies.

A final set of stated valuations are those which deal with an individual's opinions about the context in which they live their lives; for instance whether they feel safe after dark, or how strongly they trust institutions. This has been widely used in sociology in research around the 'quality of society' (Berger-Schmitt and Noll 2000; Cummins 1996; Veenhoven 1999, 2005, 2009; Wallace and Abbott 2007). This is a separate component of well-being alongside personal evaluations; one can be happy in one's self but unhappy with society. Questions around satisfaction with institutions have been features of social surveys for decades; examples would be the surveys on confidence in statistics surveyed in the last chapter (Bailey, Rofique and Humphrey 2010; Simpson, Beninger and Ormston 2015; Wilmot, Jones, Dewar, et al. 2005). Scale, here, is interesting: the approach moves from individual assessments to conclusions about much bigger entities: the 'nation' is doing well or badly because a plurality of its citizens believe it to be.

This first group of measures of 'well-being' exemplify a set of challenges that the Statistical Actors of the ONS will need to navigate. As a starting point, they show disagreements in theorisation between different academic disciplines: the 'well-being' of Dolan or Layard is a state which can be mechanically related to input measures, while for positive psychologists such as Stewart-Brown it is more a capability which acts to mediate experience. Such differences impact both on the data which needs to be gathered and on the way that data is conceptualised: the mechanistic conception can be implemented as single questions which can then be used as outcome measures within larger models. Even within this single-question approach, there are multiple questions which might be asked; about satisfaction, about affect, about 'meaningfulness'. Alongside these, there are questions about 'the quality of society', and which aspects of society are to be examined in this way. Such challenges in conceptualisation and implementation do not admit of straightforward answers, Statistical Actors with agency will need to resolve them.

\subsubsection{Preference-based approaches}

Preference-based approaches grow out of the Utilitarian economic models discussed above. If individuals are assumed to be pursuing the maximum utility available to them, then the utility of a good or service can be measured in terms of its price. This underpins the use of GDP as a measure of welfare or well-being, as more economic activity entails more expenditure and so the securing of more well-being. It also underpins judgements of 'value for money' or 'cost-effectiveness' in the provision of public services (see Section 4.1.4.), as it suggests that the value of a service is directly related to revealed preference displayed in its demand (see Fujiwara and Campbell 2011).

There are obvious difficulties with such interpretations, which stem in part from the assumptions required by economic theory if the stated preference approach is to work. One is that individuals are rational in the economic sense, with their preferences being consistent over time. That is, if they prefer GDP expansion over the environment in the present, it is because they understand the difficulties environmental degradation will 
bring them in the future and have decided that the benefits of GDP in the present outweigh them (Keen 2011).

However, economic theory now recognises that individuals are not rational in this sense, but that often they either lack the information necessary to determine preferences, or fail to process such information and so, at best, are boundedly rational (see the work of Akerloff, e.g., 2002). Additionally, as individuals have limited resources, it is not possible to distinguish between things which individuals would like to have but can't afford and things which they don't want at all. This is related to the fact that the approach is only possible where choices are apparent; most often this is based on economic markets, but markets do not embody unconstrained choice. So while revealed preferences are central to decisions around specific government activity, the method is very difficult to interpret as reflecting 'well-being' in any broader sense.

Where markets do not exist, 'stated preference' approaches are used. These attempt to circumvent the problem of a lack of observable behaviour from which to derive judgements of utility by asking individuals about decisions they would make in hypothetical situations. These have similarly been used in cost-benefit analyses (see Fujiwara and Campbell 2011) and underpin programmes such as the 'natural capital' approach to valuing 'ecosystems services' (see, for example, de Groot, Brander, van der Ploeg, et al. 2012) and the Quality Adjusted Life Years approach to valuing healthcare interventions (see Tsuchiya and Dolan 2005). These move preference-based approaches from the economic to the social domain, showing their potential as ways of expressing non-monetary value. As with stated preference approaches, these have not been adopted in large-scale statistical programmes, partly because of the inherent unreliability of the process; there are many things individuals refuse to put a price on when asked (see work by Frey, e.g., Frey and Gallus 2013). As with observed preferences, it is hard to interpret such measures as concerning 'well-being' in any broad sense: they reflect choices offered to individuals and not the relation of those choices to broader individual conditions (Archer 2000).

However, the belief that 'utility' can be measured directly through single-question stated evaluations has led to research which substitutes preference-based approaches with stated evaluation methods for the pricing of non-market goods. The logic is that if it possible to reliably relate a given life event with a given increment of stated well-being evaluation, then the value of this life event can be expressed in terms of the increment without the need for unreliable stated preferences (Fujiwara and Campbell 2011). This leads to claims such as "an adult learning course which improves life satisfaction has a value to those who receive it of between $£ 750$ and $£ 950$ on average - derived using techniques advocated in the Green Book Annex on Social Cost-Benefit Analysis." (Cabinet Office 2013, pp.2-3). The evaluative state has been monetised, allowing it to be assessed in terms of efficiency or value for money and makes stated evaluation amenable to inclusion in economic models.

It is possible that comparability is being confused with substitutability. That is, the fact that different things have the same apparent level of impact on well-being does not mean that the impact is the same. To take an alternative example, while Blanchflower and Oswald (2004) find that divorce leads to a reduction in stated evaluation to a value 
commensurate with a reduction of income of $\$ 100,000$ per month, it remains an empirical question whether giving a divorcee $\$ 100,000$ returns them to their prior level of stated evaluation. It seems possible that it would not, that the individual involved would remain unhappy about the divorce however happy they were about their windfall, that the one would not compensate for the other. Part of the problem here is that research in psychology has shown that positive and negative affect are distinct, and not two sides of a single construct (Diener and Seligman 2004), meaning that removing one does not entail the other. This causes difficulties for a cost-benefit analysis approach and economic research on well-being of the type explored above, as both happiness caused and unhappiness avoided are expressed in the same terms. In common with other approaches which take well-being to be a state, they also fail to take account of any broader context in which the happiness or unhappiness occurs, such as its sustainability; the approach cannot deal with delayed gratification, or temporary hardships undertaken in the expectation of later gains.

These may not seem at first to be questions which will affect Statistical Actors. However, as shown in the previous chapter, the Office for National Statistics sits within a wider context of UK policy-making. It was argued that this context was driven in part by concerns around cost-effectiveness and value for money. With the use of stated evaluations as a methodology for cost-benefit analysis written into UK policy-making practice through the Treasury's Green Book (HM Treasury 2011a), there is potentially a pre-existing policy need which well-being statistics could meet. This feeds back into considerations around the theoretical debates between economists and positive psychologists discussed above, giving economic conceptions of well-being a practical weight which psychological conceptions may not have to the same extent.

\subsubsection{Objective lists}

'Objective list' approaches define a list of conditions thought by their designer to contribute to well-being, and observe these; examples could include educational achievements, unemployment or GDP. This approach entails only counting something considered to be important, meaning it is possible to read all social and economic indicators as expressions of objective list approaches. Even something as basic as demographic data could inform policy-makers on some aspect of a nation's 'well-being' (indeed, the 'Father of Statistics', William Petty, used demographic data in just such a way, with population breakdowns indicating how secure the nation was from war with France; see Buck 1977; Petty 1899). Such a reading brings within the scope of 'wellbeing' a large body of research from the developmental and environmental literatures. For example, the UN Millennium Development Goals, UN HDI and Gender Development Indices, and the New Economics Foundation's 'Happy Planet Index' tend to describe themselves in terms of 'progress', 'development' or 'sustainability', all of which can be read as correlates of well-being which take into account the future states of individuals and polities. Related to these are various economic measures designed as alternative to GDP, such as the ISEW, MEW and Genuine Progress Indicators (see details in the appendix to European Economic and Social Committee 2012). These seek to amend GDP either by including things not currently included (such as the value of non-market labour) or by re-categorising items already within GDP as costs rather 
income (such as resource depletion, defence expenditures, negative externalities like pollution; see discussion below).

Such lists necessarily deal with observable or imputable phenomena, but beyond this restriction their range is limitless covering both inputs and outputs (e.g., expenditure vs. life expectancy), measures of presence or absence (e.g., income per capita vs. fuel poverty) and levels or distribution (e.g., income per capita vs. GINI coefficient of income inequality). It is also possible to collect data at multiple scales: both from individual observations which are aggregated, and directly from entities at higher scales, such as 'the nation' or 'the economy'.

What an objective list includes will vary across observers, partly due to differences in opinion over what constitutes 'well-being' (discussed above), partly over whether these constituents are seen as components of well-being or as drivers of it, and also due to differences in aim and outlook. For example, the United Nations' Millennium Development Goals (Annan 2000; United Nations 2014; United Nations General Assembly 2000) are a list of tightly defined measures, selected for their impact on 'wellbeing', translated into nation-level targets for achievement, and aimed at developing nations. As countries develop, these minimum benchmarks become less appropriate; improving literacy rates is replaced as a component of well-being in the UK context by levels of qualifications obtained.

Similarly, the differing priorities of the organisations compiling the lists leads to diversity: the UN's 'Human Development Index' and its related 'Gender Development Index' (see United Nations Development Programme 2014) is similar in construction to the New Economics Foundation's 'Happy Planet Index' (see New Economics Foundation 2012), but the latter includes a measure of environmental footprint. Both are composite indicators, which combine measures from a short list into a single overall figure, and the inclusion of different lists of measures result in different overall results. Countries which on the UN Human Development Index list appeared to be doing well on the New Economics Foundation's account often do less well, highlighting their contention that their 'success' comes at a price which, when considered, reduces the value of their achievements. The simplicity of these indices, particularly their expression as single figures, serves their purpose as campaign tools.

Such efforts are relevant given the ambitions for the 'Measuring National Well-being' programme to complement GDP (Cameron 2010). This is an open-ended aim, representing little more than 'count something other than economic growth'. What could be counted under such circumstances is almost unlimited, and the range of different objective lists undertaken mirrors the range of different constructions of 'well-being' discussed above. As Hand (2004) observes, statistics are pragmatic responses to the problem of representation; they are representations with a purpose (see also Dalenius 1968). The variety of different objective lists and indices arises from differences in data availability, goals and uses. The institutional context of the Statistical Actors of the ONS, discussed in the previous chapter, means that they will not be using the statistical programme themselves; rather the use of the programme will fall to other state bodies. This highlights a set of challenges which will face the Statistical Actors both in the selection of objective list measures for inclusion and in the composition of the 
programme more generally: the needs of multiple potential users will need to be considered, and balanced against the need to construct a coherent programme.

\subsubsection{The composition of programmes: putting diverse measures together}

In addition to there being multiple ways of conceptualising well-being, there are multiple ways of combining measures within an official statistical programme. One way would be to have a series of separate measures, either taken from a single approach or from several, reported and tracked separately; the other would be to weight and combine measures into a single overall 'well-being' figure which could be used like GDP to indicate overall conditions across the programme. There is also the possibility of a halfway house between the two, with a single index figure presented alongside its disaggregated components.

Each approach has its advantages: a single number is easy to report and interpret as an indicator of a general area of measures, while multiple measures offer more detail and sit closer to direct policy interventions. For example, the Scottish Government's 'Scotland Performs' indicator set (see Scottish Government 2011) ties its measures to national targets, allowing the overall performance of the programme to be measured against the success or failure in meeting these targets (a similar model is used in the UK 'Sustainable Development Indicators', Department for Environment, Food and Rural Affairs 2013). Indicators which are consistent across areas or polities can be used to situate performance in a wider context, as The European Statistical Committee's 'GDP and Beyond' set of indicators hopes to do (see Sponsorship Group on Measuring Progress, Well-being and Sustainable Development 2011). However, broad sets of indicators can be difficult to interpret, so campaigning groups in particular often opt for composite indicators, as in the case of the UN HDI and Gender Development Indices, and the New Economics Foundation's 'Happy Planet Index' discussed above.

There is also a broader question about how diverse measures fit together. This is particularly the case with single index numbers: if questions of positive and negative affect are measuring different constructs (as Diener, Suh, Lucas and Smith 1999 argue that they are), how are they to be combined as part of an overall 'well-being' figure? How is data collected at the individual scale, such as subjective well-being, to be balanced against data collected at the level of the nation as an entity in its own right, such as environmental objective list measures? This remains a problem for multipleitem programmes, although here the challenge of interpretation is left to the Statistical Audience rather than the Statistical Actors; it is they who must make sense of disparate measures in determining whether 'progress' has been made.

This again presents the Statistical Actors with challenges around the potential uses of the programme by diverse parts of the Statistical Audience. Not only will the Actors need to select measures, but they will also need to present them. Neither question can be separated from the purpose of the programme which, as discussed in the previous chapter, is a function of the fragmented policy-making structure of the UK. Here there is a clear interaction of institutional and rhetorical questions which the Statistical Actors will need to resolve. 


\subsection{Summary: the diversity of the field of well-being research}

From the above, well-being research may be characterised as a multi-disciplinary field of disparate programmes which do not always agree on what 'well-being' is. In as far as 'well-being' as a concept exits, it is as a chaotic conception in Sayer's (1981, 1985, 2000) sense: an abstract idea which gathers together multiple, potentially incompatible, ideas under the guise of being a concrete entity. It is for the Statistical Actors to make sense of this field, negotiating between different approaches on their way to constructing an official statistical programme. From the discussion above, there is no obvious or non-controversial way to do this. A programme which followed mechanical conceptions of subjective well-being which treated it as a state would be open to criticism from theorists who disagreed that 'well-being' was actually measured by such approaches. The reverse is also true. Even if a subjective well-being approach could be agreed on, there may be disagreement on which subjective measure to use. A programme which included objective list measures would be open to critique from those who disagreed with the measures included or omitted; similar disputes could occur over evaluation questions related to particular areas of society or the environment.

The Statistical Actors will also face questions about users and usage. Given the role that economic conceptions of well-being play in cost-benefit analyses, there is a potential tension within the programme around whether it is for 'measuring progress' in a general sense or for 'costing progress' in relating expenditure to well-being 'outcomes'. In addition to this question of which measures to include, users and anticipated usage will impact on the way in which the programme as a whole is constructed, as a set of measures or as a single index number. There is also a question of the scale of data collection and reporting: for data to be usable at a regional or local level, it must be sufficiently granular to reliably report on that level. These questions highlight the interaction of the theoretical questions raised above and the institutional questions of the previous chapter and again show the necessary role of agency in shaping the form and content of the official statistical programme.

Contrary to the theories examined in Chapter Two, then, the subject matter of the 'Measuring National Well-being' programme does not present a straightforward domain which can be translated into either an empirical representation or a mode of control. It is a contested, messy domain, chaotic in Sayer's $(1981,1985,2000)$ sense and must be navigated by Statistical Actors. How they do this, according to what beliefs, aims and objectives, is an empirical question which Chapter Seven will explore.

\subsection{Historic statistical indicators of well-being in the UK and internationally}

With the taxonomy above in place, it is possible to characterise a great many historical statistical programmes under the heading of well-being. Indeed, extending HM Treasury's (2008) claim above that governments have traditionally considered wellbeing when formulating policy, it would be possible to cast every official indicator as a 
measure of well-being of the observed list type. In as far as official statistics monitor things which are to be promoted or suppressed, or are designed to allow action to that effect, they can be read as attempts to improve well-being. Such an expansive reading would be unhelpful, as it would obscure the differences between existing statistical indicators and current and historical attempts at creating 'well-being' programmes. These differences are of intent; indicators are designed to observe particular things. Taking the example of national income, the GDP figures which the 'Measuring National Well-being' programme is to complement, their creator Kuznets said that national income "gauges the net positive contribution to consumers' satisfaction in the form of commodities and services; the burden of work and discomfort are ignored. ...Though unable to measure them, we must recognize that their omission renders national income merely one element in the evaluation of the net welfare assignable to the nation's economic activity." (1946, pp.127-8). National income is believed to be a contributor to welfare, so is tracked; but it is tracked as national income, not as well-being.

However, with this distinction in mind, it is possible to draw strong parallels between historical statistical efforts and present self-described 'well-being indicators'. One framework which draws such parallels is that of Bache, who distinguishes two 'waves' of well-being research (Allin 2013; Allin and Hand 2014; Bache 2013; Bache and Reardon 2013). The first wave is built around the social indicators movement of the $1960 \mathrm{~s}$, the second describes the present international attention to well-being. While this framework does pick out two clear periods of international interaction and co-operation on statistical programmes which go beyond the immediate needs of social administration and seek instead to assess the conditions in which individuals are living, it doesn't recognise more broadly conceived programmes created between these periods. This creates the danger of an artificial periodisation, with the second wave becoming little more than an updated version of the first, rather than being a distinct movement which draws extensively on national and international efforts immediately prior to it. Such an approach would not fit with the conception of official statistics as created by agents acting in context.

With that in mind, rather than attempting a chronology with implied or expressed periodisation, this section will attempt to categorise statistical movements by concern: social description, correction to GDP, extension of GDP, and holistic 'well-being' programmes. This relates more clearly the aims and objectives of statistical creators to statistical outcomes, rather than collapsing disparate actors into flat time periods. In this manner, it is in keeping both with the methodology of Chapter Three, and with the discussion of theoretical context above.

\subsubsection{Early frameworks for social description}

It was shown in the previous chapter how official statistics in the UK adapted first to the needs of the Second World War, and then to increased social responsibilities of government arising from the creation of the Welfare State and an interventionist economic policy (see Section 4.1.). While this led to an increased focus on social indicators, the concerns of emergent statistics were primarily administrative and sharply focused. While it is possible to see increased statistical output in terms of observed lists 
approaches as components of well-being, this would be misleading; there was no holistic aim or construct that indicators such as 'unemployment rate' were serving, such indicators were designed to serve specific administrative objectives.

Broader conceptions of 'society' and 'progress' start to develop within the statistical policy discourse in the 1960s in America, against a backdrop of social unrest and fears of social decline. Robert Kennedy delivers a hustings speech suggesting the limitations of $\mathrm{GNP}^{11}$ against a backdrop of civil unrest arising from the Vietnam conflict and the Civil Rights Movement; he explicitly lists as among the things counted by GNP which do not contribute to well-being the napalm being dropped on Vietnam and the policing of inner city riots (Kennedy 1968). This speech built on the 'Great Society' speech of Lyndon B. Johnson a few years earlier, which highlighted growing anomie and social inequality in the aftermath of the post-War boom (Johnson 1964). The background to this move to broaden indicators away from GDP shares features with the modern setting for Cameron's (2010) launch of the ONS' programme and his party's earlier work on well-being (Quality of Life Group 2007). These came at a similar period of social disquiet, prompted by a collapse of the financial system with attendant declines in living standards, a scandal involving rampant expenses fraud by politicians and a decade-long involvement in unpopular military actions overseas; Cameron quoted Kennedy's speech in launching the ONS programme (Cameron 2010, np.).

Although it would be easy to see the 1960s development of the 'Social Indicators' movement as a reaction to this growing sense of a gap between social well-being and measures of wealth, it is hard to draw any concrete relation between the two. The first development in the movement was an effort at outlining an 'accounting system for society' by administrators of NASA (Bauer 1966b), an explicitly technical solution to the technical problem of trying to assess what impact NASA's work was having on society $^{12}$. Bauer reasoned that to understand the impact on society, you needed both a baseline of where society is and a conceptual apparatus that allowed you to track how it changed and which enabled you to ascribe the sources of that change. The proposed framework for doing this is explicitly systemic: social elements and activities are to be categorised and treated as stocks and flows passing through the system, agglomerating into units of varying scale (household, family, company, city, and so on). Such a system would allow the design and assessment of government policy to influence, and potentially rationally plan, the direction of the system in the same way that monetary and fiscal policy could for the economy (Gross 1966; Innes 1989; Schneider 1976).

This first attempt at a system of social indicators cannot easily be described as directed at well-being. However, as it was targeted at understanding society as a whole, the

11 The distinction between GNP and GDP is minor - the first looks at all production by citizens of a nation regarless of their location, the second all production by citizens and non-citizens within national borders. Up until the late 1970s, GNP was the preferred measure for governments and international comparisons, more recently GDP has been used. As they are structurally near-identical figures used for almost the same purposes, they will be treated as interchangeable in the present analysis.

12 As an indicator of the potential scope of this impact, which the statistical programme would ideally observe, Bauer observed that a potential knock-on effect of the space programme was in changing "how we feel about God" and that such changes would need to be measured by any comprehensive social indicator programme (Bauer 1966a, p.3). 
movement was taken up by a disparate group of social researchers explicitly relating social outcomes to political and economic activity, with a view to modifying the latter to improve the former (Smith 1981). In the UK, the General Social Survey was launched in 1971 (Office for National Statistics 2011), allowing the interaction between social factors such as socio-economic group and health status to be drawn clearly and in realtime. A year earlier, Social Trends was launched, collecting together social data collected across government in one annual publication and collecting additional information to fill in perceived gaps. The Head of the Central Statistical Office, in launching Social Trends noted that limitations on this programme - while stating that the CSO were working towards a system of integrated social statistics, he also noted that it was not clear what aspects of society should be measured, or how. However:

"Be that as it may, one can readily agree that the things in life about which people are most concerned include having enough to eat, being healthy and living out a natural span of life, being housed in a congenial environment, carrying out some form of satisfying activity at work and in leisure hours, having sufficient education to be able to make the most of their abilities, having security against war and crime, being assured of personal liberty and justice, and so forth. The sum total of these things adds up to the quality of life but the particular value, or weight, put on each of the components varies from person to person. Even on the assumption that it is possible to agree on an overall measure of health, housing, etc., the various indicators cannot satisfactorily be combined into a single index as there is no objectively agreed weighting system, such as the price system employed in the National Accounts, which would assess the value of improved health against improved housing." (Moser 1970, pp.10-11)

Moser here suggests that the approach used to understand society should be the objective list. He observes though that there is no a priori way of arriving at such a list, or combining its measures into a single index; these are subjective questions. These questions foreshadow those of modern well-being programmes: as was shown above, what constitutes well-being, and what should be prioritised, remains a live question for the Statistical Actors of the Office for National Statistics in $2010 .{ }^{13}$

Internationally, the UN developed a programme of statistics, aimed at creating a coherent system of national social accounts (United Nations Department of Social and Economics Affairs Statistical Office 1975), as did the OECD, who actually labelled their programme as concerned with 'well-being' (see Organisation for Economic CoOperation and Development 1973). Similar programmes were instituted across the world, including the first publication of the 'Gross National Happiness' index of Bhutan in 1972 (Ura, Alkire, Zangmo, et al. 2012). However, the systematic framework of social stocks and flows imagined by Gross (1966), does not ever materialise (see Smith 1981 and Innes 1989 for further comments on the limitations of the movement). The disparate collection of measures, which in the UK are largely collected by decentralised departments for discrete policy aims despite their collection in Social Trends, never

13 It is worth observing that similar questions were raised around Utilitarian philosophies and ideas of 'the good', Spencer 1970. 
inform a holistic programme of government. The programmes established in the 1970s are subject to severe retrenchment in the 1980s, with Social Trends becoming shorter and more expensive for users as the decade wore on (Levitas 1996b).

However, the movement led to the creation of many social statistics which still exist, as does the sense that social well-being is something which can be measured beyond the merely pragmatic aims of administrators in pursuit of discrete policy aims (Innes 1989). New social indicators and programmes of measures are developed much later than Bache's (2013) 'two wave' model would suggest: the OECD first publishes Society at a Glance, a publication analogous to Social Trends, in 2000 (see Organisation for Economic Co-Operation and Development 2014). There are also ongoing extensions to the areas that social indicators survey: the European Community releases its 'Laeken Indicators' looking at poverty and social exclusion in 2001 (European Economic and Social Committee 2012), and this builds on conceptual developments which lead to the UK creating both statistics and a government agency around 'social exclusion' in 1997 (see Office of the Deputy Prime Minister 2004). While these do not represent holistic programmes trying to conceptualise society in the manner of the Social Indicators movement they do represent a continuing development in non-economic markers of social progress.

\subsubsection{Attempts to modify GNP and GDP}

An alternative approach to the problems with GNP raised by Kennedy (1968) and others was attempts to modify GDP. Kuznets, as the key figure in the development of GNP in America during the Second World War (see Kuznets 1938) was always clear that it was a limited statistic for a limited purpose (see Kuznets 1946, quoted above). That purpose was as a measure of economic activity, not as a measure of economic or broader welfare; it offers no judgement on what the activity is. In as far as this leads to the counting of illth (Ruskin 2001), such counting is a design feature and not a flaw. It does, however, become a flaw when the statistic is used in a manner for which it was not designed; economic output and economic welfare are distinct concepts, one quantitative and one qualitative. This led to a number of attempts to adjust the calculation of GNP to incorporate qualitative judgements and so provide a indication of 'success' or 'progress'.

The first of these is Nordhaus and Tobin's (1973) 'Measure of Economic Wellbeing' (MEW). This utilised the base data used to calculate US GNP but recategorised certain items: defence expenditure, for example, became an intermediate good rather than an output, on the basis that it is a necessary feature of produced goods and services which is funded by taxation, so should be included in the price of those goods and services. Counting it separately in addition to produced output is, on this argument, a doublecounting which artificially raises GNP. After a number of such adjustments, they showed that their MEW was normally lower than GNP, but strongly correlated with it. This allowed them to conclude that GNP was thus actually quite a good measure of progress, if not absolute levels of success. The finding, however, is unsurprising, as the MEW made relatively small adjustments to GNP and was based solely on data from the National Accounts making it likely to correlate with it (Daley and Cobb 1994). 
The modest extent of these adjustments was criticised by later authors who sought to include different or more extensive sets of 'illth' or negative externalities. Subsequent efforts include Zoltas' (1981) 'Economic Aspect of Welfare' index, Cobb and Daly's (1989) 'Index of Sustainable Economic Wellbeing' (ISEW) and Cobb, Halstead and Rowe's (1994) 'Genuine Progress Indicator' (see European Economic and Social Committee 2012 for a time-line of these well-being measures, and Daley and Cobb 1994; and Fioramonti 2013 for discussion). These indices are arbitrary in their composition: all their adjustments could be justified given their disparate aims, just as the calculations of GDP could be, but there is no internal logic to a concept like 'GDP' or 'Sustainable Economic Wellbeing' to determine what should be included and how it should be characterised. In addition to the value-based criteria of inclusion, inclusions and adjustments shift over time and space as new data and analysis methods become available. These two factors can be seen in the shifts in the inclusion of externalities over time. For example, Nordhaus and Tobin (1973) count defence expenditure as an intermediate good and pollution as a negative externality but felt that technology would overcome the problems of resource depletion; Daly and Cobb (1994) reject this second argument, and are able to add resource depletion as an externality, partly because they are interested in sustainability, and partly because it is possible to calculate resource depletion in ways not available to Nordhaus and Tobin.

\subsubsection{Attempts to extend or replace GDP}

It should be noted that the above adjustments to GDP can never advance beyond economic concerns. Ultimately, the data they are based on are economic inputs and outputs expressed in markets (or, as in the case of Daley and Cobb's 1994 inclusion of production in the domestic sector, outside of markets but with imputed values). GDP can take account of other concerns, environmental, sustainability or social, only through pricing these as externalities or stock depletions. This is both difficult to perform and often runs counter to the aims of authors: if Kennedy's (1968) admonitions that there is more to life than GNP are read to mean 'there is more to life than the economic', trying to price the smiles of children for inclusion in a "GNP-plus" measure is a grossly inappropriate response (in this light, see Franklin and Tabb's 1974 critique of GNPadjustments; the problem, they argue, is not what is included in neoclassical calculations, but neoclassical calculations themselves; c.f., Gibson-Graham 1996; Illich 1978; Lefebvre 1976)

Thus a number of authors and organisations have sought to re-contextualise GDP as a single item in a multi-item index or composite indicator, either denying GDP as a central aim or placing it in a broader context of alternative social goals. In the former category are Morris' (1979) 'Physical Quality of Life' Index and Miringoff and Miringoff's (1986) 'Index of Social Health' (for these, see European Economic and Social Committee 2012), and, it could be argued, the various UK Indices of Multiple Deprivation (see Payne and Abel 2012). These are limited statistical efforts designed to highlight particular aspects of well-being, and not attempts at holistic conceptions. Objective list approaches such as the UN's 'Millennium Development Goals' (United Nations General Assembly 2000) or Sen's Capability Approach (Sen 1985) could also 
be included.

In the latter category are several efforts by the UN and its agencies - the UN Development Programme's Human Development Index and Gender Related Development Index (see United Nations Development Programme 2014), and the UN 'Sustainable Development Indicators' (see United Nations 2001). Also notable is the New Economic Foundation's 'Happy Planet Index' discussed above (see New Economics Foundation 2012), another model created by the New Economics Foundation for domestic use (New Economics Foundation 2011a; this model also informed Foresight Mental Capital and Wellbeing Project 2008), the World Wildlife Fund's 'Living Planet Index' (see WWF 2012) and the Economist's 'Economist Intelligence Unit Quality of Life Index' (Economist Intelligence Unit 2005). These approaches tend to take a small number of indicators in addition to GDP (often at least literacy rates and life expectancy) and combine them to produce a single indicator. This approach is partly dictated by the purpose of the research efforts: the UN and, to a lesser extent, the New Economics Foundation indices are interested in the standards of welfare in less economically developed countries. The data which is available for such countries is limited, restricting the possibilities open to organisations seeking to produce consistent and comparable measures. At the same time the aims of these indices and measures, which include consciousness-raising and, in the case of the UN, to aid in the targeting of resources are aided by small, easy-to-interpret programmes.

In comparing the attempts to modify GNP and those to provide alternatives, one thing is immediately apparent. Adjusting GNP is largely an unofficial, academic exercise (although both the MEW and ISEW were later taken up by national governments), while alternative indicators often bear the stamp of international cross-governmental organisations. One reason for this may be the existence of a tight international framework which governs the production of GNP; the UN administer the System of National Accounts (see United Nations, Organisation for Economic Co-Operation and Development, International Monetary Fund and European Union 1993), the OECD act as intermediaries disseminating interpretation and best practice at the level of the major economies, and the European Union do the same at the European level. It would be very difficult to shift the focus of GDP at an international level, and countries unilaterally attempting to do so would lose the ability to judge their national conditions in a wider international context.

\subsubsection{Recent attempts at holistic measures of well-being}

One of the features of the various statistical programmes above is their relatively small centre of focus. The Social Indicators movement of the late 1960s and 1970s was predominantly about national measures of social phenomena. Measures attempting to adjust or build on GDP move through phases, incorporating first social, then environmental, then sustainability concerns. While in the academic context, we can often see all three (Daley and Cobb's 1994 ISEW is one such example), at the level of NGOs and cross-governmental organisations the focus has been on composite measures of a small number of indicators (such as the UN Human Development Index), or indicator sets with specific aims and targets (such as the UN Millennium Development 
Goals or the disparate social indicators collected in Social Trends).

If the claims of a 'second wave' by Bache (2013) and Bache and Reardon (2013) are pointing at something distinct from this continual and on-going work on aspects of wellbeing, they are pointing at measures which explicitly set out be holistic programmes looking at 'well-being' in a broad sense that includes individual and social welfare, environmental concerns and, increasingly, the interests of future generations. The first of these in an OECD nation (remembering that Bhutan had published its 'Gross National Happiness' indicator set for the first time in 1972), was Australia's 'Measures of Australia's Progress' in 2004 (see Australian Bureau of Statistics 2012). This indicator set includes measures of sustainability, economic welfare and social cohesion (although the last of these only exists in place-holder form, no satisfactory measure having yet been developed), bringing together the multiple concerns of earlier disparate programmes to compile a set which characterises 'progress'.

The agenda for such holistic measures is largely set internationally, making approaches to well-being measurement less pluralistic than the domestic developments of the Social Indicators movement. The OECD held their second world forum on 'Measuring and fostering the progress of societies' in Istanbul in June 2007. The communiqué which this meeting produced, 'The Istanbul Declaration' (Organisation for Economic Co-Operation and Development 2007), signed by representatives of the European Commission, Organisation of the Islamic Conference, UN, UNDP and World Bank, called on domestic statistical offices to develop or further develop their existing societal indicators. In November of the same year, the European Commission and Parliament, the Club of Rome and WWF held a conference titled 'Beyond GDP', calling for social and environmental indicators to complement GDP and inform policy. This was formulated by the Commission as the 'GDP and beyond' communiqué, which instructed Eurostat to start developing such measures (Commission of the European Communities 2009), a programme supported by both the European Parliament (see European Parliament 2011) and the European Economic and Social Committee (European Economic and Social Committee 2012; Radermacher, Mercy, Leytheinne, et al. 2010). The G20 Leaders' Summit in Pittsburg (2009) and UN General Assembly (2012) issued similar calls to its members. These efforts have encompassed both the development of frameworks for well-being (see, for instance, figures 5.1.b and 5.1.c above) and bestpractice guidance for measurements of novel components (see, for instance, Organisation for Economic Co-Operation and Development 2013b on the measurement of stated well-being).

A key influence to the later development of statistical programmes was the report of the Commission on the Measurement of Economic Performance and Social Progress (Stiglitz, Sen and Fitoussi 2009, generally referred to as the 'Stiglitz' or 'Stiglitz-SenFitoussi' report, after its lead authors). This commission had been established by the French President in the wake of the most recent financial crash as a GDP-adjustment programme, and its recommendations included a call to develop environmental and social measures to extend GDP. Since its publication, this report has been widely cited to give legitimacy to new statistical programmes (see, for example, Commission of the European Communities 2009; Matheson 2010; Organisation for Economic CoOperation and Development 2013a) and numerous of its members went on to work on 
well-being programmes elsewhere (see, for example, Section 4.2.4.'s discussion of fastpolicy networks). The Commission's emphasis is on GDP extension, and not well-being (Noll 2011). It includes calls to measure subjective evaluations of well-being, but with the goal of contextualising GDP. The majority of the Commission's recommendations relate to extending the production boundary, bringing items such as human knowledge and the natural world within the scope of national accounts.

\subsubsection{Statistical and policy developments in the UK in the lead-up to the 'Measuring National Well-being' programme}

The ONS' 'Measuring National Well-being' programme can be read as a development arising from the international attention given to metrics well-being; it was launched in 2010 (see Section 1.3.), many of its justificatory documents cite the Stiglitz-SenFitoussi report (2009, see, e.g., Matheson 2011; Beaumont 2011), and it comes as Eurostat, who have the power to require national bodies to collect statistics, are developing their own programmes. However, while the ONS' programme is closely linked to international development, its driving force was local. Allin, who was closely involved with the development of the programme, suggests that the initiative lay with the ONS (see Allin 2007, p.46; 2013, pp.8-9), while Matheson (2011), the National Statistician at the time, suggests the programme came at the suggestion of the Prime Minister (p.2). Whichever of these it was, there was clearly a desire to avoid merely following external programmes; Cameron (2010) in launching the programme making it clear that "I would rather we were in the vanguard of doing this rather than meekly following on behind." (np.).

Cameron's concern may be partially around the fear that international developments were taking away some of his thunder; he was talking about 'Gross National Happiness' as an alternative to GDP as early as 2006 (Cameron 2006). On becoming leader of the Conservative Party, he formed the Quality of Life Policy Working Group, whose report A Blueprint for a Green Economy (Quality of Life Group 2007) covered a range of social, economic and sustainability concerns, conceptualised in one chapter under the heading of 'well-being' and called for the use of Daly and Cobb's Index of Sustainable Economic Well-being as an alternative to GDP. By the time of the 2010 election, this was a manifesto commitment to 'develop a measure of well-being that encapsulates the social value of state action' (Conservative Party 2010, p.38), a much more limited commitment but one which is fulfilled a matter of months later in the launching on the ONS programme.

We might find some explanation for this interest in well-being in the ability of wellbeing discourses to provide legitimacy for policy-makers and policies (Scott 2015). On becoming leader of the Conservative Party, Cameron set out to define 'a compassionate conservatism' (Cameron 2005), shifting the Party's image from that which one key figure within the party had identified as being 'the nasty party' (May 2002). This was followed by a financial crash in 2007 and a political expenses scandal in 2009, both of which contributed to a general lack of trust in politicians (see European Commission 2013). This primary need to improve the standing of politicians and of Conservatives specifically was supplemented after the financial crash by the more prosaic fact that 
material conditions had rapidly deteriorated for many as house prices and employment fell.

However, while Cameron and the Conservatives may have taken the lead in prompting a holistic statistical programme described as 'well-being', support for the concept came from across the political spectrum (see the multi-party contributions to New Economics Foundation 2011b). The previous Labour administrations had also developed detailed statistical sets dealing with similar issues in the form of the Department for the Environment's 'Sustainable Development Indicators' (see National Statistics and Department for Environment, Food and Rural Affairs 2004a, b). While their name suggests a focus on environmental policy and sustainability, the indicators come out of the White Paper A Better Quality of Life (Department for Environment, Transport and the Regions 1999), which ties concerns around sustainability with issues of intergenerational fairness. Both this and the subsequent policy update 'Securing the Future' (HM Government 2005) call for the development of a 'tool kit' of indicators to monitor and guide government action. The measures which are produced (National Statistics and Department for Environment, Food and Rural Affairs 2004a, b), are very detailed: the set has 154 indicators with 18 'headline' indicators, covering issues ranging from fuel poverty to mortality rates from circulatory diseases in the under $75 \mathrm{~s}$. This is predominantly an observed list approach which combines presence data (e.g., 'levels of crime') and absence data ('fuel poverty'), absolute levels ('new business start-ups net of closures') and distributions ('regional variations in GDP'), stocks ('qualifications at age $19 ')$ and flows ('education participation rate'); and which includes a small number of stated measures such as fear of crime. Measures are both inward and outward looking (in addition to statistics about the UK, there are figures of the state of the world's fisheries and global population), present- and future-focussed.

Such a diverse set of statistics doesn't allow the co-ordination of government action towards a single aim, but instead collates measures already collected to target multiple policy areas. This is not dissimilar to Social Trends, but adds to that publication a sense of purpose: statistics are gathered together not based on their domain of reference, but because they relate to a particular purpose ('sustainable development'). The measures were presented in historical context, with indications as to whether they had improved or deteriorated over time, closely tying them to ideas of government action and intervention. As a programme, it is hard to interpret; as some measures rise, others fall or stay stable, so it is difficult or impossible to say that 'sustainability' is being attained or even moved towards. This is further complicated by the contested nature of 'sustainability' itself. The question of how to interpret the programme is a problem that will be common to all multi-measure sets. The programme also lacked any consideration of stated evaluation, hedonic or eudaimonic issues, being focussed instead on social, economic and environmental conditions, not what individuals felt about them.

\subsection{Summary: Pre-existing statistical programmes as guides for the 'Measuring National Well-being' programme}

Although the 'Measuring National Well-being' programme is a novel development in British statistics, the preceding sections have shown that it is not unprecedented. It has 
parallels in the expansion of social statistics in the 1960s and early 1970s which were part of a larger theoretical project to establish systems of social indicators. While such systems never materialised, they increased the range of social statistics produced by official bodies and, in the UK, led to the creation of Social Trends, the previous repository of British social statistics. The retrenchment seen in UK official statistics in the 1980s did not lead to an abandonment in the development of social indicators. In academic circles, there were continued efforts to reform GNP and GDP calculations, taking account of issues such as negative externalities, distribution and sustainability. In campaigning circles, there was increased attention to indicators of health and environmental stress as counterpoints to well-being. These alternative conceptions of 'progress' or 'success' are available to the Statistical Actors of the ONS in 2010 when set the challenge of measuring well-being.

This challenge arises in a specific political context; it is championed in the wake of social disquiet about both the financial and political systems. It also occurs at multiple political scales, as European and international bodies pursue policies of well-being monitoring and promotion separately from direct domestic policy concerns. This potentially establishes divergent pressures or policy commitments which the ONS, as a domestic body within an international statistical framework, will need to respond to.

As with the theoretical debates over 'well-being', it can be seen that the Statistical Actors of the Office for National Statistics have neither a blank sheet of paper nor an obvious 'correct' answer to the question of well-being measurement in 2010. Instead, there are diverse precedents, influences and demands which will need to be responded to. Such responses will be made by the Statistical Actor, agents operating within the institutional frameworks discussed in the previous chapter. This, again, confirms the suitability of 'Measuring National Well-being' as a case study of a social process; there are clearly contextual issues which agents will need to navigate together.

\subsection{Conclusion: the contexts of official statistic-making must be navigated}

The present and the preceding chapter have outlined the institutional and theoretical context in which the ONS 'Measuring National Well-being' programme sits. They have shown some of the complexities of these contexts. They suggest that, contrary to the literatures explored in Chapter Two, there is no straightforward relationship between the intention behind the official statistic and the outcome of the statistic. The putative desire to construct a technology of control, or to objectively count aspects of the external world to inform policy, occurs within a setting of multiple and competing concerns and pressures. In as far as they are desired, they must be expressed under conditions of resource constraint, competing institutional and theoretical influences, competing and sometimes conflicting aims and objectives. The form and the content of the official statistic which is made are not independent of these conditions, but will be shaped by them and by the responses to them of Statistical Actors. The extent to which these Actors are conscious of the conditions, how they conceive of them and what they do in response to them, are empirical questions. It is to those questions that the following chapters turn. Chapter Six will focus on the ways in which institutional structures examined in the previous chapter were responded to by Statistical Actors. Chapter 
Seven will explore responses to the theoretical context. It should be noted that this is a slightly artificial distinction, and that in practice these contexts will bleed into each other. Their distinction here and in the following chapters is followed as an organisational device for the purpose of clarity, rather than a claim of actual divisions and boundaries in the external world. 


\section{Chapter Six}

\section{Questions of practicality: how the institutional context of UK statistic- and policy-making shaped the 'Measuring National Well- being' programme}

Following the methodology set out in Chapter Three, the preceding two chapters looked, respectively, at the institutional and theoretical context in which the Office for National Statistics stood in 2010 when the 'Measuring National Well-being' programme was launched. This chapter, and the chapter which follows, builds on this by examining the ways in which Statistical Actors responded to this context. These chapters ask the question, 'How did Statistical Actors create the "Measuring National Well-being" programme?'. They do so through an examination of interviews with Statistical Actors, both those formally part of the Office for National Statistics and those who served on the programme's two advisory panels. These are supplemented with the minutes of these panels, and of the one meeting of the General Statistical Services' Methodological Advice Committee which discussed the programme. (An overview of the various panels and consultations are given as figure 3.1., a list of documents consulted is given as table 3.2..) Following the protocol set out in Chapter Three, interview participants have been anonymised and their responses as given in interviews appear in single quotation marks to indicate that they are not verbatim quotes, but reconstructions of conversations, approved by the participants. (A list of interviews is given as table 3.1..)

These two empirical chapters loosely follow the division established by Chapters Four and Five between institutional contexts for the statistical programme and theoretical ones. As discussed previously (see Section 5.7.), this is an artificial distinction; as will be seen in what follows, there is a great deal of interaction between institutional and theoretical factors. However, making this distinction helps bring to the surface a tension which runs throughout the work of Statistical Actors: they are seeking a statistic which is theoretically coherent but which also meets the practical aims of the programme's commissioners and users. There is a continual balancing of these practical and theoretical requirements, which runs through both the inclusion of advisers as Statistical Actors, and the debates that these have. This balancing will be a running theme in what follows, which focuses on the way that institutional structures shaped the 'Measuring National Well-being' programme.

The chapter will proceed as follows: Section 6.1. will outline the impetus behind the programme, arguing that it owed more to international networks of Statistical Actors than it did to domestic policy-making concerns. Section 6.2. builds on this by showing the difficult balancing act Statistical Actors at the ONS had in co-ordinating the specific desires of policy-actors with the very general aims of the programme and the specific goals of international actors. It will be argued that this resulted in a programme which pleased relatively few policy actors. Section 6.3. will note the challenges of budget and the ways in which these impacted on the programme, suggesting that they acted to restrict the possibilities of the programme by limiting what questions could be asked. Section 6.4. will note the difficulties the Statistical Actors had in conveying the programme, and the effects this had on design, arguing that scepticism and misunderstanding on the part of the media led to features which were accessible rather than theoretically pure. The chapter will end with Section 6.5., which summarises the 
interactions of the Statistical Actors with each other and with their context.

To aid in the understanding of the specific issues which Statistical Actors were debating, the 41 measures of the programme are listed as Appendix C, with outputs from 2014/15 given in various forms in Appendix D.

\subsection{Origins: 'well-being' as a domestic solution to an international question}

'I suppose there were two key things which happened. 2009 was probably the starting point, when the Stiglitz-Sen-Fitoussi Commission, the Commission on Measuring Economic and Social Performance, reported to the then President Sarkozy [of France]. They argued that GDP was inadequate as a measure of social performance, that you needed to take in wider measures encompassing society and the environment as well as the economy. That had world-wide impact, and in the UK was influential on David Cameron. In 2010, as Prime Minister, he asked the National Statistician to take forward work on providing measures of well-being. This meant taking practical steps to ensure the government was focused on quality of life, not just on growth. Jil Matheson [the National Statistician] acted on this to establish the Measuring National Well-being programme.' (William, senior figure in MNW programme, ONS)

'Our efforts ramped up with the Stiglitz-Sen-Fitoussi [CMEPSP] report. That was formally set up by President Sarkozy to report to him, but had the backing of the OECD and Eurostat, and had a view to producing recommendations with international resonance. The UK had an interest in that - three UK academics sat on the Commission, so we couldn't ignore it. It was also supported administratively by the ONS' French counterparts, INSEE, so we were getting messages through the standard channels and had to pay attention. It was very helpful for the ONS' efforts to have the CMEPSP report.' (Oscar, senior figure in MNW programme, ONS)

It was noted in Section 5.4.4., which addressed international programmes and calls for programmes which looked at well-being, that the Stiglitz-Sen-Fitoussi Commission (also known by its formal title, the Commission on the Measurement of Economic Performance and Social Progress; Stiglitz, Sen and Fitoussi, 2009) was used as a touchstone to justify the academic and policy worth of well-being measurement projects. It is apparent both from interviews and meeting minutes that this is not merely a rhetorical device, but that the Commission genuinely set an agenda. The two interview excerpts above are typical; when asked where their involvement with the MNW programme started, institutional actors both within government (such as Alfie and Emily) and the ONS itself (Oscar and William, quoted above) cited the Commission as a starting point. Oscar, a key figure in the development of the programme at the ONS, suggested that the Commission's framework was the one limitation on the programme, laying out the requirements that the programme needed to meet. 
This grounding of the programme in the Stiglitz-Sen-Fitoussi report is notable because that Commission's remit was as a GDP-extension programme, as discussed in Section 5.4.4.. While the Commission's report draws on the wider literature around social and environmental gaps created by the use of economic statistics as a primary policy-driver (and thus owes much to the debates explored in Section 5.4.3.), its focus is on bringing these currently non-economic areas within the scope of the 'economic', extending GDP to include them. The effects of this can be clearly seen in the presentation which Stephen Hicks of the ONS makes to the General Statistical Services' Methodological Advisory Committee (GSS MAC) on the intellectual framework which the ONS is developing. That presentation lists the priorities for the programme, which include both "valuing the activities outside of the production boundary", such as household production, and "recognis[ing] the Stiglitz-Sen-Fitoussi conclusion that it is important for Statistical Offices to look at the value of the stock of all types of capital that have a bearing on the quality of life, including produced, human, natural and social capital" (GSS MAC Minutes, 19 June 2013, p.29; Stiglitz, Sen and Fitoussi 2009, are specifically interested in the use of stocks in understanding sustainability, see their Recommendation 11, p.17). This approach brings the ONS into direct conflict with the public: the Technical Advisory Group minutes of 29 March 2012 (p.3) record an extensive debate over the appropriateness of stock measures within the programme, a point which runs through the National Debate (Evans 2011). The influence of the Commission's report as an external exemplar pushes the programme in particular directions.

This international influence occurs within a domestic context. As was shown in Section 5.4.5., domestic politicians in the UK had previously drawn on and developed wellbeing discourses (for instance in the Labour Government's 'Sustainable Development Indices', Department for Environment, Food and Rural Affairs, 2013 and National Statistics and Department for Environment, Food and Rural Affairs, 2004a; and in the Conservative Party's 'Quality of Life Group, 2007). Oscar, a senior figure within the programme from the ONS, claimed a similar national statistical interest, pointing out that the ONS directorate for social statistics had changed its title to 'Societal Well-being' at some point in the mid-2000s and that the Commission is merely giving impetus to work the ONS already has in train. As President Sarkozy's sponsorship of the Commission strengthens the political case for well-being (as indicated by its citation in Cameron 2010, np.), the involvement of INSEE, the French official statistical agency, as the Commission's secretariat creates a similar statistical impetus. As Oscar put this, 'Developing a programme as a response to CMEPSP would allow us [the ONS] to look Eurostat in the eye, showing that we were taking the report seriously'.

In light of the material reviewed in Section 4.2.4., Oscar's comment can be seen as pointing to the existence of a fast-policy network, characterised by policy-advocates and -actors moving between different international instantiations of the same policy idea. Three UK-based economists (Atkinson, Oswald, Stern) sit on the Stiglitz-Sen-Fitoussi Commission, and all three come to advise the ONS through the Advisory Forum. More than this, two of the Commission's lead authors, Sen and Stiglitz, also sit on the Advisory Forum. Giovannini, at the time head of the Italian official statistical agency, who Bache (2013) lists as being a key figure in advocating for well-being statistics in 
Europe, also sits on this panel; as does Cotis of INSEE and Radermacher and Durand, who head up similar projects at Eurostat and the OECD respectively (Advisory Forum Membership List). The UK programme, however strong its national roots, draws heavily on similar projects elsewhere, with key figures moving between projects, carrying ideas in both directions.

It should be noted here that Oscar's 'looking Eurostat in the eye' is a national statistical office concern, and not a government one. Hicks, in his GSS MAC presentation discussed above, claims the presence of "The demand for wider measures of quality of life and progress" (GSS MAC Minutes, 19 June 2013, p.28), a high-level and abstract demand which is, at best, only very abstractly expressed in the development of measures of the "stock of all types of capital" (p.29). The decentralisation of official statistics into a separate, arms-length, department of government (as discussed in Section 4.1.2.), strengthened by the Statistics and Registration Services Act 2007, creates a distinct identity and context for the ONS' work. This creates a divergence between the political narrative of well-being, and the statistical project: the Statistical Actors of the ONS seek to create a statistic which meets international standards of coherence and coverage, with domestic needs as a separate concern. This results in a programme containing elements of both national and international concern: well-being is articulated in ways which express international theoretical concerns (such as those for stock measures) as well as ways which draw more strongly on issues coming from local policy need and views presented in the National Debate.

This can be seen clearly in the minutes of the first meeting of the Advisory Forum, in which Cotis and Radermacher give a presentation on international work on well-being (AF Minutes, 11 February 2011, pp.1-2). This presentation is interesting, because the Forum is explicitly set up to advise the National Statistician on how to translate the national debate 'What matters to you?' into a well-being programme ("The Forum's role will be to discuss the main themes emerging from the national debate and help design new measures."; Advisory Forum Terms of Reference, p.1). There is an explicit contextualisation here of national grass-roots opinions within the work of international statistical organisations; it is the international which forms the framework for the interpretation of the domestic and not the other way around. Radermacher goes further than this, highlighting the possibility of the UK becoming a nodal point within a larger network of well-being statistical programmes: "The UK could play a key role in helping Europe and the Commonwealth countries and the US to work together in developing standardised measures of well-being." (p.2).

This international outlook is thorough-going: it appears that the ONS themselves would have liked more international guidance. In interviews with Oscar and William of the ONS, at several points they referred to the difficulty of being first-movers in the international field. As William put it, 'It's exciting, but also a little scary. It is easier to follow the rulebook than to write it.'. Stephen Hicks, at the GSS MAC meeting of 19 June 2013 (reported in GSS MAC Minutes, 21 November, p.6) states the observation of the National Statistician that, "The OECD has created a better life index and guidance on measuring subjective well-being, Eurostat will publish a quality of life index later this year or early next year and the UN, World Bank, EU and OECD countries are all looking to the UK as world leaders." This was supported by an interview with Jack, a 
statistician from an international NGO who sat on the Technical Advisory Group, who cited the ONS' work as influencing that of his own body. This creates a complex interplay between the domestic concerns of the national debate and the international networks of which the ONS is a part. The Statistical Actors of the ONS need to create a programme which both captures domestic well-being and which forms a part of a wider emergent international statistical conception of what well-being is. At the same time, by being a nodal point within that wider emergent international conception, domestic innovations become influential at a greater scale.

The dual contexts of domestic politics and international statistical networks leads to some dispute over the ownership of the project. Hicks explains the programme's origins to the GSS MAC in this way:

"This came to a head in October 2010, when David Cameron and Jil Matheson attended a policy conference hosted by then head of the civil service, Lord Gus O'Donnell. There was an identified need to measure the impact of policy on well-being." (GSS MAC Minutes, 21 November 2013, p.5)

William, another senior figure at the ONS, offered a similar origin tale in his interview. Oscar, however, who by the time of our interview had left the ONS, was much less willing to credit politicians with any involvement beyond the public launch of the programme. From his account there is an impression of an ONS-directed project which goes through the rigmarole of securing funding in the 2010 Spending Review in an effort to produce a programme meeting international requirements of quality and coherence, only to see it hijacked by the Prime Minister and be labelled ever-after as 'Mr Cameron's Happiness Index':

'I can't say if he [David Cameron] wanted to launch the programme or was invited to, but he formally launched it alongside the National Statistician Jil Matheson. After which point the media always badged it as 'Mr Cameron's Happiness Index', which is wrong on all three counts really - it wasn't his programme, he only launched it; it isn't just about happiness; and it's not an index, you can't put all the components into a single number.' (Oscar, senior figure at the ONS)

The neutrality of civil servants makes this account impossible to substantiate (neither Stephen Hicks nor William would be able to criticise Prime-Ministerial bandwagonjumping if it were the case), but the fact that Oscar offered such an account underscores the tension between the political and statistical. Statistical Actors are creating official statistics as professionals, but their work is used within a political context; this can lead both to a sense of appropriation of their work for political purposes and, as in Oscar's quote, a sense that their work is being misused or misunderstood.

This tension between professional and political leaves the Statistical Actors of the ONS with something of a balancing act. There are national requirements established by the Prime Ministerial launch and central government funding, but these are incredibly vague and aspirational. The desire for 'measures of how the country is doing' (Cameron 
2010, np.) are not, as will be shown in Section 6.2. below, supported by precise policy needs. Against this, there is international network of policy-advocates and actors, and the potential for future international policy requirements. This balance can be seen in play by noting the TAG minutes of 11 April 2011, with the AF minutes of 25 July 2011:

"ONS also have to consider future international compliance with Eurostat, OECD etc.” (TAG Minutes, 11 April 2011)

"The group discussed further the balance between national and international requirements. The view was that a flexible approach was needed which allowed for national differences (there may be some key indicators which are country-specific) whilst retaining a common set for comparability internationally. A research programme should be in place to converge measures internationally over time." (AF minutes, 25 July 2011)

These extracts possibly allow an understanding of the GDP-extension focus outlined by Hicks above: if there is a movement in the European context towards, for instance, measures of Human Capital, the ONS needs to be prepared for that. The ONS can present it alongside measures highlighted by the public in the national debate, or those specifically required by government stakeholders, meeting current and future requirements for international compliance within a currently-funded programme. Where the national aims of the programme remain abstract, the concrete needs of international bodies allow the programme to be given definite form.

The desire for international compatibility discussed in the quotes above does not come only from the ONS, but also from Statistical Actors from academic communities who sat on the Advisory Panel and Technical Advisory Group. However, the academic interest in comparability is justified by appeal to an international knowledge-community rather than an international statistical one. For instance, the TAG meeting of 4 February 2011 concludes by discussing the wording of the four proposed subjective well-being questions:

"The meeting ended on a discussion of the international consensus and how the work of the ONS will fit into this. The group opinion reflected the view that by moving from established questions there is a risk of not leading the international agenda and being open to criticism. ... Dr Eric Harrison (City) - Life experience questions have been on European Social Survey core since the start. Why are government doing this when it is already done in academia, polling organisations?” (TAG Minutes, 4 February 2011, p.3)

This point is later reiterated by Michelson (of the New Economics Foundation) and Kroll and Layard (of the LSE) (p.4). For the academics, there seems to be a perception that the Government, through the ONS, are repeating work previously well-studied by academia, and not building on academic findings. This is illustrated by an extract from the interview with Thomas, an academic sociologist: 'They decided on different wording. It was slightly frustrating, but the inclination with any new project is to start from scratch, rather than to see what has already been done.' 
As will be seen in the next chapter, the claim to 'starting from scratch' is somewhat overstated; the point in dispute here is the precise wording of four questions selected, in part, for their comparability with existing measures (Dolan, Layard and Metcalfe 2011). This highlights a tension between Statistical Actors, who come from diverse backgrounds and read questions of well-being differently.

There are thus three different competing sets of aims and beliefs around the statistic: policy-makers are looking for a high-level discursive 'measure of how the UK is doing', the ONS are looking for a coherent programme which both stands up in an international (and particularly European) context and which insures against future legislative requirements, and academics are looking for varying degrees of theoretical purity. The picture which emerges from this is one of complex intersecting aims within the programme. The sources of this were highlighted in the previous two chapters, and the current section has shown how they played out. The ONS as an institution is beholden to UK policy-makers, but fits within a wider international framework of both requirements and expertise. It is reacting to an issue with both domestic and international roots. For this programme, it incorporates as Statistical Actors academics who are integrated in international networks to various extents; networks both related to the specific statistical question of well-being (as in the case of those who've previously sat on agenda-setting bodies such as the Stiglitz-Sen-Fitoussi Commission) and the theoretical questions it incorporates (as in the case of economists such as Layard). This creates competing demands - for solutions which satisfy national domestic requirements such as cost-effectiveness, which meet professional standards both locally and internationally held, which are compatible with other statistics both statistically and theoretically. The 'Measuring National Well-being' programme reflects a multi-level geography of official statistic-making which impacts on the form and content of the official statistic.

\section{2. 'Well-being' as a statistic with users but no use}

'The aim was to produce an accepted and trusted set of National Statistics which help people to monitor national well-being.' (William, senior figure at the ONS)

The previous section has noted the influence of the ONS' international position on the 'Measuring National Well-being' programme. However, this was largely an institutional need - a matter of 'looking Eurostat in the eye' and ensuring future compatibility with legislative requirements - and doesn't reflect the guidance of actual policy need. Going up a level, and examining the work of organisations like the OECD or European bodies who form the international policy context for the programme, their aims are vague and aspirational: "Better policies for better lives" (Organisation for Economic Co-Operation and Development 2014, p.21) or "to provide indicators that do what people really want them to do, namely measure progress in delivering social, economic and environmental goals in a sustainable manner" (Commission of the European Communities 2009, p.11). Domestically, there is a mirror in the programme's stated aim "to develop and publish an accepted and trusted set of National Statistics which help people to understand and monitor national well-being" (Matheson 2011, p.3; faithfully reproduced by William of 
the ONS above), and the political discourse around 'How we are doing' (Cameron 2010, np.).

In the current section, it will be argued that there is a disconnection between the statistical programme and any potential policy applications; that the programme was designed prior to and largely unrelated to any defined policy need. This section will draw heavily both on interviews with ONS personnel and with stakeholders from government departments who were involved in the design of the programme as Statistical Actors. It does not deal with the life of programme once it enters the policymaking world, as this is outside of the control of Statistical Actors. Instead, it recognises the role which potential end-users played in its construction and the way they brought policy needs (or lack of them) into the statistic-making process. That is, it looks at the aims Statistical Actors tried to meet with the programme, rather than how the programme has actually been used

The traditional model of statistic-making is what Oscar, a senior figure at the ONS, described as the 'producer model':

'ONS is a non-ministerial department, but it's part of government, so there are established processes of consultation. A consultation goes out, respondents are given time to reply, the ONS produces something which it thinks will meet the needs revealed. This underplays the process slightly ONS actively encourages responses, for example from user groups, and there are supporting cross-governmental bodies who offer advice as things develop, but at the end, the ONS sees itself as the statistic producer. We know best, and we then check that people are happy.'

That was inappropriate as a way of moving forward on measuring national well-being,

'All the time we were conscious that we didn't know what the requirements of the programme were, how the data would be used, even what 'well-being' was - so we set out to consult. It was so wide and open-ended I don't really want to call it a consultation, What Matters to You? was a national debate. We needed to formulate a programme of work that would be open.'

This openness comes, in part, because well-being is constructed as a corrective to an existing statistic, GDP, and not from any pre-existing conceptual framework. We can see this in the use of the Stiglitz-Sen-Fitoussi report discussed above, and in the discursive framing of policy-makers at the domestic and international levels (Cameron 2010; Commission of the European Communities 2009; United Nations General Assembly 2012; this lack of a framework is also discussed in the previous and the next chapter). The challenge the ONS was given by policy-makers and by its own need to respond to the international context was merely to 'count something different', without any specific instructions as to what that something was.

This created immediate problems for the Statistical Actors of the ONS. As William, a senior figure at the ONS, expressed this: 
'The starting point for every statistical collection is the end use - you start with what it will be used for. That gives you an idea of how accurate the collection needs to be - how often you need to collect it, how detailed. Survey design is almost exclusively about how accurate you need to be - are you going to have to disaggregate it, and by what, so you know how large the sample size needs to be. We had that in mind, but for 'Measuring National Well-being' we also had a funding envelope. So it wasn't a fully blank page, but there was a patch of blue sky.'

More than lacking any definite end-use, the programme also lacks definite end-users. Stephen Hicks in the GSS MAC meeting of 19 June 2013 (p.6) reports the thinking of the National Statistician as being that: "These statistics should be used in policy, but also wider in society by the public.", that is, their target audience is 'everyone'. The resulting remit of the programme is incredibly broad, as illustrated in William's paraphrasing of the aims and scope of the programme given at the start of this section.

The ONS' response to the breadth of this remit was to incorporate as many potential users as possible; the Advisory Forum and Technical Advisory Group contain representatives from Whitehall Departments and the Devolved Administrations, the programme is backed by a consultation process within government which interviewees described as 'unprecedented' (Thomas, an academic, and Emily, from a Whitehall Department), the programme is based on a national debate which received around 34,000 separate responses and involved around 175 public events (interview with William, of the ONS; c.f., Matheson 2011). In lieu of direction, the ONS went for inclusion.

Contributions by Statistical Actors within government will be covered in more detail below (Section 6.3), but here it is worth noting the way that the opinions of the public were, necessarily, filtered through existing conceptual frameworks at the ONS. As Emily, at a Whitehall Department, expressed this: 'their public consultation (they asked people "what matters most to you?") and the range of answers they got is enormous everything from "work is important" to "going to the beach and making sandcastles with my children is important". Some poor soul then has the job of making sense of that.' Describing this sense-making process, William, of the ONS, said:

'It's more of an art than a science. We read through them all and looked for common themes we could fit them under. And there were common themes. In a way they were subjective decisions - do we split the environmental domain into natural and built, or the "What we do" domain into work and leisure to get a sense of the work-life balance, but generally the themes were clear.'

The TAG minutes of 21 June 2012 note the constraints on this 'art' (p.6): "Julie Newton (BRASS) pointed out that there are many different domains that are important for wellbeing for all ages. However, at some point measures have to be cut down so that they can be used by policy makers, as it is not practical to ask survey questions on every single aspect of well-being." Thus 'going to the beach and making sandcastles' is collapsed into a higher level of abstraction, determined by ONS, with the dual aims of 
having something which, though not currently required, might be of use to policymakers and which fits with internationally emerging statistical conceptions. There is also the additional constraint that the 'funding envelope' is not limitless (interview with Oscar, of the ONS, above) .

A further element of this is the scale at which the programme reports. As Oscar, of the ONS, expressed the programme, 'The ultimate point of the ONS programme was not to produce a detailed map of individual well-being'. However, as Charlie, an NGO-head with a policy-making background, pointed out, this almost precludes use at the national level as the national levels of well-being are insensitive and reasonably immobile; they cannot show the impact of policy. The national level is also inappropriate for regional policy-makers; Amelia, an academic in public health, felt that local actors needed a comprehensive picture of well-being in their areas if they were to identify pockets of abnormal well-being. The lack of direction from policy-makers resulted in a programme which was potentially unable to fulfil any need at all.

The lack of connection between the official statistic and any pre-existing policy use challenges the accounts of official statistics presented in Chapter Two. Their strongest challenge is to critical readings of statistics that suggest they are technologies of control: if this is the intention of Commissioning Actors, this is not reflected in the work of the Statistical Actors. Indeed, it is not even clear that there is anyone commissioning the statistic; it is launched by the Prime Minister but is largely left as an ONS project, shaped by their wider professional needs. There is also a challenge to readings of the statistic as reflecting the external world, as the project proceeds without much direction over what in the external world should be counted or why. Instead, the Statistical Actors are presented with a task with almost no limitations, and are left to draw on the views of Statistical Audiences, interpreting and balancing these views as they attempt to compose a programme which is useful, or at least usable, for both Actors and Audience. The specific complexities of this task are explored further in the following sections.

\subsubsection{Geographies of well-being: devolution and its impacts}

As discussed in Sections 4.1.3. and 4.2.2., the devolution process confirms and extends pre-existing limited independence on the part of Scottish, Welsh and Northern Irish (and, to an extent, London) policy-makers and statistical bodies. Formerly they acted as autonomous Whitehall departments, with their own statistical teams; they remain as autonomous bodies with independent statistical teams but now also have the impetus of additional responsibilities and separate governments answerable to separate local electorates with policies separate from those of the UK government. This independence creates areas of potential conflict, where the ONS collect statistics at a UK level for policy-areas now reserved to devolved administrations.

These conflicts surfaced in a number of interviews and official documents. The Membership List for the Advisory Forum, for instance, notes a desire for autonomy on the part of the Scottish administration: 
"Scottish Government officials are working with ONS to co-ordinate, as far as it is practical, the UK-wide Measuring Well-being Programme. The work in Scotland will be co-ordinated through the Measuring National Wellbeing: Cross-UK Steering Group. Scottish Government officials, however, stop short of full membership of the Advisory Forum.” (p.2)

The commitment to work "as far as is practical" is telling; the Scottish have their own established statistical work on well-being through the Scotland Performs framework, which the UK programme cuts across (Scottish Government 2011). As a result, the UK programme is of limited use or interest to the Scottish Administration, and not a productive use of their resources. While they were represented on the Technical Advisory Group, they appear to have had a watching brief, as indicated by the minutes of the meeting of 11 April 2011:

"Will this be an ONS or joint publication with other departments? Given this is a devolved issue; the Scottish Chief Statistician would wish to consult about publication with the National Statistician." (p.3)

Again, independence is asserted: the Scottish representatives see 'well-being' as a devolved issue. This means both that a UK programme runs the risk of commenting on an area it has no remit to comment upon, and that 'well-being' stands as an issue for the Scottish Administration itself to define. Given that their programmatic aims diverge from that of the UK government, their definition is somewhat different; Scotland Performs, for instance, includes the Warwick-Edinburgh Mental Well-being Scale (WEMWBS; see Chapter Five) which the ONS eschewed in favour of their four subjective well-being questions (Scottish Government 2011). Ava, an academic working in public health, characterised this as, 'The Scottish approach is different, they'd started earlier and saw well-being as explicitly multidimensional'.

While the Devolved Administrations are in the position of pursuing local aims and seeking to avoid UK impositions, the Statistical Actors of the ONS are in the reverse position. They are answerable to the UK government, and thus need a programme which covers the Devolved Administrations but which doesn't necessarily meet any or all of their needs. As Oscar, of the ONS, commented on the inclusion of WEMWBS in Scotland, 'If it works for them, then great.' The divergent programmes are almost an advantage to the Statistical Actors of the ONS, resolving disagreement by allowing both sides of the argument representation somewhere. This does, however, act to strengthen the divides between polities created by devolution; there are now distinct electorates using distinct statistical programmes to inform themselves of the performance of distinct governments; and also distinct policy actors using distinct statistics to inform distinct policies.

This is most clearly expressed in the Advisory Forum minutes of 11 February 2011:

"This was followed by a discussion about what was meant by 'national'. Forum members felt it was important to harmonise across the UK where possible. However, potential differences in requirements across the four countries of the UK were noted. The need to have large enough samples to 
provide relevant statistics at small area level (e.g., through sample boosts in sparsely populated areas) was also raised. Jil [Matheson, the National Statistician] confirmed that the subjective well-being questions asked on surveys from April 2011 onwards will cover England, Scotland, and Wales, because that is the coverage of ONS's integrated household survey. The intention is to work with NISRA [Northern Ireland Statistics and Research Agency] and include questions in their Northern Ireland household survey, although this still needs to be confirmed. Some members stressed the need to harmonise across Europe and beyond. This was discussed further in agenda item 3." (p.2)

Alongside the differences in policy requirements, this quote highlights particular technical problems posed by devolution. Samples now need to be representative of multiple polities rather than a single one, meaning that in certain places they need to be larger. Surveys of potential areas of well-being, such as the Citizenship Survey, would not meet such requirements in their current form. This provides technical and financial challenges to the Statistical Actors of the ONS. There are also questions again of the international context, which impacts on the Devolved Administrations as much as on the ONS.

This should not be read, however, as a story of conflict. Jacob, at a Devolved Administration, suggested that the ONS were much easier to work with than were many (unnamed) Whitehall Departments with similar cross-UK remits. The ONS, he felt, understood that there were needs for information in the Devolved Administrations which were distinct from those in the UK as a whole. In response to problems arising from the 2001 Census, the ONS had established structures to promote the sharing of best practice throughout the constituent nations of the UK, including a specific fournation committee on well-being. ${ }^{14}$

In a similar way to the influence European statistical developments have on the ONS' work, the existence of the 'Measuring National Well-being' programme influenced developments in the Devolved Administrations. While the Administrations can conduct their own surveys with their own measures, for instance both Scotland and Wales now include $W E M W B S$ in their own national surveys, the use of the four subjective wellbeing questions rather than $W E M W B S$ in the rest of the UK makes the results hard to contextualise (interview with Jacob, of a Devolved Administration). The response of his Devolved Administration to this has been to include the ONS questions on their own national survey in addition to WEMWBS, alongside a booster sample taken by the ONS for the Annual Population Survey. Jacob noted the greater flexibility that Devolved Assemblies had in adjusting their surveys to include additional questions, suggesting that such relative eclecticism 'wouldn't be possible for the ONS, who had, I believe, a struggle with their methodology committee to include any subjective well-being questions on the Annual Population Survey at all.' The existence of a supra-national (in this case UK) context influences action, leading to a spill-over of particular

14 Parenthetically, while this committee is alluded to in the quotation from the Membership List of the Advisory Forum above, this deep-structure of UK statistic-making would not have been apparent to me had Jacob not mentioned it in passing in his interview. This discovery points to the benefits of the interview approach followed in this research in uncovering aspects of the official statistic-making process not publicly documented. 
operationalisations of well-being. However, this is adjusted accordingly to meet local needs.

It can be noted that this perception of localised variation is not shared by Statistical Actors at the centre of the well-being creation. In interview, for instance, Oscar, of the ONS, painted a picture of a much more homogeneous well-being movement:

'I recently came across the term 'multilevel governance', which sounds quite grand but that is what was going on. After the ONS programme started there was a UN Resolution calling on member states to pursue measures of wellbeing. The OECD also started work through their 'Better Life' programme. Eurostat, the European Commission and the European Parliament all released commitments relating to the 'GDP and Beyond' programme, which Eurostat is taking forward with national statistical offices on a voluntary basis. The constituent nations of the UK also took it up - Wales recently launched a Well-being for Future Generations bill. ${ }^{15}$

It is clear, both from the variations introduced into the UK programme discussed in the previous section, and from the variations present within the Devolved Administrations of the UK, that such a reading is too simple. The statistical programmes that the wellbeing agenda informs are distinct, with ideas being re-characterised to suit local needs. That Oscar does not perceive this highlights differences arising from positionality: the Statistical Actors of the ONS are in a position to define well-being for the Devolved Assemblies, they do not need to take on board variations, subversions or corrections. Such alternative conceptions remain invisible to them.

Diversity in measurement is also the case at sub-national levels. Emily (in a Whitehall Department) and Ava (an academic in public health) both noted that, despite the uniform legislative context of Local Authorities discussed in Section 4.2.2., the use of the ONS' data was varied. Jessica, an academic working for a public policy NGO, went further, saying, 'But well-being has increasingly become part of the local agenda over the last five years, and Local Authorities have started to generate local data and ignore the national results as irrelevant.'. Basing her claim on knowledge of Public Health England, Jessica suggested that Local Authorities were generating model-based estimates of well-being as a way of getting around limitations of sample size in the ONS data. Here the claim of Oscar, from the ONS, above that the ONS saw the purpose of the programme to produce a broad national picture of well-being comes up against local requirements to consider well-being in a policy context. Without the ability to conduct their own research in the way that the Devolved Administrations can, local policy actors are limited in their use of the ONS data.

There are, then, complex interactions between the Statistical Actors involved in producing official statistics, partly created by the divergent needs established by Devolution and the responsibilities of local government. These impact both on the way in which the Statistical Actors of the ONS go about their work, as they seek to balance national and sub-national aims and objectives. They also impact on the work of

15 Passed into law as Well-Being of Future Generations (Wales) Act 2015, this builds on Social Services and Well-Being (Wales) Act 2014. 
Statistical Actors and users at the sub-national level, who seek both to influence the national statistic and are influenced themselves by it.

\subsubsection{Competing purposes of potential end-users: decentralisation of policy and its impacts}

'There is always going to be difficulty for the ONS, who need to create a statistical set which makes sense to measure a complicated concept, which doesn't tie directly into the government priorities. The ONS approach covers everything, but the focus of government departments is specific. It's useful to have the two types of programme [our specific and the ONS' general], and it's useful to have commonality between the two. So [we] may have a different set of specific measures to the ONS, but we share subjective measures to allow us to make comparisons.' (Jacob, Devolved Administration)

As discussed in Section 4.2., the status of the Devolved Administrations can be read as an extension of the status of Whitehall Departments, a new geographical twist on historic policy-making fragmentation. It was argued at the start of the present section that official statistic-making in the UK is normally determined by policy needs and that the 'Measuring National Well-being' programme had no such needs beyond its broad programmatic aims. This sub-section seeks to better substantiate that latter claim.

Self, Joloza and Beaumont, in the GSS MAC meeting of 19 June 2013 (p.37) report that, "The National Statistician has stated that any indication provided by the MNW programme as to whether measures of national well-being are getting better or worse should have appropriate methodological background and be endorsed by appropriate stakeholders." This is problematic, as the stakeholders listed elsewhere by the ONS include nigh-on everyone in the UK (see above). Looking at policy-making bodies, it is notable how patchy is the representation of Whitehall Departments on the Advisory Forum and Technical Advisory Group. The Department for Work and Pensions, for instance, attend only a handful of meetings, the Ministry of Justice and Department of Business, Innovation and Skills attend only one, and ministries such as Defence, and Culture, Media and Sport don't attend any (TAG Minutes, all; see also Appendix A). In the case of the last, a representative of Sport England is listed as a member of the Technical Advisory Group, but doesn't attend any meetings. On the other hand, Education send a representative to the first few meetings of the Technical Advisory Group before tailing off, while Defra, and the Departments for Communities and Local Government; and Health send representatives to all or almost all meetings. There is thus very different levels of buy-in to the programme across Whitehall, reflecting the difficulty of cross-cutting programmes which was highlighted in Section 4.2.1..

In addition to these formal meetings, interviews highlighted the importance of informal structures of official statistic-making. Emily, who worked for a Whitehall Department which did regularly attend meetings, noted discussions outside of these formal face-toface gatherings: 'We've been consulted on that [children's well-being] twice in the last year [2013-14], so the conversation is still open. And you work with them for so long that you form close working relations, you can normally just pick up the phone and talk 
to them, rather than waiting for a consultation.' These structures are largely the result of agency on the part of Statistical Actors; a 'picking up the phone' to make a point to an Actor believed to have influence. Alfie, who worked for a Whitehall Department, noted that these working relations were often personal, a result of the circulation of civil servants within Whitehall; he himself had come to the project not because of any particular departmental buy-in but because he had formerly worked at the ONS. This is evidence of a distributed network of relevant statistical expertise outside of the ONS, similar to the network of well-being advocates in the European setting. The influence these informal structures and networks have on the final form and content of the official statistic is unclear as their informality hides them from official records, although it is worth noting that they did not form a major part of interviewees' accounts of the process of production of the 'Measuring National Well-being' programme.

Caution should also be taken in reading involvement in meetings as the Department having any particular desire or use for well-being data. Alfie, from a Whitehall Department, was explicit on this, 'I wasn't there to represent the Department, the Department didn't really have a position beyond "We would like to see this done well".' Further, as will be discussed in Section 6.2.3. below, most Departments who provided interview participants were not using data from the programme in their policy-making. The exception to this was Emily's department, who had already incorporated the wellbeing agenda into their work prior to the creation of the programme:

'We do use the data, particularly the subjective well-being data, because it's new and unique. [Our departmental responsibility] and well-being get caught up together, they're almost seen as synonymous, so they're inherent in what we do. So we don't struggle with the question of 'what is this for?' as much as some other departments might. Well-being should sit coherently in what we do.'

This response was not typical, however, which may not be surprising. Departments have always had the power to collect data to support their work, and have used it. Those not already considering well-being were thus unlikely to have specific policy-aims which well-being data could inform, and were thus limited both in their involvement and in the contribution they sought to make. This is a factor in the failure of the broad programmatic aims to translate into the sort of specific requirements that, on the accounts from the Statistical Actors of the ONS above, normally inform statistical development.

However, while generally lacking any positive vision for the statistic, departments did come into conflict with the ONS over the relation between the programme's aims and their own departmental ones. For example, Amelia, from a Whitehall Department, related discussions she had with the ONS over the representation of sub-groups of the population which her department were responsible for. She argued that that the 'national' in 'national well-being' meant that this sub-group needed sampling, which the surveys the ONS were using as vehicles for the subjective well-being questions failed to do. The same objection can be seen in two extracts from the TAG meeting minutes of 4 February 2011 (both p.3): 
"It was also noted that the survey will not pick up those not in households or [under] ${ }^{16}$ sixteen. This could lead to allegations of it not being a measure of national well-being."

"Karen Hancock (DfE) - IHS misses out all those not in a household or [under] 16; prisoners, armed forces, children etc."

This complaint is similar in structure to the sampling questions raised by the Devolved Administrations above. Those, however, were questions of reporting: are sufficient individuals in a relevant population being sampled to allow their results to be analysed separately; and is this 'well-being' as the Devolved Administration understands it? The current objection is one about coverage: are the relevant population being included in the programme at all? As a further element to this, there are theoretical questions about whether the concept of 'well-being' itself is uniform across population sub-groups. The TAG meeting of 21 June 2012 is devoted to discussing the question of children and well-being, with Tim Andrews of the Department for Business, Innovation and Skills being quoted as commenting that "different SWB questions may be needed at different stages of life" (p.4). Ultimately, this line of argument was successful, with the ONS launching a separate well-being programme for children in 2014.

There is an interplay here between departmental desires for coverage and limitations on cost, which are accentuated by the fragmented nature of Whitehall policy-making. Amelia's disagreement with the Statistical Actors of the ONS over their claim to a 'national' statistic was seen as an effort on her part to shift responsibility (and so cost) from her department onto the ONS. As she expressed this:

'at the 2010 Spending Review, the Secretary of State cut funding for [survey], the Department's survey of [sub-population] opinions, which would have been a potential vehicle for questions about well-being. The ONS felt we were trying to shift responsibility to them, so that the additional sampling of [sub-population] would come out of their budget and not ours. My point was that there was nothing in their remit which said they shouldn't be addressing [sub-population's] well-being - they were measuring "National" well-being'.

When asked about this, the response of Oscar, from the ONS, was to return to the argument that the programme was intended to be a high-level national picture:

'There were [criticisms from Departments saying "you need to cover this group"], and we responded in two ways. One is to point out that the ONS sample is huge, so they can normally do some analysis with the group they need - the information is there for them to get out. The other is to say that the ONS has no proprietary interest in the questions, so government departments can take them and supplement them. ... The ONS programme sets the broad national picture - you can drill down, but only so far. And then comes the time where you have to pick it up yourself.'

16 The minutes here use 'over', which is factually incorrect, and so likely to be an error. It has been corrected for sense here and in the quote following. 
At the same time as some departments were seeking to extend the ONS' remit (as the ONS saw it), there is the possibility that others sought to keep certain statistics (and their attendant funding) under their control. Jessica, an academic, suggested that 'There was also a period where Defra got quite upset because they'd already been putting together sustainable development indicators and they thought this was a duplication. They wanted a lot more sustainability in there.' A similar point was made by Thomas, another academic. Their accounts were, however, was not supported in interviews with representatives of the ONS or of Whitehall Departments. It is interesting that responsibility for the Sustainable Development Indices shifted from Defra to the ONS midway through the programme, which may have short-circuited any potential dispute about institutional power-centres.

These can be read as conflicts between Statistical Actors, arising from typical institutional disagreements about resources and responsibilities. Another way of reading these is as the system of consultation working as it should, allowing the Statistical Actors of the ONS to co-construct the statistic with the Statistical Audience, accommodating their needs as far as the ONS' overall requirements allowed. On this reading, the role Statistical Actors from Whitehall and the Devolved Administrations played was in modifying the ONS' proposals to ensure they were generally usable, rather than being able to shape the programme to meet their own specific policy needs. For example, Emily described her department's role in adjusting the questions in the "Health" domain of the programme:

'They then proposed their set of ten domains and headline measures within each domain which went out to consultation which is probably where we had most impact. For example, within the initial set of domains, the health domain had one really weird question - something like "Are you satisfied with your state of mental health" - and we were able to adjust that, to tell them that it wasn't an appropriate question to ask people and there were more relevant measures which could be included in the health domain.'

This account is supported by comments in the minutes of the TAG meeting of 29 March 2012 (p.3), which record 'SSatisfaction with mental health' was not considered to be a good question; there are many excellent measures of mental health available which could be used instead." Isla, from a Whitehall Department, describes a similar process, where the expertise of her department was, with external NGOs working in the same area, able to fill a gap in the ONS' proposed programme:

'We wanted local indicators if possible, but also considered how well the indicators reflected key policy areas and the evidence in those areas initially the suggested measures didn't include any indicator on [policy area]. ... [Policy area] was something that had come up in the public debate, although not prominently. I think it was initially excluded from the list of proposed indicators because the ONS had done a lot of analysis on the Understanding Society survey to see what drove well-being. But that survey is didn't include [policy area] question, so there was a lack of evidence on [policy area] and wellbeing in the source they had used.' 
This response is also interesting in the light of William's comments earlier about the processing of the national debate. It was argued at the time that this debate is necessarily filtered through existing modes of thought by the Statistical Actors of the ONS, and Isla's comments support this. However, by consulting, these Actors are able to incorporate thinking from a wider group of Statistical Actors, which compensates for their oversights.

This sub-section has shown the impact of the fragmented governmental system on the process of official statistic-making. Statistical Actors from Whitehall had varying degrees of interest in the 'Measuring National Well-being' programme, and a diversity of aims: to obtain measures which would fit their pre-existing policy needs, to shift responsibilities for measurement from their department to the ONS, to ensure they are not lumbered with unsuitable statistics. These aims were separate from those of the Statistical Actors of he ONS, which was to produce a general programme which met international standards and which had the potential for use. This meeting of the specific and the general needed to be negotiated by the Statistical Actors, emphasising once more the role of agency in determining the final form and content of the official statistic.

\subsubsection{A programme which pleases most people a little, but not a lot}

'My motto is 'use it or lose it' - if we're not using data then why are we spending money collecting it? It's starting to be used, I've heard of departments using it as before and after data for policy evaluation, and for considering the design of longer-term policies. I'd like to see it used more in considering joined-up policies - so health people aren't just looking at the health data, but they're thinking about employment, because that impacts on health. The OECD coined this, but I like thinking of this as 'Better policies for better lives'. Ultimately that's what we're trying to do - provide data which will allow the design of policies which improve people's lives.' (William, senior figure, ONS)

The previous sub-section argued that there was little desire within Whitehall for the data the programme was producing and, where there was, it often fell into conflict with the aims and objectives of the ONS. This section develops this argument, by suggesting that the programme which the ONS produced was not generally found to be useful by Whitehall Departments. This lack of use confirms the gap between the desires of stakeholders and those of the Statistical Actors of the ONS, arising from the lack of involvement of Commissioning Actors in the statistic-making process.

Continuing the story of Amelia, in her Whitehall department, from above: following her dispute over whether her policy group were covered by the surveys on which subjective well-being questions were being placed, she turned to her Secretary of State to see how far the point should be pushed:

'I sounded out the Secretary of State to get their views on well-being, and it was apparent that they were not interested. They thought we already had 
measures of well-being [in a Departmental KPI] and additional measures were superfluous.'

Interestingly, given the Prime Ministerial backing to the programme, the Secretary of State in question had actually reversed departmental policy, which had historically included well-being as a core aim, preferring instead to fall back on specific output measures as a performance yardstick. Their thinking was that this output was the marker of the department's success and so, in as far as the Department could improve wellbeing at all it was through this output. We can see here a version of the problems raised in Section 4.2. regarding cross-departmental schemes; departments have specific aims and objectives, and will pursue these unless incentivised to do otherwise. This is particularly the case with something as diffuse as well-being, where the contribution of any given department's work will be invisible at the national level at which the data is reported.

Elsewhere, departments were less openly resistant to the programme, but carried on using the measures they already had. Elsewhere in Whitehall, for instance, James suggested: 'Some of the indicators come from elsewhere, and have been re-packaged as part of the programme. We still use those we used before, but possibly in their original sense rather than as 'well-being' statistics.'. The newer data, particularly subjective wellbeing, did not inform policy, while the data designed with policies in mind continued to be used.

Again, the picture was not uniform across departments. As mentioned above, Emily, who felt her department was already involved with well-being prior to the programme's development, reported that she and her colleagues were making use of the new data in an experimental fashion. Isla said something similar, reporting that some of the ONS' subjective evaluation questions were being added to their existing departmental surveys:

'We'll be getting the data on that soon, which I'm really excited by. For us it's not so much the measure itself but the relationship between measures - if well-being goes up, that's not especially interesting unless we know why. When I told the story about well-being having risen because unemployment had fallen, colleagues were interested in that because of how it linked to our policy areas. Hopefully we'll get data which allows us to do the same with [policy area].'

This use of the ONS' questions in their own existing surveys follows the suggestion of Oscar, a senior figure at the ONS, above, for departments to undertake their own research using the programme's measures and establishes it as a touchstone or reference point, itself outside of direct policy usage. The problems of scale discussed above, both in terms of geographical samples and coverage of policy sub-groups, leaves Whitehall departments in a similar position to the Devolved Administrations. They are presented with a national picture but one which is often too broad to integrate with their policy aims. Explaining this, Jacob, from a Devolved Administration, said:

'This highlights a difficulty that the ONS have as an independent body which we don't - they are trying to produce a programme which is 
conceptually sound and which makes sense across all government departments. Our work has to be conceptually sound, but instead aligns with government aims - we are a policy-delivery body, so our indicators expose policy effects.'

Lacking any direct policy need, the national programme falls between stools: the Statistical Actors of the ONS work to create something coherent and crossgovernmental, but this results in a non-specific programme which departments have to modify if they are to make it useful. This leads to a lack of uptake, particularly in departments where there isn't any obvious overlap between their work and well-being. As Alfie, in a Whitehall Department, put it, 'There hasn't been as much movement as some might have hoped though. The trouble is that the answer is always roughly the same -7.2 , or there-abouts. There are distributional differences between regions or groups, but I don't think the thinking's gone very far as to what the causal chain is or how you'd intervene. It's not very much used - if you set it as a target, how would you drive it?' In line with this, the TAG minutes of 3 December 2012 (p.2) note: "It would be helpful to have a policy link for each of the domains (e.g., for the health domain the Department of Health) in order to get take up from government departments." (p2)

This leaves the programme in the situation William, of the ONS, outlines at the start of this sub-section: not greatly used, particularly in a cross-cutting sense (a point also made by Isla, at a Whitehall Department, 'For me, the question is to what extent does it allow us to design holistic policies to influence well-being. And we're not really there yet.'). Possibly, however, his hopes are unrealistic; echoing the critique of evidence-based policy outlined in Section 4.2.3., Amelia, at a Whitehall Department, pointed out that well-being can only ever be one consideration of government: 'It's part of the evidence that you can use in making the case for the funding of programmes, for instance, but only part - there are still the questions around whether the programme is effective, feasible, \&c.'

The picture that arises from the statistic-making process is thus one which is quite close to the 'producer' model that Oscar, at the ONS, had felt was inappropriate for well-being (quoted above). The national debate is filtered through existing frameworks of thought, and then adjusted in light of feedback from potential parts of the Statistical Audience. This feedback is limited by the perception by many Whitehall departments that they are not and will not be users. Not only does this mean there is no direct policy-aim which the programme fulfils, but also that the Statistical Actors of the ONS act to ensure that the programme is too broad to fulfil such aims. Instead, departments supportive of wellbeing as an aim either use what measures the programme has which they were already using, or add subjective well-being questions to their own existing surveys. The Cabinet Office acts to ensure that any new departmental surveys address subjective well-being questions, but cannot make well-being a priority where it isn't already (interview with Alfie, Whitehall Department). This fits the model of previous attempts at crossgovernmental programmes where, unless incentivised or coerced, independent departments continued to act independently (see Section 4.2.1.).

The previous sub-section argued that, against the critical accounts of Chapter Two, Whitehall Departments were not trying to influence the design of the 'Measuring 
National Well-being' programme to ensure social control; the present section argues that there was little attempt to shape its outputs for control (or much else) either. In this sense, the programme better resembles native accounts, where the external world is counted without political interference; although, as was shown previously, the factors determining what aspects of the world are counted, and how, are not independent of political context.

\subsection{The role of finance and structure: money is a limiting factor}

'The programme was and still is presented as developmental, and it occurred during a period of austerity. We got the funding we needed, but it wasn't exhaustive, we still need to recycle things from elsewhere.' (Oscar, senior figure, ONS)

Setting the context of the programme, the minutes of the GSS MAC of 3 November 2010 (p.2), state that the 2010 Spending Review means that: "there would be a reduction in resource [for the ONS] from $£ 144$ million to $£ 131$ million by $2014 / 15$; a decrease of $8.5 \%$ (17.4\% in real terms). The biggest component of this was the reduction in capital ... additional funding was approved for the Beyond 2011 Census project and for Societal Well-being (now being known as National Well-being); an extension of the measure of GDP to cover a broader scope". (Also notable in this quote, in light of the discussion of the Stiglitz-Sen-Fitoussi report as a basis for the programme above, this characterisation of the MNW as a GDP-extension project.) The minutes go on to say that an area for cost-saving would be work done with other government departments, but that there was severe limitations on the scope for cutting these: "As most of this work is statutory, early indications are these joint projects will continue, but redesign of sample sizes may be necessary." (p3; see also Penneck 2014).

This financial constraint continues throughout the programme, both for Statistical Actors within the ONS and within Whitehall more broadly. The minutes of the GSS MAC meeting of 14 November 2012 report (p.4): "Martin [Brand, chairing the meeting] spoke of the financial challenges to ONS for 2013-14. ONS was going through another cost savings exercise; the government had set challenging targets. ONS now had to pay VAT on some transactions, and there had been a significant cost involved in improving the ONS website. ONS would be awaiting the autumn statement to see if departmental budgets would undergo further cuts." While this does not appear to have led to staffing cuts at the ONS, as it did in Whitehall more broadly, this will have constrained options for increasing staff numbers to assist with the new programme.

There are two major effects of this financial constraint. One is that the Statistical Actors of the ONS are reliant on existing statistics for much of the bulk of the programme, having been given additional funding only to develop the subjective well-being measures proposed by the Stiglitz-Sen-Fitoussi report and to carry out the national debate. As Oscar, at the ONS, put this, 'So we needed to put a proposal in to fund this work - the resources were there to set it up, but we weren't funded for the collection of subjective well-being data. So we had to make a bid for money to fund the programme at the Spending Review, which at the time was providing funds for several years.' This 
is additional money over the top of a budget which is being cut, allowing the creation of a new stream of work at a time when others are being shut down.

The second is that the ONS are able to use the funding for the programme, and its prestige as a Prime Ministerially-endorsed project, to support their core activities. Stephen Hicks, in the presentation to the GSS MAC of 19 June 2013 (p.29) introduced above, says:

"The Office for National Statistics (ONS) approach to measuring National
Well-being has been to make better use of already existing socio-economic
indicators and supplementing those with subjective well-being estimates.
Highlighting alternative measures of national economic activity other than
GDP is necessary to better reflect the material well-being of the nation.
However, equally important is to develop further, and make better use of,
household survey information on income, consumption and wealth and to
link, where possible, to data from the National Accounts."

It was previously argued that Hicks' presentation had emphasised the role of the programme as a GDP-extension programme. Here that emphasis is tied to the recycling that Oscar, at the ONS, was talking about above: with money constrained, the programme provides the justification to develop information on income, consumption and wealth. Putting aside arguments over whether or not these are integral parts of wellbeing, these are all core areas for the ONS. It appears that the programme is being used to insulate these areas from cuts, allowing development work to happen which may not have occurred otherwise.

There were claims by participants of more concrete impacts of austerity on the programme, in the form of cuts to surveys which could have been used to test or carry questions. Thomas, an academic working principally on national and cross-national surveys, said, 'It was unfortunate that the programme started under austerity. It started out as an experimental programme, but as soon as it gets going, the Citizenship Survey is axed and space frozen on the Integrated Household Survey, which limits the room to experiment. It's unfortunate, but understandable.' Jessica, at a Whitehall department, also cited the loss of the Citizenship Survey as a problem for the programme's development, as did the minutes of the TAG meeting of 29 March 2012 (p.3). Interestingly, when asked directly about this, Oscar, at the ONS, claimed that 'the Cabinet Office found ways of doing the Citizenship Survey by other means', while not commenting on other surveys. This response is interesting, because it doesn't quite reach the heart of the question: Thomas and Jessica both point to material in the Citizenship Survey (which, among other things asked questions about the practising of religion, ethnic integration and various aspects of community involvement) which would have been of use to the consideration of well-being. The decision by the Department of Communities and Local Government to defund the survey represents a withdrawal of information. This information would have been of particular relevance to the investigation of policy sub-groups, such as ethnic minorities. With the exception of information on volunteering, none of the information that was available in the Citizenship Survey now appears in the 'Measuring National Well-being' programme. 
The loss is particularly notable in a context of recycling of measures. As Jessica, at a Whitehall department, put this, 'As an effect of recession, one of the things which ended up driving the inclusion of measures was data availability, so where no measure already existed, it was harder for the ONS to justify inclusion.' This is supported by the ONS' responses to comments on the National Debate which asked for an inclusion of measures of faith (see Beaumont 2012). Those comments noted the lack of existing measures on which the ONS could draw, and come at a time when the Citizenship Survey, which had such measures, was out for consultation with a presumption of cancellation.

This is an extreme example of a more general point: the reliance on existing surveys necessarily limits what can be asked, both in terms of the number of additional questions and their type. Existing surveys are a source of time-series data, which may be threatened if the survey is changed too dramatically. As the TAG meeting minutes of 11 April 2011 (p.3) put this: "For each survey and choosing between them, there was a limitation on the number of questions to ask because of; finance, response burden, difficulty of asking some questions on a household survey. It is possible for more than four questions to be used on the Integrated Household Survey but it is a balancing act." Thomas, an academic who works on national and cross-national surveys, reported that the Statistical Actors of the ONS had met resistance from the GSS Methodology Advisory Committee when trying to expand the Annual Population Survey at all, a point which Jacob, at a Devolved Administration, also alluded to when commenting on the greater flexibility he had to collect data through his own National Survey.

William, at the ONS, put a more positive spin on all of this:

'So we looked at what matters to people - we asked the public, academia, looked at the recommendations of the Stiglitz Commission. They called for better attention to the household, things outside the market, human, social and environmental capital. We then looked at whether we had data already available. Is there administrative data, do we need to create a new survey instrument? For subjective well-being, there was no administrative data we could use, but there was the Annual Population Survey, which could serve as a vehicle for questions. That had the benefit of providing all sorts of other information, which means you can assess the influence of other factors on well-being.'

This comment seems to set up a decision between the use of existing administrative data and the creation of a new survey instrument, to resolve it through the use of an existing survey instrument. This has the advantage of offering information on other factors, but this could also have been true of a new survey instrument. The decision to proceed with existing surveys precludes many of the options for well-being questions which were discussed in Technical Advisory Group meetings. For example, it excludes alternative measures of mental well-being: 'Space and cost are limiting factors. Take Felicia Huppert's work - if you have room for 50 items, her EU-SILC module [EU Statistics on Income and Living Conditions, an annual Eurostat survey conducted by the ONS through the Annual Population Survey] is the best there is.' (Jessica, Whitehall Department). Huppert's work could be carried out because there was an entirely new 
survey instrument created at the European level for it administered to those taking the Annual Population Survey, its fifty questions (or the Warwick-Edinburgh Mental Wellbeing Scale's 14) could not be slipped onto an existing and on-going survey.

As a counterpoint to this, it seems inevitable that space and cost would have always ruled out certain options. Alfie, at a Whitehall Department, for instance, commented: 'The ONS were trying to get a large sample, so didn't want a long questionnaire. Think about the implications of what was being asked - go through every household and get information from every member on their education, their health status, and so on you'd end up with something mammoth. The ONS needed to turn out something quickly, with a limited budget.' This may be somewhat overstating the case, however: both the EU-SILC containing Huppert's 50 questions, and the WEMWBS, containing Stewart-Brown's 14, have been carried out at the scale of either the UK or its component nations (albeit with much smaller samples), and the APS itself is not a short questionnaire. The problem seems to be not the ambition of any new survey instrument, but its costs, particularly at a time when detailed surveys on a smaller scale, such as the Citizenship Survey, are being cut back.

What this means is that the Statistical Actors of the ONS must, to a large extent, re-use data collected for other purposes, spreading the programme across multiple sources. These are both vulnerable to future cuts by the Whitehall Departments conducting them (in the manner of the Citizenship Survey), and are subject to differences in coverage, time, period, granularity and salience. This is a statistical expression of the problems caused by the fragmentation of responsibilities discussed in Chapter Four; departmental silos create distinct official statistics. It also produces the inverse of the problems of the programme's use: rather than departments not using the programme because it doesn't speak to their specific targets, the programme itself is vulnerable to losing data should it stop being useful to the department collecting it. A lack of 'joined-up' government means both that the programme isn't used consistently, and creates the danger that it will itself break up.

More positively, the specialised nature of the ONS, arising from the fragmented system of government, allows it to do things that would not be possible for a non-specialist organisation. Despite the overall constraints of budget, the funding the ONS received allowed them to conduct a large and impressive amount of testing on the subjective well-being questions. As Jack, a statistician at an international organisation, put this:

'The ONS did some very valuable work on their subjective well-being questions. They ran questions in the monthly household opinion survey, using split-samples, which allowed them to perform randomised trials on the wording, order of questions, and so on. This was fantastically useful, and absolutely transformative, teaching us a huge amount about how the questions worked. The ONS were able to test in a way that no civil research programme could.'

This point is reiterated by Smith in the TAG minutes of 30 May 2012 (p.4), who notes the influence this work had on the OECD's creation of best-practice guidelines for the measuring of subjective well-being, and again by Smith and Kroll in the TAG minutes 
of 3 December 2012 (p.7). In interviews, both Thomas (an academic) and Jessica (at a Whitehall Department) were similarly impressed, the former in an interview which was otherwise somewhat critical of the development process.

Even here, however, concerns about money had an impact. Discussing the testing programme in the GSS MAC meeting of 19 June, the following exchange occurred (p.20): "Patrick [Sturgis of the MAC] thought the 160,000 sample size [in the Annual Population Survey, which carries the four subjective well-being questions] might be more than enough and suggested randomising the questions to get more out of the sample. Stephen said the main problem here was cost." This highlights a general tradeoff which runs throughout the programme between quality (whether in terms, as here, of tested validity or, as discussed above, of coverage or cohesiveness) and cost.

Through a number of discussions of the interactions between Statistical Actors and their impact on the form and content of the 'Measuring National Well-being' programme, this sub-section has highlighted the interaction of Statistical Actors with resource constraints. The financial restraints on the Statistical Actors of the ONS necessitated a recycling of existing statistics within the programme and limited its scope. As a result, the 'well-being' programme included a large number of statistics designed for reasons other than well-being, and was less ambitious in its innovations than it might have been. Both these points will be returned to in the following chapter, where the theoretical implications of these decisions are examined. For the present, it is worth noting again the role of agency in determining the form and content of the programme, and the way in which this conflicts with existing understandings of official statistics which portray design decisions as determined either by the state of the external world, or by desires to create technologies of social control.

\subsection{Explaining the programme: producing something comprehensible}

Without a policy-need to direct them, the Statistical Actors of the ONS turned to the public as a Statistical Audience, both in the national debate and later on. However, at the same time they were attempting to produce a programme which met international requirements and was coherent sometimes ran into conflict with this. This section explores this conflict.

The national debate had a role both in surveying the public and in engaging them. As the Terms of Reference for the Advisory Forum put this, the Debate aimed "to engage the public, civic society organisations and experts in an extensive and well conducted debate in helping to develop appropriate measures of national well-being and presenting them effectively, independent of government." (p.2), with the result of delivering "an agreed and trusted set of National Statistics which people turn to first to understand and monitor national well-being." (p.1). In the light of the discussions of integrity in section 4.1.5., it is worth noting the explicit depoliticisation of the programme raised by that first point. The success of this attempt will be examined in more detail below.

While the Debate was broad in its outreach, decisions about what constitutes an 'appropriate' measure rest with the ONS, rather than the public. This leads to some 
difficult decisions. For example, the TAG minutes of 11 April 2011 record concern:

"That the measures converse with the public was felt by all to be vital to the success of the project. However this should not result in trivialising the measures" (p.3)

This concern is mirrored by earlier discussions on the balance between wording questions in such a way that respondents could understand them and wording them in such a way that they were theoretically valid (TAG minutes, 4 February 2011); and later discussions on the presentation of findings (TAG minutes 30 May 2012). As discussed above, the decision did not always fall on the side of the public: measures on faith were requested and not included, while 'Human Capital' was not requested but was. This inclusion was sufficiently controversial that the GSS MAC queried whether the Measuring National Well-being programme was the appropriate place for it (GSS MAC Minutes, 21 November 2013, p.16). In this case, the need for a measure to meet the requirements of the Stiglitz-Sen-Fitoussi report seems to be over-riding public opinions of appropriateness: the ONS response to such objections is that the indicator needs to be explained better, rather than being replaced (see Beaumont 2012, p.19).

While not always deferring to public opinion, efforts were made throughout the development process to present the programme in a comprehensible way. Oscar, at the ONS, reported that the Advisory Forum were recruited as ambassadors to help promote the programme at National Debate events and in fora they were already part of, although this is not reflected either in the Terms of Reference of the Forum, or in the interviews conducted with Advisory Forum members. However, there were members of the Technical Advisory Forum recruited specifically for their presentational expertise. Charlie, who worked for a public policy NGO, identified himself as such, and described the problem of striking the balance between the validity of measures and their presentation: 'I argued, and I don't know how successful I was in this, against focusing on aggregate well-being figures. They are pretty meaningless, they don't vary much. Instead I argued for focussing on the section of the population reporting low well-being.' This, for him, was necessary to bring the public on board: not only is it difficult to alter the aggregate figures very much, but also there is 'a scepticism in the public around whether it [well-being] is a legitimate area that the government should intervene on'. This comment, and Oscar's citation of the media mocking of 'Mr Cameron's Happiness Index' above, suggests there are limits on the form the programme can take which arise from what the public as Statistical Audience will accept.

This feeds into concerns about the integrity of statistics which were discussed in Section 4.1.6.; there was a concern throughout the programme that it would be seen as illegitimate, and evidence that this concern was justified. For instance, Tinkler and Snape, in their presentation to the GSS MAC of 19 June 2013 (pp.64-8) report on the findings of a 'citizen users' panel looking at the presentation of subjective well-being data. This data had initially been presented with thresholds, reporting the findings from a 11-point Likert scale as being 'High', 'Medium', 'Low' or 'Very Low'. These thresholds were based on the underlying distribution of the data which was different for the three positively-worded questions from that of the negatively-worded one. This disparity, while making sense from the point of view of statistical coherence, confused users: 
"People are unclear why the thresholds have been set where they are and related to this, some citizen users questioned whether ONS might be trying to present the figures in a particular light." (p.67). Similarly Self, Joloza and Beaumont in the GSS MAC minutes of 19 June 2013 minutes (p.45), discuss the amount of thought which was devoted to developing a sophisticated and methodologically valid indicator of change in well-being measures and the limitations imposed by the need to explain these indicators to a lay audience.

The ONS were not helped in this by "mis-reporting by the press", as Tinkler and Snape put it (p.67). Disappointment with press coverage was a running theme in interviews. Thomas, an academic, summarised the position:

'As much as your [researcher's] brief is looking at where the programme comes from, from the public's point of view everything rests on how it is presented. We had dilemmas as a Group about how to deal with the press. We knew that there was a lot of effort going into creating robust, credible, accessible, multiple measures, but when the press got it they always sold it as 'happiness'. Even broadsheets saw it as trivial, thinking it 'was not the business of government to measure happiness'. On the libertarian left there was a sense that the government should leave us alone; there was a touch of 1984-style paranoia, that this was a measure to pacify the masses. ... Outside of the Technical Advisory Group, I thought the ONS' outreach programme was enormously impressive. They went to a massive number of public meetings, it was a formidable piece of public social science. They really tried to engage with the public.'

Those involved in the development process knew how much work was going in to the programme, but saw their efforts undermined by press over-simplification. Emily, in Whitehall, too, criticised the press' focus on happiness: 'I don't think it was reflected well in the media. Stories like 'Rutland is the happiest place in the UK' - it's always Rutland - or 'We've found the meaning of happiness and it's 7'. They always use happiness, and it frustrates me.'

The ONS' initial response was to involve the press more in comprehensive briefings to ensure that they had the opportunity to understand the programme. William, at the ONS, described this:

'The thing about the press is that they have a story to tell. One of the big efforts we made was in bringing journalists in, having media briefings: it's not just about about happiness, this is the difference between evaluation and flourishing, happiness and anxiety are separate. We took people through this - here are outcomes, here are inputs and you can't understand them without looking at the set overall. You can't just look at GDP, or at happiness, this area feeds into that and you need to look at the broad spectrum, I call it the 'wide lens'. And then they report it as happiness. You get it a lot less now, we've worked hard. There's the occasional cheap shot: 'why is government spending money on this?', but the recent reporting has been more considered. You can't guarantee good quality coverage, you can't guarantee 
the press.'

He later expanded on 'working hard'; the efforts of the Statistical Actors of the ONS can be read as an attempt to turn the press' lackadaisical approach to their advantage:

'We've done more with infographics and podcasts. That makes things easier for them, they can take them and use them, and we're happy for them to do that. We don't charge, and as long as they source us we're happy. It's the same with the story, if we can write a good commentary which explains what things mean, they can just copy and paste it - it makes their job easy and it means there isn't a problem with misunderstanding.'

Something of this effort can be seen in a comparison between figures D.1. and D.2.2 in Appendix D; the former is from the statistical release on personal well-being in the UK in 2014/15 (ONS 2015b), the latter is an info-graphic which accompanied that release. This second figure is simpler in the message it conveys, more visually arresting and has a pictographic representation of 'satisfaction' to aid in comprehension. That journalists found this approach useful can be seen in the fact that ITV's online news pages use the figure. ${ }^{17}$

This does not speak volumes for the quality of the UK press; what is happening is that the Statistical Actors of the ONS are securing accurate coverage by producing that coverage themselves. They are in something of a Catch 22 situation: to ensure that the programme is accurately represented, and so trusted, they must themselves write the accounts of the third parties who are supposedly scrutinising them. To be clear, this is not in any way to accuse the Statistical Actors of the ONS of misrepresentation, but to highlight the lack of scrutiny which results from a press who need their job to be made easy and the way that this influences the actions of Statistical Actors. This feeds into questions of integrity raised in Section 4.1.6.: the guarantor of that integrity is the professionalism of the statistic-makers themselves, in lieu of the professionalism of the media.

The present section has argued, as the previous ones have, that institutional factors shaped the actions of Statistical Actors. In this case, the lack of obvious policy use for the programme and the need to it to be accepted by the public led to a large-scale outreach and public consultation programme. This did not result in the public being incorporated as Statistical Actors and co-designing the programme; rather their contributions were weighed against other objectives held by Statistical Actors and included or excluded accordingly. The need for public acceptance also determined the ways in which the programme was presented, with Statistical Actors devoting substantial efforts to ensuring that the programme was correctly reported, and so understood by the public.

17 http://www.itv.com/news/2015-09-23/happy-list-reveals-uk-towns-and-cities-where-people-feelmost-positive-and-where-they-dont/ (Accessed 10 December 2015) 


\subsection{Summary: interactions between Statistical Actors and their institutional context and the influence of these the form and content of the statistical programme}

This chapter has surveyed the complex interactions between various Statistical Actors, principally those in Government and at the ONS, and the way they have moved within the 'Measuring National Well-being' programme's institutional context (outlined in Chapter Four). Drawing on interviews and material from meetings of various bodies, it has suggested that Actors have responded to various aspects of this institutional context, and that this has influenced the final form and content of the statistical programme.

A key argument of this chapter is that there was no specific policy need underpinning the 'Measuring National Well-being' programme, but only vague and aspirational rhetoric around complementing GDP. This had a number of consequences. One was that Statistical Actors from within the ONS moved to develop a programme built around international Statistical Actors and statistical conceptions of well-being, hedging against future requirements to produce data such as 'Human Capital'. Another was that there was only limited buy-in to the programme by Statistical Actors from outside of the ONS. Those in Devolved Administrations sought as much as possible to make the programme compatible with their own efforts, but did not see the programme itself as especially important. Those in Whitehall sometimes sought to incorporate their policy concerns into the programme, but generally ignored it as irrelevant to their needs. In place of this, Statistical Actors within the ONS sought to ensure public buy-in, but this too was limited by the aim of ensuring a fit with international objectives. Throughout, Statistical Actors reacted to limitations on financial resources in the face of austerity, shaping the measures they included in the programme and the survey devices used to convey them.

This account supports the claims made in Chapters One and Two that the statisticmaking process was an inherently social one, and that the over-looking of this had led to an explanatory gap in the literature. This is not a case of a neutral organisation developing measures which simply transmit class or biopolitical control in a Marxian or Foucauldian manner; instead, this is set of actors with agency negotiating a variety of requirements within distributed networks of power and influence. Nor is this the case of an organisation able to unambiguously record an external reality in a positivist or an empiricist sense; instead actors are continually adjusting and compromising their measures in the light of competing aims and objectives to achieve something which is workable rather than something theoretically pure.

This argument will be further developed in the following chapter, which addresses some of the theoretical disagreements which arose within the development process, and seeks to situate them within social interactions between individuals. 



\section{Chapter Seven \\ Questions of theory: how the theoretical context of UK statistic- and policy-making shaped the 'Measuring National Well-being' programme}

As outlined in Chapter Three, the present and preceding chapters examine directly the statistic-making process. Taking the structural and theoretical context of the 'Measuring National Well-being' programme identified in Chapters Four and Five, this empirical material investigates how the Statistical Actors who constructed the programme went about their work. The previous chapter looked at the institutional context of the statistical programme, and how this was navigated by Statistical Actors. This chapter will look at the theoretical context: given the breadth and diversity of theoretical positions outlined in Chapter Five, how did the Statistical Actors go about resolving theory into a statistical programme?

This chapter focuses quite closely on the Actors themselves, their theoretical interpretations of 'well-being' and the interactions between them. While the previous chapter argued that there was no direct policy need which informed the 'Measuring National Well-being' programme, it did observe a competition between practical demands and theoretical positions. The example that arose several times was the inclusion of the Warwick-Edinburgh Mental Well-being Scale (WEMWBS), which had been in use in Scotland but which was not included in the ONS programme until very late on in the process. This chapter will expand on that debate, which proved to be a relatively important (and, in places, contentious) one within the consultations the ONS held with expert groups. It will be noted that what appears, on paper, as a theoretical debate became, in practice, a personal one. The ideas which were being debated were embodied in individuals, and the seemingly impersonal debate about the general shape of the programme was experienced as a personal process.

To situate this debate, it is worth briefly returning to the taxonomic material laid out in Chapter Five, Section 5.1.. This argued for two major divergent approaches in subjective well-being research. Public health approaches focused largely on positive mental functioning, using detailed barrages of questions to gain deep understandings of individuals or small groups. Economic and non-applied psychological approaches tended towards using smaller question sets, and often single questions, within wider surveys, which could then be fed into regression models to gain broad understandings of drivers and correlates of well-being. While the former is interested in the nature of an individual's well-being, the latter is more interested in the generalities of well-being itself. In this difference in focus there is contained a larger theoretical disagreement over whether 'well-being' is something holistic, and so requiring a multi-item assessment, or whether it is something that can be captured by a single question relating to lifesatisfaction, affect or flourishing. There is also a question about the nature of wellbeing: whether well-being is a state which is caused and observable, or whether it is a set of capabilities which are only imputable. These differences are played out in the material discussed below.

The chapter will proceed as follows: Section 7.1. will look at the ways in which Statistical Actors within the ONS recruited external advisers. It will argue that there was a predisposition to the recruitment of economists which in turn predisposed the 
programme towards conceptions of well-being dominant in economics and of subjective well-being in particular. Section 7.2. notes the ways in which the dispute around the nature of well-being became embodied, with theoretical disputes experienced by individuals as personal ones. This is a key example of Statistical Actors acting as agents, for reasons unrelated to the formal institutional or theoretical structures they operate within. Section 7.3. extends the discussion out from considerations of subjective wellbeing and towards the programme as a whole and the measures it incorporates. It argues that the measures were included in the programme because they were considered useful, not because they were specific to the question of well-being. The chapter ends with Section 7.4., which gathers together the arguments of the chapter, underscoring the argument that agency is central to explaining the form and content of official statistics.

\subsection{Setting up the dispute: a new area, with old contacts}

'There is always going to be difficulty for the ONS, who need to create a statistical set which makes sense to measure a complicated concept, which doesn't tie directly into the government priorities.' (Jacob, TAG member, Devolved Administration)

'Subjective well-being is probably the most vague aspect of the programme - what is it we are trying to measure? If it's functioning, then 'satisfaction' doesn't cover it. Satisfaction is useful, but misses key aspects of success or achievement and context.' (Jessica, TAG member, NGO in the area of public health)

As discussed in the previous chapter, and highlighted by Jacob's quote above, there was no direct policy need to direct the 'Measuring National Well-being' programme. This made the statistic-making process more open-ended than it would normally have been, and increases the importance of theoretical debate in shaping the decisions of Statistical Actors. Theoretical soundness became relatively more important than any particular practical end-point, given that there was no such end-point to work towards. This can be seen in the range of Statistical Actors involved: alongside the government departments, Devolved Administrations and representatives of international statistical organisations discussed in the previous chapter, the two Advisory Groups included a very large number of academics from a variety of fields. This extensive academic involvement was of a piece with the large-scale public and governmental consultations discussed in the previous chapter. Asked how typical this was, Jacob, a Technical Advisory Group member and representative of a Devolved Administration who was regularly involved in statistical consultations said:

'Not all that typical. You see elements of it across their [the ONS'] work, but not to that extent. The nearest parallel would be the Census, where there's a long-term programme of discussions with users and advisory groups business, academics, the public sector, government departments. Normally things happen on a much smaller scale though - there are usually technical 
groups (mostly made up of government analysts), sometimes there are invited expert advisers such as academics (which happens with population data, and probably happens with key economic data). The difference with the MNW was the scale and the extent.'

This resulted in the ONS establishing two different advisory panels. The Advisory Forum was a high-level group chaired by the National Statistician, whose membership included four winners of the Swedish Bank prize for Economics (Sen, Stiglitz, Kahneman, Krueger), and no academic below the grade of Professor. Additionally, it included four knights (Atkinson, Marmot, Etherington, Rose) and two lords (Layard, Stern), as well as a number of holders of lesser honours; in all, a quarter of those group members who were eligible for British honours possessed them (see Appendix A for an annotated list of members of the two groups). The Technical Advisory Group was both larger and has a more diverse membership in terms of seniority: while some of the academics from the Forum move across to join the Technical Advisory Group (Layard, for example), most do not and the group also includes a relatively large number of individuals below the rank of Professor (including doctoral candidates such as Kroll).

The aims of the two groups were also somewhat different: the Advisory Forum aimed

- "to provide advice to the National Statistician, to deliver credible measures of subjective well-being, and of wider national well-being, to meet policy and public needs

- to offer advice on the progress of the national debate to develop appropriate measures of well-being that the National Statistician is leading."

(Terms of reference for Advisory Forum)

while the Technical Advisory Group aimed

- "to provide advice on the development of subjective well-being measures for inclusion in ONS social surveys

- to consider and provide advice on other broader measures of wellbeing, for example development of income measures relating to the national accounts and environmental accounting and sustainability issues

- to advise on the development of conceptual frameworks for the measurement of national well-being

- to provide advice on the presentation and reporting of national wellbeing statistics"

(Terms of reference for Technical Advisory Group)

The former is slightly broader in its aims, addressing high-level questions about how to interpret the national debate and produce a statistical programme. The latter's aims are more detailed, focusing on the measures actually included in the programme. As Oscar, 
of the ONS, described the aims and membership of these two groups:

'The two groups had different roles. The Advisory Forum was high-level. It was partly chosen by asking ourselves 'who do we want?' - we were trying to get as many people from as many backgrounds as we could: business, academics, NGOs - so we tried to think about who would best be involved. Certain names were suggested by the Cabinet Office and the Prime Minister's Office, which we didn't automatically accept. We were looking for advocates for the programme, for friends. They would be pursuing things that they were already interested in - Matthew Taylor, for example, the head of the RSA [Royal Society for the Arts], was previously in government, he had people he could bring aboard, and signalled an interest. It was good if they had things to say, but they were really there to advocate, to help the National Debate go well. This was a challenge particularly when talking to business, and that is still a problem. The Forum doesn't meet all that often, but it keeps in touch by email, and at the time of the National Debate was encouraged to do things through their own channels - media pieces, blog-posts and the like. The Technical Advisory Group were there to focus especially on subjective well-being, which was a new area. We knew Paul Dolan, Richard Layard, a number of academics in North America had views. We didn't expect them to drop everything to take part, and didn't think they would be able to, but would be able to steer the programme and comment on our work.'

One thing to note about this comment is the distance between Oscar's account of the purposes of the Advisory Forum ('to advocate, to help the National Debate go well') and the aims as set out in the Terms of Reference quoted above ("to provide advice... to deliver credible measures"). This distance was reflected in interviews and correspondence with Advisory Forum members: when discussing their involvement, they tended to see it entirely in terms of meeting attendance (or, in most cases, they saw their lack of meeting attendance as representing a lack of involvement). One spoke of attending events as part of the National Debate, but suggested this was something they had done of their own accord rather than as part of their duties. This distance suggests either a miscommunication between those selecting the groups and the group members themselves, or a development of aims as time went on (potentially, ultimately, ending as a post hoc re-writing of the aims of the group after it had closed).

It seems likely that the latter is at least partially the case. The Advisory Forum was initially slated to meet "around every two months" (Advisory Forum Terms of Reference), but in fact met only twice, four months apart, in February and July 2011 (AF Minutes, 11 February 2011 and 25 July 2011; confirmed in email from ONS Measuring Well-being Team, 29 July 2014). The second of those opens with the National Statistician observing a "low turnout" (AF Minutes, 25 July 2011, p.1), making it possible that the group faded away through lack of participation. This would certainly fit with the weight of accounts received from Forum members suggesting that their contribution was slight. Such accounts are supported by the problems experienced in attempting to interview Advisory Forum members: reflecting their seniority, they were very hard to access and generally too busy to offer anything other than a cursory email. 
An initial round of five emails to Forum members was met with replies by their assistant staff declining involvement due to other commitments. Subsequent requests for written information on involvement garnered 14 responses, of these ten replied to say that their involvement was slight.

It seems likely that the ONS faced similar problems: while it made perfect sense to turn to leaders in various fields as a way of securing expertise and legitimacy for the programme, such people were potentially too busy to involve themselves fully in a consultation process. This will have been particularly the case for those based in North America (Kahneman, Krueger, Sen, Stiglitz, Helliwell) for whom attending meetings in person would have proved very difficult, reducing opportunities for involvement and, possibly, the sense of connection to the programme as a project.

Members may have engaged in the Forum through email; Oscar, of the ONS, suggests above that this was the encouraged means of communication. It was not possible to gain access to these emails as part of the present research, and this lack arguably may be obscuring a vibrant and engaged group. However, the responses received to enquiries regarding the involvement of Forum members suggests that, if this was the primary mode of engagement with the group, it was taken up very unevenly. Several individuals listed as members replied that they had no involvement whatsoever, several more suggested that their involvement went no further than attending a single, press-friendly, event (such as a 'round-table on well-being with David Cameron', unattributed Advisory Forum member). From this, it seems sensible to take attendance at meetings as a proxy for wider engagement, supporting the picture of a Forum which was big on names but somewhat smaller on outputs.

This lack of activity by the Forum suggests it was limited in its ability to meet its stated aims of offering advice. However, the approach of recruiting 'big names' may have offered other benefits, such as conferring legitimacy onto the project. That this is an ancillary aim of the recruitment process is suggested both by the seniority of the panel and by Oscar's quote above: he expresses a keenness to recruit 'from as many backgrounds' as possible. In this, the ONS were partially successful: alongside the academics and representatives from government sit a small handful of representatives from business (Havelock, Price, Rose) and the charitable sector (Etherington, Phillips). As Oscar observes, this is not a large segment of the Forum, but their presence serves to indicate the inclusive aims of the programme. In this way, Forum members have indirect impacts on the programme: while they do not act to directly influence the form and shape of the programme, they offer it a prestige and a legitimacy that makes it easier for other Statistical Actors to act.

In contrast, the Technical Advisory Group was somewhat more successful in meeting its stated aims: it does meet about as often as intended and its minutes show a relatively large core of committed members. This too may be the result of the manner in which members were recruited. While Oscar, above, spoke of Advisory Forum members coming from a brainstorm-like process for people who could advocate, William, another senior figure at the ONS, described a much more focused process for recruiting the Technical Advisory Group: 
'Often [members were selected] by connections - people knowing people. That sounds stranger than it is - if I were doing new work on [statistic], I've previously worked with [your supervisor], I know he knows about them, so naturally I'd ask him if he was free to offer advice. Because this was a new area for us, there were limits to that approach, so we also reviewed published literature, and asked academics who had written in this area people like Layard and Dolan. It's not just a pool of academics, their work was all relevant. Obviously it's dependent on who's available and who's willing. We don't pay them, but hopefully they find it helpful. It's a two-way thing, they help us and we help them.'

This account was supported in interviews; when asked how they came to be involved, several academics spoke of relationships with the ONS going back years. Harry (TAG member, academic in economics), for instance, first worked with the ONS in the 1980s and both he and Oliver (TAG member, academic in statistical theory) had spent time on the Government Statistical Services' Methodology Advisory Committee (GSS MAC). This approach to recruitment, as William said, is not strange: ${ }^{18}$ the first people Statistical Actors within the ONS are likely to think of when looking for advice will be those who have given them advice previously. Such people are both visible and have proven that they can fit into established modes of statistical production.

Such an approach did, however, lead to a preponderance of economists sitting on the Group; while, as was seen in Chapter Five, there are bodies of well-being theory outside of economics, their theorists are not likely to have previously interacted with the ONS. A good example of this is the inclusion of Stewart-Brown, one of the lead authors of the Warwick-Edinburgh Mental Well-being Scale (see Stewart-Brown, Platt, Tennant, et al. 2011; Tennant, Fishwich, Platt, et al. 2006). As an author of a key well-being instrument, in use in the United Kingdom at the time of the programme (and so surveyed in Waldron 2010, the ONS' desk-research on what statistics were already collected on well-being), she is someone who it would be natural to turn to. However, several interviewees suggested that she was overlooked initially, and it was only on the advice of Actors within the Department of Health that she was included (interviews with Jessica, TAG member, NGO in public health, and unattributed). Stewart-Brown was known to the Department of Health, who, via bodies such as Public Health England, collect the majority of official statistics in the area of mental functioning; she was not known to the ONS, whose work rarely ventures into the realm of public health.

Versions of this story were repeated by other non-economist academics. Jessica, who worked for a public health NGO, suggested she was included 'possibly as a second thought', because her organisation had expertise in data collection. Thomas, an academic sociologist, felt he was there 'in someone else's stead', because his manager, who the ONS had originally turned to for their expertise in survey design, felt they had a conflict of interest given that they were currently sitting on the GSS MAC, and so would be evaluating the programme for the GSS. George, a psychologist, wasn't invited himself, but was sent by his professional association. In all four cases, these noneconomists are there by accident or through the involvement of a third party.

18 Indeed, as noted in Chapter Three, one interview with an actor at the ONS was secured through existing connections between them and a supervisor - the social links operate in both directions. 
Up to a point, this shows the ONS' recruitment systems working; a diverse panel was secured, and there was room for interested parties to push themselves or their nominees forward. At the same time, however, this does lead to a continuity in approach. By turning to people they know, the ONS ensure a panel which has economists making up more than half of its members, whose views are built around particular models of subjective well-being. Their approach is consonant with the work of the ONS: they utilise large datasets and relate small numbers of well-being questions to larger sets of inputs and outputs; such large datasets are exactly what is produced by official social surveys. The proponents of such models also suit the Statistical Actors of the ONS: as people who have worked with them before, they know the limitations and constraints of the ONS' processes, they know what is possible and what it likely to feasible. The recruitment process, then, sets up a group divided between a bulk who were invited in and are likely to give the Statistical Actors of the ONS an answer in line with the usual approach, and a remainder who are included less automatically and who are less habituated to the ONS' practices and conventions.

The construction of a committee which is sympathetic to pre-existing approaches is strengthened by the involvement of international statistical organisations, as discussed in the previous chapter. It was argued there that there was a potential tension between national needs, as embodied in the national debate, and international ones, which were converging on particular forms of statistical programmes which would be shared (and so comparable) internationally. Jack (TAG member, representative of an international statistical organisation), for instance, spoke of being selected for involvement because he was producing guidelines on subjective well-being for his own organisation. As argued in Chapter Five, such measures arise out of the Stiglitz-Sen-Fitoussi GDPextension project and calls at a European level for additions to GDP, placing international Statistical Actors on the side of economists in seeing well-being as a state rather than a capability.

As a final point in the establishment of theoretical disputes, it is worth briefly considering geography. Not only were most academic Statistical Actors economists, most were based in London. The London School of Economics, for instance, regularly sent three members to meetings of the Technical Advisory Group. Partly this is good fortune: it happens that the LSE has a strong research programme in economic conceptions of subjective well-being, based around the work of Layard and Dolan. However, while these two would have been natural choices for invitations to join the programme even had they been at institutions outside of London, the same is not necessarily true of their colleague Kroll, at the time a doctoral candidate. It was easier for those based in London to attend meetings, which, in this case, meant the presence of an LSE-bloc, altering the dynamics of discussions. (For more casual members, even the distance involved in getting across London to the ONS proved too difficult: Harry, an academic economist, reported that a change of job, from an office around the corner from the ONS to one in East London, spelled the end for his attendance.)

For those not in London, teleconferencing was possible, but immediately sets up a barrier between those in the meeting and those phoning in. Thomas (TAG member, academic sociologist) reported that Stewart-Brown, based in Warwick, attended in this 
manner, and that this damaged the reception of the points she was making. (Although, contrary to such accounts, the minutes of meetings which Stewart-Brown attended do not list her as attending virtually, although they do list others as such.) It can be observed here that technology has, in one way, acted to collapse distance, allowing those outside of London to contribute in ways they could not have done fifteen years ago, making possible the involvement of North American experts, for example. In another way, however, it does not bring people fully together; there is still a physical barrier intervening between individuals in and out of the room, they cannot see the impact their points are making or even if they are being attended to. Thus the locating of TAG meeting in London made a difference to who was able to be a Statistical Actor and the impact those individuals were able to have.

As with the relatively poor attendance of the Forum meetings, the partiality of the Technical Advisory Group may not represent any failure on the part of the Statistical Actors at the ONS. The stated purpose of the Group, laid out in their terms of reference quoted above, is to offer various types of advice. This does not specify what sort of advice is sought; the recruitment of Statistical Actors who already think in terms of large datasets and high-level aetiologies fall within such aims. The introduction, albeit largely accidentally, of those previously unknown to the Statistical Actors of the ONS may introduce some creative tension and serve to legitimise the project as being theoretically broadly-based, but may equally hinder statistical-construction by resulting in equivocal or unactionable advice. Even if Statistical Actors within the ONS do not know in advance exactly what form and content they want the statistical programme to have, they will have beliefs about what is feasible. Recruiting sympathetic advisers ensures that advice will tend towards the feasible, while including non-sympathetic advisers allows it to be said that a range of views were sought. As these latter views are less likely to match beliefs about what is feasible, they are always less likely to be accepted, especially in the face of a weight of sympathetic advice.

This section has argued the use of academic knowledge in the statistic-making process was not a simple matter of turning to available experts. There was a predisposition to turn to particular types of experts, those who were then inclined to offer particular types of advice. This meant that the process of developing a new statistical programme was firmly inclined towards existing modes of thought. This was compounded first by the difficulties of securing involvement by senior figures who might have offered broader perspectives, and then by geographical constraints which encouraged the involvement of particular groups of actors. To an extent, this is inevitable: the interpretation of advice is always in the hands of Statistical Actors within the ONS, so what is treated as 'good' or 'useful' advice is a function of pre-existing beliefs. Such beliefs will also shape who is thought of as a 'good' adviser: those who have previously given 'useful' advice, or those whose work suggests a sympathy with pre-existing thought. That this pattern was not broken with by the ONS results in a path-dependency around the 'Measuring National Well-being' programme which is played out in the section below. 


\subsection{The embodiment of theory: theoretical disputes as personal disputes}

'There isn't really something, "well-being", out there in the world, so what you have to do is define what you mean by "well-being" and, at the same time, say how you are going to measure it. Different people may have different definitions - I might say that I am not counting economic measures in my definition, while you might feel that income questions are necessary pre-requisites and so have to be included. Both are legitimate, but they don't represent anything 'out there' - we are defining 'well-being' and counting it at the same time, and if you change your definition you will gain different results. There isn't a right definition, but there will be some which are useful for certain purposes. You can define things in such a way that they allow you to predict other outcomes, for example. So it's very different from a representational measurement, but still useful.' (Oliver, TAG member, academic in statistical theory)

Building from the previous chapter, and above, there is a lack of clear policy-need for the 'Measuring National Well-being' programme, and many of those invited to advise on it are economists. They are not, however, all economists; by accident or design, the Statistical Actors of the ONS recruit as advisers representatives of all the major positions outlined in Chapter Five (see Sections 5.2. and 5.3.). While not true of every member, most have well-established theoretical positions. For example, Layard is a leader in the field of happiness economics, Stewart-Brown was a lead author on the WEMWBS (above), Huppert led the team who put together the EU-SILC's psychological well-being module (see Chapter Five), and Kinderman also developed a psychological well-being scale (Pontin, Schwannauer, Tai and Kinderman 2013). This creates the space for a discussion around the nature of well-being and its measurement. As Jacob, a statistician for a Devolved Assembly, put this, 'The Technical Advisory Group was large, with over 20 people at meetings. This meant a lot of different views and perspectives, which was helpful - there was a lot of input for the ONS to work with.'. This point was reiterated by Alfie, a statistician at a Whitehall Department:

'The interesting thing was the range of people involved - it ranged from people like Richard Layard, who's a hard-line Utilitarian, to people on the more psychological and public health side of things who had completely different views. Paul [Allin, who initially headed up the programme] did a really good job in navigating towards a set of measures which were broad enough not to rule any of those conceptions out - there is data collected which will be useful regardless of starting position.'

This quote acts as a caution to the argument of the previous section, which was that the Statistical Actors of the ONS were pre-disposed to particular interpretations of 'wellbeing'. Alfie suggests instead that a plurality of views were presented and incorporated into the measures, highlighting the role of Actors within the ONS in resolving differing viewpoints. This reiterates the argument of Chapter Five, that a heterogeneous theoretical context requires the agency of Statistical Actors if it is to be made sense of.

Alfie's sense that the programme offered something to all the diverse theoretical 
positions represented in the Technical Advisory Group was not universally shared. Relatively quickly in the advisory process, a clear divide opened up in the Advisory Group between academics working in economics and those working in public health. As this was summarised by Ava, an academic working in public health:

'The Advisory Group were dominated by social science perspectives, which see well-being as being determined by external factors. For economists, for instance, well-being is determined by income, education, access to resources. They are uncomfortable with the idea that well-being can be determined by internal factors. The ONS think in those terms, so those were the groups they initially turned to - social scientists and economists.'

As outlined at the start of this chapter, the difference in approach which Ava is talking about has two main aspects. One regards how well-being is determined: on the 'state' side, single-question subjective well-being measures, predominately life satisfaction measures, are most widely used; those looking at well-being as a capability prefer multiitem measures of functioning, as determined through an instrument such as WEMWBS or the EU-SILC. The other, related, factor is what this means: whether subjective wellbeing is amenable to analysis using mechanistic causal models. As discussed in Chapter Five, such an approach is valued in economics because it allows the calculation of the average utility brought about by an intervention. For the Actors involved in public health, however, well-being was not seen as being subject to general relations with external factors in the same way. The value of 'well-being' is not as an end-point in calculations of utility and efficiency, but as a basis from which an individual can act in the world.

This can be seen in an example from the Advisory Group minutes of 4 February 2011:

"A key point of discussion was what variables go on the left hand side of the equation. One view held that well-being was the only variable on the left hand side and all over [sic] variables were determinants of it. The alternate view was that some of the determinants were left hand side variables themselves and should be measured." (p1)

It is interesting that well-being is here being considered as 'an equation' at all. In principle, it need not be; the programme could instead be read as a non-formally related basket of measures, with well-being rising as the measures as a whole rise. To think of it as an equation is already to think about it in mechanical terms, as a matter of causes and effects. Such a conception is useful for those interested in rational maximisation, as it allows the question 'which cause has the largest effect?' or 'what is the most costeffective intervention in terms of effect-per-pound? For those for whom 'well-being' is a set of capabilities such models are misleading; well-being does not appear as an outcome measure, but stands in the background mediating other factors. As highlighted in Chapter Five, economic research already considered subjective well-being measures as outputs, and used existing social surveys to make arguments relating to the wellbeing impacts of external factors. The discussion highlighted in the quote above shows this methodology being built in to the ONS programme. This is possibly a function of the weight of economists on the Advisory Group, both in terms of influence and 
number.

A number of potential explanations for the dominance of the mechanistic, state model of thinking were put forward in interviews by Statistical Actors with different theoretical backgrounds. Jessica, an academic working for a public health NGO, suggested that the recruitment discussed above was a key factor:

'Key to the programme was a split in the Technical Advisory Group between two groups - economists and psychologists. Well-being was traditionally seen as a health issue, until it was picked up by the Sen-Stiglitz-Fitoussi report, which made self-report measures much more of an issue for economists. The Cabinet Office initially tried to appeal to economists and ended up stacking the group with them.'

This 'stacking of the group' meant potential ignorance of measures and constructs which don't appear in the economic literature (and so a tendency towards single-question measures, such as satisfaction, which appear in global surveys; and a suspicion that more complex measures could be collapsed into single-question measures anyway or, at least, that single measures were good enough). As Jessica went on to say:

'Politically, the point of well-being was to slant away from economic thinking, but the Cabinet Office had turned to economists because that was what they knew. Sarah Stewart-Brown had to fight to even get onto the TAG. The economists on the Group then perpetuated the model they already had. Which has its uses, but it isn't branching out. We had a number of big discussions around this - we had the $W E M W B S$ which is a validated, multidimensional model used elsewhere in the UK, so why not make use of it?'

Added to this, the fact that the Statistical Actors of the ONS had started by recruiting people they knew meant that there were many members of group who were already comfortable with the practices of the ONS. They were automatically insiders, by virtue of having been invited. From the perspective of the Statistical Actors of the ONS, even the economists in attendance who they hadn't themselves invited were approaching the problem in a familiar way, making them easier to listen to. As George, an academic psychologist, put this:

'They [the ONS] were very welcoming, but there's an obvious hierarchy, which you expect, and you know how you fit in. The economists are comfortable, they've worked there before. It goes roughly: ONS, then the economists close to the ONS, then other economists, social statisticians and everyone else.'

Again, as with the question of recruitment, there is no implied criticism here (and there certainly wasn't from George, who saw this hierarchy as a perfectly reasonable factor for him to work with and around). As argued above, it is understandable that the Statistical Actors of the ONS would first turn to those they'd worked with before and that they would be better able to accept the arguments they were putting forward. Existing social structures here work to create durable social networks through the 
actions of agents. This highlights the way that individuals and their decisions shape the results of the statistic-making process, but also the subtle, unspoken constraints on that agency. Had the Statistical Actors of the ONS opted to recruit via alternative channels which resulted in fewer economists sitting on the Technical Advisory Group, the statistical conception of well-being would be much less likely to be focused on the mechanical relation between subjective well-being and its 'determinants'.

This can be extended: not only were the Statistical Actors of the ONS largely recruiting from economists, they also turned to three of them to write a scoping paper at the very beginning of the programme, surveying the field of subjective well-being. This paper, Dolan, Layard and Metcalfe (2011), proposed that the ONS ask four subjective wellbeing questions, covering satisfaction, eudaimonia and positive and negative affect (see Chapter Five). As Oscar, at the ONS, described the importance of this paper:

'The Layard et al. paper was very important. The ONS had an intern for a while doing desk research - what were the sources of well-being data that already existed, how was well-being understood ${ }^{19}$. We felt we needed to commission research in how to move beyond this - we didn't have the expertise in the office, so we commissioned advice really.'

'Advice' underplays the role that this paper had: the questions the paper proposed became the questions the Advisory Group were to discuss. While they changed the wording (over the protests of Layard, who was attending meetings and so 'advising' on his 'advice', see AF Minutes, 4 February 2011), the four questions proposed in the 2011 paper were the four questions that were tested by the ONS and which formed the subjective well-being component of the programme. There is an element of pathdependency here, as the minutes of 30 May 2012, p.5, suggest: once testing had started, there became costs attached to changing the questions or format. By the minutes of 3 December 2012, p.4, the Advisory Group are suggesting that the ONS should not even adjust the wording of its subjective well-being questions for at least 10 years, to allow a series of comparable data to be established. The subtext of this last point is that, even if the questions being used are in some sense inadequate, it is better to be half-right and have time-series data than to be fully-right and not.

As Thomas, an academic sociologist, described the role of the Dolan, Layard and Metcalfe (2011) paper:

'It was obvious when I joined, as is often the case - policy never comes out of a blue sky, some group always sets the agenda. So when the ESRC have a new funding programme, someone always writes their evaluation criteria programmes are pre-steered. This had the handprints of the LSE all over it. There was a background paper written by Paul Dolan which reviewed the literature and they suggested members for the group. So the individualistic approach was hard-wired in - at the first meeting of the group, the four items they ended up using were already on the agenda. The ONS was clearly steered towards the individual and modest in terms of the survey space it was making available for the programme. The rules of engagement were

19 This will be Waldron (2010). 
very clear.'

Thomas' reference here to 'the individualistic' approach is a different version of the objection to the mechanistic, state approach to characterising well-being discussed above. The objection is that well-being is being treated as a property of individuals rather than as one of larger entities such as communities. This treats 'national wellbeing', for instance, as the aggregation of individual well-beings, rather than something separate or emergent.

While Thomas' claim that the authors of Dolan, Layard and Metcalfe (2011) were involved in the recruitment of members of the Advisory Forum and Technical Advisory Group was not supported in other interviews (compare with Oscar of the ONS' account of the recruitment process above), he was right to claim a key role for them in setting the agenda. For example, the first set of Advisory Forum minutes (5 January 2011) record:

"He [Paul Dolan] stressed the need to consider how the measures will be presented. Added to that he stated that subjective measures should cover measures of experience (sense of enjoyment and other emotional responses) and measures of evaluation, (a broader sense of satisfaction), as well as eudemonic [sic] accounts (a sense of purpose, meaning and 'worthwhileness')." (p.3)

What is happening at this point is Paul Dolan is presenting to the Forum, the majority of whom already share his position as economists working with subjective well-being or are statisticians sympathetic to it, a paper which represents the only survey of the field the ONS commissioned. Unsurprisingly, by the time the first Technical Advisory Group meeting is held a month later, this 'advice' has become an operating position:

"Stephen Hicks (ONS) set out the current questions ONS plan to ask on the Integrated Household Survey (IHS) from April." (p2)

There is already by this point very little room for manoeuvre. The decision has been made to pursue subjective well-being along the lines of the 'state' model. The most that critics can do is adjust the wording and try to secure coverage for their own constructions of well-being elsewhere in the programme.

Again, this need not be taken as a criticism. Thomas, the sociologist who above was noting the 'fingerprints of the LSE' was not surprised by this, as he says 'policy doesn't come out of the blue'. George, a psychologist, was somewhat more forthright in his assessment of his standing relative to the economists on the panel:

'Honestly, I felt fine. In a sense, I saw part of my role as being a representative, and that's two way - what would we say about this, what are the ONS saying about this? I don't expect to say "Do it my way" or "Do it our way", but we did influence this. And it's not about "us", there were other bodies who were influencing and pushing similar points. Some of my colleagues suggested that I should be more forceful and impose myself, but 
psychologists need to understand that the ONS and politicians aren't just sitting there waiting for people to tell them how to do their jobs. They have ideas and objectives, and what we're offering is just one facet of that.'

The point here is similar to that made earlier when talking about recruitment: the Statistical Actors of the ONS have to start somewhere. It makes sense both that they will seek out people who think along the same lines that they do, and that those people are likely to deliver them ideas they find persuasive. Given that the starting-point that Oscar and William of the ONS identified in their interviews was the Stiglitz-SenFitoussi report (see previous chapter), a report written by economists who were looking at GDP-extension using the ideas familiar to them from their field, it is unsurprising that the Statistical Actors of the ONS turned to economists and were sympathetic to their suggestions. The point remains, however, that the consultation through the Advisory Forum and Technical Advisory Group was limited from the beginning; while the final form of the programme was not predetermined, it was strongly prefigured.

There is an interplay here with practical and funding issues, which were flagged-up in the previous chapter. One of the benefits of focusing on four subjective well-being questions is that it is possible to add them to existing surveys without unduly extending these surveys. By the same token, once they had decided not to create a bespoke wellbeing survey instrument, the Statistical Actors of the ONS were limited in the space on the existing survey they would be extending that they could devote to well-being (see Sections 4.1.4. on the financial pressures underlying the programme and 4.2.5. on the context of austerity in which the programme arose). Dolan, Layard and Metcalfe's (2011) four-question suggestion is thus a workable solution, and one which becomes locked-in quite quickly. The decision to opt for four subjective well-being questions also provides the background for the debates around question wording which were discussed in the previous chapter: while one of the selling-points of the four-question approach is that it allows international comparability, the wording becomes one of the few things the academic Statistical Actors can influence (see Sections 4.1.3. on geographical networks and 4.2.4. on fast policy networks).

It is within this context that the public health academics, sociologists and psychologists are operating: they have been invited to advise, but find that a decision they might have advised against has already been taken. To return to the public health academic Jessica's explanation of the problem above, 'Economists have this idea of life satisfaction, but to a psychologist, what is "life-satisfaction"?' (see also Sections 5.2. and 5.3.). This difference in conception becomes expressed through two debates, one around the wording of the four subjective well-being questions, and on around whether or not some measure of mental functioning should be included. An example of the former comes from the Technical Advisory Group minutes of 4 February 2011:

- "Professor Felicia Huppert (Cambridge) - Life satisfaction muddles experience and expectation. Satisfaction not used in health, advertising etc anymore. 'How good is your life' is a better question.

- Sally McManus (Natcen) - Satisfaction in health is explained by demographic variables in health. Old 'Mustn't grumble', young 'optimistic'. Experience is a much wider used measure in health." (p2) 
The thorough-goingness of these objections should be noted. What is being expressed in the minutes as an objection to wording ('you should use "how good" not "satisfied"') can be read as an objection to the question itself ("'satisfaction" doesn't mean anything'). Ultimately, it is an objection which fails: Layard argues against the use of 'good' as "not being subjective well-being" (p.2) and the meeting concludes with Allin of the ONS thanking participants for their contribution and promising only that they will be considered. Such consideration did not result in a change to the wording; the question the programme currently uses is "Overall, how satisfied are you with your life nowadays?" (see Office for National Statistics 2014b, p.7, fn.1)

The failure of Huppert, McManus and any others who agreed with them to alter the wording is partly due to the pressure for international comparability (see TAG Minutes of 4 February 2011, p.4) and partly because their objection is understood as being to wording and not content. When 'good' and 'satisfied' are seen to be interchangeable, the fact that 'good' is used in non-economic contexts does not provide a reason to break with international comparability or with the established body of economic well-being research that rests on this comparability. That the move to change the subjective wellbeing questions were understood as objections to wording rather than content is suggested by the fact that no interviewees outside of public health and psychology mentioned question wording as being an issue at all. Instead, they saw debates of the Advisory Group as focusing on attempts by non-economists to include additional measures of mental functioning alongside the four Dolan, Layard and Metcalfe (2011) questions.

For example, when Jack, a statistician with an international organisation, was asked directly about whether the diversity of conceptions of well-being represented in the Advisory Group led to disagreement, he said:

'No. There was striking consensus on the way to move forward. The only real disagreement was between some of the health psychologists and some of the economists over the framing of subjective well-being. Other than that there was an extremely high consensus.'

When pushed on this disagreement, he said:

'It was an isolated disagreement, connected to the fact that some group members had recently developed their own subjective well-being measures which they championed over more established measures with existing bodies of research support.'

This latter comment betrays a very limited view of the well-being literature. The two group members he is most likely to be referring to are Huppert, author of the EU-SILC's eudaimonic well-being module, and Stewart-Brown, who was author of the WEMWBS. While it may be fair to say that these do not have time series of the same length which subjective well-being questions do, it is completely inaccurate to imply they lack research support (see Chapter Five for a discussion). Again this arises naturally through the process of seeking advice in the way the Statistical Actors of the ONS did: those whose views are most likely to be appreciated are those whose advice is closest to the 
Statistical Actors of the ONS' starting position. Those who have been brought in from other fields carry with them knowledge which is alien and which may seem less reliable. This is read by Jack as self-interest, in comparison with his reasoned appeal to established research.

From the other side of the debate, Jack's attitude of suspicion was itself written off. In the terms of Ava, an academic in the field of public health:

'There's a mindset thing, which is probably the arrogance of economists they have research which looks at this so it doesn't occur to them that other people may also have looked into it. So they make sweeping judgements about alternative measures, and pick up things from other disciplines without necessarily fully understanding them.'

What comes out of the comparison of these two comments is the limited room that there was within the Technical Advisory Group for dialogue, which arose because the two camps didn't really understand each other. What is at stake is not a question of 'how do we count well-being?', but the more basic question of 'what is well-being?'. WEMWBS or the $E U-S I L C$ measures are championed by those in public health and psychology not because it is the pet measure of one of the participants, but because those in public health and psychology see it as counting well-being while questions of life-satisfaction do not. For those on the other side of the debate, 'well-being' is a relatively simple output measure, assessed by individuals and more-or-less captured by overlapping subjective well-being questions. While conceivably there is room for improvement on the wording of the subjective well-being questions, their essential correctness means that concerns such as the existence of time-series datasets, rather than theoretical purity, influence the decision over what measure to use.

In this context, the framing of Oscar at the ONS is interesting:

'The main schism in the group was between people who had a particular approach and stuck to it, and those who thought the multiple approaches that the ONS adopted were useful. Those from a psychology background particularly said 'we've been researching this for years, and you need to be able to drill down into people's condition, you need something like WEMWBS to properly understand well-being'.'

What this framing misses is that the 'multiple approaches the ONS adopted' were, in fact, 'a particular position' which originated in the Dolan, Layard and Metcalfe (2011) paper, and that was then 'stuck to' throughout the advisory process. The debate is not between 'those championing multiple perspectives' and 'those championing one', but between a particular established set of subjective well-being questions and indicators of mental functioning. The argument by the non-economist is that one is well-being, and one is not. As Ava (TAG member, academic in public health) expressed this:

'Economists use life satisfaction, occasionally happiness, that's their starting point. That's not a very good well-being measure, satisfaction varies 
according to level of well-being. At the lower end of the scale, you evaluate your life according to external referents, satisfaction is about how you're doing relative to other people - do you have the bigger car, the bigger house. At the higher end, the referents are internal, and it's about how contented you are - the size of the car doesn't matter, you're happy with smaller car. So it's a flawed measure, a lot of what it's asking is about comparison. But economists are coming in with this measure, and they think they have the question stitched up.'

In this light, what Oscar is suggesting is something of a compromise position - of multiple measures because there is no agreement on what 'well-being' is - is nothing of the kind. Instead, it is a position from a particular standpoint, that of the Dolan, Layard and Metcalfe (2011) paper, strengthened through discussions with advisory groups largely made up of those who already work from that standpoint. Although Oscar may genuinely believe this to be a compromise position, maximising the number of conceptions the programme incorporates, it is only because he is persuaded of the essential correctness of the position to start with.

With Statistical Actors holding differing positions on 'well-being', personal dynamics impacted on the way the debate was conducted. Jessica, who worked for a public health NGO, described the difficulties those in psychology and public health had in conveying their position:

'Sarah Stewart-Brown tended to hold back - the WEMWBS was her measure, so she didn't want to look like she was pushing it. My expertise was more practical than theoretical, so I didn't feel I was in a position to argue too strongly for it either. But after the meetings, I did circulate emails to say - we have a measure, it's multidimensional, it's validated, we could use it.... Both Felicia [Huppert] and Sarah are strong voices, but they were both from the psychology side and both had their own measures, so possibly they failed to pull together against the economists who were solid in their opposition to WEMWBS. I don't know though.'

This quote is particularly interesting given Jack's earlier writing-off of the debate as being between those with research evidence and those with their own new measures, as it suggests that Huppert and Stewart-Brown were conscious of this as a weakness in their negotiating position. If they did hold back on those grounds, Jack's comment suggests that their modesty brought them no advantage. This highlights an additional hurdle which psychologists and those in public health had to overcome: not only were they in the minority and arguing against an entrenched position, they were also divided amongst themselves and trying not to be seen to push themselves forward.

As a further potential hurdle for the psychologists and public health specialists to overcome in securing recognition for their views, they were also predominantly *female and facing an Advisory Group which was predominantly *male. As one participant, who

* Following the protocol set out in Chapter Three, gendered terms will be preceded by an asterisk to make clear that they are ascriptional. Gender was not asked about in interviews, so it is generally not known how Statistical Actors self-identified. 
didn't want to be identified, described her experience:

'There is also an element of male chauvinism.... These things work subtly, but it was a factor. Women's voices tend to not to be heard as strongly as men's on these committees and it was primarily women who were contributing the psychology perspective.'

The participant's desire not to be identified is itself telling; she had already endured the experience of having her views written off, partly, she felt, because of her gender, and did not want the fact that she was conscious of this to be treated as another reason for other group members to write her off. This quote can be compared with George, a *male psychologist, who above said that *he 'felt fine' during the consultation process. George had rationalised *his experience as one of a hierarchy which had economists at the top and *himself somewhere towards the bottom, and so did not expect to be listened to. This allows *him to depersonalise the experience of not being listened to. This, possibly, is a luxury of *his gender; as a *man among *men, chauvinism is not something *he is subject to and so will not be how *he experiences the situation.

To summarise the arguments of this section, the initial recruitment of an economistdominated panel, and the commissioning from economists of an early position paper sets up the 'Measuring National Well-being' programme with economic conceptions of well-being at its core. While holders of rival theories argue that such a conception is not actually a conception of well-being at all, both economists and those at the ONS fail to accept or perhaps understand this objection. They experience such objections as a series of attempts to gain more exposure for pet measures, or as arguments to change the wording of questions. Those from non-economic backgrounds experience themselves as ignored or sidelined. These disagreements, on the non-economic side at least, are experienced personally, as 'arrogant' economists ignoring them, with a potential chauvinistic aspect in addition.

These interactions between Statistical Actors again show the importance of agency and social relations in determining the final form and content of official statistics. The choice of advisers is partly the result of pre-held beliefs and social networks, and the existence of these makes advice easier to accept, which in turn strengthens confidence in advisers. At the same time, these beliefs make contrary arguments harder to understand and still harder to accept. The ability of Statistical Actors to push forward unpopular arguments is affected by a series of personal factors, such as the inability to present a united front and the role of gender. Throughout, Statistical Actors are considering theory as embodied, personal factors; associating positions with preconceptions around the individual making it, second-guessing their reasons and using these as a reason to accept or reject them.

\subsection{Conceptual issues beyond subjective well-being}

While subjective well-being was a key focus of the advisory process, it was not the whole of the programme. Ultimately, the programme included 41 headline measures, plus a raft of 'domain' measures released on a less regular basis, which amounts to a re- 
branding of the ONS' social statistics programme. The existence of domain measures also allows an extension of the programme into areas where data was not formerly collected by the ONS; for example, the TAG minutes of 11 April 2011 note, "Roughly three-quarters of WEMWBS questions are planned for the eudemonic testing module." (p2). This provides some context to Oscar of the ONS's complaint, quoted earlier, about the difference between those who wanted one measure and those who wanted multiple measures; somewhere within the programme, all of the main conceptions of well-being outlined in the taxonomy of Chapter Four were included. On one potential reading, those arguing for mental functioning measures were missing this bigger picture.

However, this is a bind that Statistical Actors of the ONS partially get themselves into through the emphasis on headline measures. Introducing the TAG minutes of 26 January 2012 (p.1), Paul Allin, the meeting's chair and head of the programme at the time, notes that the programme is about much more than subjective well-being, welcomes the group's support in getting away from the media misconception that the programme is merely 'Mr Cameron's Happiness Index'... and then introduces a meeting which only has subjective well-being on the agenda. This is in keeping Terms of Reference for both the Forum and Advisory Group, quoted above, which focus on subjective well-being for reasons of its novelty. The focus on subjective well-being, however, elevates it as part of the programme, both in the minds of participants in the advisory process and within the programme's conceptual framework.

William, of the ONS, describes this:

'We found a range of indicators from various sources, but had gaps, particularly in subjective well-being. We drew on advice, particularly from academics working in this area, and developed four questions which were included in the Annual Population Survey - looking at evaluations of overall life satisfaction, reports of happiness and anxiety, and eudaimonic wellbeing. Those are based on a scale of $0-10$, with 0 being 'not at all' and 10 being 'completely'.'

Subjective well-being questions are being developed here as well-being questions. Other areas which appear on the programme - from unemployment to the public debt:GDP ratio - are pulled across as they are from their existing statistical programmes. There is an interaction here with questions of finance, as raised in Section 4.1.5. and discussed in the previous chapter. However, there are a set of conceptual problems around whether a statistic developed for a particular purpose can serve as part of a well-being programme.

This was touched on in the TAG meeting of 29 March 2012 (p.3), which raises "The need to be mindful that when measures are taken out of context they can lose meaning, there needs to be a lot of consultation on the draft new measures with the producers of the statistics which are included." When this point was put to Jack, who worked for an international statistical organisation, he brushed it off:

'Conceptually, there might be a problem there, but practically not at all - it's almost a nonsensical question. Where you don't have data for a concept, you 
create a new measure, but if you already have a measure it would be foolish to recreate it. Things like unemployment have a long history, large evidence bases and are very well measured. Where there were gaps, like in subjective well-being, the ONS sought expert advice - from health psychologists, nonhealth psychologists, economists, civil society groups, the OECD - and developed measures to fill those.'

This misses the thrust of the objection, which is whether or not it is appropriate for existing measures to be placed in the context of well-being; that 'unemployment as counted' and 'unemployment qua well-being' might be separate things (with the latter constituting a gap). Oliver, an academic looking at statistical theory, was more sympathetic, but felt that the question was one of whether there would be sufficient benefit to a re-calculation:

'But yes, in an ideal world perhaps, some of these contributory statistics and data streams might be collected differently or given different pragmatic definitions. A lot of these are already collected and are incorporated into international standards, and are already quite good.'

As in the previous chapter, there is an international context in which existing statistics sit: taking the example of unemployment, its definition is mandated at the European level (see Commission Regulation 1897/2000, Article 1.1. and Annex 1), which means that any UK-level redefinition (for instance, one which counted distance from the labour market in the manner of International Labour Organization 2013) would need to run alongside the existing statistic. There would thus be a doubling up of unemployment figures, a pattern which would also be necessary with other statistics within the programme. It is from here that Jack forms his 'practically nonsensical' position. As an additional explanation, the lack of specific policy driver offers little incentive to shift away from statistics which are tied to other policy rationales and ways of thinking.

However, this distinction between the practical and the conceptual highlights the construction of the programme as a set of practical responses. As William of the ONS expressed things above, the Statistical Actors of the ONS started from what already existed and paid to develop new measures where they did not. But then there was the problem of making the measures they had cohere with one another. As Jessica, who was from a public health NGO, expressed this:

'One of the odd aspects of the programme was the conflation of measuring well-being as an outcome (perhaps including subjective well-being, perhaps as measures of how well people are doing in life), and measuring predictors of well-being. What do you do with something like income - is it a driver or a result? When psychologists look at the things which influence well-being, income falls out of their models (when you control for debt). But there are historic conceptions - we promote income because we assume it's an enabling factor for a better life. So there were challenges - while income was being pushed for inclusion despite being unimportant, relationships were initially left out.' 
This description is supported by the TAG minutes of 3 December 2012 (pp.4-6) which discussed at length the ONS' regression models which sought to explain the subjective well-being data. This discussion sits very awkwardly with arguments that subjective well-being are not the whole of the programme, but fits very well with a mechanistic approach which looks at large datasets and aggregate movements. In his interview, Alfie, a statistician working in Whitehall, distinguished between a 'cost-benefit' strand of well-being theory, and a 'public health' strand. The former is interested in economic questions of maximising subjective well-being output as efficiently as possible, so treats subjective well-being as an output and everything else as an input. As discussed above, the 'public health' strand is more interested in well-being as a mediator between individuals and their external conditions. Alfie argued that the decision to place subjective well-being questions on the Annual Population Survey served the former but not the latter, an argument in keeping with Thomas' criticism of 'individualistic' approaches (above) and with the public health academics' arguments against subjective well-being (above). Retaining existing statistics also serves a cost-benefit analysis approach: without the trouble of creating new survey instruments, the Statistical Actors of the ONS retain access to large datasets suitable for regression modelling, and so for 'discovering drivers' of well-being.

On a smaller scale, this can be seen in the way that the new measures are constructed. The minutes of the TAG of 30 May 2012 (p.4) note that, conceptually, the two affect questions make most sense as binary-response questions. However, "A binary response to the affect questions would lose the ability to provide distributions - this is something that is of most use to policy makers". This goes beyond the mere recognition of importance of policy concerns, as when the minutes of the preceding meeting (29 March 2012, p.3) observe: "[An issue raised was] The importance of considering the measures in relation to policy and the Cabinet Office". Rather, this is a call for data of a particular type to drive policy, but in the light of the previous chapter, there is no specific policy to be driven. Conceptual purity is sacrificed for what is essentially a hedging of bets, making the statistic as useful as possible by allowing differences and inequalities to be visible in the data in the hope that this will make the data interesting to policy-makers.

However, pragmatism does not result in an equality of viewpoints; the measures selected and the emphasis given to them permits some actions while precluding others. While two-thirds of the WEMWBS measures were included on the eudaimonic testing model (which is used for one of the measures of population mental health, see Appendix C), ensuring mental functioning was represented as part of the programme, there were four subjective well-being measures collected on a larger scale through the Annual Population Survey, on a more regular basis, released as headline measures and included within the ONS' regression models. As Thomas, an academic sociologist, put this:

'The minutes the ONS put out aren't very detailed, so you won't have the full shape of the discussions, but I'll sum it up like this - those interested in the individualist approach saw perceptions of society as driving well-being. They saw life satisfaction as the dependent variable, so everything else both perceptions of society, and its constituents like trust in government or sense of community - as drivers. That meant any interest in them was subsidiary and secondary - we could look at them later, once life 
satisfaction was established and we were looking for things to explain or predict it.'

On this reading, the media are not entirely incorrect in their focus on subjective wellbeing; subjective well-being did become the focus of the programme. While alternative conceptions, such as positive mental functioning or evaluations of the quality of society, were not excluded from the programme, they were not central to it. While they are available to be acted on in some form, they have a clear secondary status. Reviewing subsequent policy papers, Alfie (TAG member, statistician in a Whitehall Department) is correct in arguing that the 'cost-benefit' strand of well-being thought has predominated; the Green Book (HM Treasury 2011a), papers by Fujiwara of the Treasury (Fujiwara 2013; Fujiwara and Campbell 2011) and progress updates from the Cabinet Office (2013) collapse well-being policy into the statistical relation between interventions and movements in subjective well-being. This is, of course, what happiness economists have been doing all along.

To summarise the arguments of this section, the emphasis on economic conceptions of well-being spread beyond the new measures devised for the programme. By considering well-being as a mechanical process, with inputs and outputs, the ONS effectively avoided conceptual questions about the appropriateness of 'input' measures. This also fitted with wider cross-cutting needs to keep costs down and to not duplicate existing statistics. It does, however, raise questions about the programme as a 'well-being' programme, rather than as an extension of existing social statistical collection programmes. Similar questions are raised by the construction of novel measures, which were more influenced by questions of practicality than of theoretical purity. This again highlights the role that Statistical Actors play in negotiating theoretical and institutional contexts.

\subsection{Conclusion: 'Measuring National Well-being' and multiple conceptions of 'well-being'}

'The aim was to produce an accepted and trusted set of National Statistics which help people monitor national well-being'

William (ONS)

Question: With that in mind, the ONS seem to be in a thankless position. 'They're always going to get it wrong? Yes, up to a point. But consider GDP - there are three different ways of measuring it, and the way we currently count it is due to change soon as a result of shifts at the European level. But people don't really think about it, they live with it. If they dug down, they'd be pulling their hair out; this is a problem for something as well-established as GDP, it's not something novel in the case of well-being.' 
With only a few exceptions, everyone spoken to in the process of this research was positive about the work of the ONS in constructing the 'Measuring National Well-being' programme. The extent of the consultation, and of the public debate, and the roles played by first Paul Allin and then Glenn Everett in managing the debates of the Technical Advisory Group were highlighted in interviews for particular praise.

However, while the conduct of the process was praised, the result did not meet with the same levels of approval. For instance, Tomlinson, who sat on the Advisory Forum, and Kelly (2013), negatively characterise the programme as evidence of a "behavioural social policy" (p.152); similar doubts over the framing of subjective well-being in the programme are held by Scott (2015) and Sointu (2005). As Oliver, an academic looking at statistical theory, suggests in the quote above there is a certain inevitability about such negative readings; the ONS gathered together Statistical Actors from diverse backgrounds and created a programme which was polyglot in its conception of wellbeing. From the last chapter, there is also an element of difficulty which Oliver has overlooked; in as far as there is no predetermined practical purpose for the statistic, beyond its and William's vague ambitions quoted above, the programme is more vulnerable to theoretical critiques. This can be seen in the comments of Jessica (TAG member, NGO working in public health):

'I think in the end the ONS did a fantastic job in balancing all the demands on them, but they did end up with four distinct questions which can't be combined into a single measure, which make them hard to summarise and to communicate, and which leaves them slightly tokenistic.'

For Jessica, and others who held to non-mechanistic models of well-being, the programme doesn't measure well-being. It gestures towards well-being, but does so in a way which serves existing agendas and ways of doing things; cost-benefit analyses and regression models which look for drivers of life satisfaction. This can be understood both as a result of the ONS filtering 'well-being' through their existing modes of thinking, and through their recruitment of like-minded advisers to the Advisory Forum and Technical Advisory Group. This made it very hard for the relatively few members of these groups who did not hold to economic conceptions to get their points across. While the ONS did listen, and did include alternative conceptions within the wider programme, the focus of the programme remained mechanistic.

As a balance to this, it is worth noting the thoughts of George (TAG member, academic psychologist):

'The question isn't "was this a good job, is this the best we could do, have they got it exactly right?", but "what would things be like if we weren't thinking about well-being?" It would be like Detroit, it would be shit. I think some people have got hung up on trivialities, "you've done it wrong - you should have done it my way". They've done something, we can talk about it, we can adjust it over time.'

While this is somewhat overstated - much of the programme already existed as social 
statistics collected by the ONS or government departments, and the elevation of particular statistics into 'headline measures' makes others correspondingly less prominent and visible - it highlights a point which Oliver also alludes to above. The running down of the Technical Advisory Group and the elevation of the subjective wellbeing measures to 'National Statistic' status does not entail the end of the development of the programme; GDP, which the 'Measuring National Well-being' programme is to complement, has been adjusted on a continual basis since its development in the 1930s, most recently to include black-market activities (Abramsky and Drew 2014). The existence of a programme provides both a set of measures which can be adjusted and a focus for debate around what well-being is.

The reverse of this is also true: the existence of a programme validates and entrenches certain conceptions of well-being while obscuring others. 'Well-being' in policy and debate is not the 'well-beings' of the multiple conceptions included in the programme, but the 'well-being' of the headline measures. As the minutes of the TAG for 3 December 2012 (p.4) observe: 'It would not be sensible to change the wording for at least 10 years'. George may be happy to work with the statistic he has for the next ten years, but this was not a position universally held.

The contrast in the readings of the programme made by Oliver, Jessica and George highlights the key argument of this chapter. In Chapter Five, the theoretical landscape of well-being was surveyed. The present chapter has seen that landscape embodied in debates and discussions between individual Statistical Actors. Those debates were largely not settled on theoretical grounds, but on interpersonal ones: by who was trusted, who was listened to, who was in a majority, who could make themselves understood. Uncovering these debates has shown the value of understanding official statistics as a social process by showing that the form and content of the programme is influenced by Actors with agency interacting with each other and with their institutional contexts. For example, it has shown how the four subjective well-being questions came out of early decisions by Statistical Actors at the ONS to seek advice from those whose work they were familiar with, and the way in which affinities with economic approaches protected these questions from critiques from other disciplines. As will be discussed in the final chapter, this does not preclude any of the readings of official statistics outlined in Chapter Two, but does provide them with new questions to answer. 


\section{Chapter Eight \\ Understanding official statistic-making as a social process}

\subsection{Summary of the thesis and its arguments}

This thesis has set out to answer the question, 'Does an examination of official statisticmaking as a social process add to the understanding of official statistics' form and content?'. This question arose out of Chapter One, which noted the literature around the 'peopled state' (Jones 2007; Peck 2001) and argued that official statistics were objects constructed by agents within structures and institutions and, as a result of this, an understanding of statistics required an examination of that agency at play. It suggested that while official statistics are discussed in the academic literature, there is a gap in that literature around their construction. It was argued that this gap was an important one to fill, as the conditions of production will set the limits of possibility for the official statistic, defining the opportunities and constraints which determine its form and content.

Expanding on these arguments and previous work on the complexity of the state (Rhodes 1992), Chapter One developed a simple conjectural model to describe the production of official statistics. It posited a division between Commissioning Actors, who request a statistic, the Statistical Actors who produce it, and the Statistical Audience, who receive it. Even this very simple division of responsibilities creates a necessary set of interactions between actors, where the finalised official statistic is an outcome of these interactions. If, as seems likely, these categories of actors are themselves are not homogeneous, but made up of multiple individuals with diverging aims, powers and interests, then the outcome of the statistic-making process cannot be read as a simple expression of the will of the Commissioning Actors, or as some neutral expression by the Statistical Actors of theory or empirical fact. Rather, as a made product, the official statistic is highly contingent, the result of the interactions of individual actors with each other, their institutional contexts, resource constraints, technological abilities and so on.

Chapter Two contrasted this set of suppositions with two broad strands of existing literature around official statistics: the 'critical', which mainly covered writings in the Foucauldian and Marxian traditions, and the 'native', which covered writings by official statisticians and statistical theorists. The critical literature suggested that the official statistic was a technology of control, designed to allow 'action at a distance' (Latour 1987) on populations, either as a broad expression of power (Miller and Rose 2008) or as an expression of class control (Miles and Irvine 1979). While it was accepted that it was possible that official statistics were used in this way, it was argued that the conjectural model of Chapter One meant that official statistics could not have been fully intended in this way. The space between the Commissioning Actors who wanted to control and the Statistical Audience who was to be controlled was made highly contingent by the presence of Statistical Actors, meaning that the intention of Commissioning Actors could not be simply translated into a statistical output. Control was in no way guaranteed by the statistic. The native explanation of statistics was insufficient for similar reasons, assuming that the statistic-making process was merely a codifying of empirical fact (see, for example, Jones and Fender 2011). Given the nature of the conjectural model, there could be no guarantee that such a codification was possible; constraints and limitations could prevent it, as could the social nature of the 
interactive process of construction.

Against these two readings, Chapter Two suggested a more fruitful way of understanding official statistics could be found in utilising the insights of the literature on social construction (e.g., Hacking 1999; MacKenzie 1981). This literature takes seriously the fact that objects are made by people, and so are influenced by the knowledge, resources, abilities, interactions and environmental constraints of those people. Such an approach captures the premises of the conjectural model and suggests methods through which it could be tested. This allowed the development of four specific questions: How can the official statistic-making process be understood as a social process? What are the components (institutions, theories, individuals, technologies, \&c.) of that process? How do these components interact to produce the official statistic? What are the implications of this for our understanding of the official statistic?

Chapter Three built on this social constructionist literature to propose an epistemology of official statistic-making, and an attendant methodology and research design. It suggested that, as a social process, official statistic-making is best explored socially, through direct engagement with the individuals involved, their institutional and theoretical contexts and the interrelations of these. The 'Measuring National Well-being' programme of the UK Office for National Statistics was proposed as a case study where such an approach could be undertaken. Unlike the majority of official statistics produced globally, this programme is relatively recent in origin, which meant that the individuals involved were still available to comment on the process of production. While it was not possible to observe directly the process of statistic-making, this could be partially observed through interviews with individuals involved in the process, supported by the examination of meeting minutes and other secondary material. By allowing the explication of the official statistic-making process, this methodology makes a direct and original contribution to the literature around official statistic-making.

As a starting point to this examination, Chapters Four and Five outlined the institutional and theoretical background to the 'Measuring National Well-being' programme. These were aspects of the world which Statistical Actors would be forced to engage with, such as the institutional form of the Office for National Statistics and the theoretical literature on 'well-being'. These chapters noted the complexity of the statistical programme's situation and the number of choices that would need to be made by the Statistical Actors. This material further problematises the literatures of Chapter Two by making clear that the official statistic cannot be a neutral object, but instead must be the product of negotiation and decision. They make contributions to the literatures around the Office for National Statistics, policy-making in the UK, wellbeing theory and well-being measurement.

Chapters Six and Seven built on the previous chapters by showing how actors with agency navigated the institutional and theoretical contexts outlined in Chapters Four and Five. There were a number of key findings in these chapters in relation to the 'Measuring National Well-being' programme. It was shown that the programme owed more in its origins and development to international networks of policy actors than it did domestic policy-making concerns. These international networks shaped the programme, leading to a result not greatly appreciated by domestic actors. The nature of 
the programme was further influenced by the recruitment processes of the Statistical Actors of the ONS, which favoured those they already knew. It was shown that limited budgets restricted the possibilities of the programme, leading to a recycling of measures. The need for understanding in the face of a sceptical public and lax media led to further features of the programme which were practical rather than theoretically pure. Throughout the official statistic-making process, Statistical Actors engaged with each other as embodied individuals, experiencing their theoretical or professional disputes as personal ones, acting for reasons which were not fully practical or theoretical. More generally, they show the contested and contingent nature of the outcome of the statisticmaking process by linking the form and content of the official statistic with the circumstances of its creation.

The present, final, chapter will return to the research questions posed in Chapter Two, examining how the material in Chapters Four to Seven help in understanding official statistic-making as a social process. From this, it will be possible to re-examine the conjectural model of Chapter One and the question of whether understanding official statistic-making as a social process adds to the understanding of the form and content of official statistics. It will also return to Chapter Three by noting the limitations of the methodology and research design which were used. Finally, it will suggest directions that further research might take. It notes a key contribution of the study, which is to develop a way of explaining the form and content of official statistics. While this has been shown in the case of the 'Measuring National Well-being' programme, it is more widely applicable to official statistics in general.

\subsection{How does approaching official statistic-making as a social process affect the} understanding of its form and content?

The 'Measuring National Well-being' programme resulted in 41 'headline' statistical measures, with a raft of sub-measures. While a great many of these were statistics which were already collected by the Office for National Statistics or other central government departments, several, most notably those addressing questions of subjective well-being, were novel. Does an understanding of the official statistic-making process as a social process aid the understanding of the form that the programme took and the content that it included? This section will suggest that it does by summarising the findings of Chapters Four to Seven, showing that various features of the 'Measuring National Wellbeing' programme can be explained in terms of their origins in agential responses to institutional and theoretical contexts.

As Chapters Four and Five outlined, the Statistical Actors of the ONS started the process as part of an institution within a fragmented system of government, where power was dispersed through departmental and geographical power centres. Their datasets were used within a hierarchy of 'evidence' for official policy-making, and subject to scrutiny on the grounds of integrity and legitimacy. In approaching 'wellbeing', they were approaching a contested field, in which at least four distinct theoretical constructs vied for position within a chaotic conception (Sayer 1981, 1985, 2000). They were also approaching it in the wake of an international movement towards well-being measurement, based around the GDP-extension work of the Commission for Measuring 
Economic and Social Progress (Stiglitz, Sen and Fitoussi 2009). Even stated at this high level, it is possible to see how the Statistical Actors came to produce the programme they did: one which included all four conceptions of well-being outlined in the taxonomy of Chapter Five, but emphasised those with economic applications; which offered some measures with specific policy uses to domestic policy actors, but not many; which closely resembled other programmes internationally.

This interplay between domestic and international concerns, in particular, was not something which would have been easy to foresee using the existing approaches outlined in Chapter Two. Particularly, theories based on control would likely posit a tighter relation between central government policy-makers as Commissioning Actors and the outcome of the statistical programme with the aim of securing a statistic suitable for acting on populations. This was not the case, partly because central government was not unambiguously the sole body of Commissioning Actors, with much of the impetus instead coming from Statistical Actors within the ONS itself as a reaction to their international context. It is also partly because of the fragmented nature of UK government: the ONS were a semi-independent body amongst other semi-independent bodies. These latter bodies had little or no interest in the statistical programme, which meant that they provided little steer to the development process. This left the Statistical Actors within the ONS to pursue their own priorities, producing an official statistical programme which was not primarily directed at the objects of government. This goes some of the way to explaining Bache and Reardon's observation that 'well-being' appears to be a policy solution in search of a problem (2013, p.909), and explains how Statistical Actors within the ONS come to be disappointed that central departments do not make more use of the data the programme produces.

Instead, the existence of a 'fast-policy network', in Peck's (2002) sense, gave rise to a programme which closely resembled those being created at the same time internationally. Indeed, it makes more sense to say that these international programmes were co-created with the UK version. These programmes grew out of a central starting point in the form of the Stiglitz-Sen-Fitoussi report (Stiglitz, Sen and Fitoussi 2009), which emphasised economic conceptions of well-being. Combined with a tendency to recruit economists as advisers, this gave rise to a programme which favoured measures amenable to economic approaches: built around large datasets, suitable for mechanistic causal analysis, based on the conception that 'utility' was an output of a set of largely material and emotional drivers. Tracking this fast-policy network and observing the ways in which Statistical Actors move between international programmes challenges the appearance of an essential core to 'well-being' which is suggested by the convergence of the UK and international models. As highlighted both by the debates covered in Chapters Six and Seven, and the divergent models of well-being put forward by Devolved Administrations within the UK, this convergence is less to do with the nature of 'well-being' and more to do with the process of official statistic-making in the UK and internationally.

This balancing of aims and objectives by Statistical Actors within the ONS - reflecting their own institutional needs, the needs of domestic and Devolved government, and the interests of international bodies and researchers - shows the importance of multiple political and social scales in the construction of statistics. The agency of Statistical 
Actors is played out across and in reference to these scales; it is not the case that any one scale fully restricted or shaped their actions. Rather, Actors navigated between the needs and interests of parties at multiple scales, balancing a programme which offered potential uses to domestic policy-makers while meeting international standards and the internal objectives of Statistical Actors within the ONS.

In this way, it is possible to explain aspects of the form and content of the 'Measuring National Well-being' programme by reference to the social process of production it underwent: elements like its foregrounding of the four subjective well-being questions, its recycling of existing UK statistics, its inclusion of Human Capital. That this advances the understanding of the programme can be seen particularly in this last point. As discussed in Chapter Six, this was a measure that the Methodological Advisory Committee of the Government Statistical Service, the quality-control and standards agency of UK official statistics, could not understand the inclusion of (GSS MAC Minutes, 21 November 2013, p.16). It can be understood in terms of Statistical Actors within the ONS developing within the programme what they expected to be a future internationally-required statistic while they had funding available to do so through the 'Measuring National Well-being' programme.

Having outlined a broad answer to the original broad research question of Chapter One, this chapter will now proceed to examine in more detail the three specific research questions of Chapter Two.

\subsubsection{How can the process of official statistic-making be understood as a social process?}

The first of the research questions set out in Chapter Two is a relatively simple one: does it make sense to consider the statistic-making process as a social one? Chapters Four to Seven suggests that it does; the statistic-making process has been shown to be one of actors, interacting, negotiating situations and challenges which were created by their institutional and theoretical circumstances.

Chapter One posited a simple conjectural model in which Statistical Actors, in producing the official statistic, interacted with Commissioning Actors and a Statistical Audience. It was argued in Chapter Two that existing models ignored this interaction, suggesting either a direct route through from the Commissioning Actors to the Statistical Audience, or an abstract process of empirical discovery on the part of the Statistical Actors. This failed to represent the statistic-making process as envisaged by the simple conjectural model, which instead suggested contingency in the outcomes of programmes arising from the complex social nature of the process.

This complexity ran through Chapters Four to Seven. One aspect was the fuzzy boundaries between Commissioning Actors, Statistical Actors and Statistical Audience. For one, it is not entirely clear who the Commissioning Actors are in this case. While the Prime Minister launched the programme, some Statistical Actors at the ONS were keen to underline that it was an organisational interest prior to his involvement 
(interview with Oscar, Chapter Six; Allin and Hand 2014, p.221). The programme was created mindful of developments within wider statistical networks internationally, particularly the possibility of later legislation at the European level. It is also not entirely clear how to distribute actors between Commissioning Actors, Statistical Actors and Statistical Audience. This complexity is deepened by the ways in which the fulltime Statistical Actors of the ONS incorporated Commissioning Actors, such as those working in Whitehall and international statistical bodies, and members of the Statistical Audience, through public and Civil Service consultations. The attitude of this research has been to treat anyone working on the statistical programme as a Statistical Actor; this has the effect of incorporating individuals of diverse backgrounds and with diverse aims, objectives and interests, who were involved to varying degrees with the statisticmaking process. While this is justified on definitional grounds - these agents acted on the statistical programme, so are Statistical Actors - their contributions were organised by and filtered through the needs and interests of the permanent Statistical Actors at the ONS. Chapters Six and Seven highlighted the ways in which this organisation and filtering was conducted, privileging certain Statistical Actors from certain backgrounds, primarily those whose views could be harmonised with the interests of the permanent Statistical Actors.

In such complexities can be seen the working out of various features of the ONS' particular institutional context. The ONS is an independent central government body, moving alongside other independent central government bodies, Devolved Administrations and Local Authorities (see Chapter Four). These organisations have diverse and sometimes competing aims and responsibilities, reflecting the heterogeneous nature of 'the state' (c.f., Jessop 2008; Jones, Goodwin, Jones and Pett 2005; Jones 2007; Rhodes 1992). While the programme was launched by the Prime Minister and had the backing of the Cabinet Office, as a cross-governmental programme it lacked the grip on the fragmented objectives of government that specific departmental aims and objectives do. This left governmental actors with little interest in the programme beyond attempts to protect resources from the ONS (as Defra seemingly tried in attempts to retain control of the 'Sustainable Development Indices'), or to secure statistical resources at the ONS' expense (as the ONS appear to have felt other departments were doing; for both these incidents, see Chapter Six). This is something revealed by an approach which pays attention to the social process of official statisticmaking; the balance of influence between Statistical Actors, Commissioning Actors and Statistical Audience, and between agents within these groups, is not knowable a priori. Without engaging with the social nature of official statistic-making, it may have appeared that the 'Measuring National Well-being' programme was unproblematically commissioned by central government, with Statistical Actors at the ONS only balancing policy needs against restrictions of time, resources and theoretical coherence. This research has shown this not to be the case, supporting Chapter Two's critique of Foucauldian and Marxian accounts of official statistics as being too straightforward.

At the same time, as members of an independent body, Statistical Actors within the ONS were free within a very vague remit to produce a statistical programme which met their own professional standards. These standards were at least partially formed within an international context, both in terms of legislative requirements and industry best practice. In this they were supported by academics acting as Statistical Actors, who had 
universalising concerns and were keen on using international models of well-being to ensure comparable datasets for later study (see Chapter Seven). This meant that while members of the Statistical Audience were drawn on in formulating the programme, particularly through the What Matters to You? debate, their folk conceptions of 'wellbeing' were filtered through existing preconceptions within the ONS picked up from international and academic discourses. In this way, consultations served to confirm what was already known, rather than to create new knowledge (see Chapter Six). The convergence of the programme with international comparators, and of its subjective well-being components with pre-existing research, particularly in economics, can be explained through this attention to the social processes of official statistic-making. Without such attention, there would be the danger of essentialising 'well-being', suggesting, as the native accounts surveyed in Chapter Two do, that official statisticmaking is simply a matter of finding valid numerical representations of the external world. This is not the case, rather numerical representatives are selected form multiple possible alternatives.

The advantages of understanding the official statistic-making process as a social process can also be seen in the complex political geographies of the statistical programme. The international context, which was both professional and legislative, has been touched on above. Also relevant is the way in which Devolved Assemblies involved themselves in the programme. The Scottish Government, in particular, used the programme as a way of asserting a certain amount of independence, remaining away from the ONS' advisory panels and at times questioning the legitimacy of the ONS' programme in the context of their own measures. Both they and the Welsh Devolved Administration collected statistics based around different conceptions of well-being, essentially establishing rival conceptions for Statistical Audiences of their own electorates which challenged the UK narrative. Chapter Six, in particular, showed the interactions between Statistical Actors at the ONS and in the Devolved Assemblies, and the ways in which their opposing programmes shaped the efforts of these Statistical Actors. The existence of prior Scottish work on the Warwick-Edinburgh Mental Well-being Scale, for instance, led to Stewart-Brown becoming a Statistical Actor, laying the ground for the theoretical disputes of Chapter Seven. As was shown there, this ultimately resulted in the inclusion of positive mental functioning measures on the periphery of the programme. By tracing these interactions, it is, again, possible to explain aspects of the form and content of the 'Measuring National Well-being' programme.

Given the disputed theoretical territory into which the Statistical Actors of the ONS were walking (see Chapter Four), an approach sensitive to the social nature of official statistic-making also sheds light on the ways in which certain theoretical ideas come to dominate the programme. The process by which the permanent Statistical Actors of the ONS sought to recruit temporary Statistical Actors was intensely social: they recruited advisers they were used to working with, and accepted ideas which fitted with established modes of thought. While opinions were sought from alternative sources, they were gathered in a haphazard way and those holding them felt themselves to be marginalised and their opinions disregarded (see Chapter Seven). The result of this was a statistical programme which emphasised economic conceptions of well-being while under-playing conceptions based around mental functioning or quality of society; these economic conceptions were amenable to the sort of data that the ONS collected, with 
large sample sizes for broad-ranging surveys, and were amenable to their analytic models, which sought to explain aggregate statistical relations through mechanical models. One interviewee in Chapter Seven described the outcome of the 'Measuring National Well-being' programme as being four subjective well-being measures which didn't mesh together, while another argued they didn't capture well-being as understood by health or mental health perspectives. Attending to the social processes of the construction of the programme has offered suggestions as to how and why this outcome occurred.

On a more mundane level, the account of the process of statistic-making recorded in Chapters Six and Seven offers numerous social factors which impacted on the final form of the programme. Chapter Six noted that the Advisory Forum consisted largely of 'big name' Statistical Actors who were able to offer the programme legitimacy but little engagement. It noted the geographical constraints which promoted involvement as Actors by academics who worked near to the ONS' offices, and inhibited involvement by those further afield. Chapter Seven noted an academic Statistical Actor who felt that their gender impaired the reception of their views. Both chapters observe the disagreements and disputes between actors which those at the ONS must resolve, and the varying attitudes of participants to each other and the ONS. Such factors, and their impacts, were not predictable; they are only known because of the approach used here.

The case of the construction of the 'Measuring National Well-being' programme, then, can be understood as a social process, and such an understanding sheds light on the form and content of the programme.

\subsubsection{What are the components of the official statistic-making process?}

This second research question fleshes out the conjectural model of Chapter One. That model posited a set of Statistical Actors involved in statistical production, operating under conditions of opportunity and constraint determined by personnel, resources, technology, and so on. Chapters Four to Seven attempted to outline in more detail what these conditions of opportunity and constraint were.

As discussed at the start of the previous section, the division between the agents within the conjectural model is more fluid than that model proposed. A set of permanent Statistical Actors, working within the ONS, drew on knowledge and opinions available from diverse actors - in government, in international organisations, in academia, in NGOs, in the private sector, and in the public. To the extent that their knowledges were drawn on, these diverse actors become Statistical Actors, deliberating alongside the permanent actors of the ONS. This confirms the observation of Chapter One that the basic conjectural model is too simple: even within the three categories of actors, individuals vary in their influence over the official statistic-making process. An example of this can be seen in Chapter Seven, where one set of academics is recruited to write a paper setting out the form of subjective well-being questions, while another set of academics is recruited when this form is established and the advice they would offer against it is no longer likely to be considered relevant. As above, however, this diversity of actors confirms the need for an understanding of the statistic-making process which 
is sensitive to social processes of negotiation and debate.

This complexity suggests a development of the conjectural model, one which views Statistical Actors within a constellation of influence: at the centre are the permanent Statistical Actors of the ONS, who hold the power to accept or reject the opinions of more temporary Statistical Actors; slightly further out are those Actors they have previously worked with; further out again are economists; then there is everyone else. This model was sketched out by the academic George in an interview, and quoted in Chapter Seven. It is possible to develop this model further, taking account the length of time that Actors are involved in the official statistic-making process; this would reflect the influence gained through persistence. It would also be necessary to place Statistical Actors from central government and the Devolved Assemblies, and Actors from international bodies. As an empirical finding, this latter group were more central in terms of their influence than were the former; as suggested above, it is unlikely that this would have been predicted before the research was conducted. The exact shape of such constellations will vary across official statistics and statistical programmes (c.f., Rhodes 1992), and it is a strength of the approach taken in this research that these shapes can be determined.

A key component of the statistic-making process in the UK is the ONS itself, a specific body with a specific institutional history and position within the UK policy-making structure (see Chapter Four). As was observed a number of times in Chapter Six, the ONS is not the only source of official statistics in the UK. To varying extents, both the Welsh and the Scottish Devolved Administrations devised other ways of conceptualising well-being, based on different political and organisational aims and resting on different bodies of theory. Similarly, other Whitehall Departments were collecting statistics for their own purposes, and showed little interest in a national programme which they did not see as serving their purposes (see Chapter Six). There are, then, other ways of producing official statistics, and well-being statistics, than the one devised by the ONS. This underlines that the 'Measuring National Well-being' programme is a made object, made specifically by a particular organisation, occupying a particular position with particular interests, and drawing on particular advice from particular places. It confirms the importance of explaining its particular, contingent, form and content.

The position of the Statistical Actors of the ONS is defined by the institutional arrangements of the UK state. It was argued in Chapter Four that this is a system marked simultaneously by centralisation and fragmentation. As an example of this, the ONS have a national remit to collect well-being statistics, but no way of compelling other government departments to use the programme it creates. 'Well-being' as defined by the programme is a global concern, and so should be relevant to all Whitehall Departments and Devolved Administrations. Those Departments and Administrations, though, are functionally independent of the ONS, to a great extent functionally independent of the core of government (The Prime Minister's Office, the Treasury, the Cabinet Office), and largely define their own concerns. This freedom on the part of Devolved Administrations and Whitehall Departments left the Statistical Actors working on the programme acting in a context where there was little or no perceived need for the statistics they were producing. At the same time, the Statistical Actors of the ONS felt themselves to be acting independently of the concerns of other 
departments; instead they were interested in questions of professional pride, the coherence and integrity of the statistic, wider international contexts and so on (see Chapter Six). This resulted in a statistic which largely floated free of domestic context in a way that it could not have done had it been created by a Whitehall Department or Devolved Administration. The institutional components of the statistic-making process, the central ONS and the fragmented system they sit within, set the context for the actions of Statistical Actors and determined the possibilities of the statistical programme.

A similar point can be made about the scale at which the ONS imagined the programme. As Oscar, of the ONS, discussed in Chapter Six, the aim of the ONS was to obtain a broad national picture. This inclined them against certain types of measure, such as those around positive mental functioning, which were less suitable for this scale, and inclined them towards certain survey instruments, those with sufficient sample size and a corresponding limitation on survey length. This high-level imaginary comes from their remit as a national body, and brought them into conflict with both Whitehall Departments and Devolved Assemblies who conceived of 'national' as being more or less extensive than the ONS did. The ONS' position as a body at the UK level, another aspect of their institutional context, shapes the possibilities of its statistics, a point which the approach of this research is able to bring out.

It was also noted in Chapter Four that the institutional history of the ONS, and its links to the Treasury both from its dependence on central funding and from having the Chancellor as Minister of Statistics, weighted its output towards economic statistics. This historic orientation towards the economic can be seen in the way that the ONS went about recruiting advisers for the programme, looking primarily to economists, and in the way they conceptualised the data they obtained, within causal models. Here the attention to the social processes of official statistic-making, and particularly the contexts in which Statistical Agents acted, allow the economic slant of the 'Measuring National Well-being' programme, criticised by some participants in Chapter Seven, to be understood.

Another institutional component of official statistic-making in the UK is the ONS' funding, and the way that this acts as a constraint on their operations. The 'Measuring National Well-being' programme was funded through a one-off development grant supplied in the 2010 spending round, but represented the establishment of an on-going programme instituted at a time of austerity in public spending. This limited how elaborate the Statistical Actors of ONS could be, restricting the development of new statistics and survey instruments (see Chapter Six). It was suggested in Chapter Six that the ONS took the opportunity of funding to develop statistics less clearly conceptually related to well-being but which were likely to form future legislative requirements; if this reading is accurate, it shows the adaptability of the Statistical Actors of the ONS in navigating the space which is provided by the combination of a fragmented policy system and a centralised funding system. There is an interplay between agents and their context which an examination of the social processes of official statistic-making has made apparent.

Also relevant in this regard is the ONS' ability to draw on pre-existing statistics in their 
construction of the programme. While much of the emphasis in the programme is on subjective well-being statistics (an emphasis which is reflected particularly in Chapter Seven), the majority of the statistics in the programme were already collected either by the ONS or elsewhere in Whitehall. When the national debate, What Matters to You? and subsequent government consultations were carried out, the responses of the Statistical Audience were measured against the statistics already available to the Statistical Actors of the ONS. This created a composite programme which gathers together pre-existing social, economic and environmental statistics while badging them as if they were a coherent set. This means that in the case of the 'Measuring National Well-being' programme there is something of a path-determinacy resulting in a programme which is largely an extension of what was already done. What has been done before stands as a component within the official statistic-making process, shaping the activities of the Statistical Actors.

Another important feature of the ONS is the historic legacy of concerns around legitimacy and integrity. It was noted in Chapter Four that the ONS stood as part of a slightly Byzantine structure of institutions established by the Statistics and Registration Services Act 2007 comprising of UK Statistics Authority, ONS, Government Statistical Services and National Statistician, with responsibilities for both creating statistics and monitoring the statistical production of others. This could be seen playing out in Chapters Six and Seven, as Statistical Actors within the ONS spoke of the lengths they went to to secure accurate press coverage of their work; as Statistical Actors from outside talked about the unprecedented extent of public and state agency consultation involved in the programme; and in the UK Statistics Authority's decision in 2014 to recognise the 'Measuring National Well-being' programme as a 'national statistic' with the recommendation that its accompanying commentary be improved (UK Statistics Authority 2014a). In the context of well-being itself, concerns of legitimacy can be seen as underpinning the movement away from GDP as an inadequate measure of social progress, the suggestion being that GDP is not a legitimate way of measuring such things. At the same time, Bache and Reardon (2013) have argued that the move towards 'well-being' at the European level can be read as an effort to legitimise unelected institutions as beneficent; and Chapter Five noted that the political juncture at which the programme was launched may have promoted 'well-being' as a way of re-legitimising a distrusted political class. This highlights the role of historic public and state agency beliefs about official statistics in influencing the ways in which official statistic-making is conducted.

In light of this, it is worth noting the relative lack of importance of 'evidence-based policy' as a component within the conceptualisation of the statistic-making process. 'Evidence-based policy' had been highlighted in Chapter Four as a potential influence on the programme, as the requirement for evidence across Whitehall might lead to Statistical Actors shaping the programme to produce such evidence. The programme as constructed has 41 headline measures and a raft of sub-measures, the majority of which already existed. As several interviewees noted in Chapter Seven, this collection of many and varied indicators is very hard to read as coherent evidence of anything in particular. Conversely, actors from other government departments interviewed in Chapter Six saw this as an opportunity to provide evidence for almost anything, as the individual measures serve to contextualise each other. In this sense the statistical programme 
provides narrative support for policy, regardless of what individual empirical measures show. This mirrors many of the problems highlighted with the 'evidence-based policy' movement, as 'evidence' is often available to support multiple contradictory positions (see Chapter Four). The Statistical Actors of the ONS stand somewhat aloof from this; without the need to serve any particular policy need, there is no great need for evidence of any given kind. As a result, they tended to resist specific departmental aims for the programme in favour of a broader conceptualisation. In this way, the unimportance of policy and 'evidence-based policy' in driving the statistic-making process influenced the final form and content of the programme.

Another important component of the statistic-making process was the wider network of international actors and organisations which the Statistical Actors of the ONS formed a part of. Chapter Four noted the international impact of the Commission on Measuring Economic and Social Progress (Stiglitz, Sen and Fitoussi 2009), which both Oscar and William at the ONS highlighted in Chapter Six as being key to their work. This Commission shared several Statistical Actors with the UK programme, which also shared personnel with schemes launched at the European and OECD levels. Oscar talked about the desire to 'look Eurostat in the eye', a function of the professional pride of the ONS and their standing within an international context (see Chapter Six). At the same time, this comment hints at a wider set of legislative concerns which came out of the minutes of advisory groups explored in Chapter Six; there is a danger that if the ONS do not lead Europe in designing a programme, they will have something forced on them. This leads to the development and inclusion of measures like Human Capital, which are badly received in the public consultation and by those scrutinising the programme within the Government Statistical Service (see Chapter Six). Attention to social processes, in this case the perceptions of Statistical Actors at the ONS of their position within wider international networks of official statistic-making, helps explain this aspect of the programme.

The sharing of members between international programmes highlights the role of international networks of knowledge within statistical production. The role of the UN (through the System of National Accounts, United Nations, Organisation for Economic Co-Operation and Development, International Monetary Fund and European Union 1993), European Statistical System and OECD in harmonising statistical systems across the world can be partially seen playing out in the feedback between the ONS' testing of subjective well-being questions and the OECD's formulation of guidance on measuring subjective well-being (Organisation for Economic Co-Operation and Development 2013b). This sharing of expertise across programmes points to the existence of fast policy networks in statistical production (see Chapter Four), in which global actors create similar policies across borders (Peck 2002). Here international networks are a component of the official statistic-making process in the sense that Statistical Actors are shared between the UK and international programmes; as argued above, the uncovering of this through an attention to the social process of statistic-making provides a way of understanding the convergence of UK and international models of 'well-being'.

Set against the influence of this international network stood a smaller domestic set of Statistical Actors, some of whom were closely linked to the international network and some of whom were closely linked to the ONS. These advisers were influential largely 
to the extent that they agree with the ONS' mode of thinking (see Chapter Seven). This has the effect of playing down the role of theory, as explored in Chapter Five, since it predisposed the ONS to knowledge close to that which it already possessed. The role of advice within the process of statistical construction is largely confirmatory, in as far as the Statistical Actors within the ONS accept the advice of Statistical Actors who are known to them, have previously worked with them, and whose views are consonant with their established ways of thinking. This shows the importance of pre-existing belief structures as a component within the statistic-making process; these structures would have been hard to uncover without a direct examination of the social processes and agents involved in official statistic-making.

In light of Chapter One, then, the statistic-making process fits a more complex version of the conjectural model. The central component of this system, the Statistical Actors, comprises agents within the ONS, which has a specific institutional and historical background. It also incorporates networks of international statistical and policy actors, who tend to separate statistics from any given domestic context. There is also a role for domestic academic actors, whose role is largely in providing the ONS with knowledge that complements their own. In the case of 'Measuring National Well-being', at least, the role of governmental actors is relatively small, partly a result of the fragmentation of the UK policy sphere and, more, the lack of a specific policy requirement for the data. Various other aspects of institutional and theoretical context also play a role, including the scales at which the ONS operates, its funding and funding sources, pre-existing beliefs about legitimacy, pre-existing official statistics and measurement instruments, and the pre-existing approaches to statistical questions of the Statistical Actors. Many, if not all of these, are visible only because of the research approach undertaken in this study, which related desk-based observations about the potential components of the statistic-making process to accounts of how these played out in practice.

\subsubsection{How do the components of the official statistic-making process interact to influence the form and content of the statistic?}

The third research question formulated in Chapter Two builds on the second by asking how the components of the statistic-making process detailed above interact and influence each other. How do agents, the Statistical Actors, balance the demands of one component against another in the process of official statistic-making?

Hidden beneath the outputs of the final programme are the disagreements which ran through the statistic-making process, highlighted in Chapters Six and Seven. These were sites of social interaction in which policy and theoretical positions were embodied in individuals disputing with other individuals. They show the contingency of the final statistic by marking points at which it could have developed otherwise. While in many of their details they are specific to the 'Measuring National Well-being' programme, in their form they are applicable to all official statistics: wherever there is an institutional or theoretical context to be navigated by actors, there will be similar negotiations. The details of these negotiations are unique to every official statistic, but, as a social process, contestation between interests and actors embodying them is inevitable. 
By attending to these moments of contestation, it is possible to explain how the official statistical programme took on its final form and content, and why it did not develop otherwise. As a starting point, the functional independence of the ONS within UK governmental structures predisposes them to what Oscar, of the ONS, in Chapter Six described as 'the expert model'. That is, the ONS are the experts in statistical production, so they will manufacture first and consult second. While structurally that was not the case with 'Measuring National Well-being', formally it was; Chapters Six and Seven reveal substantial path-dependency arising from the incorporation as Statistical Actors of advisers who were sympathetic to the viewpoints of the permanent Statistical Actors of the ONS. These chapters also highlighted the role of Statistical Actors within international policy networks, individuals who also shared the outlook of the ONS' Statistical Actors. By starting their work from that of the Commission on the Measurement of Economic and Social Progress, predominately recruiting economists, and lacking direct links between the statistic and policy departments, the Statistical Actors of the ONS produced an expert model which policy-makers found it hard to engage with. As examined in Chapter Six, policy-actors within Devolved Administrations adapted or varied the programme to suit their own needs and those within Whitehall Departments largely ignored it. This pattern of contestation, and noncontestation, by Statistical Actors, and the situation of these within an 'expert model', sheds light on the final form and content of the statistical programme.

The expert model can also be seen at play in the specific interactions the Statistical Actors of the ONS had with policy departments in Chapter Six and with academics in Chapter Seven. Once the ONS Actors had established a starting point of a national-level programme which had subjective well-being as a central component, arguments for alternative approaches were largely written off as special pleading (both by actors within the ONS and by those in their international and sympathetic advisory networks). The Statistical Actors of the ONS retained an expert conception of what the programme was 'for' which did not necessarily relate either to uses by policy actors or to theoretical conceptions of what well-being 'is'. Here it can be seen that the relations between Statistical Actors impacts on the final form and content of the statistical programme; not all Actors have equal influence or power over the output of the programme. This contextualises the events of the process of official statistic-making, particularly the consultations that were undertaken, offering reasons for the success of some ideas and the failures of others. Such reasons cannot be offered without attention to the social processes of statistic-making (or, at least, cannot be offered non-speculatively).

This is not to say that the Statistical Actors of the ONS stood completely independently of the domestic policy sphere. Chapter Six notes circumstances where policy actors were able to influence changes in the programme to better suit their needs. These were largely changes in the periphery of the programme, however, as where one mental health measure is swapped for another measure or some of the Warwick-Edinburgh Mental Well-being Scale measures were included in a sub-module of the programme. Within the limits they have set, Statistical Actors within the ONS are conscious that the programme needs to be usable, so in places resist academic calls for theoretical improvements (see Chapter Seven). The definition of 'usable' here is set by the purposes of the ONS' Statistical Actors and so is limited to allowing a broad picture of the well- 
being of the nation. This includes ensuring that distributions are visible and making the data amenable to use in mechanical models, but does not include any adherence to preexisting policy needs. In this case, Statistical Actors and policy actors interact without contact: the former shape their work to their expectations of potential uses by the latter. Such a shaping of the official statistic would be invisible to accounts which did not consider social processes.

The ONS' history of concerns around statistical integrity also makes their Actors sensitive to the Statistical Audience, albeit this audience is one which is very broadly defined to include almost everyone in the UK. This can be seen recurring throughout the statistic-making process: in the wide-ranging national debate and subsequent consultations, in the careful management of the presentation of the programme in the press and in the preparations for attaining 'National Statistic' status (see Chapters Six and Seven). Without attending to the social processes of statistic-making, there would be something slightly odd about this: the 'Measuring National Well-being' programme is a statistical programme with no obvious group of users, largely divorced from department-level policy concerns and sufficiently multi-faceted to preclude easy interpretation by the public, yet a lot of effort has been placed into ensuring it is 'usable' and appears as legitimate. The approach taken in this research makes these oddities explicable by outlining the concerns and interests of Statistical Actors which drive their actions.

The ONS and its Statistical Actors are also acting within wider contexts of central government action, particularly those relating to funding. At the time that the 'Measuring National Well-being' programme was being developed, both the ONS and the central government departments it was consulting were seeing substantial cuts to their funding and staffing levels. This limited the scope of the Actors of the ONS in what they could do with the statistical programme, leading to less innovation and more recycling, as well as possibly increasing resistance to demands made by other departments. It also limited the scope for data collection as survey vehicles which might have been used were cut, either by the ONS or elsewhere in Whitehall. It also gave reasons to adapt the programme, including measures which the Government Statistical Services' Methodology Advisory Committee felt were unsuitable (see Chapter Six), but which would need to be developed, possibly without additional funding, at a later point. Again, had only the final output of the programme been examined, it would have been difficult to explain these features, but attention to the process by which these features were formed makes an explanation possible.

Even without this backdrop of explicit funding cuts, a history of resource constraints within the ONS has led to an emphasis on cost-efficiency by its Statistical Actors (see particularly the comments of William, of the ONS, on this in Chapter Six). This, combined with the legislative requirement for the ONS to produce certain types of statistic, placed limitations on the theoretical scope of the programme. Statistics were not re-developed on the conceptual basis of well-being but were pulled across from existing programmes where they were available (see Chapter Seven). Many of these statistics are harmonised by legislation across Europe, and by best practice across the OECD and UN (for instance, unemployment statistics). This resulted in a further resemblance between the UK's conception of well-being and those of its international 
fellows. Such a resemblance was resisted by some academic Statistical Actors, and encouraged by others. Here an attention to the social process of official statistic-making shows not only that disputes arose but also the ways in which context influenced their resolution; Statistical Actors interested in novel conceptions of 'well-being' and a blank sheet of paper as a starting point were always at a disadvantage.

Understanding the statistic-making process as a social one allows us to trace the history of the programme's measures in the interaction between Statistical Actors, and between these actors and their context. It highlights the contingency of the final programme while also indicating how it took on the form and content that it did, rather than any of the disputed potential options raised along the way. Such an understanding would not be possible without an examination of the social processes underlying the statistic: an approach which looked only at the final output of the programme, for example, could only speculate on the reasons for the shape of that output.

\subsection{The implications of understanding official statistic-making as a social process}

Chapter Two outlined two pre-existing theoretical approaches to official statistics, which were labelled the 'critical' and the 'native'. The former came from the Foucauldian and Marxian literatures, and centred on the role of the official statistic within the working of the state. These suggested that the official statistic was a technology of control, designed and used by agents of the state to influence the actions of citizens. The latter covered accounts by official statisticians themselves and tended to be methodological accounts of the construction of official statistics. These presented official statistics as predominantly technical problems, questions of how to most accurately and validly represent an empirical reality.

It was argued that these approaches were incomplete, as they presented the process of statistical construction as a black-box which either transmitted the controlling desires of Commissioning Actors, or more-or-less straightforwardly translated the external world into numerical representation. It was argued on the basis of the conjectural model of Chapter One that this black-box treatment was insufficient as it missed many influences which shaped the form and content of the official statistic. On the basis of the conclusions drawn from the research in this present chapter, this argument can be expanded.

Chapters One and Two argued that the presence of agency on the part of Statistical Actors meant that the desires of Commissioning Actors were not simply expressed in the official statistic. The present research sought to fill a gap in the literature about how, if at all, the desires of Commissioning Actors were transmitted and expressed. It should be clear from Section 8.2. above that critical models which suggest that the official statistic is a technology of control must be complicated by the question of 'who is doing the controlling?'. In the case of the 'Measuring National Well-being' programme, it is not at all clear who the Commissioning Actors are. While it was publicly launched by a Prime Minister who had, while in Opposition, made much of the concept, the general lack of involvement by the centre of government and the much greater involvement by international networks of policy actors created an official statistical programme with 
little direct application within domestic policy-making. Certainly, from Chapter Six, there is little direct use of it by Whitehall Departments or Devolved Administrations. The statistical programme thus appears to lack both a controlling will and, possibly, as a result, any controlling ability.

One potential way of accommodating this seeming lack of control within critical accounts is Rose and Miller's (1992) idea that 'governance is always failing'. The 'Measuring National Well-being' programme may be a situation where there was a desire on the part of state actors to control behaviour through the operationalisation of 'well-being', but that this desire was inadequately followed up or impossible to realise through the medium of an official statistic. In this respect the 'Measuring National Wellbeing' programme could be compared with health-based interventions around wellbeing, in which a narrative of personal responsibility is created around well-being with an aim of promoting behavioural change at the individual scale (such as Foresight Mental Capital and Wellbeing Project 2008). As a descriptive, rather than a normative, model, the official statistic is badly placed to secure similar individual-level change. It may, however, direct action at institutional levels, acting as a benchmark against which interventions can be measured. That this is not being done by Whitehall Departments can be read as being the result of the relative lack of control central government has over them in a fragmented policy-making system (see Chapter Four). This reading, while compatible with critical readings of official statistics, takes into account the agency of Statistical Actors and policy-makers more generally, situating it within the theoretical and institutional contexts they face.

An alternative solution to this problem of critical accounts would be to read the programme as a narrative act. Several participants quoted in Chapter Six mentioned the role the programme had played in 'putting well-being on the agenda'. Indeed, this was mentioned by one participant who did not agree with the shape the programme had taken, suggesting that even a programme they didn't believe measured well-being but which claimed it did was better than nothing. Such a position is interesting, given the relatively small part that new statistics played in the programme; there was little in the 'Measuring National Well-being' programme that wasn't already being measured. By creating and announcing a 'well-being' programme, something appears to have been done, even if no change to existing activities had actually been made; social statistics which were originally about other things are now about 'well-being'. The statistic is thus a form of appearance- or expectation-management, allowing existing policies such as austerity to be re-cast in the light of well-being (Debord 1995, 1998; Lefebvre 2008; Wark 2013). On this reading, the actual programme that Statistical Actors devise is not important; having any programme at all provides a commitment to 'well-being' and allows the recontextualisation of pre-existing statistics in those terms. The political launching of a programme which Statistical Actors within the ONS claim to have already been working on (Allin and Hand 2014, p.221) is thus an act of opportunism, rather than of principle. This reading of the programme gives a much more indirect treatment to the 'control' of the critical accounts, shifting the programme from being a tool in pursuit of control in its own right to being a component within a larger apparatus of control. The programme, on this reading, manages the appearance of general networks of state power, rather than 'well-being' per se. 
A further way of conceptualising the space between the social processes uncovered in this research and critical account of the official statistic as a technology of control is to observe the way in which the official statistic-making process was geared towards a prefigured outcome. The sections above noted a great deal of path-determinacy in the work of Statistical Actors within the ONS, established by budget constraints, preexisting expertise on economic statistics, legislative requirements for existing statistics. These established a bias toward economic thinking and expertise within the ONS and international networks of policy actors working on similarly economic conceptions. The major use for the newly developed subjective well-being statistics has been cost-benefit analyses (as in Cabinet Office 2013; HM Treasury 2011a); the programme also encompasses the monetary valuation of nature as Natural Capital and the development of monetary valuation of skills as Human Capital. The outcome of the programme can be read as a furthering of pre-existing neoliberal agendas of market extension, at the expense of counter-narratives which looked at the mental functioning or social conditions of individuals under the market (for an argument in this direction, see Tomlinson and Kelly, 2013). In this way, economic uses arose out a programme whose social processes were steeped in economic thinking. On this reading, the present study has filled in the gap between conception and action by indicating how, without ostensible compulsion from Commissioning Actors, a programme consistent with existing market-based modes of social organisation was created by Statistical Actors.

From the perspective of 'native' approaches, the present research contextualises and complicates arguments set out in Chapter Two that the official statistic is a more-or-less accurate representation of the external world. As Chapters Four and Five showed, the nature of that world is contested and, as Chapters Six and Seven showed, at numerous points the Statistical Agent was called upon to adjudicate these contestations. With no theoretical model from which to operate, the ONS purposefully went out to gain from the public a majoritarian view on 'what matters', filtered this through pre-existing knowledge and available statistics, extended it with statistics not requested by public or state users but that were relevant in an international context, and finally produced a programme disputable and disputed. There is nothing in this to suggest that Statistical Actors were not motivated by a desire to create accurate and valid representations numerous extracts from interviews and public documents in Chapters Six and Seven show that this desire was central to the activity of Statistical Actors - but shows that this desire is not the only one motivating methodological or definitional choices. The present research shows that the representational effort of official statistic-making is situated within a wider set of aims and objectives. This has been shown in the case of the 'Measuring National Well-being' programme, and will be true of official statistics more generally.

However, the present research would support a modified version of native accounts, that took the desire for accuracy and validity to be primary rather than over-riding. While there is evidence that compromises were made between objectives, as where theoretical purity in measures was sacrificed to make measures more usable for policy-makers (see Chapter Seven), there was never a suggestion that invalid measures were constructed. Even in the disputes between Statistical Actors from different academic backgrounds, no participant ever suggested that measures were being used that were understood by the ONS' Statistical Actors to be invalid. This is important given the historical concerns 
about the trust and integrity of official statistics discussed in Chapter Four; Statistical Actors were not subject to political interference in the making of the 'Measuring National Well-being' programme and, as above, were not consciously attempting to construct a technology of control. However, in keeping with pre-existing sociological critiques (Dorling and Simpson 1999b), the representations which Statistical Actors selected were not the only ones possible and their reasons for selecting them were not entirely based on technical or methodological superiority. Instead, they were valid representations of an external world which can be validly represented in multiple different ways. The present research explains how one valid representation came to be selected over alternatives.

As was suggested in Chapter Two, those who put forward a native account were always aware that it was incomplete. The present research develops the literature on this incompleteness by adding social reasons to the methodological reasons for selecting one measure over another. Oliver (TAG member, academic in statistical theory), quoted in Chapter Seven, was very clear on the contested nature of official statistics, noting the historic adjustments to and debates around GDP. Such adjustments and debates, however, are technical (Abramsky and Drew 2014); an understanding of social process of statistic-making complements these existing accounts by offering further reasons for contestation.

The present research, then, fills the gap in the literature around how official statistics are made. It has shown that the outcome of the official statistic-making process is contingent, dependent on the actions of agents. A different set of actors, in different contexts, would have produced different statistics. This point applies beyond the 'Measuring National Well-being' programme; where official statistics involve agents in their creation, the form and content of those statistics will be determined by the agents' navigation of their institutional and theoretical contexts. Attending to the social process of official statistic-making re-socialises both critical and native accounts, showing them to be over-simplistic.

In terms of the implications for official statistic-making practice, or for policy-making based on official statistics, the key contribution of this research is to further challenge the naturalisation of statistics which was touched on in Chapter One. If the official statistic is contingent, arising from particular arrangements of agents and their contexts, it cannot stand as an unambiguous comment on the external world. It is not the case that 'well-being' is rising or falling, but 'well-being as measured' is rising or falling. The how and the why of the measurement have been shown to be necessary to understanding the statistic itself.

\subsection{Reflections on the research method and its limitations}

As outlined in Chapter Three, the present study represents a more limited engagement with the official statistic-making process compared than, for example, an ethnography of statisticians. However, it was able to engage directly with Statistical Actors, and this engagement is one of its major contributions to the literatures around official statistics. The methods of interviewing and public document analysis, though, privilege salient 
moments in the official statistic-making process, such as moments of contestation, over the more quotidian activities of Statistical Actors. As a result, there is a danger that they uncover more about what wasn't included in the final programme than what was. It has been possible in the present research to make out the outline of decisions, but not always to show in detail why those decisions were made. There were large parts of the programme which were conducted by email and a large number of meetings that were not public which would have shed light on these had they been accessible.

There was also a large amount of the programme which was entirely routine, consisting of Statistical Actors within the ONS doing their day-to-day jobs, under constraints of technology, time, material resources and so on. It is likely that there were options for the programme which were ruled out before they ever reached a public meeting for reasons of mundane practicality. These were invisible to the methods of the present study. Understanding of the official statistic-making process would be greatly expanded by a closer observation of these.

It should be remembered in light of these observations that unsuccessful attempts were made to carry out an ethnographic study of statisticians in two different national contexts (see Chapter Three). In general, it proved somewhat difficult to speak to fulltime Statistical Actors: interviews with one domestic non-national statistical producer were cancelled shortly before they were due to be conducted on the grounds that statisticians were precluded by official guidelines from talking to researchers; an interview at one international statistical producer was withdrawn after the interview was conducted on the grounds that 'the views in the interview did not reflect those of the organisation'. In both these cases there is a body corporate, and actors within it, whose work plays a major role in the public sphere but who are closed to external scrutiny beyond their public pronouncements. (In passing, it should be noted that this is all the more worrying given the low level of media scrutiny of statistical bodies revealed in Chapter Six.) Given this closure, the limited access to Statistical Actors within the ONS which was possible represents an unusual and welcome departure. However, the importance of official statistics in public life suggests that while the present research may be the best investigation into official statistic-making that was possible, deeper access with a view to a more detailed understanding would be preferable.

In general, it would have been desirable to expand the number of interviews undertaken. This would, in part, have reduced the biases towards contested moments in the official statistic-making process and away from the routine and mundane. It was noted in Chapter Three that some of the difficulty in interviewing actors, particularly those involved in the Advisory Forum, arose from their elite status. With the exception of Mikecz (2012), Chapter Three does not engage with the literature around interviewing elites; it is possible that had attention been paid to this literature, more interviews would have been secured. In particular, McDowell's (1998) strategy of using existing personal networks to secure interviews could have been more thoroughly explored than it was. A key interview, with one of the Statistical Actors of the ONS was secured in this way, and it is possible that more could have been. Reasons for not making more of this method of recruitment included a reticence on the part of the researcher to place people under social obligation to undertake interviews they may not have undertaken otherwise, and a fear that poorly performed interviews would reflect badly on those who had 
recommended the interview to participants.

As a slight caveat both to the possibility of undertaking more interviews through personal connections, and to the fear that social networks would act to pressure individuals into undertaking interviews, in a number of cases social networks did not result in additional interviews. Two contacts within other state and international statistical bodies, one contact within the Civil Service and one within an NGO all declined interviews despite being asked by colleagues and friends rather than the researcher. This may have been a result of the half-hearted use of this technique, but it is suggestive that personal connections are not a magic bullet in securing participants.

Apart from this, the literature on interviewing elites could have been used to reduce some of the errors inevitably made in the process of interviewing. Most of Harvey's (2010, 2011) guidelines for the first contact with elites were met, particularly the personalisation of approaches and the use of a clear cover letter (reproduced as Appendix B) clarifying the role of the research. In common with McDowell (1998) there was also a deliberate down-playing of the position of the research within the discipline of Geography, with 'the Centre for Urban and Regional Development Studies' thought to sound more suitable to statistical actors as a site of research into their work. However, in hindsight, more could have been done to emphasise the importance of the research, to aggrandise the researcher and institution, and to underline the key role the participant would be playing (Harvey 2011). This was done to an extent with the personalised interviews, but would have benefited from re-emphasis in the more formal cover letter.

Delaney (2007), McDowell (1998) and Woods (1998) all offer advice about the dynamics of interviewing senior figures which may have made the interviews in the research easier to carry out and more productive in terms of the data they provided. Throughout the interviews, there was a consciousness both of the seniority, and so relative authority, of the participants in relation to the researcher, and a sense of imposition on them, as they had given up their time with little obvious benefit to themselves. In a number of cases, this led to interviews which partially reproduced 'official' accounts; in others the enthusiasm and generosity of the interviewee led to the researcher 'being seduced' by them (Delaney 2007). In both these situations, it became harder to ensure that it was the researcher directing the interview, and not the participant. As more experience of interviewing was gained during the research, these difficulties diminished, but it would have been helpful to be fore-armed against them in the first several interviews (see McDowell 1998 for accounts of a similar experience).

Considering those who were interviewed, they were to an extent a self-selecting sample; they were those able to find the time and inclination to be interviewed. In some cases, this may have skewed the sample towards those with axes to grind although, by way of balance, there were also a number of people keen to promote the programme and its successes. More problematically, this sample tended to exclude many of those who had risen to the tops of their field as they were already over-committed without participating in the present study. The same was true of many potential participants still employed in the Civil Service; the austerity measures discussed in Chapter Four, which have entailed large-scale cuts to staffing levels across Whitehall, meant that many civil servants did 
not have the time to be interviewed. While it was possible to circumvent this slightly by asking for a brief written statement of involvement, this is an incomplete solution (see Chapter Three). Particularly as regards the Advisory Forum, it meant that there were certain areas of the programme which proved inaccessible, even with the methodology used.

One question which might be asked of the present study is how typical of official statistics the 'Measuring National Well-being' case study is. Several participants, including those at the ONS, suggested that it was actually somewhat unusual (see Chapter Six). Reasons for this included both the fact that it was preceded by a larger than normal consultation process and that newly created statistics are themselves rare. It has been argued above that the former reason is more apparent than actual: while there is clear evidence of an impressive out-reach and consultation programme, there is less evidence that it made a radical difference to the content of the programme. The second reason is also less damaging than it appears, given the influence of international networks of statistical and policy actors. As a result of the international legislative component of statistics, this type of international expert knowledge network which was so important in this case is an established part of official statistic-making. Similar, to some degree, will be the incorporation of experts and policy-makers as Statistical Actors and the filtering of their advice through existing modes of thought. However, the question of how typical the statistic is is not answerable without similar studies being conducted elsewhere (see following section).

The issue of the international context also prompts questions over how typical the UK statistic-making process is. Comparing the dynamics of the ONS and of Eurostat, for example, the latter is functionally and structurally very different, largely acting as a coordinating body for independent national statistic-making bodies rather than as a statistical producer themselves. However, the argument that this research has made, that official statistic-making is a contingent process dependent on the social interactions of actors within and without the permanent official statistic-making bodies, seems as likely to be true elsewhere as it is in the UK. Again, this is an empirical question which would need to be resolved with further research (see following section).

\subsection{Possible directions for future research}

Building on the critiques above, the natural extension of this study would be to secure better access to an official statistic-making body and use that to gain more detailed observations of their work. These observations could come either through primary study of their day-to-day activity or through more extensive interview collection and access to fuller secondary material such as internal guidelines and policy documents. While this proved impossible in the present case, there seems no obvious reason why it should always be so.

Such a study would be able to go beyond the sort of novel statistic which has been studied here and look at the more every-day statistical work, thus also resolving one of the questions over typicality raised above. Given that most statistics are already established, how are they subsequently developed? This would likely bring in questions 
of the involvement of international networks of statisticians, the relationships between statistic-producers and statistic-users in government and elsewhere, and further questions around the role of Commissioning Actors of the conjectural model. Such a study would also benefit from taking a longer view than the present study has, which would allow it to be more sensitive to the rhythms of the social process of statisticmaking. While I was able to ask William, of the ONS, about a 'typical day', I was unable to get an impression much beyond 'it varies'; it would be worthwhile to unpack this.

The previous section also raised a more general question about the typicality of the case study used. As a test case, the 'Measuring National Well-being' programme has shown the applicability of the methodology used in the present research; it has demonstrated that the form and content of official statistics can be understood through an examination of the social processes which give rise to them. It has been speculated that the components of the official statistic-making process which were uncovered in the programme are universal; that there will always be concerns around cost, competing ideas and interests arising from institutional history and the position of the Statistical Actors within wider policy-making systems, debates around theory, and so on. Until the methodology is applied to other statistics, however, this remains speculation. Further studies should be undertaken to confirm or refute this.

This study has been focussed on Statistical Actors, noting their interactions with both Commissioning Actors and the Statistical Audience. From the literature of Chapter Two, however, there remains a question of purpose and use. Chapter Six touched on how the products of the statistical programme was used, noting fears from within the ONS that it was not being fully utilised and confirmation of these fears from those in Whitehall Departments and Devolved Administrations. Yet at the same time there was a great effort by the ONS to ensure that the statistics were accurately presented and portrayed in the press, and efforts within advisory panels to resist theoretical improvements which would make the results less 'usable'. So there are a set of questions around what uses the outputs of the programme permits, and how and why the programme is used. There are some preliminary answers to that around moves to incorporate subjective well-being in cost-benefit analyses, but ultimately this is a question which requires further examination.

Such a set of questions would situate official-statistic making within a larger life-cycle of social policy, further deepening the critical and native accounts of Chapter Two. As the present study, and the 'peopling of the state' literature (Jones 2007) shows, social policy is mediated by agents at multiple scales and levels. The present research gained some insight into this through its observation of the use, non-use and adaptations to the 'Measuring National Well-being' programme by those across Whitehall and the Devolved Assemblies. However, there is much more that could be explored here: how does the official statistic or statistical programme travel across agencies of the state at national, regional and local levels, such as within Whitehall Departments, local government or delivery bodies such as NHS Trusts? How does it shape policy, and through this impact on the lives of individuals? Such research would extend the methodological approach used in the present research to other agencies and technologies of the state; similar questions to those posed here could be posed of White Papers, or the reports of local council committees, for instance. 
Moving beyond the specific instance of a statistic, there is a further set of questions which this study raises about what an official statistic is and what it does. The present study has suggested the 'Measuring National Well-being' programme is a set of compromises between different potential theoretical understandings, largely unrelated to direct policy usages; that is, it counts 'well-being as defined', not well-being as theorised or used. The observation made at the beginning of Chapter One, that there appears to be a statistical mode of thought which is privileged in public discourse gains a new colour in light of this: one essentially arbitrarily defined object, GDP, has been complemented with another, 'well-being'. Was that substitution what was hoped for, or were the vague statements of politicians for 'measuring what matters' to produce 'better policies for better lives' only ever rhetorical? Why was another official statistic sought at all, why; if GDP didn't work, why was more expected of 'well-being'? Can we say of statistics, as Rose and Miller (1992) do of governmental control, that they are always failing? And if they are, what might one do instead? Such questions require a deeper engagement with policy actors, understanding the role of the official statistic within their wider work. 


\section{Appendix A: Statistical actors from outside the ONS}

Advisory Forum, listed membership

$\begin{array}{ll}\begin{array}{l}\text { Name } \\ \text { Professor Tony Atkinson* (Sir) } \\ \text { Professor Paul Boyle }\end{array} & \begin{array}{l}\text { Academic } \\ \text { Academic }\end{array} \\ \text { Professor Tanya Byron } & \text { Academic } \\ \text { Professor John Helliwell } & \text { Academic } \\ \text { Professor Felicia Huppert } & \text { Academic } \\ \text { Professor Daniel Kahneman } & \text { Academic } \\ \text { Professor Alan B Krueger } & \text { Academic } \\ \text { Professor Richard Layard (Lord) } & \text { Academic } \\ \text { Professor Julian Le Grand } & \text { Academic } \\ \text { Professor Robert MacCulloch } & \text { Academic } \\ \text { Professor Michael Marmot (Sir) } & \text { Academic } \\ \text { Professor Andrew Oswald* } & \text { Academic } \\ \text { Professor Gareth Rees } & \text { Academic } \\ \text { Professor Amartya Sen* } & \text { Academic } \\ \text { Nicholas Stern* (Lord) } & \text { Academic } \\ \text { Professor Joseph Stiglitz* } & \text { Academic }\end{array}$

\section{Notes}

Senior Research Fellow, Nuffield College Oxford

Chief Executive ESRC (background in quantitative social science)

Professor of the Public Understanding of Science and Chancellor, Edge Hill

University (background in public health)

Professor Emeritus of Economics, University of British Columbia

Director, Cambridge Wellbeing Institute (background in public health)

Professor Emeritus, Psychology and Public Affairs, Princeton University (recipient of 2002 Swedish Bank Prize in Economics for work on Behavioural Economics)

Professor of Economics and Public Affairs, Princeton University

Director, Centre for Economic Performance, LSE

Professor of Social Policy, LSE

Professor of Economics, Imperial College London

Director, International Institute of Society \& Health, University College London

Professor of Economics, Warwick University.

Director, Wales Institute of Social and Economic Research, Data and Methods

Professor of Economics and Philosophy, Harvard University

Professor of Economics and Government, LSE

Professor of Economics, Columbia University (received 2001 Swedish Bank Prize 
Professor Mike Tomlinson

Bridget Rosewell (OBE)

Professor Paul Dolan

Clive Bates

Dr Norman Caven

Steven Marshall

Kate Barker (CBE)

Gareth Davies

David Halpern

Trevor Huddleston

Dr Mallika Ishwaran
Academic

Academic/Devolved Administration

Academic/

Government

Devolved

Administration

Devolved

Administration

Devolved

Administration

Government

Government

Government

Government

Government in Economics)

Professor of Social Policy, Queen's University Belfast

Chairman, Volterra Consulting, and Consultant Chief Economic Adviser to the Greater London Authority

Professor of Social Policy, LSE. Associate, Cabinet Office Strategy Unit (Behavioural Insight Team)

Director-General, Sustainable Futures, Welsh Government

Chief Executive, NI Statistics and Research Agency

Chief Social Research Officer, Welsh Government

Bank of England Monetary Policy Committee; from June 2011 Office for Budget Responsibility (background in social housing administration)

Director-General, Office for Civil Society (within Cabinet Office)

Behavioural Insights Team

Chief Policy Analyst, Department for Work and Pensions

Acting Chief Economist, Defra 
Jeremy Pocklington

Amanda Rowlatt

Carole Willis

Dr Martin Weale (CBE)

Jean-Philippe Cotis

Martine Durand

Enrico Giovannini

Walter Radermacher

Stuart Etherington (Sir)

NGO

Kevin Havelock
Deputy Head of Economic Policy Co-ordination at Cabinent Office; also on board of Business in the Community (a thinktank)

Chief Economist and Director of Analysis Economics, Strategy and Better

Regulation (ESBR), Department for Business Innovation and Skills

Director of Research and Analysis, Department for Education

Bank of England Monetary Policy Committee, Senior research fellow, National Institute of Economic \& Social Research (a thinktank)

Director General, INSEE (French National Statistical Office)

International organisation

International

Organisation

International

Organisation

International

Organisation

Chief Executive, National Council for Voluntary Organisations (background in running charities)

Executive Vice President Global Ice Cream category, Unilever
Chief Statistician, OECD

President, Italian National Institute of Statistics

Director General, Eurostat 
$\sqrt{\circ}$ Geoff Mulgan

Trevor Phillips (OBE)

Mark Price $\left(\mathrm{CVO}^{20}\right.$ - awarded

2014)

Stuart Rose (Sir)

Charles Seaford

Matthew Taylor

John Kay
NGO

NGO

NGO

NGO

NGO

NGO

NGO/Academic
Chief Executive, The Young Foundation (social policy thinktank); also National Endowment for Science Technology and the Arts (charity). (Formerly director of Performance and Innovation Unit)

Chairman, Equality and Human Rights Commission

Managing Director, Waitrose; from 2011 Chairman, Business in the Community (a thinktank)

[to 2011] Chairman, Business in the Community (a thinktank)

Head of the Centre for Well-being, New Economics Foundation (a thinktank)

Chief Executive, Royal Society of Arts (formerly head of Number 10 Policy Unit)

Writer on economics for Financial Times; visiting professor of Economics at LSE

Technical Advisory Group, listed membership

$\begin{array}{lll}\text { Name } & \text { Role Notes }\end{array}$

Professor Paul Anand

Professor David Hand

Dr Eric Harrison

Academic

Academic

Academic
Professor of Economics, Open University

Professor of Statistics, Imperial College

Senior Research Fellow, City University (background in comparative social surveys)
Meetings

Attended

(max 8)

20 Commander of the Royal Victorian Order. 
Professor John Helliwell Academic

Professor Felicia Huppert Academic

Peter Kinderman Academic

Christian Kroll Academic

Professor Richard Layard

(Lord)

Dr Robert Metcalfe

Dr Julie Newton

Professor Lucinda Platt

Professor Steve Pudney

Dr Martin Seligman

Professor Sarah Stewart-

Brown

Professor Paul Dolan

Sara Grainger

Dr Steven Marshall

Academic

Academic

Academic

Academic

Academic

Academic

Academic

Academic/

Government

Devolved
Professor of Social Policy, LSE; associate, Cabinet Office Strategy Unit

(Behavioural Insight Team)

Devolved Senior Statistician, Scottish Government

Administration

Chief Social Research Officer, Welsh Government
0

2

6

5

3

2

2

1

2

0

5 
Baljit Gill

Dr Heidi Grainger

David Halpern

Karen Hancock

Dr Gemma Harper

Hugh Mallinson

Alison Patterson

Nick Rowe

Dr Martin Weale (CBE)

Government/

NGO

International Organisation

Section Head, Well-being and Household Conditions, Statistics Directorate of the OECD

Educational Psychologist and Executive Head Teacher, The Bethlem and Maudsley Hospital School

Dr John Ivens

NGO

Sally McManus

NGO

Juliet Michaelson

Government

overnment

Government

Governmen

Government

Government

Strategic Lead for Research, Sport England

Bank of England Monetary Policy Committee; Senior research fellow, National Institute of Economic \& Social Research (a thinktank)

Researcher, National Centre for Social Research (background in public health)

NGO 
Technical Advisory Group, attended more than 1 meeting without being a member

\section{Name}

Danielle DeFeo

Tim Andrews

Saamah Abdalla
Role

Government

Government

\section{Notes}

\section{Social Research Officer, Department of Health}

Head of Statistics Profession, Department of Business, Innovation and Skills

Senior Researcher, New Economics Foundation (a thinktank)
Meetings

Attended

(max 8)

3

3

2

Meetings attended

(max 8)
London School of Economics

Northern Ireland Statistics and Research Agency

ఫั
Role

Academic

Devolved Administration

Devolved Administration 
Department for Business, Innovation and Skills

Government

Department for Communities and Local Government

Government

Department for Education

Government

Department for Environment, Food \& Rural Affairs

Government

Department of Health

Government

Gallup

NGO 


\section{Newcastle \\ Matt Jenkins \\ Centre for Urban and Regional \\ Development Studies (CURDS) \\ Newcastle University \\ Newcastle Upon Tyne \\ NE1 7 RU \\ UK \\ m.jenkins2@ncl.ac.uk}

\section{Understanding statistic-making as a social practice through an examination of the UK 'Measuring Wellbeing' programme of statistics A straightforward explanation of the research}

This research asks what we are doing when we make official statistics: how do we count, and why?

As a starting point, we can observe that statistics are inherently social. They are commissioned by people, created by people and very often about people. The way those groups of people understand a statistic are potentially very different. Of the three, it is the people creating the statistic who would appear to determine its form. It is they who must realise the requests of the commissioners in such a way that the statistic can be used by, or on behalf of, those it is about.

With that in mind, this project seeks to examine the work of the producers of statistics, through an exploration of the UK Office for National Statistic's (ONS') 'Measuring National Wellbeing' programme of statistics. Official statistics in the UK are mainly the product of the ONS, so cannot be understood without reference to their practices. The Measuring National Wellbeing programme is a good case study of statistic-making as it is still a work in progress, subject to continuing development. This means that the discussions around how to translate the desire of its commissioners into a product which can be used, taking account of the technical, financial and theoretical limitations the ONS are subject to, are still ongoing. By examining how these limitations are negotiated by the organisation to produce the final statistic, the research hopes to develop an understanding of official statistics more generally, and the way they arise in their final form. 


\section{Interviews}

I have contacted you because you have been involved in some capacity in the statisticmaking process of the Measuring National Wellbeing programme, or a similar programme run by a different statistical body (such as 'GDP and Beyond'). I would like to talk to you about your work, and the Measuring National Wellbeing programme.

Interviews would be by phone at a time convenient to you and would last around half an hour to forty-five minutes, or as long as you could spare. Your answers would be anonymised, and extracts from them would then form part of my doctoral thesis, and potentially in articles appearing in academic journals. No data will be published in such a way that you can be identified. You will be offered the opportunity to review the notes of our conversation, and clarify your answers where you feel appropriate. Of course, at any point during the interview you may withdraw or refuse to answer questions.

This research project has been reviewed by the Ethics Committee of the Faculty of Humanities and Social Sciences of Newcastle University, and meets their strict requirements for ethical conduct in research. Should you have any complaint about the nature or conduct of this interview, my supervisory team are:

Andy Pike (andy.pike@newcastle.ac.uk) and Mike Coombes (mike.coombes@,newcastle.ac.uk), both at the Centre for Urban and Regional Development Studies at the University of Newcastle, address above;

and Joe Painter (j.m.painter@durham.ac.uk) of the Geography Department, University of Durham, Lower Mountjoy, South Road, Durham, DH1 3LE 


\section{Appendix C: Headline measures of the 'Measuring National Well-being' programme}

Taken from Office for National Statistics (2014e).

\section{Domain}

Measure

\section{Personal well-being}

Medium/high rating of satisfaction with their

lives overall

Medium/high rating of how worthwhile the things they do are

Rated their happiness yesterday as medium/high

Rated their anxiety yesterday as medium/low

Population mental well-being

\section{Source}

(all surveys conducted by ONS, unless otherwise indicated)

Annual Population Survey

Annual Population Survey

Annual Population Survey

Annual Population Survey

Understanding Society

\section{Notes}

Respondents were asked "Overall, how satisfied are you with your life nowadays?", using a scale from $0-10$ where ' 0 ' indicates 'very dissatisfied' and 10 indicates 'very satisfied'.

Respondents were asked "Overall, to what extent do you feel the things you do in your life are worthwhile?", using a scale from 0-10 where ' 0 ' indicates 'very non-worthwhile' and 10 indicates 'very worthwhile'.

Respondents were asked "Overall, how happy did you feel yesterday?”, using a scale from 0-10 where ' 0 ' indicates 'very unhappy' and 10 indicates 'very happy'.

Respondents were asked "Overall, how anxious did you feel yesterday?", using a scale from 0-10 where ' 0 ' indicates 'very non-anxious' and 10 indicates 'very anxious'.

Based on an abbreviated version of the WarwickEdinburgh Mental Well-being Scale 
Average rating of satisfaction with social life

Has a spouse, family member or friend to rely on if they have a serious problem
Average rating of satisfaction with family life

European Quality of Life Survey, Eurofound

European Quality of Life Survey, Eurofound

Understanding Society

\section{Health}

Healthy life expectancy at birth (male/female) Compiled from ONS data Reported a long term illness and a disability Labour Force Survey Somewhat, mostly or completely satisfied with Understanding Society their health

Some evidence indicating probable psychological disturbance or mental ill health.

Understanding Society

\section{What we do}

Unemployment rate

Labour Force Survey

Somewhat, mostly or completely satisfied with Understanding Society their job

Somewhat, mostly or completely satisfied with Understanding Society their amount of leisure time
Respondents were asked to rate their satisfaction with family life, using a scale from 1 to 10 where 1 indicates 'very dissatisfied' and 10 indicates 'very satisfied' .

Respondents were asked to rate their satisfaction with their social life, using a scale from 1 to 10 where 1 indicates 'very dissatisfied' and 10 indicates 'very satisfied' .

Respondents were asked 'Do you have a spouse, family member or friend to rely on if you have a serious problem?'

Respondents are asked to rate their satisfaction with their general health on a scale from 'completely dissatisfied' to 'completely satisfied'. Responses for 'somewhat, mostly and completely satisfied' are included.

Based on data from the General Health Questionnaire 12 questions.

Respondents were asked to rate their job satisfaction (if in employment) from 'Completely dissatisfied' to 'Completely satisfied'.

Respondents were asked to rate their job satisfaction (if in employment) from 'Completely 
Volunteered more than once in the last 12 months

Engaged with/participated in arts or cultural activity at least 3 times in last year

Adult participation in 30 mins of moderate intensity sport, once per week.

\section{Where we live}

Crimes against the person (per 1,000 adults)

Felt fairly/very safe walking alone after dark (men/women)

Accessed natural environment at least once a Natural England week in the last 12 months

Agreed/agreed strongly they felt they belonged Understanding Society to their neighbourhood

Households with good transport access to key Department for Transport services or work $(2010=100)$

Fairly/very satisfied with their accommodation Department for Communities and

\section{Personal finance}

Individuals in households with less than $60 \%$ of median income after housing costs Local Government

dissatisfied' to 'Completely satisfied'.

Adults (16+) were asked 'How frequently do you do unpaid voluntary work?'

Department for Culture, Media and Sport

Sport England

Crime Survey for England and Wales

Crime Survey for England and Wales

Respondents are asked "How safe do you feel walking alone in this area after dark?" selecting from 'Very safe', 'Fairly safe', 'A bit safe' and 'Very unsafe'

Adults (16+) were asked 'Thinking about the last 12 months, how often on average have you spent your leisure time out of doors, away from home?'. Respondents are asked to rate how their sense of belonging to their neighbourhood from 'strongly disagree' to 'strongly agree'.

Respondents are asked to rate how satisfied they were with their accommodation from 'very dissatisfied' to 'very satisfied'. 
Median wealth per household, including Wealth and Assets Survey pension wealth

Median household income

National Accounts

Somewhat, mostly or completely satisfied with Understanding Society the income of their household

Report finding it quite or very difficult to get Understanding Society by financially

\section{The economy}

Real net national income per head

National Accounts

UK public sector net debt as a percentage of Gross Domestic Product

Inflation rate (as measured by the Consumer Price Index)

\section{Education and skills}

Human capital - the value of individuals' skills, Calculations from ONS data knowledge and competences in labour market

Five or more GCSEs A* to C including English and Maths

UK residents aged 16 to 64 with no qualifications

\section{Governance}

Voter turnout (at UK General Elections)

Those who have trust in national Government
National Accounts

\section{Consumer Prices}

Department for Education and Devolved Administrations

Labour Force Survey

The International Institute for Democracy and Electoral Assistance

Eurobarometer
Respondents are asked to rate how satisfied they are with their income using ratings from 'completely dissatisfied' to 'completely satisfied'. Respondents are asked to rate how they were coping financially from 'finding it very difficult' to 'living comfortably'.

Respondents are asked if the 'Tend to trust' or 'Tend not to trust' the national government; the 


\section{The natural environment}

Total green house gas emissions (millions of Department for Energy and Climate tonnes)

Change

Protected areas in the UK (Millions hectares) Department for Environment, Food and Rural Affairs

Energy consumed within the UK from renewable sources

Department for Energy and Climate Change

Department for Environment, Food and Rural Affairs 



\section{Appendix D: Outputs of the ONS 'Measuring National Well-being' programme}

\section{Domain}

Measure

\section{Personal well-being}

Very high rating of satisfaction with their lives overall Very high rating of how worthwhile the things they do are Rated their happiness yesterday as very high

Rated their anxiety yesterday as very low

Population mental well-being
Average rating of satisfaction with family life

Average rating of satisfaction with social life

Has a spouse, family member or friend to rely on if they have $2010 / 11$

a serious problem

\section{Health}

Healthy life expectancy at birth (male/female)

Reported a long term illness and a disability

Somewhat, mostly or completely satisfied with their health

Some evidence indicating depression or anxiety

\section{$\begin{array}{ll} & \text { What we do } \\ & \text { Unemployment rate }\end{array}$}

\section{Latest}

\section{Period}

$2014 / 2015$

$2014 / 2015$

$2014 / 2015$

$2014 / 2015$

$2012 / 13$

2011

2011

\section{Previous}

$\begin{array}{rll}\text { Data } & & \text { Period } \\ & & \\ 0.288 & 2013 / 2014 \\ 0.344 & 2013 / 2014 \\ 0.341 & 2013 / 2014 \\ 0.409 & 2013 / 2014 \\ 24.6 / 35 & 2009 / 10\end{array}$

$\begin{array}{lll}8.2 / 10 & 2007 & 8.2 / 10 \\ 7.1 / 10 & 2007 & 7.0 / 10\end{array}$

0.867

\begin{tabular}{|c|c|c|c|c|}
\hline $2009-11$ & $\begin{array}{l}64.2 / \\
66.1\end{array}$ & $2006-08$ & & \\
\hline $\begin{array}{l}\text { April to June } \\
2015\end{array}$ & 0.193 & $\begin{array}{l}\text { April to June } \\
2014\end{array}$ & 0.185 & Not assessed \\
\hline $2012 / 13$ & 0.593 & $2011 / 12$ & 0.593 & \\
\hline $2012 / 13$ & 0.183 & $2011 / 12$ & 0.183 & \\
\hline
\end{tabular}

Summary of changes

since March 2015

publication

\subsection{Improving}

0.326 Improving

0.326 Improving

0.394 Improving

$25.2 / 35$ 
Somewhat, mostly or completely satisfied with their job Somewhat, mostly or completely satisfied with their amount of leisure time

Volunteered more than once in the last 12 months

Engaged with/participated in arts or cultural activity at least 3

times in last year

Adult participation in 30 mins of moderate intensity sport,

once per week.

2013-14

$2014 / 15$

2014/15

Crimes against the person (per 1,000 adults)

Felt fairly/very safe walking alone after dark (men/women)

Accessed natural environment at least once a week in the last

\section{2 months}

$2013 / 14$

Agreed/agreed strongly they felt they belonged to their

neighbourhood

$2011 / 12$

Households with good transport access to key services or work 2013

$(2011=100)$

Fairly/very satisfied with their accommodation

2013-14

\section{Personal finance}

Individuals in households with less than $60 \%$ of median income after housing costs

Median wealth per household, including pension wealth

$2013 / 14$

2010/12

$0.21 \quad 2012 / 13$

Real median household income

\author{
$0.776 \quad 2011 / 12$ \\ $0.582 \quad 2011 / 12$ \\ 0.173 .. \\ $0.834 \quad 2012 / 13$ \\ $0.358 \quad 2012-13$ \\ $57 \quad 2013 / 14$ \\ $85.8 \%$ / 2013/14 \\ $61.7 \%$
}

$0.58 \quad 2012 / 13$

$0.628 \quad 2009 / 10$

106

$0.892 \quad 2012-13$

2011

0.773

0.577

0.831

0.362

66 Improving

$85.1 \%$ / Male - Little or no

$58.0 \%$ overall change,

Female - Improving

0.55

0.66

100

0.906
Little or no overall 0.21 change 204300

Little or no overall 23690 change 
Somewhat, mostly or completely satisfied with the income of their household

\section{The economy}

Real net national disposable income per head 2014

UK public sector net debt as a percentage of Gross Domestic Product

Inflation rate (as measured by the Consumer Price Index)
2014/15

July 2015

\section{3}

$0.807 \quad 2013 / 14$

0.001 July 2014
21809 Improving

0.791 Not assessed

0.016 Not assessed

\section{Education and skills}

Human capital - the value of individuals' skills, knowledge and competences in labour market

Five or more GCSEs A* to C including English and Maths

$2012 / 13$

UK residents aged 16 to 64 with no qualifications

2014

$\begin{array}{rl}£ \text { trillion } & \\ 18.95 & 2013 \\ 0.589 & 2011 / 12 \\ 0.086 & 2013\end{array}$

$£$ trillion

18.78 Improving

0.59

0.093

\section{Governance}

Voter turnout in UK General Elections

Those who have trust in national Government

$\begin{array}{lrlrl}2015 & 0.662 & 2010 & 0.651 & \text { Improving } \\ \text { Spring 2015 } & 0.37 & \text { Spring 2014 } & 0.25 & \text { Improving }\end{array}$

\section{The natural environment}

Total green house gas emissions (millions of tonnes)

Protected areas in the UK (Millions hectares)

2014
2014
2014
2012

$\begin{array}{ll}518.7 & 2013\end{array}$

$21.393 \quad 2013$

0.072013

0.4392011

566.5 Improving

15.38

0.056 Improving

Household waste that is recycled

2012 
Life satisfaction

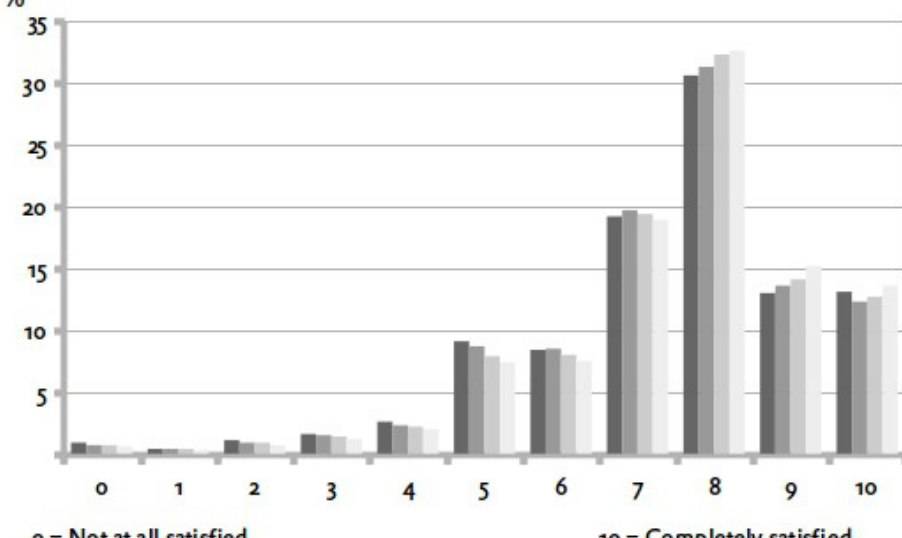

$0=$ Not at all satisfied

$10=$ Completely satisfied

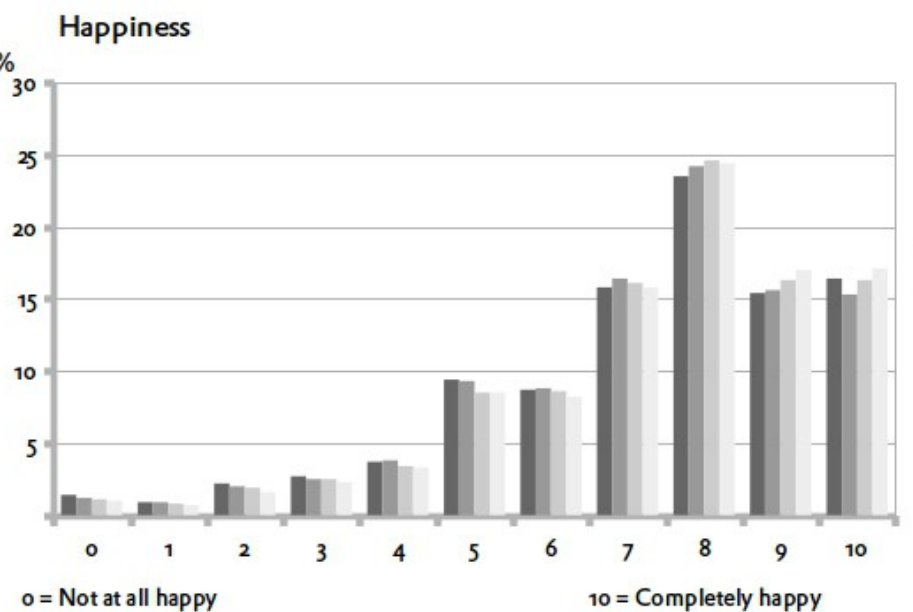

Worthwhile
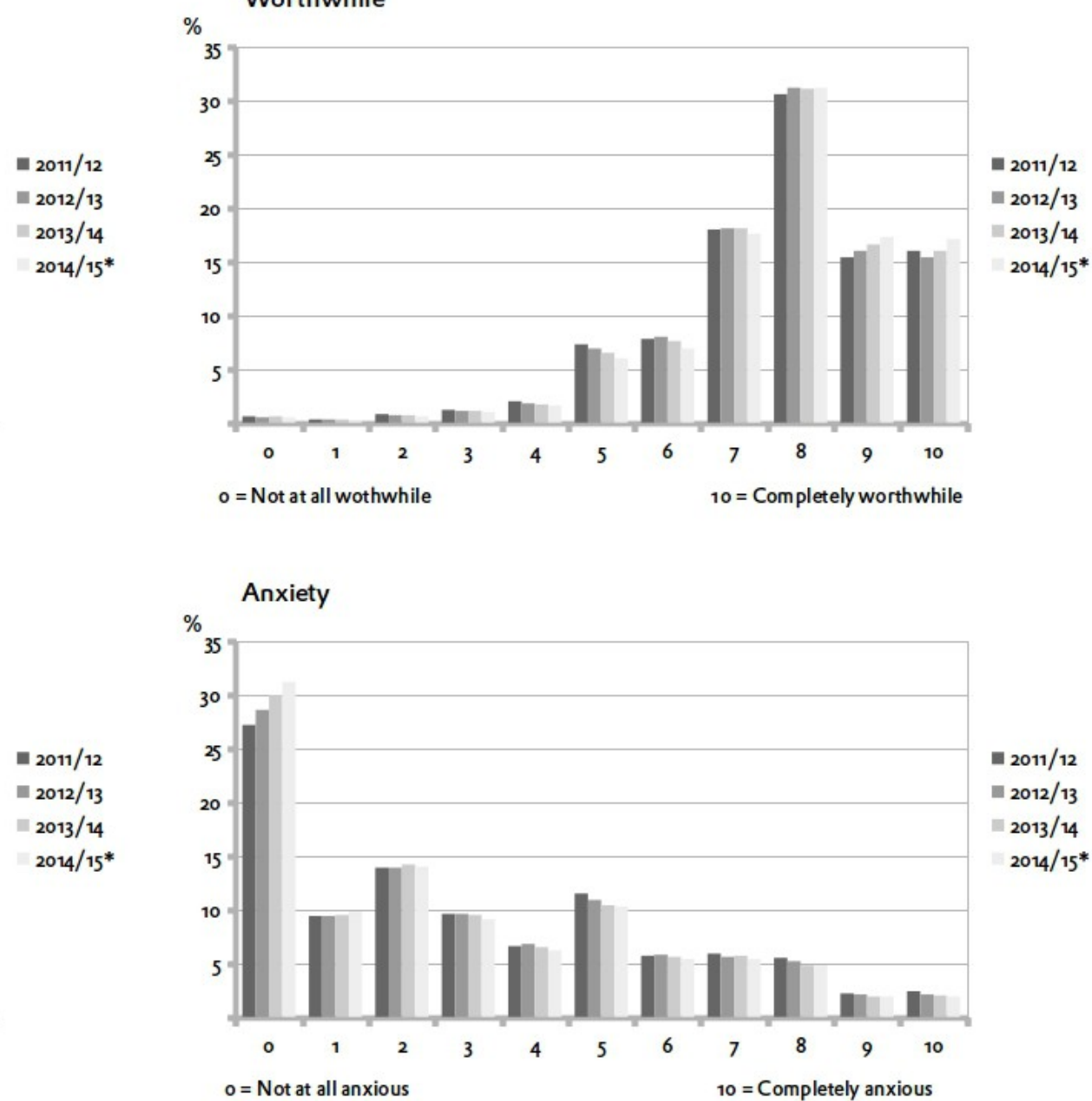

Figure D.1. Distribution of personal well-being ratings, financial years ending 2012 to 2015

Source: redrawn from Office for National Statistics (2015b), using data from Office for National Statistics (2015c) 


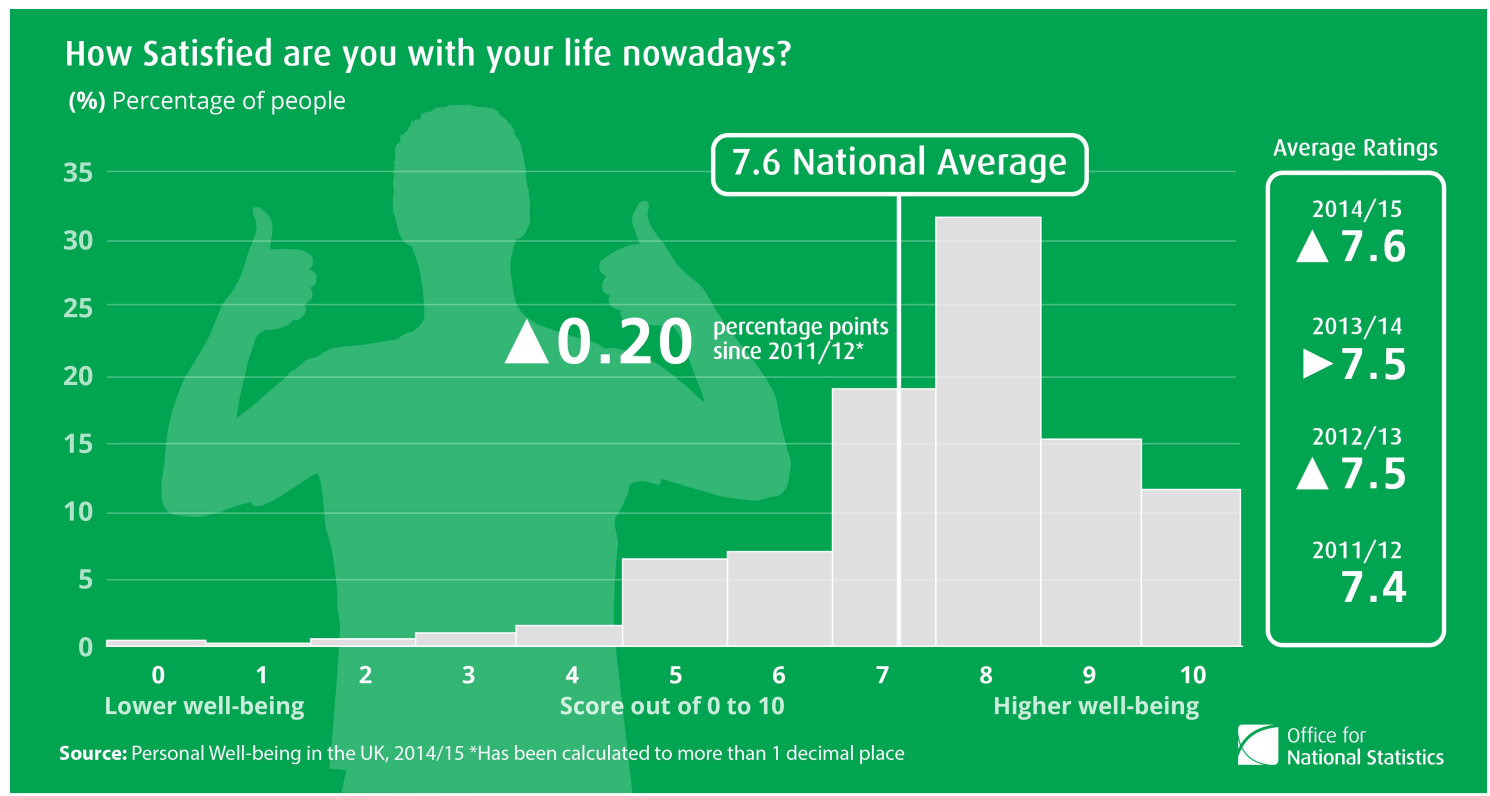

Figure D.2. How satistified are you with your life nowadays?

Source: Taken from http://www.ons.gov.uk/ons/rel/wellbeing/measuring-national-wellbeing/personal-well-being-in-the-uk--2014-15/sty-2-4-insights-into-personal-well-being.html (Accessed 10 December 2015)

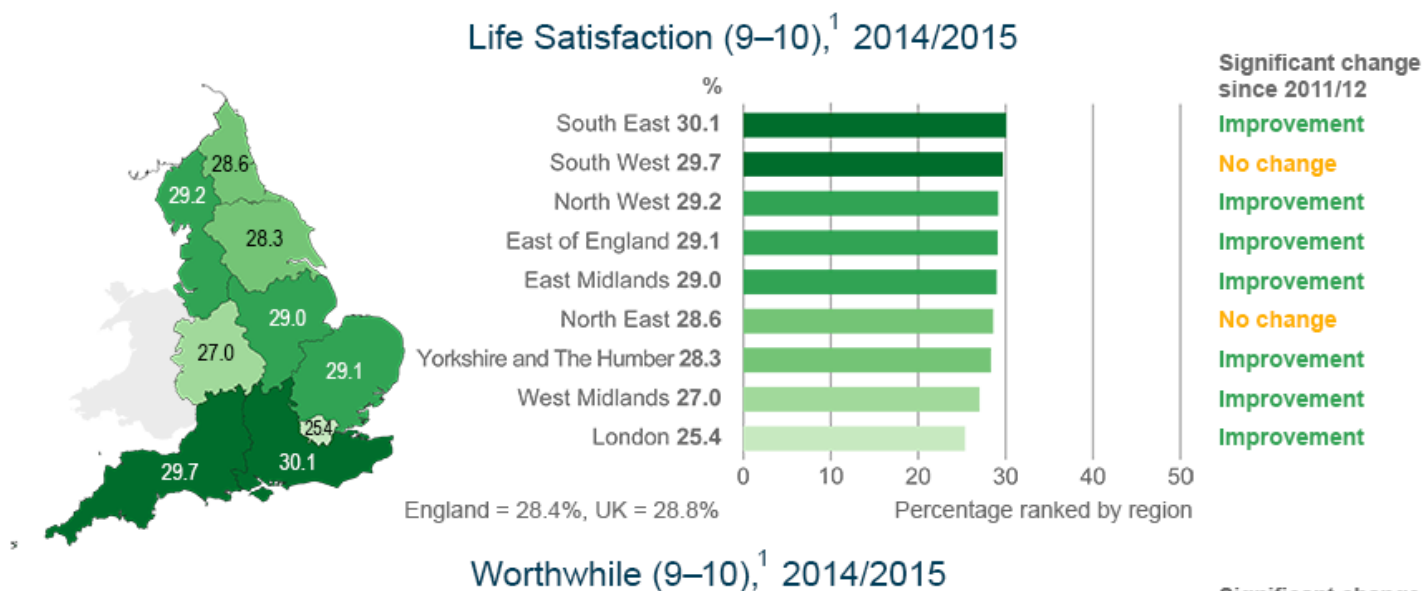

Figure D.3. Extract from Percentages rating personal well-being at highest levels: by English region for financial year ending 2015 and change since financial year ending 2012

Source: Office for National Statistics (2015b)

Note: 1 . Adults aged 16 and over were asked: "Overall, how satisfied are you with your life nowadays?" 



\section{Appendix E: Things I did when I should have been doing other things}

E.1. Up-goer Five abstract, Januray 2014

I am interested in numbers. We use numbers all the time, without really thinking about why we're using them or what sort of thing they are. Which is a bit of a problem. Some people say that numbers are a form of control, but I don't agree. I don't think you can plan a number, then make the number that you planned - things will go wrong between the plan and the number. If you can't make sure that the number matches the plan, you can't plan for control. Instead, I am going to look at the bit between the plan and the number to see what actually happens. My idea is that no one actually cares how the number is made, or what they planned for it, it is just something that happens, and that we then have to live with, like we had actually planned. This is also a problem, but a different sort of problem.

(see http://splasho.com/upgoer5/)

E.2. Lolmythesis summaries

At January 2014

Statistics are bad, and you should feel bad.

At March 2014

Statistics are things made for reasons; you may go back to your homes now, there is nothing to see here.

At April 2014

A statistic is a thing made by people who won't talk to me. Here's some speculation. You may thank me later.

At June 2014

The object of the investigation isn't important, it's what people do with it that counts. Please give me more funding to look at that.

At July 2014

Statistics are like dyanamistics, but they don't move. I'll be here all week. 
At October 2014

The statistic-making progress is either exactly as you expected it to be or a travesty of everything you hold dear, or sometimes both.

\section{At March 2015}

Statistics are things made by people, used by other people, normally for other things.

\section{E.3. Drawings}

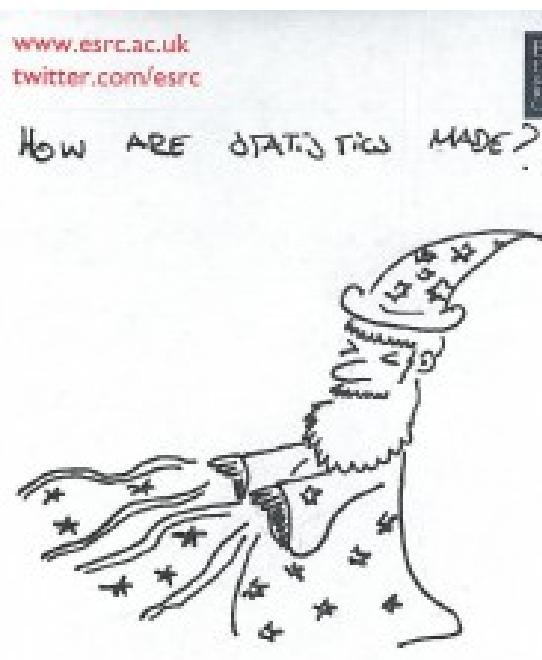

Hropatesis I. Probagir wizards.

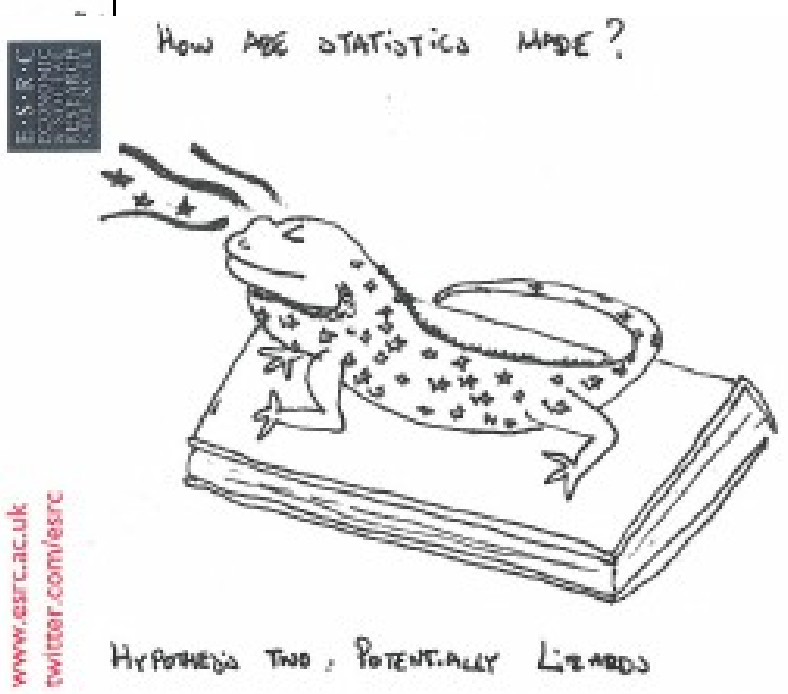


APPENDIXE

www.esre.ac.uk

twitter.comiesre

How ARE STATOTICS MADE?

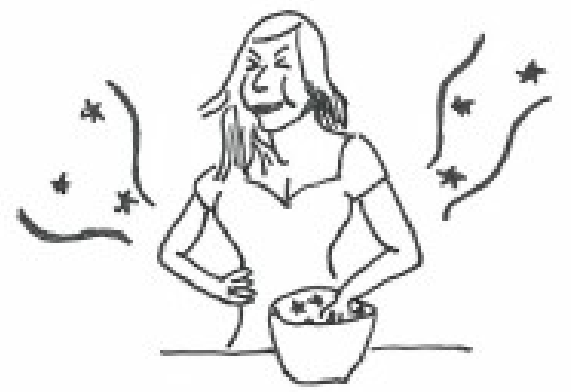

Hypotuesia three: Nigella. Tuis Exhains

WhY STATijTiC ARE SOG BUTTER

AND if YOU EAT TAEM YOW GET FAT.

How aRe STATIST:CS MADE?

How ARE STORTSTics MANE?
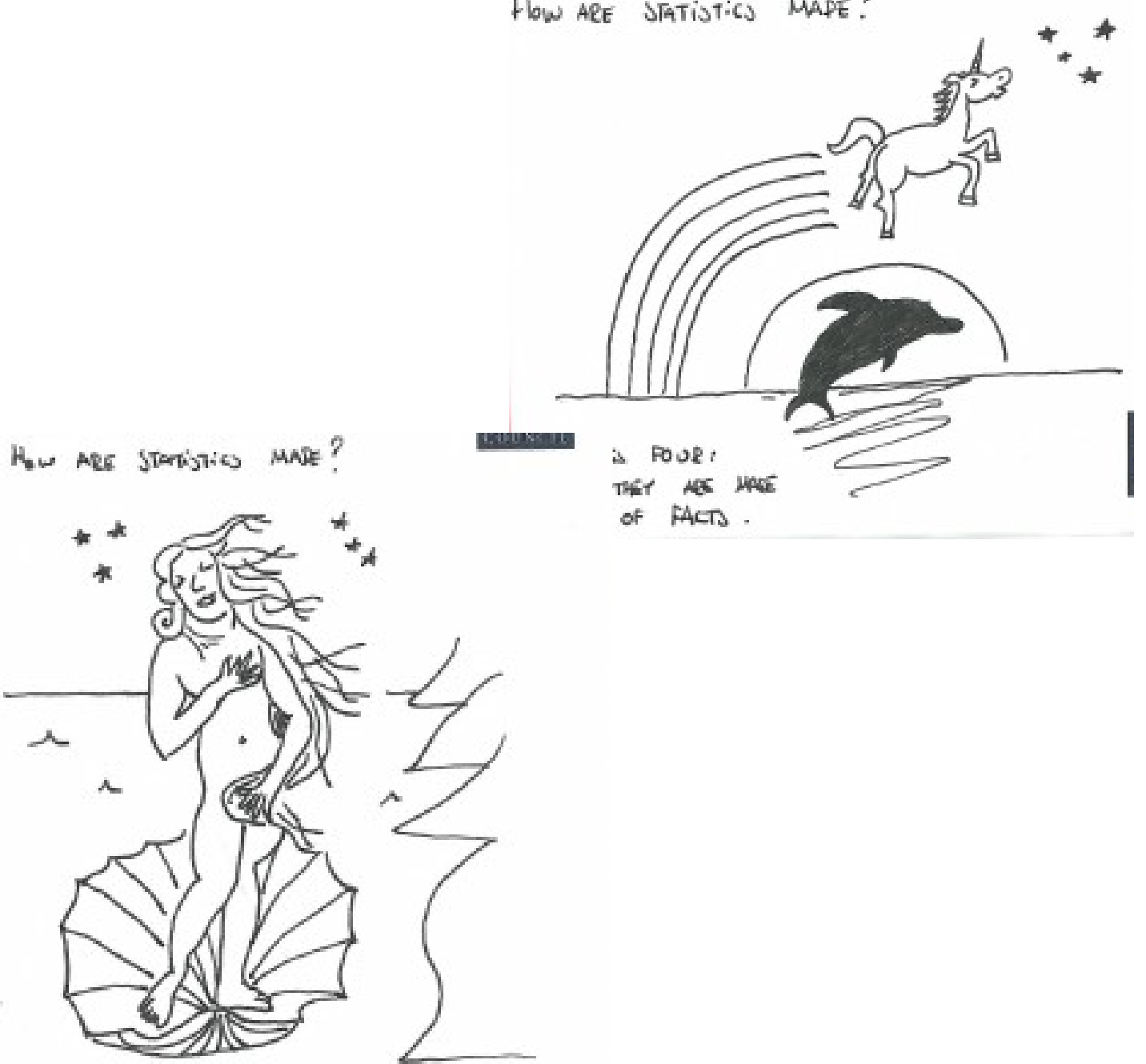

of FACT.

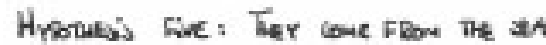


How are statistís MADE?

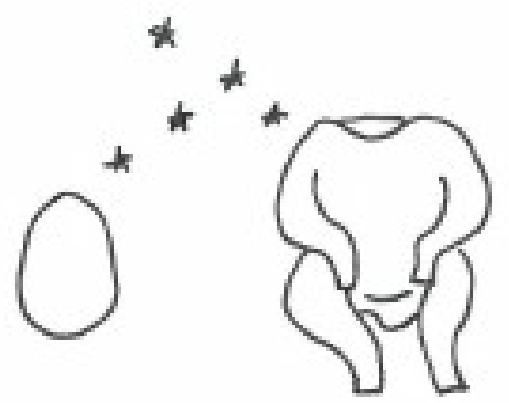

How ARE JnToris MnDe?

Hoveross ix

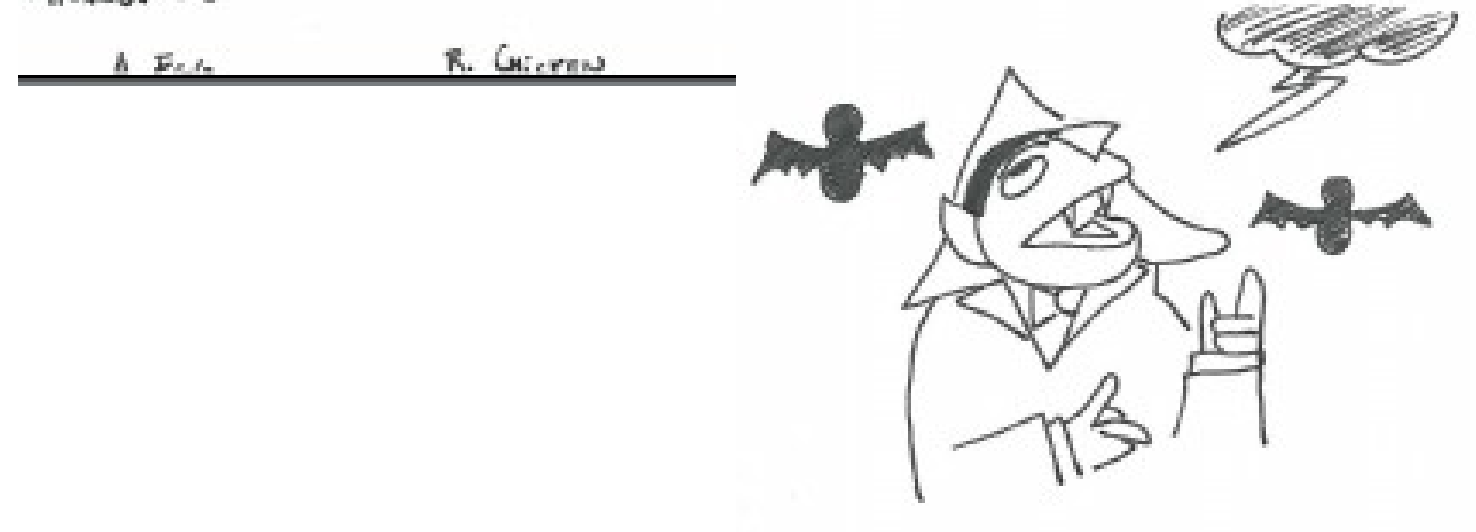

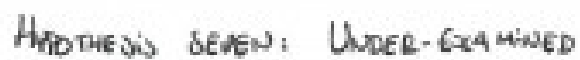

ONTOCOCNical \& ERiste MaLaGical

Assomprows.

M.

How AEE JTATISTICS MADE?

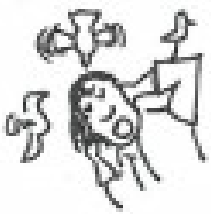

1. Birds

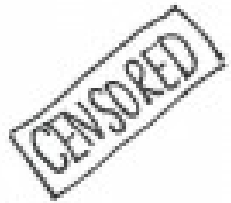

3.... do

2. Bees

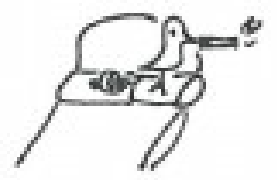

4. ¿Profir?

Hrathesis Eicent: Unanatuere hos. 
APPENDIXE

How AEE STATISTICO MADE?

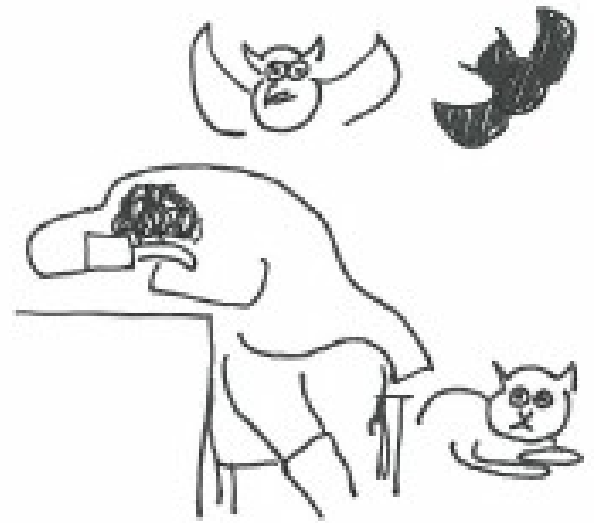

Hypordeis nine: THEY Ale thingS WHich Hapen wien we tee Trralg to do OTHE THANGS

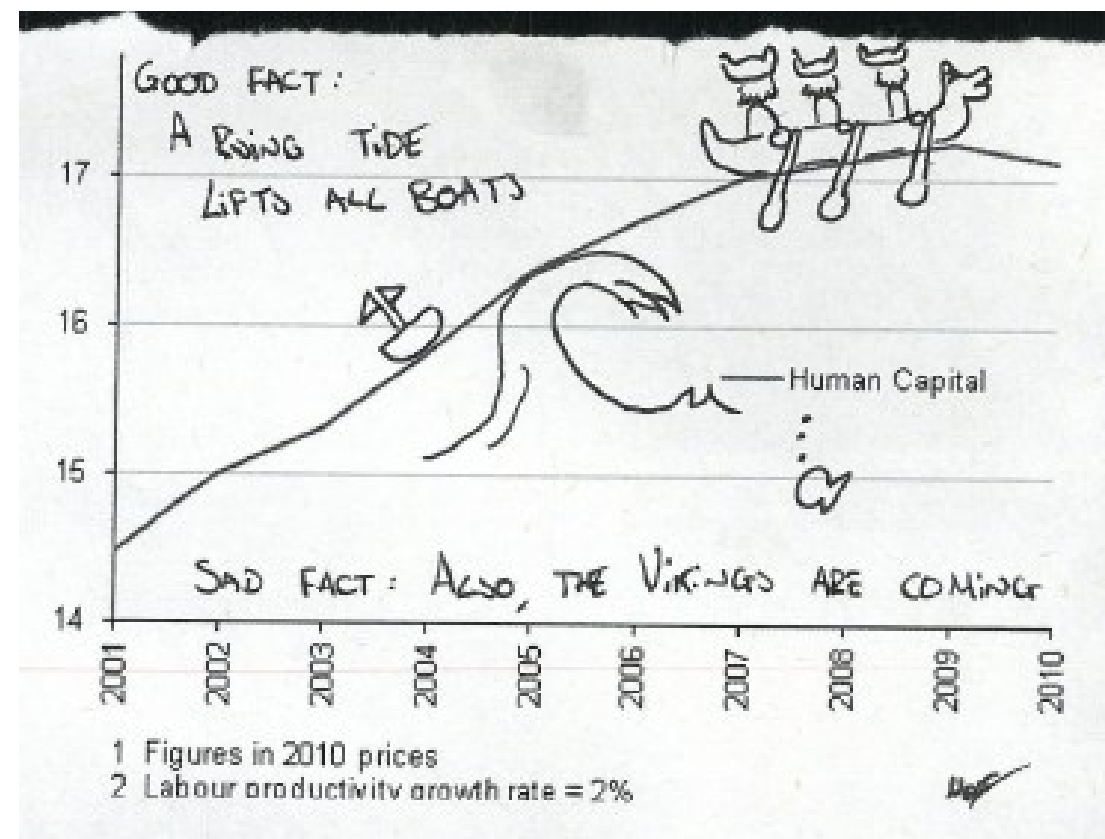





\section{References}

\section{Legislation and Statutory Instruments}

Cromwell, Thomas. 1910[1536-1557 ]. "Injunctions." In Visitation Articles and Injunctions, edited by WH Frere and WPM Kennedy, II, pp.34-43. London: Longmans, Green, and Co.

Great Britain, 1770. Corn Act, 10 Geo. III, c.39. London: HMSO.

Great Britain, 1789. Importation and Exportation Act, 29 Geo. III, c.16. London: HMSO.

Great Britain, 1836. The Births and Deaths Registration Act, 6 and 7. Will. IV, c.86. London: HMSO.

Healey, John. 2008. The Parish Councils (Power to Promote Well-Being) (prescribed Conditions) Order. SI 3095. London: HMSO.

Hughes, Beverley. 2007. The Local Authority Targets (Well-Being of Young Children) Regulations. SI 1415. London: HMSO.

Northern Ireland, 1969. Census Act (Northern Ireland), 1969, c. 8. Belfast: HMSO.

United Kingdom, 1920. Census Act, 10 and 11 Geo. V., c. 41. London: HMSO

United Kingdom, 1998. Government of Wales Act, Eliz. II, c.38. London: HMSO.

United Kingdom, 1998. Northern Ireland Act, Eliz. II, c.27. London: HMSO.

United Kingdom, 1998. Scotland Act, Eliz. II, c. 46. London: HMSO.

United Kingdom, 2000. Local Government Act, Eliz. II, c.22. London: HMSO.

United Kingdom, 2006. Government of Wales Act, Eliz. II, c.32. London: HMSO.

United Kingdom, 2007. Statistics and Registration Services Act, Eliz. II, c.18. London: HMSO.

United Kingdom, 2008. Local Transport Act, Eliz. II, c.26. London: HMSO.

United Kingdom, 2011. Localism Act, Eliz. II, c.20. London: HMSO.

United Kingdom, 2012. Public Services (Social Value) Act, Eliz. II, c. 5. London: HMSO.

United Kingdom, 2012. Scotland Act, Eliz. II, c. 11. London: HMSO.

Wales, 2014. Social Services and Well-Being (Wales) Act. Anaw. 4. Cardiff: HMSO.

Wales, 2015. Well-Being of Future Generations (Wales) Act. Anaw. 2. Cardiff: HMSO.

\section{Non-legislative sources}

Abramsky, Josh, and Steve Drew. 2014. Changes to National Accounts: Inclusion of Illegal Drugs and Prostitution in the UK National Accounts. London: ONS.

Acheson, Donald. 1998. Independent Enquiry into Inequalities in Health; Report. 
London: HMSO. (Available at:

http://webarchive.nationalarchives.gov.uk/20130107105354/

http://www.archive.official-documents.co.uk/document/doh/ih/ih.htm.) Accessed 10 August 2015.

Acker, Joan. 1989. "Making Gender Visible." In Feminism and Sociological Theory, edited by Ruth A Wallace, 65-81. Newbury Park, CA: Sage.

Adorno, Theodore W, and Max Horkheimer. 1997. Dialectic of Enlightenment. Translated by John Cumming. New York: Verso.

Akerlof, George A. 2002. "Behavioral Macroeconomics and Macroeconomic Behavior." The American Economic Review 92 (3): 411-33.

Allen, John, and Allan Cochrane. 2010. "Assemblages of State Power: Topological Shifts in the Organization of Government and Politics." Antipode 42 (5): 1071-89.

Allin, Paul. 2007. "Measuring Societal Wellbeing." Economics and Labour Market Review 1 (10): 46-52.

2013. "New Statistics for Old? The Case of the UK Measuring National WellBeing Programme." Paper given at 'Wellbeing, Resilience and Social Renewal: Which Comes First', Newcastle: University of Newcastle, 25 June 2013.

_. 2014. "Measuring Wellbeing in Modern Societies." In Work and Wellbeing: A Complete Reference Guide, by Peter Y Chen and Cary L Cooper, III:1-55. Oxford: John Wiley and Sons.

Allin, Paul, and David J Hand. 2014. The Wellbeing of Nations; Meaning, Motive and Measurement. Oxford: John Wiley and Sons.

Allsopp, Christopher. 2003. Review of Statistics for Economic Policymaking; First Report to the Chancellor of the Exchequer, the Governor of the Bank of England and the National Statistician. London: HMSO.

Alonso, William, and Paul Starr. 1987. The Politics of Numbers. New York: Russell Sage Foundation.

Annan, Kofi A. 2000. We the Peoples; the Role of the United Nations in the 21st Century. New York: United Nations.

Archer, Margaret S. 1982. "Morphogenesis versus Structuration: On Combining Structure and Action." The British Journal of Sociology 33 (4): 455-83.

—. 2000. "Homo Economicus, Homo Sociologicus and Homo Sentiens." In Rational Choice Theory; Resisting Colonization, edited by Margaret S Archer and Jonathan Q Tritter, 36-56. London: Routledge.

Aristotle. 2002. The Nichomachean Ethics of Aristotle. Translated by Christopher Rowe. Oxford: Oxford University Press.

Atkins, Liz, and David Jarrett. 1979. "The Significance of 'Significance Tests." In Demystifying Social Statistics, edited by John Irvine, Ian Miles, and Jeff Evans, 87-109. London: Pluto Press. 


\section{REFERENCES}

Atkinson, Tony. 2005. “Atkinson Review: Final Report; Measurement of Government Output and Productivity for the National Accounts." London: Palgrave Macmillan.

Audit Commission. 2000. Aiming to Improve; the Principles of Performance Measurement. London: Audit Commission.

Australian Bureau of Statistics. 2012. Measures of Australia's Progress 2012; Is Life in Australia Getting Better? Canberra: Australian Bureau of Statistics.

Bache, Ian. 2013. "Measuring Quality of Life for Public Policy: An Idea Whose Time Has Come? Agenda-Setting Dynamics in the European Union." Journal of European Public Policy 20 (1): 21-38.

Bache, Ian, and Louise Reardon. 2013. "An Idea Whose Time Has Come? Explaining the Rise of Well-Being in British Politics." Political Studies 61: 898-914.

Bailey, Rossy, Jose Rofique, and Alun Humphrey. 2010. "Public Confidence in Official Statistics 2009." In Strengthening User Engagement, by UK Statistics Authority, 33-123. London: UKSA.

Bambra, C, KE Smith, K Garthwaite, KE Joyce, and DJ Hunter. 2011. “A Labour of Sisyphus? Public Policy and Health Inequalities Research from the Black and Acheson Reports to the Marmot Review." Journal of Epidemiology and Community Health 65: 399-406.

Bandyopadhyay, Prasanta S, and Malcolm R Forster. 2011. "Philosophy of Statistics: An Introduction." In Handbook of Philosophy of Science; Volume 7: Philosophy of Statistics, edited by Prasanta S Bandyopadhyay and Malcolm R Forster, 1-50. Oxford: Elsevier.

Baran, Paul A, and Paul Marlor Sweezy. 1966. Monopoly Capital: An Essay on the American Economic and Social Order. New York: Monthly Review Press.

Barcan, Ruth. 2014. "I shouldn't really be here.” Times Higher Education Supplement 2134 (Jan 9): 34.

Barnes, Donald Grove. 1930. A History of the English Corn Laws from 1660-1846. London: George Routledge and Sons, Ltd.

Barnes, Trevor J. 1991. "Metaphors and Conversations in Economic Geography: Richard Rorty and the Gravity Model." Geografiska Annaler. Series B, Human Geography 73 (2): 111-20.

Barzelay, Michael. 2002. "The New Public Management in Context." In New Public Management; Current Trends and Future Prospects, edited by Kate McLaughlin, Stephen P Osborne, and Ewan Ferlie, 15-33. London: Routledge.

Bauer, Raymond A. 1966a. "Detection and Anticipation of Impact: The Nature of the Task." In Social Indicators, edited by Raymond A Bauer, 1-67. Cambridge, MA: MIT Press. , ed. 1966b. Social Indicators. Cambridge, MA: MIT Press. 
Beaumont, Jan. 2011. "Measuring National Well-Being - Discussion Paper on Domains and Measures." London: Office for National Statistics. (Available at: http://www.ons.gov.uk/ons/dcp171766_240726.pdf.) Accessed 17 October 2012.

2012. "Measuring National Well-Being: Report on Consultation Responses on Proposed Domains and Measures." London: ONS.

Becker, Gary S. 1962. "Investment in Human Capital: A Theoretical Analysis." Journal of Political Economy 70 (5): 9-49.

1980. Human Capital; a Theoretical and Empirical Analysis, with Special Reference to Education. 2nd Edition. Chicago: University of Chicago Press.

Bentham, Jeremy. 1962. "Introduction to the Principles of Morals and Legislation (Chapters I-V)." In Utilitarianism, On Liberty, Essay on Bentham; Together with Selected Writings of Jeremy Bentham and John Austin, edited by Mary Warnock, 33-77. London: Meridian.

Benton, Ted, and Ian Craib. 2011. Philosophy of Social Science; the Philosophical Foundations of Social Thought. 2nd ed. Basingstoke: Macmillan.

Berger-Schmitt, Regina, and Heinz-Herbert Noll. 2000. "Conceptual Framework and Structure of a European System of Social Indicators." EuReporting Working Paper 9. Mannheim: Centre for Survey Research and Methodology.

Biebricher, Thomas. 2013. "Critical Theories of the State: Governmentality and the Strategic-Relational Approach.” Constellations 20 (3): 388-405.

Blanchflower, David G, and Andrew J Oswald. 2004. "Well-Being over Time in Britain and the USA." Journal of Public Economics 88: 1250-86.

- 2008. "Is Well-Being U-Shaped over the Life Cycle?" Social Science and Medicine 66: 1733-49.

Blaug, Mark. 1972. "The Correlation between Education and Earnings: What Does It Signify?" Higher Education 1 (1): 53-76.

. 1976. "The Empirical Status of Human Capital Theory: A Slightly Jaundiced Survey." Journal of Economic Literature 14 (3): 827-55.

. 1985. "Where Are We Now in the Economics of Education?" Economics of Education Review 4 (1): 17-28.

Bordieu, Pierre, and Loïc Wacquant. 2001. "NewLiberalSpeak; Notes on the New Planetary Vulgate.” Radical Philosophy 105: 2-5.

Bowles, Samuel. 1970. “Towards an Education Production Function.” In Education, Income, and Human Capital, edited by W Lee Hansen, 9-61. Ann Arbor: UMI.

Bowles, Samuel, and Herbert Gintis. 1975. "The Problem with Human Capital Theory a Marxian Analysis." The American Economic Review 65 (2): 74-82.

1976. Schooling in Capitalist America; Educational Reform and the Contradictions of Economic Life. London: Routledge \& Kegan Paul. 


\section{REFERENCES}

Braverman, Harry. 1998. Labor and Monopoly Capital: The Degradation of Work in the Twentieth Century. New York: Monthly Review Press.

Brenner, Neil. 1997. “Global, Fragmented, Hierarchical: Henri Lefebvre’s Geographies of Globalization." Public Culture 10 (1): 135-67.

- 2004. New State Spaces; Urban Governance and the Rescaling of Statehood. Oxford: Oxford University Press.

Brenner, Neil, and Stuart Elden. 2009. "Henri Lefebvre on State, Space, Territory." International Political Sociology 3: 353-337.

Briggs, CL. 1986. Learning How to Ask: A Sociolinguistic Appraisal of the Role of the Interview in Social Science Research. Cambridge: Cambridge University Press.

. 2007. "Anthropology, Interviewing, and Communicability in Contemporary Society." Current Anthropology 48 (4): 551-80.

Brockway, George P. 1995. The End of Economic Man; Principles of Any Future Economics. New York: WW Norton.

Brown, John. 1992. "Evaluating the Performance of Central Government." In Handbook of Public Services Management, edited by Christopher Pollitt and Stephen Harrison, 25-46. Oxford: Blackwell Publishers.

Bucholtz, M. 2000. “The Politics of Transcription.” Journal of Pragmatics 32: 143965.

Buck, Peter. 1977. "Seventeenth-Century Political Arithmetic: Civil Strife and Vital Statistics." Isis 68 (1): 67-84.

Bumstead, Robert, and Richard Alldritt. 2011. "Statistics for the People? The Role of Official Statistics in the Democratic Debate." (Available at:

http://www.statisticsauthority.gov.uk/reports---correspondence/reports/conferencepapers/statistics-for-the-people--the-role-of-official-statistics-in-the-democraticdebate.pdf.) Accessed 8 January 2012.

Burchell, Stuart, Colin Clubb, and Anthony G Hopwood. 1985. "Accounting in Its Social Context: Towards a History of Value Added in the United Kingdom." Accounting, Organizations and Society 10 (4): 381-415.

Burkitt, Ian. 2015. "Relational Agency: Relational Sociology, Agency and Interaction." European Journal of Social Theory, 1-18. doi:10.1177/1368431015591426.

Burton, Frank, and Pat Carlen. 1979. Official Discourse; on Discourse Analysis, Government Publications, Ideology and the State. London: Routledge \& Kegan Paul.

Butler, Robin. 1993. "The Evolution of the Civil Service - a Progress Report.” Public Administration 71 (3): 395-406.

Cabinet Office. 2010. Ministerial Code. London: HMSO.

- 2013. Wellbeing Policy and Analysis; an Update of Wellbeing Work across 
Whitehall. (Available at:

https://www.gov.uk/government/uploads/system/uploads/attachment_data/file/224

910/Wellbeing_Policy_and_Analysis_FINAL.PDF). Accessed 4 February 2014.

Callon, Michel. 2007. "What Does It Mean to Say That Economics Is Performative?" In Do Economists Make Markets? On the Performativity of Economics, edited by Donald MacKenzie, Fabian Muniesa, and Lucia Siu, 311-57. Princeton, NJ: Princeton University Press.

Cameron, David. 2005. "Speech on Winning the Conservative Party Leadership." $B B C$ News 6 December. (Available at:

http://news.bbc.co.uk/1/hi/uk_politics/4504722.stm.) Accessed 25 August 2014.

at:

http:/www.theguardian.com/politics/2006/may/22/conservatives.davidcameron.) Accessed 21 May 2014.

- 2010. "PM Speech on Wellbeing." Speech. November 25. (Available at: http://www.number10.gov.uk/news/pm-speech-on-well-being/.) Accessed 22 October 2012.

. 2013. "Speech at the State Opening of Parliament." May. (Available at: http://www.conservatives.com/News/Speeches/2013/05/David_Camerons_Speech _at_the_State_Opening_of_Parliament.aspx.) Accessed 15 September 2013.

Carmargo, Alexandre de Pavia Rio. 2009. "Sociology of Statistics: Possibilities of a New Field of Investigation." Translated by Derrick Phillips. História, Ciências, Saúde-Manguinhos 16 (4): 1-24.

Cartwright, Nancy. 1994. Nature's Capacities and Their Measurement. Oxford: Oxford University Press.

Castel, Robert. 1991. "From Dangerousness to Risk." In The Foucault Effect; Studies in Governmentality, edited by Graham Burchell, Colin Gordon, and Peter Miller, 281-98. Chicago: University of Chicago Press.

Chancellor of the Exchequer. 1998. "Comprehensive Spending Review: New Public Spending Plans 1999-2002." Cm 4011. London: HMSO. (Available at: http://collections.europarchive.org/tna/20060919121031/http://www.archive.offici al-documents.co.uk/document/cm40/4011/4011.htm.) Accessed 10 August 2015.

Clance, PR, and SA Imes. 1978. "The imposter phenomenon in high achieving women. Dynamics and therapeutic intervention." Psychotherapy: Theory, Research and Practice 15: 241-247.

Cohen, Gerald Allan. 2000. If you're an egalitarian, how come you're so rich? Cambridge, MA: Harvard University Press.

Collier, GF. 1854. "An Account of the Metropolitan Bills of Mortality. From Their Commencement to the Present Time." The Lancet, 19 August: 141-43.

Collins, Peter. 1998. "Negotiating Selves: Reflections on 'Unstructured' Interviewing." 


\section{REFERENCES}

Sociological Research Online 3 (3): (Available at:

http://www.socresonline.org.uk/3/3/2.html.) Accessed 13 June 2014.

Commission of the European Communities. 2009. "GDP and Beyond; Measuring Progress in a Changing World.” European Commission, Brussels.

Conservative Party. 2010. Invitation to Join the Government of Great Britain. London: Conservative Party.

Craib, Ian. 1997. "Social Constructionism as a Social Psychosis." Sociology 31 (1): 115.

Crouch, Colin. 2004. Post-Democracy. Malden, MA: Polity Press.

. 2013. "From Markets versus States to Corporations versus Civil Society?" In Politics in the Age of Austerity, edited by Armin Schäfer and Wolfgang Streeck, 219-38. Cambridge: Polity Press.

Cummins, Robert A. 1996. "The Domains of Life Satisfaction: An Attempt to Order Chaos." Social Indicators Research 38 (3): 303-28.

Dalenius, TE. 1968. "Official Statistics and Their Uses.” Revue de l'Institut International de Statistique/Review of the International Statistical Institute 36 (2): $121-40$.

Daley, Herman E, and John B Cobb. 1994. For the Common Good; Redirecting the Economy toward Community, the Environment, and a Sustainable Future. 2nd ed. Boston: Beacon Press.

Davidson, Roger. 1995. “Official Labour Statistics: A Historical Perspective.” Journal of the Royal Statistical Society Series A (Statistics in Society) 158 (1): 1650173.

Davies, Huw, and Sandra Nutley. 2002. "Evidence-Based Policy and Practice: Moving from Rhetoric to Reality.” Discussion Paper 2. University of St Andrews: Research Unit for Research Utilisation.

Dean, Mitchell. 1995. "Governing the Unemployed Self in an Active Society." Economy and Society 24 (4): 559-83.

Debord, Guy. 1995. The Society of the Spectacle. Translated by Donald NicholsonSmith. New York: Zone Books.

- 1998. Comments on "The Society of the Spectacle." Translated by Malcolm Imrie. New York: Verso.

de Groot, Rudolf, Luke Brander, Sander van der Ploeg, Robert Costanza, Florence Bernard, Leon Braat, Mike Christie, et al. 2012. "Global Estimates of the Value of Ecosystems and Their Services in Monetary Units." Ecosystems Services 1: 5061.

Delaney, Kevin J. 2007. "Methodological dilemmas and opportunities in interviewing organizational elites." Sociology Compass 1(1): 208-221.

Delle Fave, Antonella, Ingrid Brdar, Teresa Freire, Dianne Vella-Brodick, and Marié P 
Wissing. 2011. "The Eudaimonic and Hedonic Components of Happiness: Qualitative and Quantitative Findings." Social Indicators Research 100 (2): 185207.

Denhardt, Robert B, and Janet Vinzant Denhardt. 2000. "The New Public Service: Serving rather than Steering." Public Administration Review 60 (6): 549-59.

Denzin, Norman K, and Yvonna Lincoln, eds. 2000. Handbook of Qualitative Research. 2nd ed. Thousand Oaks, CA: Sage Publications.

Department for Environment, Food and Rural Affairs. 2013. Sustainable Development Indicators. London: DEFRA.

Department of Health and Social Security. 1980. Inequalities in Health; Report of a Research Working Group. London: Department of Health and Social Security. (Available at: http://www.sochealth.co.uk/national-health-service/public-healthand-wellbeing/poverty-and-inequality/the-black-report-1980/.) Accessed 10 August 2015.

Department of the Environment, Transport and the Regions. 1999. "A Better Quality of Life; a Strategy for Sustainable Development.” Cm 4345. London: DETR.

- 2000. Report of Policy Action Team 17: Joining It up Locally. London: DETR.

de Saint-Exupery, Antoine. 1971. The Little Prince. Translated by Katherine Woods. London: Harcourt Brace and Company.

de Sola Pool, Ithiel. 1957. “A Critique of the Twentieth Anniversary Issue.” Public Opinion Quarterly 21: 190-98.

Dickens, Charles. 2003. Hard Times; for These Times. London: Penguin.

Diener, Ed, and Martin EP Seligman. 2004. "Beyond Money; toward an Economy of Well-Being." Psychological Science in the Public Interest 5 (1): 1-31.

Diener, Ed, Eunkook M Suh, Richard E Lucas, and Heidi L Smith. 1999. "Subjective Well-Being: Three Decades of Progress.” Psychological Bulletin 125 (2): 276302.

Directors General of the National Statistical Institutes. 2010. "Sofia Memorandum; Measuring Progress, Well-Being and Sustainable Development." (Available at: http://epp.eurostat.ec.europa.eu/portal/page/portal/gdp_and_beyond/documents/So fia_memorandum_Final.pdf.) Accessed 8 June 2014.

Doel, Marcus. 2001. "1a. Qualified Quantitative Geography." Environment and Planning D: Society and Space 19: 555-72.

Dolan, Paul, Richard Layard, and Robert Metcalfe. 2011. Measuring Subjective WellBeing for Public Policy. London: ONS.

Dolan, Paul, Tessa Peasgood, Andy Dixon, Melanie Knight, David Phillips, Aki Tsuchiya, and Mat White. 2006. Research on the Relationship between WellBeing and Sustainable Development. London: DEFRA. 
Dolan, Paul, Tessa Peasgood, and Mathew White. 2006. Review of Research on the Influences on Personal Well-Being and Application to Policy Making. London: DEFRA.

. 2008. "Do We Really Know What Makes Us Happy? A Review of the Economic Literature on the Factors Associated with Subjective Well-Being." Economic Psychology 29: 94-122.

Donovan, Nick, David Halpern, and Robert Sargeant. 2002. Life Satisfaction: The State of Knowledge and Implications for Government. London: Number 10 Strategy Unit.

Dorling, Daniel, and Stephen Simpson. 1999a. "Introduction to Statistics in Society." In Statistics in Society; the Arithmetic of Politics, edited by Daniel Dorling and Stephen Simpson, 1-6. London: Arnold.

—., eds. 1999b. Statistics in Society; the Arithmetic of Politics. London: Arnold.

Duncan, Joseph W. 1987. "Technology, Costs, and the New Economy of Statistics." In The Politics of Numbers, edited by William Alonso and Paul Starr, 395-413. New York: Russell Sage Foundation.

Duncan, Otis Dudley. 1984. Notes on Social Measurement; Historical and Critical. New York: Russell Sage Foundation.

Duncan-Smith, Iain. 2011. "Request for Assessment of Employment and Support Allowance: Work Capability Assessment Statistics under Section 12(1) of the Statistics and Registration Service Act 2007," October 18.

Dunford, Michael, and Diane Perrons. 1983. The Arena of Capital. London: Macmillan.

Dworkin, Andrea. 1982. Our Blood: Prophecies and Discourses on Sexual Politics. London: The Women's Press.

Easterlin, Richard A. 1974. "Does Economic Growth Improve the Human Lot? Some Empirical Evidence." In Nations and Households in Economic Growth: Essays in Honor of Moses Abramovitz, edited by PA David and MW Reder, 89-125. New York: Academic Press.

Economic Secretary to the Treasury. 1999. "Building Trust in Statistics." Cm 4412. London: HMSO.

Economist Intelligence Unit. 2005. “The Economist Intelligence Unit's Quality-of-Life Index." The Economist, 'The World in 2005': 1-4.

Elden, Stuart. 2004. "Between Marx and Heidegger: Politics, Philosophy and Lefebvre's The Production of Space." Antipode 34 (1): 86-105.

Engels, Frederick. 2009. The Condition of the Working Class in England. Oxford: Oxford University Press.

European Commission. 2013. "Public Opinion in the European Union; First Results." Standard Eurobarometer 80. Brussels: European Commission. 
European Economic and Social Committee. 2012. "Opinion of the European Economic and Social Committee on 'GDP and beyond - the Involvement of Civil Society in Choosing Complementary Indicators' (Own-Initiative Opinion).” Official Journal of the European Union 181 (June): 14-20.

European Parliament. 2011. "GDP and beyond - Measuring Progress in a Changing World; Resolution of 8 June 2011." Resolution 2010/2088(INI). Brussels: European Parliament.

European Statistical System Committee. 2011. "Sponsorship Group on Measuring Progress, Well-Being and Sustainable Development; Final Report.” Luxembourg: ESSC.

European Statistical System System. 2015. The ESS Report 2014. Luxembourg: Publications Office of the European Union.

Eurostat, and European Commission. 2013. European System of National and Regional Accounts; ESA 2010. Luxembourg: Publications Office of the European Union.

Evans, Joanne. 2011. "Findings from the National Well-Being Debate." London: ONS.

Fawcett, Paul, and Oonagh Gay. 2005. "The Centre of Government - No. 10, the Cabinet Office and HM Treasury.” Research Paper 05/92. London: House of Commons Library.

Fine, Ben. 1997. “The New Revolution in Economics.” Capital and Class 61: 143-48.

Fioramonti, Lorenzo. 2013. Gross Domestic Problem: The Politics behind the World's Most Powerful Number. London: Zed Books.

Fisher, Mark. 2009. Capitalist Realism; Is There No Alternative? Winchester: Zer0 Books.

Fontana, Andrea, and James H Frey. 2000. "The Interview: From Structured Questions to Negotiated Text." In Handbook of Qualitative Research, by Norman K Denzin and Yvonna Lincoln, 2nd ed., 163-645-672. Thousand Oaks, CA: Sage Publications.

Foresight Mental Capital and Wellbeing Project. 2008. "Final Project Report Executive Summary.” London: The Government Office for Science.

Foucault, Michel. 1991a. "Governmentality." In The Foucault Effect; Studies in Governmentality, edited by Graham Burchell, Colin Gordon, and Peter Miller, 87104. Chicago: University of Chicago Press.

. 1991b. "Questions of Method." In The Foucault Effect; Studies in Governmentality, edited by Graham Burchell, Colin Gordon, and Peter Miller, 7386. Chicago: University of Chicago Press.

- 2001. Madness and Civilization: A History of Insanity in the Age of Reason. Translated by Richard Howard. London: Routledge. . 2008. The Birth of Biopolitics; Lectures at the Collège de France, 1978-79. Edited by Michel Senellart. Translated by Graham Burchell. London: Palgrave 


\section{REFERENCES}

Macmillan.

Franklin, Raymond S, and William K Tabb. 1974. "The Challenge of Radical Political Economics." Journal of Economic Issues 8 (1): 127-50.

Frey, Bruno, and Jana Gallus. 2013. "Political Economy of Happiness." Applied Economics 45 (30): 4205-11.

Frey, Kathrin, and Simone Lederman. 2010. "Introduction: Evidence-Based Policy: A Concept in Geographical and Substantive Expansion." German Policy Studies 6 (2): $1-15$.

Fujiwara, Daniel. 2013. Museums and Happiness: The Value of Participating in Museums and the Arts. Stowmarket: Museum of East Anglian Life.

Fujiwara, Daniel, and Ross Campbell. 2011. Valuation Techniques for Social CostBenefit Analysis: Stated Preference, Revealed Preference and Subjective WellBeing Approaches; a Discussion of the Current Issues. London: HM Treasury.

G20. 2009. "G20 Leaders' Statement: The Pittsburgh Summit." (Available at: http://www.g20.utoronto.ca/2009/2009communique0925.html.) Accessed 4 June 2014.

Galbraith, VH. 1974. Domesday Book; Its Place in Administrative History. Oxford: The Clarendon Press.

Galton, Francis. 1909. "The Possible Improvement of the Human Breed, under the Existing Conditions of Law and Sentiment." In Essays in Eugenics, 1-34. London: The Eugenics Education Society.

Gay, Oonagh. 2010. “Civil Service Reform.” Standard note SN/PC/05769. London: House of Commons Library.

Gibson-Graham, JK. 1996. The End of Capitalism (as We Knew It); a Feminist Critique of Political Economy. Oxford: Blackwell Publishers.

Giddens, Anthony. 1984. The Constitution of Society; Outline of the Theory of Structuration. Cambridge: Polity Press.

Gill, Nick. 2009. "Presentational State Power: Temporal and Spatial Influences over Asylum Sector Decisionmakers." Transactions of the Institute of British Geographers 34: 215-33.

- 2010. "New State-Theoretic Approaches to Asylum and Refugee Geographies." Progress in Human Geography 34 (5): 626-45.

Goldsmith, Raymond W. 1950. "Measuring National Wealth in a System of Social Accounting." In Studies in Income and Wealth, edited by Conference on Research in National Income and Wealth, 21-80. Chicago: UMI.

Goodwin, Mark. 2013. "Regions, Territories and Relationality: Exploring the Regional Dimensions of Political Practice.” Regional Studies, 47(8): 1181-90.

Goodwin, Mark, Martin Jones, and Rhys Jones. 2005. “Devolution, Constitutional 
Change and Economic Development: Explaining and Understanding the New Institutional Geographies of the British State." Regional Studies 39 (4): 421-36.

Government Statistical Service. 2013. 26th Meeting of the GSS Methodology Advisory Committee; 21st November 2013. London: HMSO.

Government Statisticians' Collective. 1979. "How Official Statistics Are Produced: Views from the inside.” In Demystifying Social Statistics, edited by John Irvine, Ian Miles, and Jeff Evans, 130-51. London: Pluto Press.

Gray, Andrew, and Bill Jenkins. 1992. "The Civil Service and the Financial Management Initiative." In Handbook of Public Services Management, edited by Christopher Pollitt and Stephen Harrison, 168-78. Oxford: Blackwell Publishers.

Gross, Bertram M. 1966. "The State of the Nation: Social Systems Accounting." In Social Indicators, edited by Raymond A Bauer, 154-271. Cambridge, MA: MIT Press.

Hacking, Ian. 1991. "How Should We Do the History of Statistics?" In The Foucault Effect; Studies in Governmentality, edited by Graham Burchell, Colin Gordon, and Peter Miller, 181-95. Chicago: University of Chicago Press.

\section{Press.}

Hammersley, Martyn. 2000. The Politics of Social Research. London: Sage.

Hand, David J. 2004. Measurement Theory and Practice: The World Through Quantification. London: Wiley.

Harris, Josh, and Jill Rutter. 2014. Centre Forward; Effective Support for the Prime Minister at the Centre of Government. London: Institute for Government.

Harvey, David. 1985. “The Geopolitics of Capitalism.” In Social Relations and Spatial Structures, edited by Derek Gregory and John Urry, 128-63. London: Macmillan.

Harvey, Sally. 1971. "Domesday Book and Its Predecessors." The English Historical Review 86 (341): 753-73.

Harvey, William S. 2010. "Methodological approaches for interviewing elites." Geography Compass 4(3): 193-205.

Harvey, William S. 2011. "Strategies for conducting elite interviews." Qualitative Research 11(4): 431-441.

Heukamp, Franz H, and Miguel A Ariño. 2011. "Does Country Matter for Subjective Well-Being?” Social Indicators Research 100 (1): 155-70.

Hindess, Barry. 1977. Philosophy and Methodology in the Social Sciences. Hassocks, Surrey: The Harvester Press.

HM Government. 2005. "Securing the Future; Delivering UK Sustainable Development Strategy." London: HMSO.

HM Treasury. 2008. "Developments in the Economics of Well-Being." Economic 


\section{REFERENCES}

Working Paper 4. London: HM Treasury. . 2011a. The Green Book; Appraisal and Evaluation in Central Government. London: HMSO.

_. 2011b. The Magenta Book; Guidance for Evaluation. London: HMSO.

Hodder, Ian. 2000. “The Interpretation of Documents and Material Culture.” In Handbook of Qualitative Research, by Norman K Denzin and Yvonna Lincoln, 2nd ed., 703-15. Thousand Oaks, CA: Sage Publications.

Hogwood, Brian. 1996. Mapping the Regions; Boundaries, Coordination and Government. Bristol: Policy Press.

Hoinville, G, and TMF Smith. 1982. "The Rayner Review of Government Statistical Services." Journal of the Royal Statistical Society Series A (General) 145 (2): 195-207.

Holstein, JA, and JF Gubrium. 1995. The Active Interview. Thousand Oaks, CA: Sage Publications.

Holt, D Tim. 2008. "Official Statistics, Public Policy and Public Trust.” Journal of the Royal Statistical Society Series A (General) 171 (2): 323-46.

Hood, Christopher. 1991. "A Public Management for All Seasons?” Public Administration 69 (1): 3-19.

Hopwood, Anthony G, and Peter Miller, eds. 1994. Accounting as Social and Institutional Practice. Cambridge Studies in Management. Cambridge: Cambridge University Press.

House of Commons Treasury Committee. 2010. "Spending Review 2010; Sixth Report of Session 2010-11.” HC 544-1. London: HMSO.

Huppert, Felicia A, Nic Marks, Andrew Clark, Johannes Siegrist, Alois Stutzer, Joar Vittersø, and Morten Wahrendorf. 2008. "Measuring Well-Being across Europe: Description of the ESS Well-Being Module and Preliminary Findings.” Working paper 2008-40. Paris: Paris School of Economics.

Illich, Ivan. 1978. The Right to Useful Unemployment; and Its Professional Enemies. London: Marion Boyars.

Innes, Judith Eleanor. 1989. "Disappointments and Legacies of Social Indicators." Journal of Public Policy 9: 429-32.

International Labour Organization. 2013. "Statistics of Work and of the Labour Force; Report for Discussion at the Meeting of Experts in Labour Statistics on the Advancement of Employment and Unemployment Statistics." Department of Statistics Report MESEU/2012. Geneva: ILO.

Irvine, John, Ian Miles, and Jeff Evans, eds. 1979. Demystifying Social Statistics. London: Pluto Press.

Jenkins, Kate. 1992. “Organizational Design and Development: The Civil Service in the 
1980s." In Handbook of Public Services Management, edited by Christopher Pollitt and Stephen Harrison, 211-18. Oxford: Blackwell Publishers.

Jessop, Bob. 2001. "Institutional Re(turns) and the Strategic-Relational Approach." Environment and Planning A 33: 1213-35.

—. 2008. State Power; a Strategic-Relational Approach. Cambridge: Polity Press.

Jessop, Bob, Neil Brenner, and Martin Jones. 2008. "Theorizing Sociospatial Relations." Environment and Planning D: Society and Space 26: 389-401.

Johns, Helen, and Paul Ormerod. 2007. Happiness, Economics and Public Policy. London: Institute for Economic Affairs.

Johnson, Lyndon B. 1964. "Great Society Speech.” (Available at: http://www.hnet.org/ hst306/documents/great.html.) Accessed 8 May 2014.

Jones, Martin, Mark Goodwin, and Rhys Jones. 2005. "State Modernization, Devolution and Economic Governance: An Introduction and Guide to Debate." Regional Studies 39 (4): 397-403.

Jones, Rhys. 2007. People/states/territories. Oxford: Blackwell Publishing.

_. 2012. "State Encounters." Environment and Planning D: Society and Space 30: 805-21.

Jones, Rhys, Mark Goodwin, Martin Jones, and Kevin Pett. 2005. “'Filling in' the State: Economic Governance and the Evolution of Devolution in Wales." Environment and Planning C: Government and Policy 23: 337-60.

Jones, Rhys, Jessica Pykett, and Mark Whitehead. 2013. "Psychological Governance and Behaviour Change." Policy and Politics 41 (2): 159-82.

Jones, Richard, and Valerie Fender. 2011. "Human Capital Estimates - 2010.” London: Office for National Statistics.

Jordan, Grant. 1994. The British Administrative System; Principles versus Practice. London: Routledge.

Kahneman, Daniel, Alan B Krueger, David A Schkade, Norbert Schwarz, and Arthur A Stone. 2004. "A Survey Method for Characterizing Daily Life Experience: The Day Reconstruction Method." Science 306: 1776-80.

Kalpagam, U. 2000. "The Colonial State and Statistical Knowledge." History of the Human Sciences 13 (2): 37-55.

Kamen, Charles S. 2002. “'Quality of Life' Research at the Israel Central Bureau of Statistics: Social Indicators and Social Surveys." Social Indicators Research 58: $141-62$.

Kearns, Robin A, and Gavin J Andrews. 2010. "Geographies of Wellbeing." In The SAGE Handbook of Social Geographies, edited by Susan J Smith, Rachel Pain, Sallie A Marston, and John Paul Jones III, 309-28. London: Sage Publications.

Keat, Russell. 1979. "Positivism and Statistics in Social Science.” In Demystifying 


\section{REFERENCES}

Social Statistics, edited by John Irvine, Ian Miles, and Jeff Evans, 75-86. London: Pluto Press.

Keen, Steve. 2011. Debunking Economics; the Naked Emperor Dethroned. Revised and expanded. London: Zed Books.

Kelly, Duncan. 1999. “The Strategic-Relational View of the State.” Politics 19 (2): 10915.

Kennedy, Robert F. 1968. "Remarks at the University of Kansas, March 18, 1968." March 18. (Available at: http://www.jfklibrary.org/Research/ResearchAids/Ready-Reference/RFK-Speeches/Remarks-of-Robert-F-Kennedy-at-theUniversity-of-Kansas-March-18-1968.aspx.) Accessed 8 May 2014.

King, Anthony. 2010. "The Odd Couple: Margaret Archer, Anthony Giddens and British Social Theory." The British Journal of Sociology 61 (s1): 253-60.

Kirby, J, and E Pickover. 2014. "Doctors Raise Fears over Sharing NHS Patient Medical Records." The Independent, February 14. (Available at: http://www.independent.co.uk/life-style/health-and-families/health-news/doctorsraise-fears-over-sharing-nhs-patient-records-9133807.html.) Accessed 14 February 2014.

Kitchin, Rob, and Nicholas J Tate. 2000. Conducting Research in Human Geography; Theory, Methodology and Practice. Harlow: Pearson Education.

Knorr Cetina, Karin. 1999. Epistemic Cultures; How the Sciences Make Knowledge. Cambridge, MA: Harvard University Press.

Konzelmann, Suzanne J. 2014. "The Political Economics of Austerity.” Cambridge Journal of Economics 38: 701-41.

Koven, Michèle. 2011. "Comparing Stories Told in Sociolinguistic Interviews and Spontaneous Conversation." Language and Society 40: 75-89.

. 2014. "Interviewing: Practice, Ideology, Genre, and Intertextuality." Annual Review of Anthropology 43: 499-520.

Kuznets, Simon. 1938. “On the Measurement of National Wealth.” In Studies in Income and Wealth, Volume 2, edited by Conference on Research in National Income and Wealth, 3-61. New York: National Bureau of Economic Research.

- 1946. "Problems of Interpretation." In National Income: A Summary of Findings, edited by Simon Kuznets, 111-40. Washington, DC: National Bureau of Economic Research.

Kvale, S. 1996. InterViews: An Introduction to Qualitative Research Interviewing. Thousand Oaks, CA: Sage Publications.

Latour, Bruno. 1987. Science in Action: How to Follow Scientists and Engineers through Society. Milton Keynes: Open University Press.

. 2005. Reassembling the Social; an Introduction to Actor-Network Theory. Oxford: Oxford University Press. 
Latour, Bruno, and Steve Woolgar. 1986. Laboratory Life. Beverly Hills, CA: Sage Publications.

Law, John. 2004. After Method; Mess in Social Science Research. London: Routledge.

Layard, Richard. 2003. "Income and Happiness: Rethinking Economic Policy." Lionel Robbins Memorial Lecture, LSE, March 4. (Available at: http://cep.lse.ac.uk/events/lectures/layard/RL040303.pdf.) Accessed 7 October 2014.

. 2005. Happiness; Lessons from a New Science. London: Penguin.

Layard, Richard, G Mayraz, and S Nickell. 2008. "The Marginal Utility of Income." Journal of Public Economics 92 (1846-57).

Lefebvre, Henri. 1976. The Survival of Capitalism: Reproduction of the Relations of Production. Translated by Frank Bryant. London: Allison and Busby. 1991. The Production of Space. Translated by Donald Nicholson-Smith. Oxford: Blackwell.

- 2003. "Space and the State." In State/space; a Reader, edited by Neil Brenner, Bob Jessop, Martin Jones, and Gordon MacLeod, 84-100. Oxford: Blackwell Publishers.

2008. Critique of Everyday Life, Volume 3; from Modernity to Modernism (towards a Metaphilosophy of Daily Life). Translated by Gregory Elliot. New York: Verso.

- 2009. State, Space, World; Selected Essays. Edited by Neil Brenner and Stuart Elden. Translated by Gerald Moore, Neil Brenner, and Stuart Elden. Minneapolis: University of Minnesota Press.

Legrand, Timothy. 2012. "Overseas and over Here: Policy Transfer and Evidence-Based Policy-Making.” Policy Studies 33 (4): 329-48.

Levitas, Ruth. 1996a. "Fiddling While Britain Burns? The 'Measurement' of Unemployment." In Interpreting Official Statistics, edited by Ruth Levitas and Will Guy, 45-65. London: Routledge.

. 1996b. "The Legacy of Rayner." In Interpreting Official Statistics, edited by Ruth Levitas and Will Guy, 7-25. London: Routledge.

Levitas, Ruth, and Will Guy. 1996. "Introduction." In Interpreting Official Statistics, edited by Ruth Levitas and Will Guy, 1-6. London: Routledge.

Levy, Roger. 2010. "New Public Management; End of an Era?” Public Policy and Administration 25 (2): 234-40.

Lincoln, Yvonna, and Egon G Guba. 1985. Naturalistic Enquiry. Beverly Hills, CA: Sage Publications.

. 2000. "Paradigmatic Controversies, Contradictions, and Emerging Confluences.” In Handbook of Qualitative Research, by Norman K Denzin and 


\section{REFERENCES}

Yvonna Lincoln, 2nd ed., 163-88. Thousand Oaks, CA: Sage Publications.

Lindley, Dennis V. 2000. “The Philosophy of Statistics.” Journal of the Royal Statistical Society Series D (The Statistician) 49 (3): 293-337.

Linley, P Alex, John Maltby, Alex M Wood, Gabrielle Osborne, and Robert Hurling. 2009. "Measuring Happiness: The Higher Order Factor Structure of Subjective and Psychological Well-Being Measures." Personality and Individual Differences 47: 878-84.

Lodge, Martin. 2014. "The British Regulatory State under the Coalition Government: Volatile Stability Continued.” The Political Quarterly 85 (2): 143-47.

Lukás, Georg. 1971. History and Class Consciousness. Translated by Rodney Livingstone. London: Merlin Press.

Lund, Christian. 2014. "Of What Is This a Case? Analytical Movements in Qualitative Social Science Research." Human Organization 73 (3): 224-34.

Macfarlane, Alison. 2007. "What's Happening to Statistics?" Radical Statistics 104: 18.

MacKenzie, Donald. 1981. Statistics in Britain 1865-1930; the Social Construction of Scientific Knowledge. Edinburgh: Edinburgh University Press.

. 2009. Material Markets; How Economic Agents Are Constructed. Oxford: Oxford University Press.

Magnanti, Brooke. 2014. "Zombie Statistics on Sex Work." The Baffler Blog. September 6. (Available at: http://thebaffler.com/blog/zombie-statistics-on-sexwork.) Accessed 12 May 2014.

Mann, Michael. 2003. "The Autonomous Power of the State: Its Origins, Mechanisms and Results." In State/space; a Reader, edited by Neil Brenner, Bob Jessop, Martin Jones, and Gordon MacLeod, 53-64. Oxford: Blackwell Publishers.

Marginson, Simon. 1997. "Subjects and Subjugation: The Economics of Education as Power-Knowledge." Discourse: Studies in the Cultural Politics of Education 18 (2): 215-27.

Marmot, Michael. 2004. "Evidence Based Policy or Policy Based Evidence?" British Medical Journal 328: 906-7.

Marmot, Michael, and R Bell. 2012. "Fair Society, Healthy Lives." Public Health 126: s4-10.

Martin, Margaret E. 1981. "Statistical Practice in Bureaucracies." Journal of the American Statistical Association 176 (373): 1-8.

Marx, Karl. 1852. The Eighteenth Brumaire of Louis Bonaparte. (Available at: http://www.marxists.org/archive/marx/works/1852/18th-brumaire/ch01.htm.) Accessed 7 July 2009.

1990. Capital; a Critique of Political Economy. Translated by Ben Fowkes. 
Vol. 1. London: Penguin.

Marx, Karl, and Frederick Engels. 1977. The German Ideology. Edited by CJ Arthur. London: Lawrence and Wishart.

1992. The Communist Manifesto. Edited by David McLellan. Oxford: Oxford University Press.

Matheson, Jil. 2010. Statistics Matter. London: ONS.

. 2011. "Measuring National Well-Being; Measuring What Matters - National Statistician's Reflections on the National Debate on Measuring National WellBeing." London: ONS.

May, Teresa. 2002. "Speech to the Conservative Party Conference, Bournemouth, 7 October." Speech. October 7. (Available at:

http://www.theguardian.com/politics/2002/oct/07/conservatives2002.conservative s1.) Accessed 21 August 2014.

McDowell, Linda. 1998. "Elites in the City of London: some methodological considerations." Environment and Planning A 30: 2133-2146.

McLaughlin, Kate, Stephen P Osborne, and Ewan Ferlie, eds. 2002. New Public Management; Current Trends and Future Prospects. London: Routledge.

Mikecz, Robert. 2012. "Interviewing Elites: Addressing Methodological Issues." Qualitative Inquiry 18 (6): 482-93.

Miles, Ian, and John Irvine. 1979. "The Critique of Official Statistics." In Demystifying Social Statistics, edited by John Irvine, Ian Miles, and Jeff Evans, 113-29. London: Pluto Press.

Miller, Peter. 1991. “Accounting Innovation beyond the Enterprise: Problematizing Investment Decisions and Programming Economic Growth in the UK in the 1960s." Accounting, Organizations and Society 16 (8): 733-62.

Miller, Peter, and Ted O'Leary. 1987. "Accounting and the Construction of the Governable Person.” Accounting, Organizations and Society 12 (3): 235-65.

. 1994. "Governing the Calculable Person." In Accounting as Social and Institutional Practice, edited by Anthony G Hopwood and Peter Miller, 98-115. Cambridge: Cambridge University Press.

Miller, Peter, and Nikolas Rose. 1990. "Governing Economic Life.” Economy and Society 19 (1): 1-31.

2008. Governing the Present. Cambridge: Polity Press.

Mill, John Stuart. 1962. "Utilitarianism.” In Utilitarianism, On Liberty, Essay on Bentham; Together with Selected Writings of Jeremy Bentham and John Austin, edited by Mary Warnock, 251-321. London: Meridian.

Mincer, Jacob. 1962. "On-the-Job Training: Costs, Returns and Some Implications." Journal of Political Economy 70 (5): 50-79. 
1974. Schooling, Experience and Earnings. New York: National Bureau of Economic Research.

Mitchell, Timothy. 1988. Colonising Egypt. Berkeley, CA: University of California Press.

1991. "The Limits of the State: Beyond Statist Approaches and Their Critics." The American Political Science Review 85 (1): 77-96.

Moser, Claus. 2000. "Foreword." Social Trends 30: 13.

Moser, Claus A. 1970. "Some General Developments in Social Statistics." Social Trends 1: 7-11.

Moss, L. 1950. “The Government Social Survey.” Operational Research Quarterly (1950-1952) 1 (4): 55-65.

National Audit Office. 2001. "Modern Policy-Making: Ensuring Policies Deliver Value for Money; Executive Summary.” HC 289, Session 2001-02. London: HMSO.

National Statistics. 2000. Framework for National Statistics. London: HMSO.

- 2002. National Statistics Code of Practice; Statement of Principles. London: HMSO.

National Statistics, and Department for Environment, Food and Rural Affairs. 2004a. Quality of Life Counts; Indicators for a Strategy for Sustainable Development for the United Kingdom; 2004 Update; Updating the Baseline Assessments Made in 1999. London: DEFRA.

—. 2004b. Sustainable Development Indicators in Your Pocket 2004; A Selection of the UK Government's Indicators of Sustainable Development. London: DEFRA.

New Economics Foundation. 2011a. Measuring Our Progress; the Power of WellBeing. London: NEF.

- 2011b. The Practical Politics of Well-Being. London: NEF.

. 2012. The Happy Planet Index: 2012 Report; a Global Index of Sustainable Well-Being. London: NEF.

Newman, Janet. 2002. "The New Public Management, Modernization and Institutional Change; Disruptions, Disjunctures and Dilemmas." In New Public Management; Current Trends and Future Prospects, edited by Kate McLaughlin, Stephen P Osborne, and Ewan Ferlie, 76-91. London: Routledge.

Nissel, Muriel. 1970. "Editorial." Social Trends 1: 4-6.

Noll, Heinz-Herbert. 2005. "Researching Quality of Life in Europe: A Decade of Progress." presented at the ECSR conference "Comparative European Studies Assessing 10 Years of Sociological Research 1995-2005," Paris, November 25. (Available at: http://www.gesis.org/fileadmin/upload/institut/wiss_arbeitsbereiche/soz_indikator 
en/Publikationen/ECSR-QoL-Noll.pdf.) Accessed 09 September 2014.

. 2011. "The Stiglitz-Sen-Fitoussi-Report: Old Wine in New Skins? Views from a Social Indicators Perspective." Social Indicators Research 102: 111-16.

Nordhaus, William D, and James Tobin. 1973. "Is Growth Obsolete?" In The Measurement of Economic and Social Performance, edited by Milton Moss, 50932. Ann Arbor: UMI.

Oakley, Annie. 1981. "Interviewing Women: A Contradiction in Terms." In Doing Feminist Research, edited by H Roberts, 30-61. London: Routledge \& Kegan Paul.

O’Boyle, Brian. 2013. "Reproducing the Social Structure: A Marxist Critique of Anthony Giddens' Structuration Methodology." Cambridge Journal of Economics 37: 1019-33.

O’Donnell, Gus, Angus Deaton, Martine Durand, David Halpern, and Richard Layard. 2014. "Wellbeing and Policy." London: Legatum Institute.

Office for National Statistics. 1996. Framework Document. London: ONS. . 2010a. The Vision for 2015; a Strategy for Improvement. London: ONS. - 2010b. "Spending Review 2010 Announcement." ONS Media Centre. October 20. (Available at: http://www.ons.gov.uk/ons/media-centre/statements/olderstatements/spending-review-oct-2010/spending-review-2010announcement.html.) Accessed 17 July 2015.

- 2011. From Underwear to Aircraft Noise: Logging 70 Years of Social Change. London: ONS.

2012a. "Consultation on Proposed Domains and Measures of National WellBeing: Responses Received.” London: ONS.

_. 2012b. First Annual ONS Experimental Subjective Well-Being Results. London: ONS.

2012c. "Measures of Human Capital; a Call for Views by 28th February 2013." London: ONS.

_. 2012d. "Measuring National Well-Being - Education and Skills." London: ONS.

- 2012e. "Measuring National Well-Being - Summary of Proposed Domains and Measures." London: ONS.

_.2013a. Deaths Involving Clostridium Difficile, England and Wales, 2012. London: ONS.

- 2013b. ONS Strategy 2013-2023; Trusted Statistics - Understanding the UK. London: ONS.

. 2013c. "Poverty and Social Exclusion in the UK and EU, 2005-2011." London: ONS. 
2013d. The Census and Future Provision of Population Statistics in England and Wales; a Consultation. London: ONS.

- 2013e. Personal Well-Being in the UK, 2012/13. London: ONS.

- 2013f. Personal Well-Being across the UK, 2012/13. London: ONS.

- 2014a. Baby Names in England and Wales, 2013. London: ONS.

- 2014b. Measuring National Well-Being: Life in the UK, 2014. London: ONS. -. 2014c. Response to the ONS Consultation on Statistical Products 2013.

London: ONS.

- 2014d. UK Environmental Accounts, 2014. London: ONS.

_. 2014e. "National Well-Being Measures, March 2014 Release.” [spreadsheet] (Available at: http://www.ons.gov.uk/ons/rel/wellbeing/measuring-national-wellbeing/life-in-the-uk-2014/rft---national-well-being-measures--march-2014.xls.) Accessed 2 March 2015.

_. 2015a. "Measuring National Well-Being, September 2015 Release (data Are the Lastest Available at August 2015)." [spreadsheet] (Available at: http://www.ons.gov.uk/ons/rel/wellbeing/measuring-national-well-being/domainsand-measures---september-2015/rft-nwb.xls.) Accessed 10 December 2015.

-2015b. Personal Well-Being in the UK, 2014/15. London: ONS.

_. 2015c. "Data for Figure 1: Distribution of Personal Well-Being Ratings, 2011/12 - 2014/15." [spreadsheet] (Available at:

http://www.ons.gov.uk/ons/rel/wellbeing/measuring-national-well-being/personalwell-being-in-the-uk--2014-15/chd-figure-1.xls.) Accessed 10 December 2015.

Office for Public Services Reform. 2002. Reforming Our Public Services; Principles into Practice. London: HMSO.

Office of the Deputy Prime Minister. 2004. The Social Exclusion Unit. London: ODPM.

Olsson, Gunnar. 2000. "From A=b to A=a." Environment and Planning A 32: 1235-44.

Organisation for Economic Co-Operation and Development. 1973. "How to Measure Well-Being." The OECD Observer, 64: 36-37.

_. 2001. "The Well-Being of Nations; the Role of Human and Social Capital." Paris: OECD.

—. 2007. "Istanbul Declaration." from second OECD World Forum on "Measuring and fostering the progress of societies", 30th June. Istanbul: OECD.

- 2013a. Measuring Well-Being and Progress. Paris: OECD.

-2013b. OECD Guidelines on Measuring Subjective Well-Being. Paris: OECD.

- 2014. Society at a Glance 2014; OECD Social Indicators. Paris: OECD.

Osborne, David, and Ted Gaebler. 1992. Reinventing Government. Reading, MA: 
Addison Wesley.

Parker, Daniel. 1999. "Qualitative Data and the Subjectivity of 'Objective' Facts.” In Statistics in Society; the Arithmetic of Politics, edited by Daniel Dorling and Stephen Simpson, 83-88. London: Arnold.

Pawson, Ray, Geoff Wong, and Lesley Owen. 2011. "Known Knowns, Known Unknowns, Unknown Unknowns: The Predicament of Evidence-Based Policy." American Journal of Evaluation 32 (4): 518-46.

Payne, Rupert A, and Gary A Abel. 2012. "UK Indices of Multiple Deprivation - a Way to Make Comparisons across Constituent Countries Easier." Health Statistics Quarterly 53 (1): 1-16.

Pearson, Jonathan, James Page, and Julian Traficante. 2014. Transforming Whitehall One Year On; the Challenges of Departmental Reform in Whitehall. London: Institute for Government.

Peck, Jamie. 2001. "Neoliberalizing States: Thin Policies/hard Outcomes." Progress in Human Geography 25 (3): 445-55.

2002. "Political Economics of Scale: Fast Policy, Interscalar Relations, and Neoliberal Workfare." Economic Geography 78 (3): 331-61.

_ 2010. "Zombie Neoliberalism and the Ambidextrous State." Theoretical Criminology 14 (1): 114-110.

Peck, Jamie, and Nik Theodore. 2010. "Mobilizing Policy: Models, Methods and Mutations." Geoforum 41: 169-74.

_. 2012. "Follow the Policy: A Distended Case Approach." Environment and Planning A 44: 21-30.

Peck, Jamie, Nik Theodore, and Neil Brenner. 2012. "Neoliberalism Resurgent? Market Rule after the Great Recession." South Atlantic Quarterly 111 (2): 265-88.

Penneck, Stephen. 2014. "New Challenges Facing Official Statistics.” Statistical Journal of the IAOS 30: 3-16.

Percy, Constance, and Alice Dolman. 1953. "Comparison of the Coding of Death Certificates Related to Cancer in Seven Countries." Public Health Reports 93 (4): $335-50$

Performance and Innovation Unit. 2000a. Adding It Up; Improving Analysis and Modelling in Central Government. London: The Cabinet Office.

- 2000b. Wiring It Up; Whitehall's Management of Cross-Cutting Policies and Services. London: The Cabinet Office.

Petty, William. 1899. "Political Arithmetick." In The Economic Writings of Sir William Petty, edited by Charles Henry Hull, 1:232-313. Cambridge: Cambridge University Press.

Phillips, Richard, and Jennifer Johns. 2012. Fieldwork for Human Geography. London: 


\section{REFERENCES}

Sage.

Pickford, Stephen, John Cunningham, Robin Lynch, Jennifer Radice, and Graham White. 1989. Government Economic Statistics; a Scrutiny Review. London: HMSO.

Pollitt, Christopher, and Stephen Harrison, eds. 1992. Handbook of Public Services Management. Oxford: Blackwell Publishers.

Pontin, Eleanor, Matthias Schwannauer, Sara Tai, and Peter Kinderman. 2013. "A UK Validation of a General Measure of Subjective Well-Being: The Modified BBC Subjective Well-Being Scale (BBC-SWB)." Health and Quality of Life Outcomes 11 (150): 1-9.

Porter, Theodore M. 1986. The Rise of Statistical Thinking, 1820-1900. Princeton, NJ: Princeton University Press. . 1995. Trust in Numbers; the Pursuit of Objectivity in Science and Public Life. Princeton, NJ: Princeton University Press.

Power, Michael. 1994. "The Audit Society.” In Accounting as Social and Institutional Practice, edited by Anthony G Hopwood and Peter Miller, 299-316. Cambridge: Cambridge University Press.

. 1996. "Making Things Auditable." Accounting, Organizations and Society 21 (2/3): 289-315.

. 1997. The Audit Society; Rituals of Verification. Oxford: Oxford University Press.

Prewitt, Kenneth. 1987. "Public Statistics and Democratic Politics." In The Politics of Numbers, edited by William Alonso and Paul Starr, 261-74. New York: Russell Sage Foundation.

Prime Minister, and Minister for the Cabinet Office. 1999. "Modernising Government." White paper Cm. 4310. London: HMSO.

Public Administration Select Committee. 2013. "A Review of the Operation of the Statistics and Registration Service Act 2007.” HC 406. London: HMSO.

Quality of Life Group. 2007. Blueprint for a Green Economy; Submission to the Shadow Cabinet. London: Conservative Party.

Radermacher, Walter, Jean-Louis Mercy, Denis Leytheinne, Gallo Gueye, Gilles Decand, and Vincent Tronet. 2010. "Measuring More than 'Just' Economic Development.” Sigma; The Bulletin of European Statistics 2010 (2): 14-17.

Rayner, Derek. 1980a. Review of Government Statistical Services. London: HMSO. . 1980b. Review of Government Statistical Services; Report on the Central Statistical Office. London: HMSO.

Rhodes, RAW. 1992. Beyond Westminster and Whitehall; the Sub-Central Governments of Britain. London: Routledge. 
2005. "Everyday Life in a Ministry; Public Administration as Anthroplogy." American Review of Public Administration 35 (1): 3-25.

Rose, Gillian. 1997. "Situating Knowledges: Positionality, Reflexivities and Other Tactics." Progress in Human Geography 21 (3): 305-20.

Rose, Nikolas. 1991. "Governing by Numbers: Figuring out Democracy.” Accounting, Organizations and Society 16 (7): 673-92.

Rose, Nikolas, and Peter Miller. 1992. "Political Power beyond the State: Problematics of Government." The British Journal of Sociology 43 (2): 173-205.

Rosenthal, Robert A, and Robert S Weiss. 1966. "Problems of Organizational Feedback Processes." In Social Indicators, edited by Raymond A Bauer, 302-41. Cambridge, MA: MIT Press.

Ruskin, John. 2001. Unto This Last: Four Essays on the Principles of Political Economy. Virginia: University of Virginia Library Electronic Text Center. (Available at: http://muff.uffs.net/skola/dejum/ruskin/texts/unto-thislast/unto_this_last.pdf.) Accessed 14 December 2012.

Rutter, Jill, and Josh Harris. 2014. The Special Ones; How to Make Central Government Units Work. London: Institute for Government.

Sartre, Jean-Paul. 1968. Search for a Method. Translated by Hazel E Barnes. New York: Vintage Books.

Sayer, Andrew. 1981. “Abstraction: A Realist Interpretation.” Radical Philosophy 28: $6-15$.

. 1985. "The Difference That Space Makes.” In Social Relations and Spatial Structures, edited by Derek Gregory and John Urry, 49-66. London: Macmillan.

-2000. Realism and Social Science. London: Sage.

Schäfer, Armin, and Wolfgang Streeck. 2013. "Introduction: Politics in the Age of Austerity." In Politics in the Age of Austerity, edited by Armin Schäfer and Wolfgang Streeck, 1-25. Cambridge: Polity Press.

Schmidt, Volker H. 2001. "Oversocialised Epistemology: A Critical Appraisal of Constructivism.” Sociology 35 (1): 135-57.

Schneider, Mark. 1976. "The 'Quality of Life' and Social Indicators Research.” Public Administration Review 36: 297-305.

Scholar, Michael. 2011. "Statistics and Registration Service Act 2007: Notification in Relation to Statistics on Employment and Support Allowance: Work Capability Assessment," August 15.

Schultz, Theodore W. 1961. "Investment in Human Capital." The American Economic Review 51 (1): 1-17.

1962. "Reflections on Investment in Man." Journal of Political Economy 70 


\section{REFERENCES}

(5): $1-8$.

- 1970. "The Reckoning of Education as Human Capital." In Education, Income, and Human Capital, edited by W Lee Hansen, 297-303. Ann Arbor: UMI.

Schwandt, Thomas A. 2000. "Three Epistemological Stances for Qualitative Enquiry; Interpretivism, Hermeneutics, and Social Constructionism." In Handbook of Qualitative Research, by Norman K Denzin and Yvonna Lincoln, 2nd ed., 189213. Thousand Oaks, CA: Sage Publications.

Schyns, Peggy. 2003. Income and Life Satisfaction: A Cross-National and Longitudinal Study. Delft: Euberon.

Scottish Government. 2011. An Introduction to Scotland's National Performance Framework. Edinburgh: Scottish Government.

Scott, Karen. 2012. Measuring Wellbeing; towards Sustainability? London: Routledge. 2015. "Happiness on Your Doorstep: Disputing the Boundaries of Wellbeing and Localism." The Geographical Journal, 181: 129-37.

Searle, John. 1995. The Construction of Social Reality. London: Penguin.

Self, Abigail. 2014. Measuring National Well-Being: Insights across Society, the Economy and the Environment, 2014. London: ONS.

Sen, Amartya. 1985. Commodities and Capabilities. North Holland: Elsevier Science.

Shaw, Martin, and Ian Miles. 1979. "The Social Roots of Statistical Knowledge.” In Demystifying Social Statistics, edited by John Irvine, Ian Miles, and Jeff Evans, 27-38. London: Pluto Press.

Siltala, Juha. 2013. "New Public Management: The Evidence-Based Worst Practice?" Administration and Society 45 (4): 468-93.

Silverman, David. 2000. “Analyzing Talk and Text.” In Handbook of Qualitative Research, by Norman K Denzin and Yvonna Lincoln, 2nd ed., 821-34. Thousand Oaks, CA: Sage Publications.

- 2011. Interpreting Qualitative Data. 4th ed. London: Sage Publications.

Simpson, Ian, Kelsey Beninger, and Rachel Ormston. 2015. Public Confidence in Official Statistics. London: NatCen Social Research.

Smith, Tom W. 1981. “Social Indicators.” Journal of Social History 14 (4): 739-47.

Smith, Katherine. 2010. "Research, Policy and Funding - Academic Treadmills and the Squeeze on Intellectual Spaces.” The British Journal of Sociology 61 (1): 176-95.

Sointu, Eeva. 2005. "The Rise of an Ideal: Tracing Changing Discourses of Wellbeing." The Sociological Review 53 (2): 255-74.

Soja, Edward W. 1985. "The Spatiality of Social Life: Towards a Transformative Retheorisation." In Social Relations and Spatial Structures, edited by Derek 
Gregory and John Urry, 90-127. London: Macmillan.

Spencer, Herbert. 1970. Social Statics: Or, the Conditions Essential to Human

Happiness Specified, and the First of Them Developed. Westmead, Hants.: Gregg International Publishers.

Sponsorship Group on Measuring Progress, Well-being and Sustainable Development.

2011. Final Report Adopted by the European Statistical System Committee. Paris:

Eurostat.

Stake, Robert E. 2000. "Case Studies." In Handbook of Qualitative Research, by

Norman K Denzin and Yvonna Lincoln, 2nd ed., 435-54. Thousand Oaks, CA:

Sage Publications.

Starr, Paul. 1987. "The Sociology of Official Statistics." In The Politics of Numbers, edited by William Alonso and Paul Starr, 7-57. New York: Russell Sage Foundation.

Statistics Commission. 2008. "Official Statistics: Value and Trust." Report No. 38. London: Statistics Commission.

Stevenson, Betsey, and Justin Wolfers. 2008. "Economic Growth and Subjective WellBeing: Reassessing the Easterlin Paradox." Working paper 14282. Cambridge,

MA: National Bureau of Economic Research.

Stewart-Brown, Sarah L, S Platt, A Tennant, H Maheswaran, J Parkinson, S Weich, R Tennant, F Taggart, and A Clarke. 2011. "The Warwick-Edinburgh Mental WellBeing Scale: A Valid and Reliable Tool for Measuring Mental Well-Being in Diverse Populations and Projects." Journal of Epidemiology and Community Health 65 (Sup.II): A38-39.

Stiglitz, Joseph, Amartya Sen, and Jean-Paul Fitoussi. 2009. "Report of the Commission on the Measurement of Economic Performance and Social Change." Paris:

Commission on the Measurement of Economic Performance and Social Progress.

Stoll, Laura, Juliet Michaelson, and Charles Seaford. 2012. Well-Being Evidence for Policy: A Review. London: NEF.

Strategic Policy Making Team. 1999. Professional Policy Making for the Twenty First Century. London: The Cabinet Office.

Tennant, Ruth, Ruth Fishwick, Stephen Platt, Stephen Joseph, and Sarah L StewartBrown. 2006. Monitoring Positive Mental Health in Scotland: Validating the Affectometer 2 Scale and Developing the Warwick-Edinburgh Mental Well-Being Scale for the UK. Glasgow: NHS Health Scotland.

Terkel, Studds. 1988. The Great Divide; Second Thoughts on the American Dream. New York: Pantheon Books. . 2004. Working; People Talk about What They Do All Day and How They Feel about What They Do. New York: The New Press.

Thaler, Richard H, and Cass R Sunstein. 2008. Nudge; Improving Decisions about Health, Wealth and Happiness. New Haven: Yale University Press. 


\section{REFERENCES}

Thatcher, Margaret. 1987. Interview for Woman's Own. (Available at: http://www.margaretthatcher.org/document/106689.) Accessed 14 August 2014.

Thomas, Ray. 1984. "A Critique of the Rayner Review of the Government Statistical Service." Public Administration 62: 224-29. 1996. "Statistics as Organizational Products." Sociological Research Online 1 (3): (Available at: http://www.socresonline.org.uk/1/3/5.html.) Accessed 6 August 2013.

. 2007. "Who Is in Charge of Public Statistics?" Radical Statistics, no. 104: 118.

Tomlinson, Michael W, and Grace P Kelly. 2013. "Is Everybody Happy? The Politics and Measurement of National Wellbeing." Policy and Politics 41 (2): 139-57.

Townsend, Peter. 1996. “The Struggle for Independent Statistics on Poverty.” In Interpreting Official Statistics, edited by Ruth Levitas and Will Guy, 26-44. London: Routledge.

Tsuchiya, Aki, and Paul Dolan. 2005. "The QALY Model and Individual Preferences for Health States and Health Profiles over Time: A Systematic Review of the Literature." Medical Decision Making 25: 460-67.

UK Statistics Authority. 2009. Code of Practice for Official Statistics. London: UKSA. . 2013. Annual Report and Accounts 2012/13. London: UKSA.

. 2014a. "Statistics on Personal Well-Being (produced by the Office for National Statistics)." Assessment Report 277. Assessment of Compliance with the Code of Practice for Official Statistics. London: UKSA.

. 2014b. "The Geography of Economic Statistics - Interim Report.” Monitoring Review 2/14. London: UKSA.

United Nations. 2001. Indicators of Sustainable Development: Guidelines and Methodologies. New York: UN.

. 2014. The Millennium Development Goals Report 2014. New York: UN.

United Nations Department of Social and Economics Affairs Statistical Office. 1975. "Towards a System of Social and Demographic Statistics." Series F, No. 18. Studies in Methods. New York: UN.

United Nations Development Programme. 2014. Human Development Report 2014; Sustaining Human Progress: Reducing Vulnerabilities and Building Resilience. New York: UNDP.

United Nations General Assembly. 2000. "United Nations Millennium Declaration. Resolution Adopted by the General Assembly on 8 September 2000." Resolution 55/2. New York: UN General Assembly.

. 2012. "The Future We Want. Resolution Adopted by the General Assembly on

27 July 2012.” Resolution 66/288. New York: UN General Assembly. 
United Nations, Organisation for Economic Co-Operation and Development, International Monetary Fund, and European Union. 1993. System of National Accounts. New York: UN.

Ura, Karma, Sabina Alkire, Tshoki Zangmo, and Karma Wangdi. 2012. An Extensive Analysis of GNH Index. Thimphu, Bhutan: Centre for Bhutan Studies.

Vaneigem, Raoul. 2003. The Revolution of Everyday Life. Translated by Donald Nicholson-Smith. London: Rebel Press.

Veenhoven, Ruut. 1999. "Quality-of-Life in Individualistic Society; a Comparison of 43 Nations in the Early 1990's.” Social Indicators Research 48: 157-86.

2005. “Apparent Quality-of-Life of Nations: How Long and Happy People Live.” Social Indicators Research 71: 71-86. . 2009. "Well-Being in Nations and Well-Being of Nations; Is There a Conflict between Individuals and Society?" Social Indicators Research 91: 5-21.

Waldron, Sam. 2010. "Measuring Subjective Wellbeing in the UK." Working paper. London: ONS.

Wallace, Claire, and Pamela Abbott. 2007. "From Quality of Life to Social Quality: Relevance for Work and Care in Europe." Calitatea Vietii 18 (1-2): 109-23.

Walters, William. 1994. "The Discovery of 'Unemployment': New Forms for the Government of Poverty." Economy and Society 23 (3): 265-90.

Ward, Reg, and Ted Doggett. 1991. Keeping Score; the First Fifty Years of the Central Statistical Office. London: HMSO.

Wark, McKenzie. 2013. The Spectacle of Disintegration. London: Verso.

Washer, Peter, and Helene Joffe. 2006. "The 'Hospital Superbug': Social Representations of MRSA." Social Science and Medicine 63: 2141-52.

Watson, David, Lee Anna Clark, and Auke Tellegen. 1988. "Development and Validation of Brief Measures of Positive and Negative Affect: The PANAS Scales." Journal of Personality and Social Psychology 54 (6): 1063-70.

Whitehall Wellbeing Working Group. 2005. Update Summary on the Use of Wellbeing Concepts in Developing and Appraising UK Government Policy. London: Whitehall Wellbeing Working Group. (Available at: http://www.empho.org.uk/Download/Public/9077/1/Wellbeing\%20in \%20Government\%20-\%20W3G7.doc.) Accessed 21 July 2014.

Whitehead, Mark, Rhys Jones, Jessica Pykett, and Marcus Welsh. 2012. "Geography, Libertarian Paternalism and Neuro-Politics in the UK." The Geographical Journal 178 (4): 302-7.

White, Nicholas. 2006. A Brief History of Happiness. Oxford: Blackwell Publishers.

Williams, Charlotte, and Gerry Mooney. 2008. "Decentring Social Policy? Devolution and the Discipline of Social Policy: A Commentary." Journal of Social Policy 37: 


\section{REFERENCES}

$489-507$.

Wilmot, Amanda, Jacqui Jones, Abigail Dewar, Peter Betts, Rosalyn Harper, and Eleanor Simmons. 2005. Public Confidence in Official Statistics; a Qualitative Study on Behalf of the Office for National Statistics and the Statistics Commission. London: ONS.

Wilson, Fiona. 2001. "In the Name of the State? Schools and Teachers in an Andean Province." In States of Imagination; Ethnographic Explorations of the Postcolonial State, edited by Thomas Blom Hansen and Finn Stepputat, 313-44. Durham: Duke University Press.

Wood, Michael. 1999. Domesday: A Search for the Roots of England. London: BBC Worldwide.

Woods, M. 1998. "Rethinking elites: networks, space, and local politics." Environment and Planning A 30: 2101-2119.

Working Party on Official Statistics in the UK. 1991. "Official Statistics: Counting with Confidence." Journal of the Royal Statistical Society Series A (Statistics in Society) 154 (1): 23-44.

Working Party on the Measurement of Unemployment in the UK. 1995. "The Measurement of Unemployment in the UK." Journal of the Royal Statistical Society Series A (Statistics in Society) 158 (3): 363-417.

WWF. 2012. Living Planet Report 2012; Biodiversity, Biocapacity and Better Choices. Gland, Switzerland: WWF.

Young, Robert M. 1979. "Why Are Figures so Significant? The Role and the Critique of Quantification." In Demystifying Social Statistics, edited by John Irvine, Ian Miles, and Jeff Evans, 63-74. London: Pluto Press. 